\title{
Advances in measurements of particle cycling and fluxes in the ocean
}

\author{
By
}

Stephanie Anne Owens

B.S., Sewanee: The University of the South, 2007

Submitted in partial fulfillment of the requirements for the degree of Doctor of Philosophy

at the

MASSACHUSETTS INSTITUTE OF TECHNOLOGY
and the
WOODS HOLE OCEANOGRAPHIC INSTITUTION

February 2013

\section{(C) 2013 Stephanie Anne Owens \\ All rights reserved.}

The author hereby grants to MIT and WHOI permission to reproduce and to distribute publicly paper and electronic copies of this thesis document in whole or in part in any medium now known or hereafter created.

Signature of Author

Joint Program in Oceanography/Applied

Ocean Science and Engineering Massachusetts Institute of Technology and Woods Hole Oceanographic Institution

December 21, 2012

Certified by

Dr. Ken O. Buesseler Thesis Supervisor

Accepted by

Dr. Bernhard Peucker-Ehrenbrink Chair, Joint Committee for Chemical Oceanography Woods Hole Oceanographic Institution 


\title{
Advances in measurements of particle cycling and fluxes in the ocean by \\ Stephanie Anne Owens
}

\author{
Submitted to the Department of Marine Chemistry and Geochemistry, \\ Massachusetts Institute of Technology - Woods Hole Oceanographic Institution \\ Joint Program in Oceanography/Applied Ocean Science and Engineering \\ on December 21, 2012 \\ in partial fulfillment of the requirements for the degree of Doctor of Philosophy
}

\begin{abstract}
The sinking flux of particles is an important removal mechanism of carbon from the surface ocean as part of the biological pump and can play a role in cycling of other chemical species. This work dealt with improving methods of measuring particle export and measuring export on different scales to assess its spatial variability. First, the assumption of ${ }^{238} \mathrm{U}$ linearity with salinity, used in the ${ }^{238} \mathrm{U}-{ }^{234} \mathrm{Th}$ method, was reevaluated using a large sample set over a wide salinity range. Next, neutrally buoyant and surfacetethered sediment traps were compared during a three-year time series in the subtropical Atlantic. This study suggested that previously observed imbalances between carbon stocks and fluxes in this region are not due to undersampling by traps. To assess regional variability of particle export, surface and water-column measurements of ${ }^{234} \mathrm{Th}$ were combined for the first time to measure fluxes on $\sim 20 \mathrm{~km}$ scales. Attempts to relate surface properties to particle export were complicated by the temporal decoupling of production and export. Finally, particle export from ${ }^{234} \mathrm{Th}$ was measured on transects of the Atlantic Ocean to evaluate basin-scale export variability. High-resolution sampling through the water-column allowed for the identification of unique ${ }^{234} \mathrm{Th}$ features in the intermediate water column.
\end{abstract}

Thesis Supervisor: Ken O. Buesseler

Title: Senior Scientist, Woods Hole Oceanographic Institution 


\section{Acknowledgements}

I feel so very lucky to have had the opportunity to work with my advisor, Ken Buesseler. Most graduate students are not required to travel extensively and spend weeks at sea with their advisors, but as an oceanography student, I was fortunate to have Ken as both a mentor and a friend. In addition to the many things Ken has taught me about science, I hope he has also instilled in me his skills of diplomacy that I got to witness for five years as his student. I also blame Ken, but thank him, for developing my interest in politics, particularly as it relates to science. Without his encouragement and support, I might not have had the courage to apply for my Knauss Fellowship. Outside of the office, I have to thank both Ken and his wife, Wendi, for being such good friends to Paul and myself. It was so special to have you be such an integral part of our wedding and I look to you as role models for our relationship.

My secondary support system was my thesis committee, made up of Phoebe Lam, Dave Glover, and Mick Follows. Your continued support, suggestions, and encouragement over the last three years have helped me get to this point. Thank you also, to the chair of my defense, Carl Lamborg, for his support over my time at WHOI. In addition to those mentioned above, through various projects, I have had the opportunity to work with a large group of scientists whose support and assistance I appreciate including Ken Sims, Matthew Charette, Bill Jenkins, Rachel Stanley, Jim Valdes, Rod Johnson, Mike Lomas, Dave Siegel, Debbie Steinberg, Hugh Ducklow, Hein de Baar, Micha Rijkenberg, and Pere Masque. Those who I may have omitted here have been acknowledged in the relevant thesis chapters.

My time at WHOI would not have been the same without the members of Café Thorium. I owe so much to Steve Pike - my thesis would likely be significantly shorter or at least consist of less data points without Spike. We make a great team on land and at sea and I will sincerely miss seeing him on a daily basis. Andrew McDonnell was my student cohort in the lab for much of my thesis and I have missed him over the last two years. Thankfully, email makes it easy to pester him with my questions now and then. I look forward to working with Andrew more in the future as we publish our work. Thank you to the other members of Café Thorium over the last five years including Kanchan Maiti, Erin Black, Meg Estapa, Kuanbo Zhou, and Crystal Breier for being great colleagues and friends.

A significant amount of my time in graduate school was spent at sea collecting samples and data so I must thank the crews of the R/V Atlantic Explorer, R/V Oceanus, ARSV LM Gould, RVIB NB Palmer, R/V Knorr, and RRS James Cook.

WHOI's Marine Chemistry and Geochemistry department and the MIT-WHOI Joint Program would not run smoothly without the likes of Donna Mortimer, Sheila Clifford, and the Academic Programs staff. Thank you for making this experience possible for all students.

I have made a great number of great friends over the past five years, all of whom cannot be named here. I must give special thanks however to Carly Buchwald, Erin Bertrand, Abigail Noble, Dan Ohnemus, Maya Yamato, Kim Popendorf, Meredith White, Jeff Kaeli, Meagan Gonnea, and Naomi Levine. Carly Buchwald deserves a special 
mention, as my roommate for $3+$ years. Thank you for putting up with me for so long and being such a great friend. Regardless if one of us has been at sea or away for several weeks, we can still pick back up where we left off. Yours is a friendship that all others will be stacked against.

My family, including those who aren't with us today, are truly the key to any of my success. They have constantly believed in and supported me, no questions asked. From deciding to do SEA, to applying to graduate school, and deciding on the MITWHOI Joint Program, they have had my back every step of the way. I hope you can realize all that you have done for me. Thank you also to my new family, the Morrises/Bemands for welcoming me into your fold.

During my time as a student, I was so very fortunate to meet my wonderful and very-recent husband, Paul Morris. While we may never understand the little twists and turns that bring people together, I am so thankful that they turned out the way they did. Having someone who understands what it means to write and finish a thesis was so helpful. Paul set up the final springboard to get me to the point of completing my thesis, from making sure I had dinner every night to distracting me when I needed a break. Now that it's over, I can't wait to first, go on our honeymoon, and next plan and build our lives together.

Funding support is critical for making the science we do everyday possible and is one of the reasons that I chose to apply for a Knauss Fellowship. I am grateful therefore to the funding sources for my work and me over the last five years. For three years, I was supported by NASA Headquarters under the NASA Earth and Space Science Fellowship Program (Grant NNX10AO72H). Specific projects were funded by grants from the National Science Foundation, including Carbon Flux Through the Twilight Zone - New Tools to Measure Change (OCE-0628416), WAPflux - New Tools to Study the Fates of Phytoplankton Production in the West Antarctic Peninsula (ANT-0838866), and GEOTRACES Atlantic Section: Trace Element Sources and Sinks Elucidated by ShortLived Radium and Thorium Isotopes (OCE-0925158). I received support for books and computers from the MIT Henry G. Houghton Fund and travel support to Bermuda from the MIT Scurlock Fund. Finally, I thank WHOI Academic Programs for their generous supplemental support to the above funding. 


\section{Table of Contents}

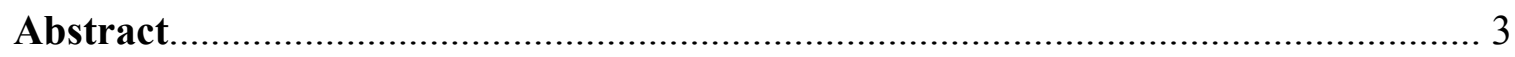

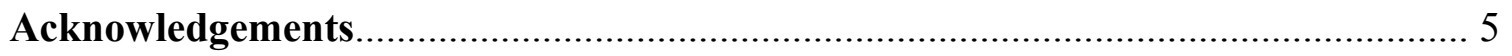

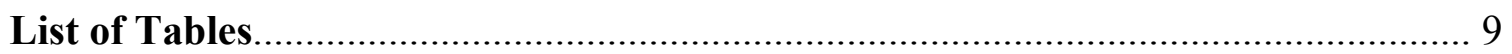

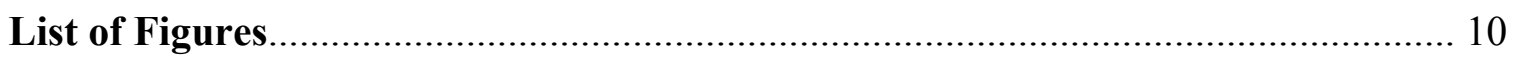

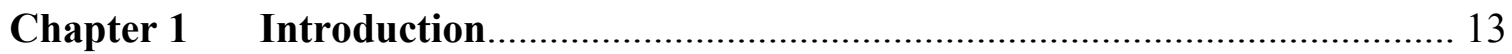

Chapter 2 Re-evaluating the ${ }^{238} \mathrm{U}$ - salinity relationship in seawater: Implications for the ${ }^{238} \mathbf{U}-{ }^{234} \mathbf{T h}$ disequilibrium method................... 29

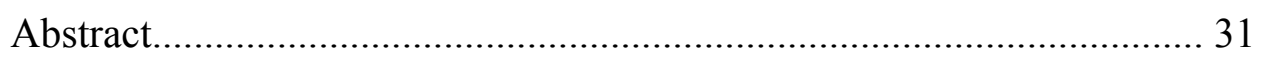

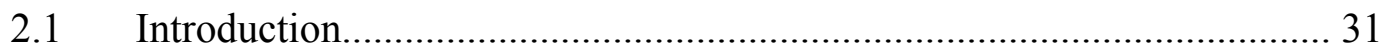

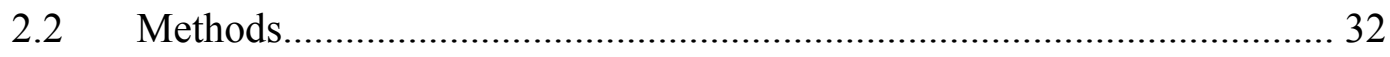

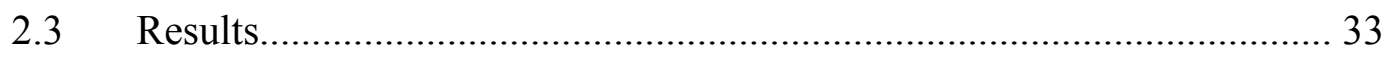

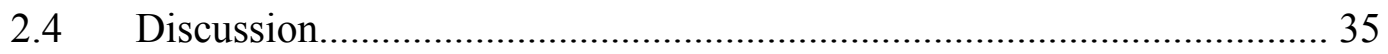

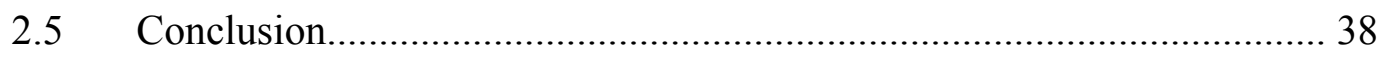

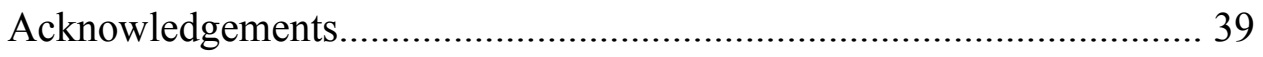

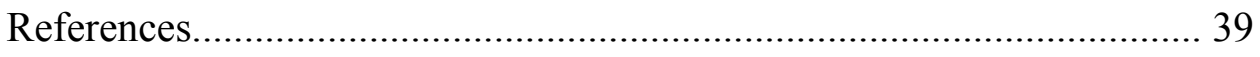

Chapter 3 A new time series of particle export from neutrally buoyant sediment traps at the Bermuda Atlantic Time-series Study site........................ 41

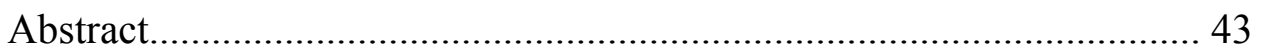

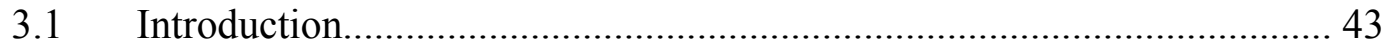

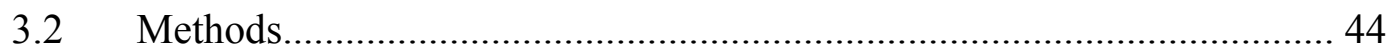

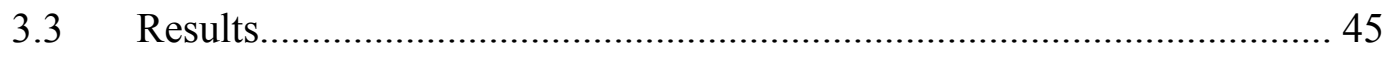

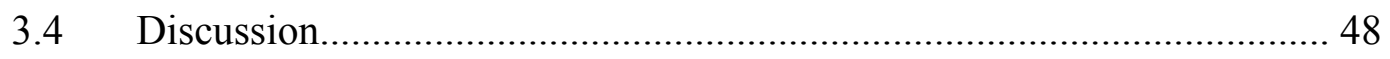

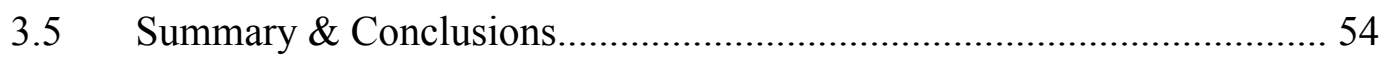

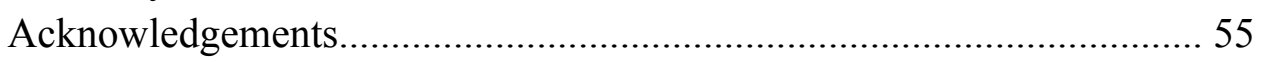

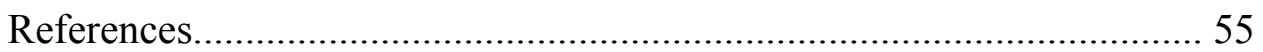


Chapter 4 Temporal and spatial variability of particle export off the West Antarctic Peninsula.

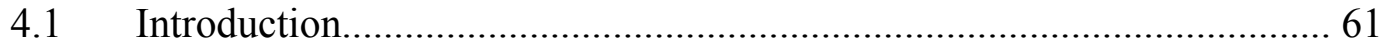

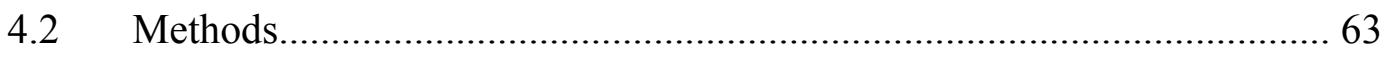

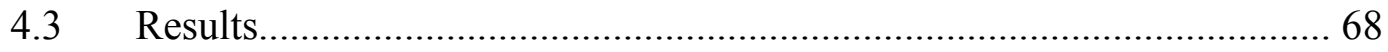

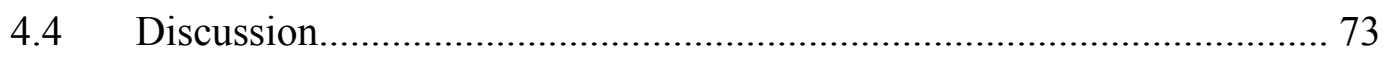

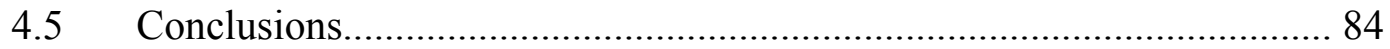

Acknowledgements................................................................. 85

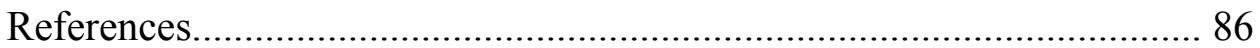

Chapter 5 Thorium-234 as a tracer for particle dynamics in the Atlantic Ocean

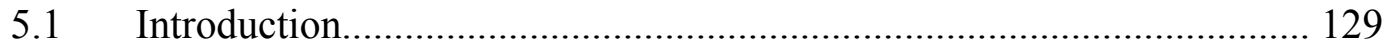

5.2 Methods........................................................................................ 130

5.3 Results \& Discussion.................................................................... 134

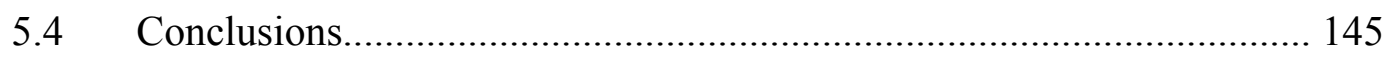

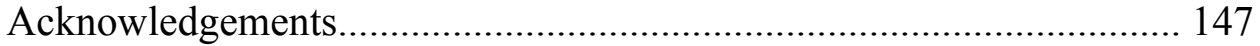

References...................................................................... 148

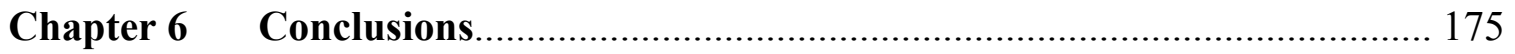

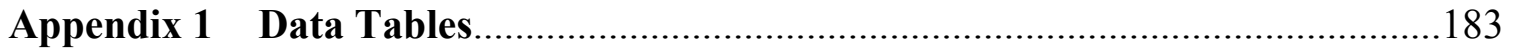

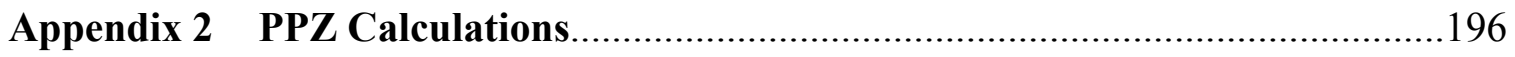




\section{List of Tables}

\section{Chapter 2}

Table 1: ${ }^{238} \mathrm{U}$ concentration measurements made by ICP-MS......................................... 34

Table 2: Comparison of ${ }^{238} \mathrm{U}$ results to previous studies........................................... 36

\section{Chapter 3}

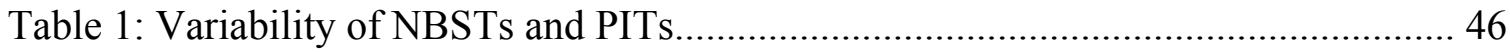

Table 2: Blank flux values from this and prior studies for NBSTs and PITs................. 48

\section{Chapter 4}

Table 1: ${ }^{238} \mathrm{U}$ and total ${ }^{234} \mathrm{Th}$ versus depth from the West Antarctic Peninsula............... 91

Table 2: Key depths, ${ }^{234} \mathrm{Th}$ fluxes, $\mathrm{C} /{ }^{234} \mathrm{Th}$ ratios, and $\mathrm{C}$ fluxes at CTD sites............... 101

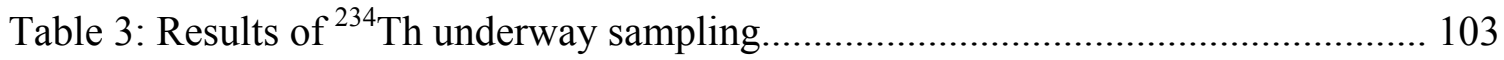

Table 4: Comparison of sediment trap and water column flux measurements.............. 106

\section{Chapter 5}

Table 1: ${ }^{234} \mathrm{Th}$ and $\mathrm{C}$ fluxes on Atlantic GEOTRACES cruises................................... 153

Table 2: Regional summary of carbon flux estimates............................................. 155

\section{Appendix 1}

Table 1: Monthly fluxes from NBSTs at BATS..................................................... 184

Table 2: Underway sensor, nutrient, and chlorophyll data from WAP........................ 186

Table 3: Total ${ }^{234} \mathrm{Th}$ profile data from Line W cruise, 2010....................................... 190

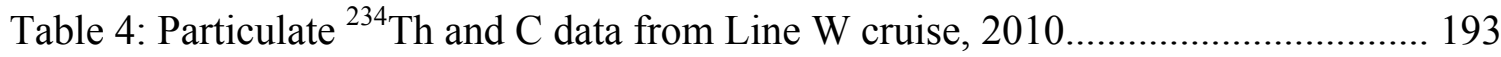




\section{List of Figures}

\section{Chapter 1}

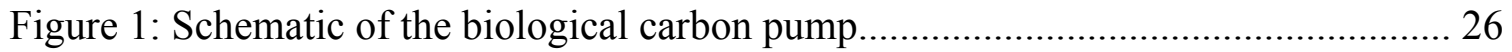

Figure 2: Export versus primary production in various ocean regions.......................... 27

\section{Chapter 2}

Figure 1: ${ }^{238} \mathrm{U}$ concentrations versus salinity for this and prior studies.......................... 33

Figure 2: Profiles of ${ }^{238} \mathrm{U}$ at the Bermuda Atlantic Time-series Study site..................... 37

Figure 3: Profiles of ${ }^{234} \mathrm{Th}$ at the Bermuda Atlantic Time-series Study site..................... 38

\section{Chapter 3}

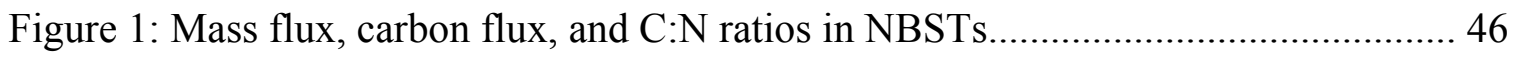

Figure 2: Contribution of sinking versus swimmer carbon flux................................... 47

Figure 3: Results of swimmer removal method comparison....................................... 48

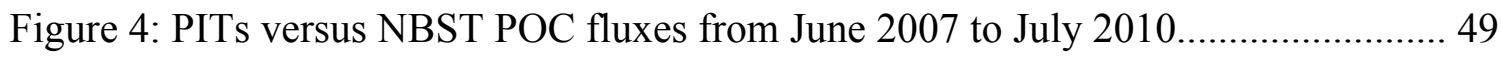

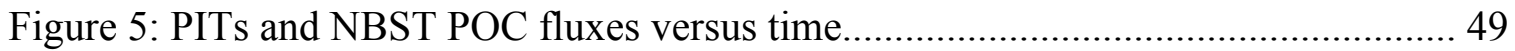

Figure 6: PITs and NBST POC fluxes versus depth..................................................... 50

Figure 7: Results of two-month method and trap inter-comparison experiment............. 51

Figure 8: POC flux versus primary production for NBSTs and PITs............................. 51

Figure 9: Deployment and recovery positions for NBSTs and PITs in 2008.................. 52

Figure 10: Frequency of low-flux POC measurements in NBSTs and PITs................... 53

Figure 11: Export ratios and mineral/POC ratios versus time for NBSTs...................... 54

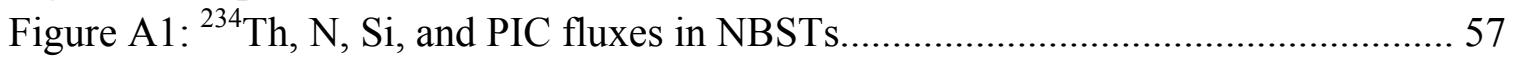

Figure A2: Average and maximum current speeds from PITs array.............................. 58

Figure A3: Weekly sea surface height at BATS during study .................................... 58

\section{Chapter 4}

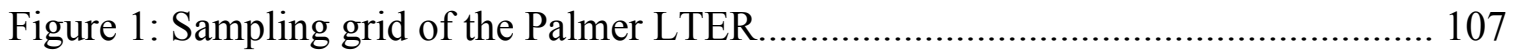

Figure 2: Water-column and underway sampling sites............................................ 108

Figure 3: Sample CTD profile with key depths........................................................ 109

Figure 4: Summary of ${ }^{234} \mathrm{Th} /{ }^{238} \mathrm{U}$ ratios with fluorescence and transmission................ 110

Figure 5: ${ }^{234}$ Th fluxes at PPZ in summer and autumn off the WAP............................. 111

Figure 6: Underway versus surface bottle measurements of ${ }^{234} \mathrm{Th} /{ }^{238} \mathrm{U}$....................... 112

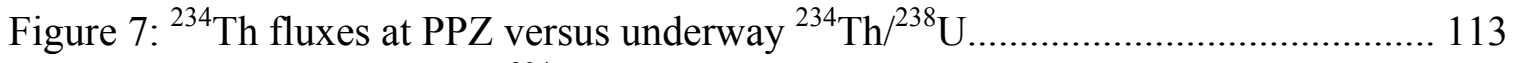

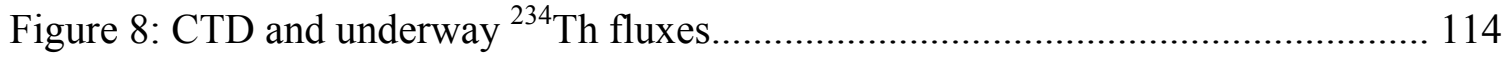

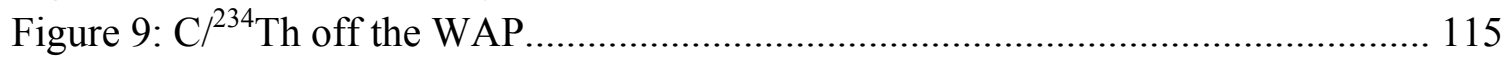

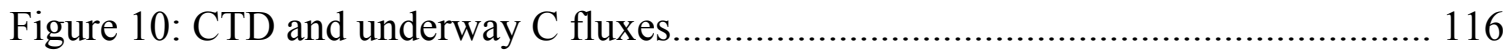




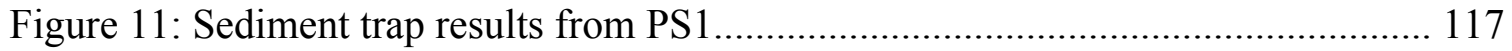

Figure 12: Sediment trap results from PS2 .......................................................... 118

Figure 13: Sediment trap results from PS3 .............................................................. 119

Figure 14: ${ }^{234}$ Th profiles with key depths in January 2010 ....................................... 120

Figure 15: ${ }^{234} \mathrm{Th}$ profiles with key depths in March/April 2010.................................. 121

Figure 16: Across shelf $\mathrm{C}$ fluxes from CTD and underway measurements.................. 122

Figure 17: Along shelf $\mathrm{C}$ fluxes from CTD and underway measurements................... 123

Figure 18: Monthly mean chlorophyll $a$ concentrations from MODIS........................ 124

Figure 19: Carbon flux measurements versus biological properties............................ 125

\section{Chapter 5}

Figure 1: Map of sampling locations of ${ }^{234}$ Th on Atlantic GEOTRACES cruises......... 156

Figure 2: Total ${ }^{234} \mathrm{Th}$ profiles of upper $500 \mathrm{~m}$, US GEOTRACES Leg 1..................... 157

Figure 3: Total ${ }^{234}$ Th profiles of upper $500 \mathrm{~m}$, US GEOTRACES Leg 2 ..................... 158

Figure 4: Total ${ }^{234} \mathrm{Th}$ profiles of upper $500 \mathrm{~m}$, Dutch GEOTRACES.......................... 159

Figure 5: Summary of ${ }^{234}$ Th deficits in the Atlantic Ocean......................................... 160

Figure 6: Fluorescence profiles and PPZ depths from US GEOTRACES Leg 1...........161

Figure 7: ${ }^{234} \mathrm{Th}$ fluxes at the PPZ in the Atlantic Ocean.............................................. 162

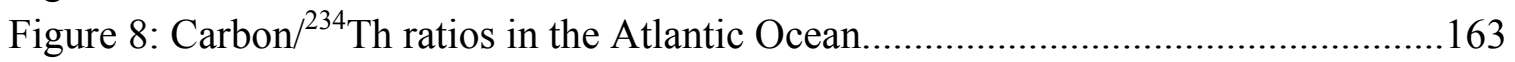

Figure 9: Carbon/ $/{ }^{234} \mathrm{Th}$ ratio compilation for the Atlantic Ocean................................. 164

Figure 10: Carbon fluxes at the PPZ in the Atlantic Ocean........................................ 165

Figure 11: Comparison of carbon flux estimates to previous studies............................ 166

Figure 12: Influence of Mediterranean Outflow Water on ${ }^{234} \mathrm{Th}$................................. 167

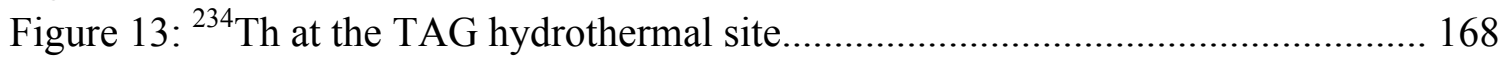

Figure 14: Full water column profiles of ${ }^{234} \mathrm{Th}$ on US GEOTRACES Leg 1............... 169

Figure 15: Full water column profiles of ${ }^{234}$ Th on US GEOTRACES Leg 2............... 171 


\section{Chapter 1: Introduction}

\section{Marine particles and the biological carbon pump}

Particulate organic matter (POM) in the ocean, primarily produced during photosynthesis in the sunlit surface, is a key component of many biogeochemical cycles. Most of the POM created in the surface ocean is recycled there and only a small amount escapes as passively sinking particles. This sinking flux of POM alters the distribution of oxygen, nutrients, and trace elements in the ocean (Whitfield and Turner, 1987). In some regions, aeolian supply of dust particles and riverine supply of terrestrial particles can contribute to the pool of sinking particles. Particle-reactive elements can also adsorb onto particle surfaces. Vertical gradients are established in chemical species that are removed from the surface layer of the ocean with POM and then remineralized or redissolved at depth. Although this sinking flux is a small fraction of the total primary production, it is the source of seafloor sediments and an important energy source for pelagic and benthic life (Honjo, 1996).

Sinking particulate organic carbon (POC) is the primary pathway for removal of carbon from the surface ocean in the biological carbon pump (BCP; Figure 1). Other 
removal pathways in the BCP include entrainment of dissolved organic carbon (DOC) below the mixed layer and active transport of POM via vertically migrating zooplankton (Ducklow et al., 2001). The BCP is a key component of the global carbon cycle because of its ability to isolate carbon from the atmosphere for hundreds to thousands of years. Without the BCP, it has been predicted that atmospheric carbon dioxide could rise by 200 ppmv (Sarmiento and Toggweiler, 1984). If the POC is remineralized before it reaches the seafloor, it can be stored in the deep ocean as dissolved inorganic carbon (DIC), as long as the water mass is not ventilated to the atmosphere. Of the estimated $5-15$ GTC $\mathrm{y}^{-1}$ that leaves the euphotic zone, only about $1 \%$ reaches the sediments (Ducklow et al., 2001). An exception to this is in continental shelf regions, where rates of primary production and export can be significantly higher (Smith and Hollibaugh, 1993).

The processes that regulate export from the upper ocean, including primary production by phytoplankton, particle aggregation, consumption and egestion by zooplankton, are generally known (Boyd and Trull, 2007). Also known is that the composition and succession of the phytoplankton and zooplankton communities can play an important role in regulating export (Boyd and Newton, 1995; Boyd and Newton, 1999). For example, some species produce dense biominerals that may increase the sinking rate and thus transport of material out of the euphotic zone. What is less certain is how these processes interact to determine the magnitude and efficiency of the export by the BCP. The relationship between particle flux and primary production (Figure 2) is not simple (Buesseler, 1998). One framework used to address the relationship between these two processes is that of new and export production (Dugdale and Goering, 1967; Eppley and Peterson, 1979). Primary production is driven by "new" and "regenerated" nitrogen where "new" nitrogen is supplied from outside the euphotic via mixing or nitrogen fixation and "regenerated" nitrogen is that which is recycled in the euphotic zone. Over sufficiently large time and space scales, new production should equal the export production (Eppley and Peterson, 1979). When new production is measured, the ratio of new to primary production is termed the "f-ratio." Similarly, when export production is measured the ratio between export and primary production is called the "e- 
ratio." This framework has been useful for parameterizing global models of carbon export, particularly by using relationships between the $\mathrm{f}-$ and e-ratios and sea surface temperature (Laws et al., 2000; Henson et al., 2011). However, these models do not describe the biological pump mechanistically, as a sum of its component processes. Surface food web/particle export models include production, grazing, and export, however they require detailed geochemical and biological information that is unique to specific regions of the ocean (Michaels and Silver, 1988; Boyd et al., 2008). The largest limitation to modeling particle export is the lack of observations in both time and space of the contributing processes and resultant flux (Boyd and Trull, 2007).

\section{Methods of measuring particle export}

Eppley (1989) outlined four primary methods of measuring new or export production in the ocean: 1) bottle incubations to measure nutrient uptake, 2) geochemical mass balance of oxygen, carbon dioxide, nutrient, and gas tracers, 3) collection of sinking particles by upper ocean sediment traps, and 4) the ${ }^{238} \mathrm{U}-{ }^{234} \mathrm{Th}$ disequilibrium method.

The latter two methods are the ones employed in this work and are the most direct way of measuring export production on small temporal and spatial scales.

Sediment traps are rain gauge-like instruments that capture particles as they settle through the water column. Although conceptually simple, there are several issues associated with sediment trap design and methodology that may bias flux results (Buesseler et al., 2007). The first issue is the hydrodynamic issue, over or undercollection caused by horizontal flow over the mouth of the trap and trap motion on a mooring line (Gardner, 1985; Gust et al., 1996). Free-drifting, neutrally buoyant sediment traps that flow with the water in which the particles are sinking have been developed to address this issue (Valdes and Price, 2000; Lampitt et al., 2008). To date however, they have only been used in a limited number of studies, including this work, and have not yet been widely adopted by longer-term sediment trap programs. The second issue is the "swimmer" issue, the inadvertent collection of live zooplankton that are not a true part of the passively sinking flux (Michaels, 1990; Steinberg et al., 1998). 
Swimmer carbon can contribute significantly to the total carbon flux collected in the trap, thus the systematic removal of these swimmers is important for accurate determination of carbon flux. Swimmer removal methods include passing samples through mesh screens to segregate swimmers by size, manual picking of the swimmers from samples, and also engineering modifications to the traps. Solubilization, the dissolution of particulate material in the trap after collection, is the third issue. This has been addressed by using brines and poisons to inhibit microbial degradation of particulate material and by limiting the length of deployments and time until sample processing (Lee et al., 1992; Lamborg et al., 2008). Some elements such as phosphorus, however, are subject to significant dissolution, making determination of their export flux difficult (Antia, 2005; Buesseler et al., 2007). Sediment trap types and methodologies vary widely from study to study which can be problematic when trying to compare results. Despite these issues, sediment traps are still the most direct way of sampling the sinking particle flux.

An alternate method for measuring particle flux is the ${ }^{238} \mathrm{U}^{2}{ }^{234} \mathrm{Th}$ disequilibrium method. This method takes advantage of the contrasting properties in seawater and difference in half-lives of this parent-daughter pair to measure export occurring on the scale of days to months (Bhat et al., 1969; Coale and Bruland, 1985, 1987). ${ }^{238} \mathrm{U}$ is highly soluble in seawater and has a long half-life of $4.468 \times 10^{9}$ years. In contrast, ${ }^{234} \mathrm{Th}$ is very short-lived $\left(\mathrm{t}_{1 / 2}=24.1 \mathrm{~d}\right)$ and is highly particle reactive in seawater. As a result of the large difference in half-lives of this pair, when no ${ }^{234} \mathrm{Th}$ or ${ }^{238} \mathrm{U}$ is removed from or added to the system, the two are in secular equilibrium (Activity of ${ }^{234} \mathrm{Th} /{ }^{238} \mathrm{U}=1$ ). When ${ }^{234} \mathrm{Th}$ is scavenged onto sinking POM in the upper ocean, a deficit of ${ }^{234} \mathrm{Th}$ relative to ${ }^{238} \mathrm{U}$ is created. By integrating over area this deficit, a flux of ${ }^{234} \mathrm{Th}$ can be derived. Then, the flux of other species can be determined by multiplying the ${ }^{234} \mathrm{Th}$ flux by the elemental: ${ }^{234} \mathrm{Th}$ ratio on sinking particles (Buesseler et al., 2006). When applied to POC, the ratio between POC export derived from ${ }^{234} \mathrm{Th}$ and primary production has been defined as the ThE ratio (Buesseler, 1998). Although this method does not directly capture the sinking flux as sediment traps do, it can be implemented at higher spatial resolution. This isotope pair can also be used to trace other particle transport processes 
including resuspension of sediments at the seafloor and hydrothermal plumes (Bacon and Rutgers van der Loeff, 1989; Kadko et al., 1994; Waples et al., 2006).

Early methods of measuring ${ }^{234} \mathrm{Th}$ in seawater required hundreds of liters of seawater, which limited the depth and spatial resolution that could be achieved (Rutgers van der Loeff et al., 2006). In recent years, smaller volume methods that require as little as $1 \mathrm{~L}$, but typically $4 \mathrm{~L}$ (Benitez-Nelson et al., 2001; Buesseler et al., 2001; Pike et al., 2005), were developed and have since been applied widely (Buesseler et al., 2008a; Buesseler et al., 2008b; Cai et al., 2008; Martin et al., 2011). This method requires knowledge of the ${ }^{238} \mathrm{U}$ activity in seawater. Measuring ${ }^{238} \mathrm{U}$ directly can be labor intensive. Instead, ${ }^{238} \mathrm{U}$ is determined from its conservative or linear relationship with salinity (Chen et al., 1986; Pates and Muir, 2007). Although this relationship holds over a large salinity range, deviations have been reported (Delanghe et al., 2002; Robinson et al., 2004). Thus, care should be taken when applying this technique. A second source of uncertainty in this method is the determination of appropriate $\mathrm{POC} /{ }^{234} \mathrm{Th}$ ratios on sinking particles (Buesseler et al., 2006). This ratio is best measured on particles collected by sediment traps or in situ pumps with multiple size-fraction stages. POC/ ${ }^{234} \mathrm{Th}$ ratios are known to vary between regions and increase with depth. It is therefore important that POC/ ${ }^{234} \mathrm{Th}$ ratios are measured at the depth to which the ${ }^{234} \mathrm{Th}$ flux calculations are integrated; a value too shallow would overestimate and a value too deep would underestimate the $\mathrm{C}$ flux from the region of particle production.

Sediment traps and ${ }^{234}$ Th can be useful tools when used in combination as they provide complementary information on particle export of a region. Samples from sediment traps can be analyzed for a range of parameters including, but not limited to, carbon, biominerals such as silica and calcium carbonate, and a suite of trace metals. Upper ocean sediment traps are typically deployed for $3-5$ days and provide information about material sinking across a depth horizon during that deployment period. In contrast, ${ }^{234}$ Th sampling can be carried out at higher spatial resolution than can be achieved with sediment traps and integrates over a longer period, up to several weeks, as determined by its half-life. A significant effort has been made to use water-column ${ }^{234} \mathrm{Th}$ to determine 
the collection efficiency of sediment traps (Knauer et al., 1979; Bacon et al., 1985; Buesseler, 1991). The mismatch of the temporal and spatial scales over which the two methods integrate has made this approach difficult, however. Lagrangian and multi-week sampling efforts are required to properly calibrate sediment traps (Buesseler, 1994; Buesseler et al., 2008b; Lampitt et al., 2008; Cochran et al., 2009). In addition a calibration factor determined for ${ }^{234} \mathrm{Th}$ may not be the same as the calibration factor for other particulate species. Together, however, these two methods can vastly increase our understanding of particle export.

\section{Variability of particle export}

One challenge in understanding the relationship between upper ocean processes and particle export is the temporal and spatial variability of the processes that regulate it and of the export itself. The advent of satellite oceanography has allowed us to observe the variability of both physical and biological fields in the surface ocean. Less is known however about variability of export. Models provide the greatest amount of spatial coverage of particle export. Modeling studies based on relationships between export efficiency and temperature, described above, are limited by the number of measurements of new or export production available (Laws et al., 2000; Henson et al., 2011). Inverse models, which use distributions of physical and chemical parameters to derive rates or fluxes, integrate over the history of a water mass and thus average over large spatial scales (Schlitzer, 2002; Usbeck et al., 2003; Schlitzer, 2004). These model studies do, however, highlight the basin-scale variability of particle export.

Field-studies and models have investigated the small-scale variability of phytoplankton and zooplankton (Mackas and Boyd, 1979; Yoder et al., 1993; Abraham, 1998; Garçon et al., 2001; Mahadevan and Campbell, 2002; Martin, 2003; Lévy and Klein, 2004). Generally heterogeneity is higher in zooplankton relative to phytoplankton, which are more heterogeneous than the physical parameters such as temperature and salinity. As export flux is a product of complex interactions between mixing, phytoplankton, and zooplankton, it is likely that the scales of variability of export are of a 
similar scale to phytoplankton or smaller. Results from studies using ${ }^{234} \mathrm{Th}$ and underwater cameras have hinted at this smaller scale variability of export (Guidi et al., 2007; Buesseler et al., 2008b; Guidi et al., 2008). A recent study modeling export flux

and measurements of ${ }^{234} \mathrm{Th}$ has demonstrated the heterogeneity of export on scales of 100 $\mathrm{km}$ and less (Resplandy et al., 2012). There are few measurements of export flux on these scales, however. Another factor to consider is that spatial variability of export could lead to misinterpretation of results when only a few measurements by sediment traps or ${ }^{234}$ Th are made within a specific region (Resplandy et al., 2012).

Particle export can vary on seasonal and interannual scales as a result of physical, nutrient, phytoplankton, and zooplankton variability on these scales. For example, off the Western Antarctic Peninsula, daily export rates vary over four orders of magnitude during the year due to changes in water column stratification and nutrient supply (Ducklow et al., 2008). This range of variability is also observed interannually. In other regions pulses of export may occur as a result of episodic events like delivery of dust to the surface ocean, supply of nutrients to the surface by eddies, or salp blooms. Particle flux can also be temporally separated or lag biogeochemical changes in the euphotic zone. This can preclude drawing simple relationships between euphotic zone properties and export when both are measured simultaneously. Time-series studies are invaluable for overcoming these obstacles to understanding particle flux and its controlling properties (Boyd and Trull, 2007; Ducklow et al., 2009).

\section{This thesis}

This work includes four independent chapters on aspects of particle export and cycling and a concluding chapter summarizing the overall results and discussing recommendations for future avenues of research. Chapters 2 and 3 address improvements in methods to measure particle export while Chapters 4 and 5 present results from studies investigating the variability of export on regional and basin scales. The overarching aim of this work is to advance the methods used to measure export and 
how they are applied in order to increase our understanding of export production by the BCP.

In Chapter 2, the linear relationship between ${ }^{238} \mathrm{U}$ and salinity is reassessed using high precision mass spectrometry techniques. The impetus for this work was the observation of anomalous deficits of ${ }^{234} \mathrm{Th}$ at depths of $\sim 800 \mathrm{~m}$ in the subtropical North Atlantic. ${ }^{238} \mathrm{U}$ was analyzed to determine whether these features were due to changes in ${ }^{238} \mathrm{U}$ or ${ }^{234} \mathrm{Th}$. Chapter 3 presents the first time-series of particle flux measured using neutrally buoyant sediment traps. These traps were deployed concurrently with traditional, surface-tethered traps at the Bermuda Atlantic Time-series Study (BATS) site. In addition to comparing fluxes collected by these contrasting sediment trap models, methods of sample processing were also rigorously examined.

In Chapter 4, the results of a survey of particle export off the Western Antarctic Peninsula are reported. Water-column ${ }^{234} \mathrm{Th}$ and sediment traps were used to evaluate along and across shelf trends in particle flux. In addition, surface samples of ${ }^{234} \mathrm{Th}$ were collected every 10 to $20 \mathrm{~km}$ over a large region of the Peninsula to assess smaller scale variability of export. Repeat sampling in the summer and autumn allowed for the observation of seasonal changes in export in this region. Finally, in Chapter 5, two transects of the Atlantic Ocean are used to observe large-scale variability in export. These extensive surveys also included high depth resolution measurements of ${ }^{234} \mathrm{Th}$, which are discussed further in the context of particle cycling at ocean boundaries, including continental shelves, the seafloor, and hydrothermal vents. 


\section{References}

Abraham, E.R., 1998. The generation of plankton patchiness by turbulent stirring. Nature 391, 577-580.

Antia, A.N., 2005. Particle-associated dissolved elemental fluxes, revising the stoichiometry of mixed layer export. Biogeosciences Discussions 2, 275-302.

Bacon, M.P., Huh, C.A., Fleer, A.P., Deuser, W.G., 1985. Seasonality in the flux of natural radionuclides and plutonium in the deep Sargasso Sea. Deep Sea Research 32, 273-286.

Bacon, M.P., Rutgers van der Loeff, M.M., 1989. Removal of thorium-234 by scavenging in the bottom nepheloid layer of the ocean. Earth and Planetary Science Letters 92 (2), 157-164.

Benitez-Nelson, C.R., Buesseler, K.O., van der Loeff, M.R., Andrews, J., Ball, L., Crossin, G., Charette, M.A., 2001. Testing a new small-volume technique for determining ${ }^{234} \mathrm{Th}$ in seawater. Journal of Radioanalytical and Nuclear Chemistry 248 (3), 795-799.

Bhat, S.G., Krishnaswamy, S., Lal, D., Rama, Moore, W.S., $1969 .{ }^{234} \mathrm{Th} /{ }^{238} \mathrm{U}$ ratios in the ocean. Earth and Planetary Science Letters 5, 483-491.

Boyd, P., Newton, P., 1995. Evidence of the Potential Influence of Planktonic Community Structure on the Interannual Variability of Particulate OrganicCarbon Flux. Deep-Sea Research I 42 (5), 619-639.

Boyd, P.W., Gall, M.P., Silver, M.W., Coale, S.L., Bidigare, R.R., Bishop, J.K.B., 2008. Quantifying the surface-subsurface biogeochemical coupling during the VERTIGO ALOHA and K2 studies. Deep-Sea Research II 55, 1578-1593.

Boyd, P.W., Newton, P.P., 1999. Does planktonic community structure determine downward particulate organic carbon flux in different oceanic provinces? DeepSea Research I 46 (1), 63-91.

Boyd, P.W., Trull, T.W., 2007. Understanding the export of biogenic particles in oceanic waters: Is there consensus? Progress in Oceanography 72 (4), 276-312.

Buesseler, K.O., 1991. Do upper-ocean sediment traps provide an accurate record of particle flux? Nature 353, 420-423.

Buesseler, K.O., 1998. The decoupling of production and particulate export in the surface ocean. Global Biogeochemical Cycles 12 (2), 297-310.

Buesseler, K.O., Antia, A.N., Chen, M., Fowler, S.W., Gardner, W.D., Gustafsson, O., Harada, K., Michaels, A.F., van der Loeff'o, M.R., Sarin, M., Steinberg, D.K., Trull, T., 2007. An assessment of the use of sediment traps for estimating upper ocean particle fluxes. Journal of Marine Research 65 (3), 345-416.

Buesseler, K.O., Benitez-Nelson, C.R., Moran, S.B., Burd, A., Charette, M., Cochran, J.K., Coppola, L., Fisher, N.S., Fowler, S.W., Gardner, W., Guo, L.D., Gustafsson, O., Lamborg, C., Masque, P., Miquel, J.C., Passow, U., Santschi, P.H., Savoye, N., Stewart, G., Trull, T., 2006. An assessment of particulate organic carbon to thorium-234 ratios in the ocean and their impact on the application of ${ }^{234} \mathrm{Th}$ as a POC flux proxy. Marine Chemistry 100 (3-4), 213-233. 
Buesseler, K.O., Benitez-Nelson, C.R., Rutgers van der Loeff, M., Andrews, J., Ball, L., Crossin, G., Charette, M.A., 2001. An intercomparison of small- and largevolume techniques for thorium-234 in seawater. Marine Chemistry 74 (1), 15-28.

Buesseler, K.O., Lamborg, C., Cai, P., Escoube, R., Johnson, R., Pike, S., Masque, P., McGillicuddy, D., Verdeny, E., 2008a. Particle fluxes associated with mesoscale eddies in the Sargasso Sea. Deep-Sea Research II 55 (10-13), 1426-1444.

Buesseler, K.O., Michaels, A.F., Siegel, D.A., Knap, A.H., 1994. A three dimensional time-dependent approach to calibrating sediment trap fluxes. Global Biogeochemical Cycles 8 (2), 179-193.

Buesseler, K.O., Pike, S., Maiti, K., Lamborg, C.H., Siegel, D.A., Trull, T.W., 2008 b. Thorium-234 as a tracer of spatial, temporal and vertical variability in particle flux in the North Pacific. Deep-Sea Research Part I-Oceanographic Research Papers 56 (7), 1143-1167.

Cai, P., Chen, W., Dai, M., Wan, Z., Wang, D., Li, Q., Tang, T., Lv, D., 2008. A highresolution study of particle export in the southern South China Sea based on Th234/U-238 disequilibrium. Journal of Geophysical Research 113.

Chen, J.H., Edwards, R.L., Wasserburg, G.J., 1986. ${ }^{238} \mathrm{U},{ }^{234} \mathrm{U}$ and ${ }^{232} \mathrm{Th}$ in seawater. Earth and Planetary Science Letters 80 (3-4), 241-251.

Coale, K.H., Bruland, K.W., 1985. ${ }^{234} \mathrm{Th}:{ }^{238} \mathrm{U}$ disequilibria within the California Current. Limnology and Oceanography 30 (1), 22-33.

Coale, K.H., Bruland, K.W., 1987. Oceanic stratified euphotic zone as elucidated by ${ }^{234} \mathrm{Th}:{ }^{238} \mathrm{U}$ disequilibria. Limnology and Oceanography 32 (1), 189-200.

Cochran, J.K., Miquel, J.C., Armstrong, R., Fowler, S.W., Masqué, P., Gasser, B., Hirschberg, D., Szlosek, J., Rodriguez y Baena, A.M., Verdeny, E., Stewart, G., 2009. Time-series measurements of Th-234 in water column and sediment trap samples from the northwestern Mediterranean Sea. Deep-Sea Research II 56 (18), 1487-1501.

Delanghe, D., Bard, E., Hamelin, B., 2002. New TIMS constraints on the uranium-238 and uranium-234 in seawaters from the main ocean basins and the Mediterranean Sea. Marine Chemistry 80 (1), 79-93.

Ducklow, H.W., Doney, S.C., Steinberg, D.K., 2009. Contributions of Long-Term Research and Time-Series Observations to Marine Ecology and Biogeochemistry. Annual Review of Marine Science 1, 279-302.

Ducklow, H.W., Erickson, M., Kelly, J., Montes-Hugo, M., Ribic, C.A., Smith, R.C., Stammerjohn, S.E., Karl, D.M., 2008. Particle export from the upper ocean over the continental shelf of the west Antarctic Peninsula: A long-term record, 19922007. Deep-Sea Research II 55, 2118-2131.

Ducklow, H.W., Steinberg, D.K., Buesseler, K.O., 2001. Upper Ocean Carbon Export and the Biological Pump. Oceanography 14 (4), 50-58.

Dugdale, R.C., Goering, J.J., 1967. Uptake of new and regenerated forms of nitrogen in primary productivity. Limnology and Oceanography 12 (2), 196-206.

Eppley, R.W., 1989. New production: history, methods, and problems. In: Berger, W.H., Smetacek, V.S., Wefer, G. (Eds.), Productivity of the Ocean: Present and Past. Wiley \& Sons, New York, pp. 85-97. 
Eppley, R.W., Peterson, B.J., 1979. Particulate organic matter flux and planktonic new production in the deep ocean. Nature 282 (5740), 677-680.

Garçon, V.C., Oschlies, A., Doney, S.C., McGillicuddy Jr., D.J., Waniek, J., 2001. The role of mesoscale variability on plankton dynamics in the North Atlantic. DeepSea Research II 48, 2199-2226.

Gardner, W.D., 1985. The effect of tilt on sediment trap efficiency. Deep Sea Research $32,349-361$.

Guidi, L., Jackson, G.A., Stemmann, L., Miquel, J.C., Picheral, M., Gorsky, G., 2008. Relationship between particle size distribution and flux in the mesopelagic zone. Deep-Sea Research I 55 (1364-1374).

Guidi, L., Stemmann, L., Legendre, L., Picheral, M., Prieur, L., Gorsky, G., 2007. Vertical distribution of aggregrates $(>110 \mu \mathrm{m})$ and mesoscale activity in the northeastern Atlantic: Effects on the deep vertical export of surface carbon. Limnology \& Oceanography 52, 7-18.

Gust, G., Bowles, W., Giordano, S., Huettel, M., 1996. Particle accumulation in a cylindrical sediment trap under laminar and turbulent steady flow, An experimental approach. Aquatic Sciences 58, 297-326.

Henson, S.A., Sanders, R., Madsen, E., Morris, P.J., Le Moigne, F., Quartly, G.D., 2011. A reduced estimate of the strength of the ocean's biological carbon pump. Geophysical Research Letters 38 (L04606).

Honjo, S., 1996. Fluxes of Particles to the Interior of the Open Oceans. In: Ittekkot, V., Schafer, P., Honjo, S., Depetris, P.J. (Eds.), Particle Flux in the Ocean. John Wiley \& Sons, New York, pp. 91-154.

Kadko, D., Feely, R., Massoth, G., 1994. Scavenging of Th-234 and phosphorus removal from the hydrothermal effluent plume over the North Cleft segment of the Juan de Fuca Ridge. Journal of Geophysical Research 99, 5017-5024.

Knauer, G.A., Martin, J.H., Bruland, K.W., 1979. Fluxes of particulate carbon, nitrogen, and phosphorus in the upper water column of the northeast Pacific. Deep-Sea Research 26 (1), 97-108.

Lamborg, C.H., Buesseler, K.O., Valdes, J., Bertrand, C.H., Bidigare, R., Manganini, S., Pike, S., Steinberg, D., Trull, T., Wilson, S., 2008. The flux of bio- and lithogenic material associated with sinking particles in the mesopelagic "twilight zone" of the northwest and North Central Pacific Ocean. Deep-Sea Research Part IiTopical Studies in Oceanography 55 (14-15), 1540-1563.

Lampitt, R.S., Boorman, B., Brown, L., Lucas, M., Salter, I., Sanders, R., Saw, K., Seeyave, S., Thomalla, S.J., Turnewitsch, R., 2008. Particle export from the euphotic zone: Estimates using a novel drifting sediment trap, Th-234 and new production. Deep-Sea Research Part I-Oceanographic Research Papers 55 (11), 1484-1502.

Laws, E.A., Falkowski, P.G., Smith, W.O., Ducklow, H., McCarthy, J.J., 2000. Temperature effects on export production in the open ocean. Global Biogeochemical Cycles 14 (4), 1231-1246. 
Lee, C., Hedges, J.I., Wakeham, S.G., Zhu, N., 1992. Effectiveness of various treatments in retarding microbial activity in sediment trap material and their effects on the collection of swimmers. Limnology \& Oceanography 37 (1), 117-130.

Lévy, M., Klein, P., 2004. Does the low frequency of the mesoscale dynamics explain a part of the phytoplankton and zooplankton spectral variability? Proceedings of the Royal Society of London A 460, 1673-1687.

Mackas, D.L., Boyd, C.M., 1979. Spectral analysis of zooplankton spatial heterogeneity. Science 204, 62-64.

Mahadevan, A., Campbell, J., 2002. Biogeochemical patchiness at the sea surface. Geophysical Research Letters 29 (19), 1926.

Martin, A.P., 2003. Phytoplankton patchines: the role of lateral stirring and mixing. Progress in Oceanography 57, 125-174.

Martin, P., Lampitt, R.S., Perry, M.J., Sanders, R., Lee, C., D'Asaro, E., 2011. Export and mesopelagic particle flux during a North Atlantic spring diatom bloom. Deep-Sea Research I 58, 338-349.

Michaels, A.F., Silver, M.W., 1988. Primary production, sinking fluxes, and the microbial food web. Deep Sea Research 35, 473-490.

Michaels, A.F., Silver, M.W., Gowing, M.M., Knauer, G.A., 1990. Cryptic zooplankton "swimmers" in upper ocean sediment traps. Deep-Sea Research I 37 (8A), 1285 1296.

Pates, J.M., Muir, G.K.P., 2007. U-salinity relationships in the Mediterranean: Implications for Th-234/U-238 particle flux studies. Marine Chemistry 106, 530545.

Pike, S.M., Buesseler, K.O., Andrews, J., Savoye, N., 2005. Quantification of ${ }^{234} \mathrm{Th}$ recovery in small volume sea water samples by inductively coupled plasma mass spectrometry. Journal of Radioanalytical and Nuclear Chemistry 263 (2), 355360.

Resplandy, L., Martin, A.P., Le Moigne, F., Martin, P., Aquilina, A., Mémery, M., Lévy, M., Sanders, R., 2012. How does dynamical spatial variability impact Th-234 derived estimates of organic export? Deep-Sea Research I.

Robinson, L.F., Belshaw, N.S., Henderson, G.M., 2004. U and Th concentrations and isotope ratios in modern carbonates and waters from the Bahamas. Geochimica et Cosmochimica Acta 68 (8), 1777-1789.

Rutgers van der Loeff, M., Sarin, M.M., Baskaran, M., Benitez-Nelson, C., Buesseler, K.O., Charette, M., Dai, M., Gustafsson, O., Masque, P., Morris, P.J., Orlandini, K., Baena, A.R.Y., Savoye, N., Schmidt, S., Turnewitsch, R., Voge, I., Waples, J.T., 2006. A review of present techniques and methodological advances in analyzing ${ }^{234} \mathrm{Th}$ in aquatic systems. Marine Chemistry 100 (3-4), 190-212.

Sarmiento, J.L., Toggweiler, J.R., 1984. A new model for the role of the oceans in determining atmospheric pCO2. Nature 308, 620-624.

Schlitzer, R., 2002. Carbon export fluxes in the Southern Ocean: results from inverse modeling and comparison with satellite-based estimates. Deep-Sea Research II 49 (9-10), 1623-1644. 
Schlitzer, R., 2004. Export production in the equatorial and North Pacific derived from dissolved oxygen, nutrient and carbon data. Journal of Oceanography 60 (1), 5362.

Smith, S.V., Hollibaugh, J.T., 1993. Coastal Metabolism and the Oceanic OrganicCarbon Balance. Reviews of Geophysics 31 (1), 75-89.

Steinberg, D.K., Pilskaln, C.H., Silver, M.W., 1998. Contribution of zooplankton associated with detritus to sediment trap "swimmer" carbon in Monterey Bay, CA. Marine Ecology Progress Series 164, 157-166.

Usbeck, R., Schlitzer, R., Fischer, G., Wefer, G., 2003. Particle fluxes in the ocean: comparison of sediment trap data with results from inverse modeling. Journal of Marine Systems 39 (3-4), 167-183.

Valdes, J.R., Price, J.F., 2000. A neutrally buoyant, upper ocean sediment trap. Journal of Atmospheric and Oceanic Technology 17 (1), 62-68.

Waples, J.T., Benitez-Nelson, C., Savoye, N., Rutgers van der Loeff, M., Baskaran, M., Gustafsson, O., 2006. An introduction to the application and future use of ${ }^{234} \mathrm{Th}$ in aquatic systems. Marine Chemistry 100 (3-4), 166-189.

Whitfield, M., Turner, D.R., 1987. The role of particles in regulating the composition of seawater. Aquatic Surface Chemistry: Chemical Processes at the Particle-Water Interface. John Wiley and Sons, New York, NY, pp. 457-493.

Yoder, J.A., Aiken, J., Swift, R.N., Hoge, F.E., Stegmann, P.M., 1993. Spatial variability in near-surface chlorophyll a fluorescence measured by airborne oceanographic lidar (AOL). Deep-Sea Research II 40, 37-53. 


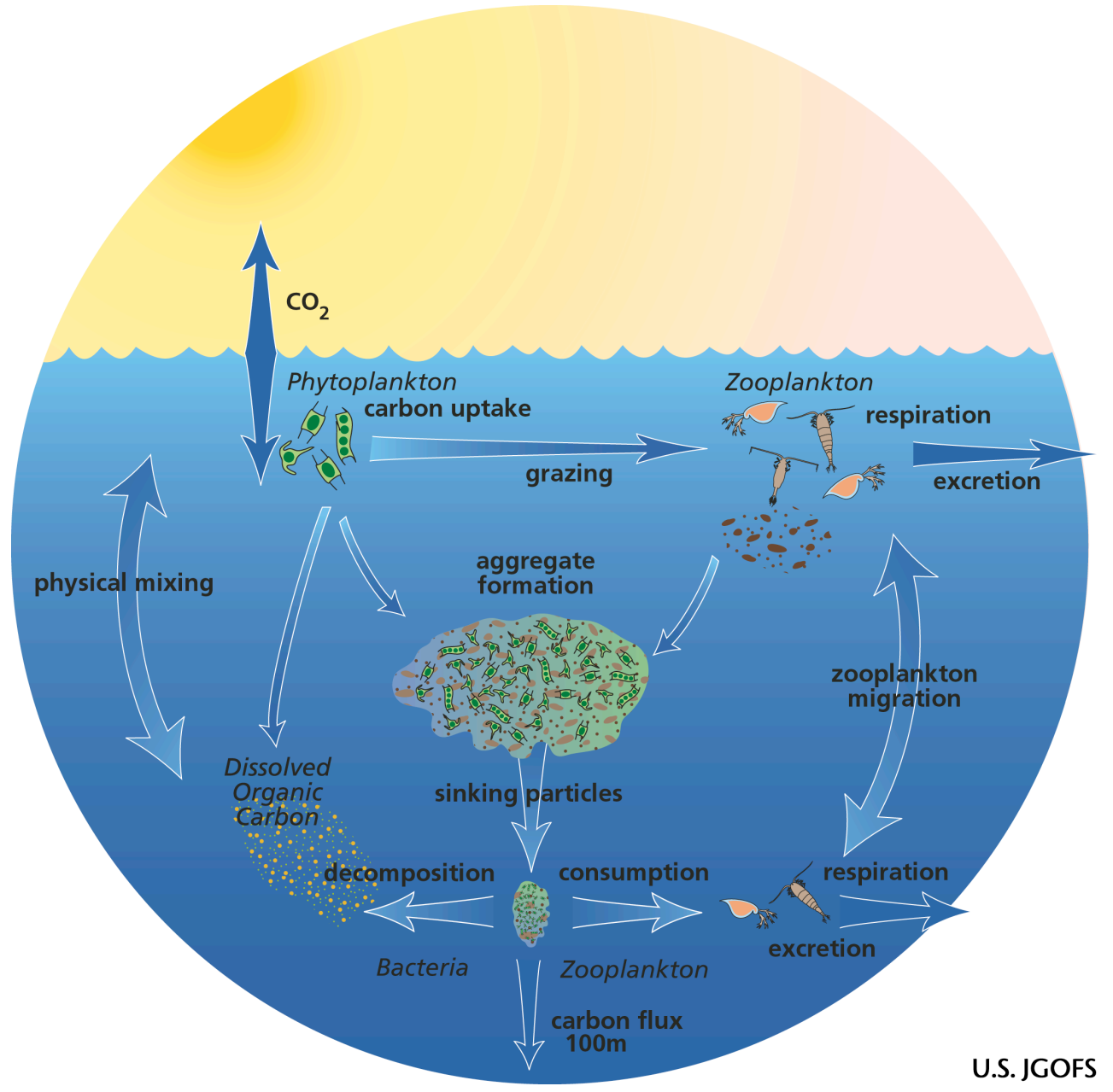

Figure 1 Schematic of surface ocean processes that compose the ocean's biological carbon pump. Phytoplankton take up carbon dioxide and nutrients in the sunlit region to create dissolved (DOM) and particulate organic matter (POM). A fraction of the organic matter produced becomes isolated below this layer by passive sinking of particles, downward mixing of DOM, or active transport by zooplankton. Within this surface layer and below it, POM can aggregate, be grazed, or remineralized. (Reproduced with permission from U.S. JGOFS office: http://usjgofs.whoi.edu/general_info/gallery.html) 


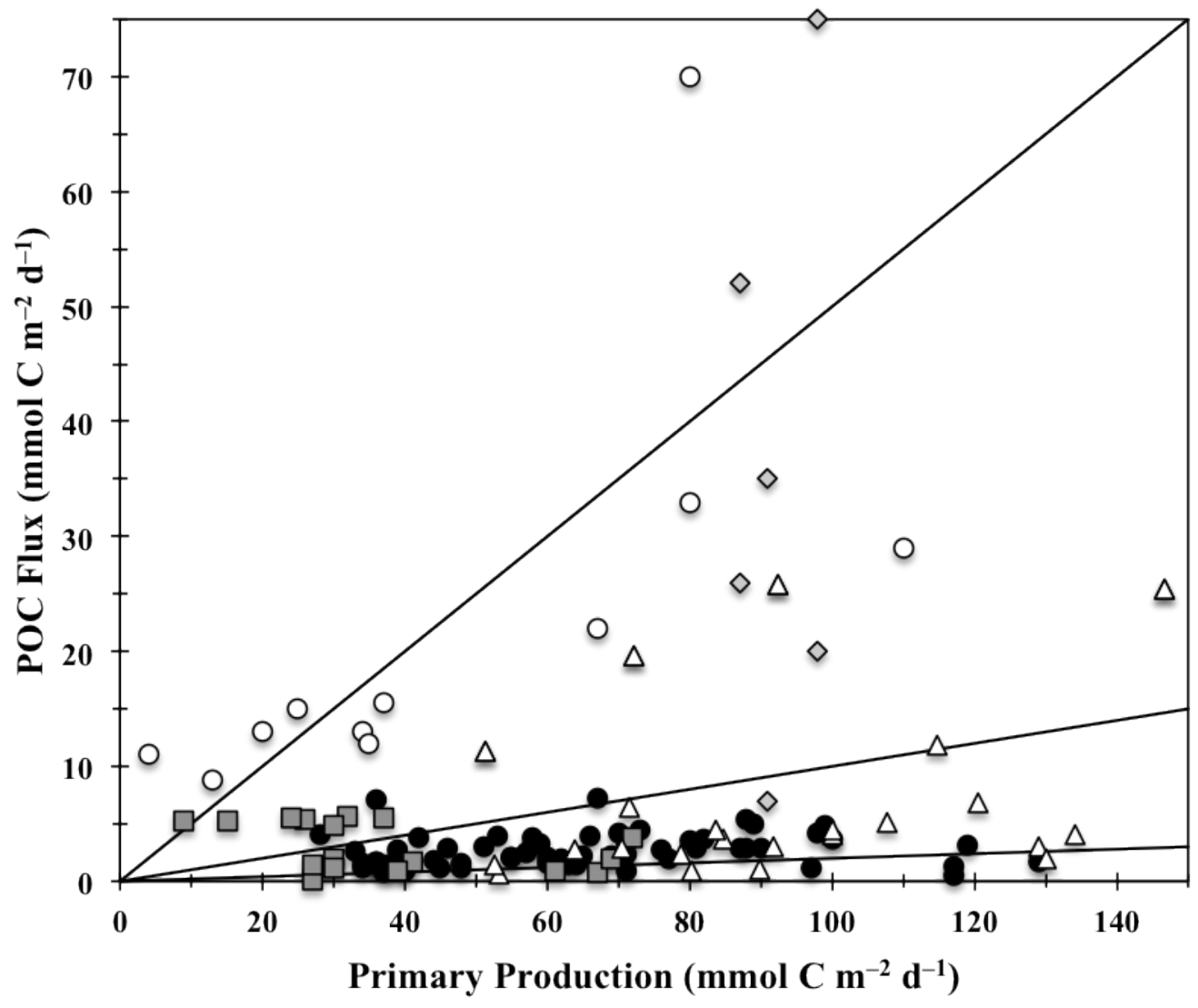

- Equatorial Pacific

$\square$ Subtropical Atlantic

$\triangle$ Arabian Sea

O High Latitudes

$\diamond$ North Atlantic

Figure 2 Carbon flux versus primary production measurements from the equatorial Pacific, subtropical Atlantic, Arabian Sea, the Arctic and Southern Ocean, and the north Atlantic. Ratios between export and primary production vary widely within and between oceanic regions. Reproduced from Buesseler, 1998. 


\section{Chapter 2:}

Re-evaluating the ${ }^{238} \mathrm{U}$ - salinity relationship in seawater: Implications for the ${ }^{238} \mathrm{U}-{ }^{234} \mathrm{Th}$ disequilibrium method

This chapter was originally published in Marine Chemistry by Elsevier and is reproduced here with their permission.

Re-evaluating the ${ }^{238} \mathrm{U}$ - salinity relationship in seawater: Implications for the ${ }^{238} \mathrm{U}-$ ${ }^{234}$ Th disequilibrium method. Marine Chemistry. S.A. Owens, K.O. Buesseler, K.W.W. Sims, 2011. 127 (1-4), 31-39. 


\title{
Re-evaluating the ${ }^{238} \mathrm{U}$-salinity relationship in seawater: Implications for the ${ }^{238} \mathrm{U}_{-}{ }^{234} \mathrm{Th}$ disequilibrium method
}

\author{
S.A. Owens ${ }^{\text {a,b, } * \text {, K.O. Buesseler }}{ }^{a}$, K.W.W. Sims ${ }^{c}$ \\ a Department of Marine Chemistry and Geochemistry MS\#25, Woods Hole Oceanographic Institution, 266 Woods Hole Road, Woods Hole, MA 02543, USA \\ b MT-WHOI Joint Program in Oceanography/Applied Ocean Science Engineering, 266 Woods Hole Road, Woods Hole, MA 02543, USA \\ ' Department of Geology and Geophysics, University of Wyoming, Dept. 3006, Laramie, WY 82071, USA
}

\section{A R T I C L E I N F O}

\section{Article history:}

Received 23 May 2011

Received in revised form 13 July 2011

Accepted 14 July 2011

Available online $\mathrm{xxxx}$

\section{Keywords:}

Uranium

Salinity

Salinity

Particle export

\begin{abstract}
A B S T R A C T
The concentration of ${ }^{238} \mathrm{U}$ in seawater is an important parameter required for applications of uranium decayseries radionuclides used to understand particle export and cycling in marine environments. Using modern mass spectrometer techniques, we re-evaluated the relationship between ${ }^{238} \mathrm{U}$ and salinity in the open ocean. The new ${ }^{238} \mathrm{U}$-salinity relationship determined here is based on a larger sample set and a wider salinity range than previous work in the open ocean. Four samples from 500 to $1000 \mathrm{~m}$ in the subtropical Atlantic deviated significantly from their concentration predicted from salinity; these low concentrations are hypothesized to be the result of a remote removal process rather than analytical bias or local removal of uranium. We also bring attention to unique deficits of ${ }^{234} \mathrm{Th}$ in the mesopelagic zone of the subtropical Atlantic and encourage future applications of ${ }^{234} \mathrm{Th}$ to delve into the cause of these features. Determining the concentration of ${ }^{238} \mathrm{U}$ in the open ocean is critical for minimizing uncertainty in the ${ }^{238} \mathrm{U}-{ }^{234} \mathrm{Th}$ disequilibrium method, which is a key tool for understanding particle flux to the deep ocean.
\end{abstract}

(c) 2011 Elsevier B.V. All rights reserved.

\section{Introduction}

The marine geochemistry of uranium has been studied for several decades beginning with measurements of its speciation and distribution in the ocean (Ku et al., 1977) and expanding to studies of its daughter isotopes for tracers of past and present marine processes (Cochran, 1992). Measurements of uranium by alpha spectroscopy were some of the earliest to report conservative behavior of uranium with respect to salinity in the open ocean (Ku et al., 1977). A linear relationship between salinity and uranium concentration could only be established for the Antarctic and Arctic Oceans, due to the narrow range of salinities of the samples analyzed however. Later work used mass spectrometric techniques to perform similar measurements in the Atlantic and Pacific Oceans (Chen et al., 1986; Chen and Wasserburg, 1981). The relationship established by Chen et al. (1986) is still the most widely referenced value for determining uranium concentrations in seawater from salinity.

Despite the widespread use of the Chen et al. (1986) relationship, non-conservative behavior or deviations from this relationship have been reported in the open ocean. In a study of the Atlantic Ocean, it was hypothesized that low uranium-238 concentrations relative to salinity were due to the influence of Mediterranean Outflow Water (MOW) (Delanghe et al., 2002) but later work found no evidence to support this hypothesis (Schmidt, 2006). In another notable instance,

* Corresponding author. Tel.: +1 508289 3843; fax: +1 5084572193.

E-mail addresses: sowens@whoi.edu (S.A. Owens), kbuesseler@whoi.edu (K.O. Buesseler), ksims7@uwyo.edu (K.W.W. Sims).

0304-4203/\$ - see front matter (c) 2011 Elsevier B.V. All rights reserved. doi:10.1016/j.marchem.2011.07.005
Robinson et al. (2004) measured higher values of ${ }^{238} U$ in the Bahamas than predicted from salinity. In a review of ${ }^{234} \mathrm{Th}$ methodology, Rutgers van der Loeff et al. (2006) compiled ocean ${ }^{238} \mathrm{U}$ data and described possible causes of deviations from conservative behavior particularly sedimentary and estuarine addition and removal processes. Most recently, work in the Mediterranean Sea revealed higher ${ }^{238} \mathrm{U}$ concentrations than predicted from salinity (Pates and Muir, 2007). Pates \& Muir (2007) hypothesized that deviation from the Chen et al. relationship may be significant in the Mediterranean Sea due to its large river inputs and its restricted exchange with the open ocean. They proposed a revised ${ }^{238} \mathrm{U}$-salinity relationship, which combined previously published mass spectrometry data with their own, although they were not able to rule out analytical bias as a cause of variability between the studies. The resulting relationship between ${ }^{238} \mathrm{U}$ and salinity was not significantly different from that of Chen et al. however it resulted in a larger uncertainty than previously published (Pates and Muir, 2007).

The Chen et al. (1986) uranium-salinity relationship is frequently utilized in the ${ }^{238} \mathrm{U}-{ }^{234} \mathrm{Th}$ disequilibrium method, which is used to quantify particulate export flux and elucidate particle dynamics. This method takes advantage of the contrasting chemical behavior of uranium and thorium in seawater (Bacon et al., 1996; Bhat et al., 1969; Buesseler et al., 1992). At pH values and $\mathrm{CO}_{2}$ concentrations typical of oxic seawater, the predominant uranium species, $\mathrm{U}(\mathrm{VI})$, is highly soluble and occurs as a stable carbonate ion complex, $\mathrm{UO}_{2}\left(\mathrm{CO}_{3}\right)_{3}^{4-}$ (Djogic et al., 1986). In contrast, Th(IV), the stable ion of thorium under oxic conditions, is highly particle reactive (Santschi et al., 2006). The $4.47 \times 10^{9} \mathrm{y}$ half-life of ${ }^{238} \mathrm{U}$ 
(Jaffey et al., 1971) greatly exceeds the 24.1 day half-life of its daughter, ${ }^{234} \mathrm{Th}$. Due to the large difference in the half-lives of this parent-daughter nuclide pair, when there are no external forces adding or removing either of the two isotopes from the system, ${ }^{238} \mathrm{U}$ and ${ }^{234} \mathrm{Th}$ achieve a state of secular equilibrium after 5 to 6 half-lives of ${ }^{234} \mathrm{Th}$. At secular equilibrium, the activity of ${ }^{234} \mathrm{Th}$ is equal to the activity of ${ }^{238} \mathrm{U}$. In the surface ocean, a deficit of ${ }^{234} \mathrm{Th}$ activity (relative to ${ }^{238} \mathrm{U}$ ) occurs when ${ }^{234} \mathrm{Th}$ sorbs to particulate matter and is removed as that material sinks. An excess of ${ }^{234} \mathrm{Th}$ can occur when dissolution or remineralization of sinking particles occurs, releasing ${ }^{234} \mathrm{Th}$ into solution deeper in the water column. This approach requires knowledge of the activity of both ${ }^{234} \mathrm{Th}$ and ${ }^{238} \mathrm{U}$ in seawater and the uranium-salinity relationship is a convenient means of estimating ${ }^{238} \mathrm{U}$ activity. Quantifying the uncertainty in the ${ }^{238} \mathrm{U}$-salinity relationship can also be important for minimizing uncertainty in estimates of ${ }^{234} \mathrm{Th}$ flux. As illustrated in Fig. 6 of Pates \& Muir (2007), a $1 \%$ difference in uncertainty of ${ }^{238} \mathrm{U}$ measurements can result in up to a $5 \%$ difference in ${ }^{234} \mathrm{Th}$ flux uncertainty.

Motivation for this work stemmed from observations of ${ }^{234} \mathrm{Th}$ during the Eddy Dynamic Mixing, Export, and Species (EDDIES) program in the Sargasso Sea, which studied the effect of eddy-induced changes on biogeochemical cycling (Buesseler et al., 2008a; McGillicuddy Jr. et al., 2007). Typically, deficits of ${ }^{234} \mathrm{Th}$ are constrained to the euphotic zone as a result of marine particle formation through primary production and subsequent removal by passive sinking of the particles (Bacon et al., 1996; Buesseler et al., 2008a, 2008b). In EDDIES however, at least three profiles of ${ }^{234} \mathrm{Th}$ were collected showing a ${ }^{234} \mathrm{Th}$ deficit relative to ${ }^{238} \mathrm{U}$ between 500 and $1000 \mathrm{~m}$ defined by at least three individual samples in each case. This ${ }^{234} \mathrm{Th}$ deficit tended to be co-located with the local oxygen minimum zone. This feature could be due to anomalous ${ }^{238} \mathrm{U}$ behavior at these depths or a particle repackaging process that was reflected in the ${ }^{234} \mathrm{Th}$ profile. Unfortunately, no samples for ${ }^{238} \mathrm{U}$ were collected during the EDDIES program. In other studies of ${ }^{234} \mathrm{Th}$, similar features have been observed in one or two samples from intermediate depths however, because of its utility as a measure of export flux, most studies focus sampling efforts on the euphotic zone, providing limited depth resolution through the mesopelagic (Benitez-Nelson et al., 2001a; Coppola et al., 2005; Schmidt, 2006). In this work, we attempt to capture these unique ${ }^{234} \mathrm{Th}$ features with paired measurements of ${ }^{238} \mathrm{U}$ and ${ }^{234} \mathrm{Th}$ and increased sampling resolution through the mesopelagic zone to highlight unique and previously undescribed behavior of both ${ }^{238} \mathrm{U}$ and ${ }^{234} \mathrm{Th}$ at these depths. Finally we propose an alternate ${ }^{238} \mathrm{U}$-salinity relationship developed from a large set of ${ }^{238} \mathrm{U}$ measurements that encompasses a wide range of salinity values and was obtained using sensitive mass spectrometric techniques.

\section{Methods}

\subsection{Study sites}

Samples were collected on three cruises to the Bermuda Atlantic Time-series Study site (BATS) on the R/V Atlantic Explorer in July 2007 , June 2008, and September 2009, a cruise (SIRENA) across the tropical Atlantic on the R/V Oceanus in August 2009, and on three cruises to the Southern Ocean on the ARSV Laurence M. Gould in January 2009 and 2010 and on the RVIB Nathaniel B. Palmer in March 2010. Salinity values for the Southern Ocean samples were taken from CTD sensors, which were calibrated on an annual basis and exhibit an insignificant amount of drift between calibrations (e.g. $+0.00010 \mathrm{psu}_{\text {month }}{ }^{-1}$ ). Salinity values for samples from the BATS site and the tropical Atlantic were made using a salinometer either on land or at sea.

\section{2. ${ }^{238} U$ Sampling and concentration measurements}

Collection vials for ${ }^{238} \mathrm{U}$ were prepared by washing them in a $10 \%$ $\mathrm{HCl}$ solution followed by $5 \% \mathrm{HNO}_{3}$ solution, rinsing with ultra-clean water $(18.2 \mathrm{M} \Omega$ ) before and after each step. The vials were rinsed with the sample water three times before filling and were then sealed with Parafilm $\otimes$ to prevent evaporation. Samples were stored in a dark, room-temperature environment until preparation for analysis.

${ }^{238} \mathrm{U}$ concentrations were determined by isotope dilution (ID) using a Thermo Scientific ELEMENT 2 Inductively Coupled Plasma Mass Spectrometer (ICP-MS). Teflon ${ }^{\circledR}$ vials were used throughout sample preparation and were subjected to rigorous cleaning including soaking and boiling in $50 \% \mathrm{HCl}$, soaking in aqua regia $\left(1: 3 \mathrm{HNO}_{3}\right.$ and $\left.\mathrm{HCl}\right)$, soaking and boiling in $50 \% \mathrm{HNO}_{3}$, and a final boil in weakly acidifed $\left(\mathrm{HNO}_{3}\right)$ water with generous rinses of ultra-clean water between each step. Sample aliquots of $5 \mathrm{~mL}$ were spiked with a well-calibrated ${ }^{233} \mathrm{U}$ spike to achieve ${ }^{238} \mathrm{U} /{ }^{233} \mathrm{U} \approx 10$; the collection vial, the spike bottle, and the Teflon vial into which the sample and spike were aliquoted, were weighed when sample or spike was removed or added in order to precisely determine the mass of sample and spike in each analysis aliquot. Samples were equilibrated and digested over the course of two days. First, samples were allowed to evaporate overnight at $75{ }^{\circ} \mathrm{C}$ in a laminar flow bench. After cooling, $1 \mathrm{~mL}$ concentrated $\mathrm{HNO}_{3}$ was added to each sample, which was then capped and returned to the hot-plate for $15 \mathrm{~min}$. Then $1 \mathrm{~mL}$ of Milli-Q water was added to each sample and samples were capped and left to sit overnight at room temperature to allow complete equilibration and digestion. Uranium was purified and separated from salts using anion exchange columns. Eichrom $2 \mathrm{~mL}$ acid-cleaned columns were prepared using $1 \mathrm{~mL}$ of pre-conditioned $\left(50 \% \mathrm{HCl}\right.$ and dilute $\mathrm{HNO}_{3}$ with Milli-Q rinses) Eichrom AG1 $\times 8$ anion exchange resin. Each column was further conditioned with Milli-0, $10 \mathrm{M} \mathrm{HCl}, 1 \mathrm{M} \mathrm{HCl}$, Milli-O, and $7 \mathrm{M}$ $\mathrm{HNO}_{3}$. The dissolved samples $\left(\sim 7 \mathrm{M} \mathrm{HNO}_{3}\right)$ were loaded onto the columns and the sample dissolution vials were carefully rinsed with additional $7 \mathrm{M} \mathrm{HNO}_{3}$. To collect uranium, the columns were eluted with Milli-Q, $1 \mathrm{M} \mathrm{HCl}$, and $1 \mathrm{M} \mathrm{HBr}$. Samples were dried overnight at a low temperature and then sample vials were stored in bags until analysis.

Immediately prior to analysis, samples were brought up in $1 \mathrm{~mL}$ of $5 \%$ $\mathrm{HNO}_{3}$ and quickly measured in analog mode. Based on the initial intensity of the major isotope, ${ }^{238} \mathrm{U}$, the samples were then diluted such that all isotopes of $U$ were measured in ion counting mode. The instrument was tuned using the NBS-960 standard to achieve flat peak tops and stable signal intensity. Mass fractionation corrections were made by bracketing samples with the NBS-960 standard $\left({ }^{238} \mathrm{U} /{ }^{235} \mathrm{U}=137.88\right)$ and using the linear average to correct the measured ${ }^{238} \mathrm{U} /{ }^{235} \mathrm{U}(0.04-2.76 \%$ correction) and ${ }^{238} \mathrm{U} /{ }^{233} \mathrm{U}(0.07-4.55 \%$ correction) ratios. Similarly, samples were blank corrected using bracketed blank acid samples. Background signals of ${ }^{233} \mathrm{U}$ and ${ }^{238} \mathrm{U}$ were less than $0.50 \%$ of the spike and sample signals. Prior to data collection, the in-growth of the NBS-960 or sample signal was observed until it appeared stable, at which point data collection was initiated. Each sample was analyzed in triplicate, so that each reported value is the average of these individual measurements. The propagated error includes the standard deviation of these three measurements, the uncertainty associated with weighing the sample and spike, and the uncertainty on the ${ }^{233} \mathrm{U}$ spike calibration. The measurement sequence for a single sample was: blank-NBS-960blank-sample-sample-sample-blank-NBS960 and so forth. Samples of the International Association for Physical Sciences of the Ocean (IAPSO) Standard Seawater (OSIL P149) were analyzed to assess the reproducibility of the measurements over multiple runs on the ICP-MS and to establish a laboratory standard for future studies of ${ }^{238} \mathrm{U}$ in seawater. The calibration of our ${ }^{233} \mathrm{U}$ spike has also been verified in several studies using equilibrium rock standards (Sims et al., 2008).

\section{3. ${ }^{234}$ Th sampling and analysis}

${ }^{234} \mathrm{Th}$ was determined using the $4 \mathrm{~L}$ method of co-precipitating ${ }^{234} \mathrm{Th}$ with $\mathrm{MnO}_{2}$ and beta counting the samples on low background, coincidence detectors (Risø National Laboratories) either on land or at sea as soon as possible after collection (Benitez-Nelson et al., 2001b; Buesseler et al., 2001). Detector efficiency and background were determined at regular intervals over the period of this study. Final 
sample counts, after five half-lives ( $>4$ months), were performed to account for detector background and interfering beta emitters. Recovery efficiencies of the $\mathrm{MnO}_{2}$ precipitation step were determined using a ${ }^{230} \mathrm{Th}$ yield monitor (Pike et al., 2005). The reported error on ${ }^{234} \mathrm{Th}$ values includes the counting error of the initial and final counts and the uncertainty of the percent recovery determination. In cases where multiple samples were collected at the same depth, the uncertainties of the ${ }^{234} \mathrm{Th}$ values are the standard deviation of these measurements.

\section{Results}

The samples analyzed for ${ }^{238} \mathrm{U}$ concentration in this study encompass a wider salinity range (32.688-37.102) than most other works that employ high precision mass spectrometric techniques (Fig. 1, Table 1). Andersen et al. (2007) is the only other study that has a wider salinity range $(25.90-34.96, \mathrm{n}=20$; see Table 2$)$. The propagated error on the concentration measurements was $1.5 \%$. To establish the reproducibility of our method, replicate analyses of IAPSO Standard Seawater and samples from the BATS site were made. Here a sample replicate is defined as a unique $5 \mathrm{~mL}$ aliquot from a single sample collection vial that has been equilibrated with ${ }^{233} \mathrm{U}$, purified via column chemistry, and measured on the ICP-MS. IAPSO Standard Seawater (Salinity $=34.994$ ) was measured nine times with an average ${ }^{238} \mathrm{U}$ concentration of $3.116 \pm 0.028 \mathrm{ng} \mathrm{g}^{-1}$ and a relative standard deviation (RSD) of $0.9 \%$ (Tables $1 \& 2$ ). When two samples from the BATS site in June 2007 ( 100 and $800 \mathrm{~m}$ ) were analyzed in triplicate, the resulting RSD of the three measurements was $1.2 \%$ and $0.6 \%$ respectively (Table 1 ). The RSD for all samples analyzed in this study (normalized to $S=35$, without the four low BATS samples) is higher at $1.9 \%$ and may represent natural variability of ${ }^{238} \mathrm{U}$ concentration in the ocean relative to salinity (Table 2).

The linear relationship of ${ }^{238} \mathrm{U}$ with salinity in the open ocean provides a convenient way to estimate ${ }^{238} \mathrm{U}$ concentrations/activities without performing time-intensive analysis. Most of the samples analyzed in this study appear to vary linearly with salinity except for the four deepest samples from the BATS site in June 2007, which have lower ${ }^{238} \mathrm{U}$ concentrations than might be expected (Fig. 1a). These points are between 16 and $32 \%$ lower than predicted using the Chen et al. (1986) relationship. Possible explanations for these anomalously low values will be explored in the Discussion.

In prior studies of the relationship between ${ }^{238} \mathrm{U}$ and salinity, the standard procedure has been to normalize ${ }^{238} U$ concentrations of samples to a salinity of 35 and take the average and standard deviation of the normalized values in order to establish a conversion factor from salinity to ${ }^{238} \mathrm{U}$ concentration/activity. The narrow salinity range of samples collected in a single study often precludes the determination of a robust linear relationship. By normalizing all the data, linearity or conservative behavior is inherently assumed, and the standard deviation is used to describe the goodness of fit. With this data set we were able to perform a linear regression $(n=87$, excluding IAPSO samples and low concentration BATS samples) and determine an $R^{2}$ value for the fit. In units of $n g^{-1}$, the equation for the best-fit line with an $R^{2}$ of 0.78 is:

${ }^{238} \mathrm{U}( \pm 0.061)=(0.100 \pm 0.006) \times S-(0.326 \pm 0.206)$.

The root mean squared (rms) error for the regression is $0.061(1 \sigma)$; for a sample with a salinity $(S)$ of 35 , this results in a ${ }^{238} \mathrm{U}$ concentration of $3.174 \mathrm{ng} \mathrm{g}^{-1}$ with a $1.9 \%$ uncertainty.

For ${ }^{234} \mathrm{Th} /{ }^{238} \mathrm{U}$ disequilibrium studies however, the activity per unit volume ( $\mathrm{dpm} \mathrm{L}^{-1}$ ) rather than the mass per unit mass $\left(\mathrm{ng} \mathrm{g}^{-1}\right)$ is required. To convert from units of mass to activity we use Eq. (2):

$$
\begin{aligned}
{ }^{238} \mathrm{U}\left(\mathrm{dpm} \mathrm{g}^{-1}\right)= & { }^{238} \mathrm{U}\left(\mathrm{ng} \mathrm{g}^{-1}\right) \times 10^{-9} \times 1 / \mathrm{m}_{\mathrm{a}}\left({ }^{238} \mathrm{U}\right) \times \mathrm{N}_{\mathrm{A}} \\
& \times \ln (2) \times 1 / \mathrm{t}_{1 / 2}\left({ }^{238} \mathrm{U}\right)
\end{aligned}
$$

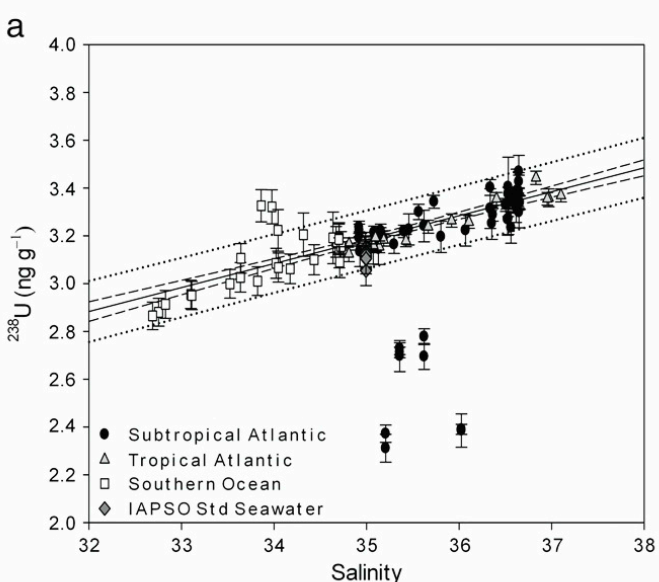

b

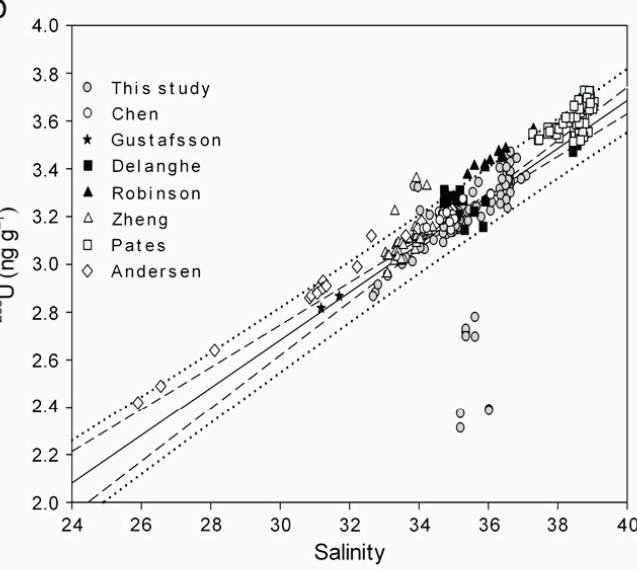

Fig. 1. Dissolved ${ }^{238} \mathrm{U}$ in seawater as a function of salinity. a) Results of mass spectrometry measurements of ${ }^{238} \mathrm{U}$ concentration in the subtropical and tropical Atlantic Ocean and the Southern Ocean. Also shown are measurements of IAPSO Standard Seawater used to confirm analysis reproducibility. The solid line is the best-fit line through all the data excluding the low subtropical Atlantic values and the IAPSO Sta interval for the linear regression and the dotted lines denote the $95 \%$ prediction interval (the range within which future observations of ${ }^{238} \mathrm{U}$ vs. salinity should fall). Note that the anomalous Southern Ocean and subtropical Atlantic samples fall outside of the $95 \%$ prediction interval. b) Results from previous mass spectrometry studies of ${ }^{238} \mathrm{U}$ in the open ocean and from this work. Note the change in the scale for the $\mathrm{x}$-axis. The lines are from the data in this study only (Fig. 1a), including the regression (solid), 95\% confidence interval (dashed), and 95\% prediction interval (dotted) lines.

where $m_{a}$ is the atomic mass of ${ }^{238} \mathrm{U}(238.050783 \mathrm{amu}), \mathrm{N}_{\mathrm{A}}$ is Avogadro's constant $\left(6.022 \times 10^{23} \mathrm{~mol}^{-1}\right)$, and the half-life of ${ }^{238} \mathrm{U}$ is $4.468 \times 10^{9} \mathrm{y}\left(2.348 \times 10^{15} \mathrm{~min}\right)$. The second conversion step that is required is from units per mass $\left(\mathrm{g}^{-1}\right)$ to units per volume $\left(\mathrm{L}^{-1}\right)$, which can be achieved by multiplying by the sample density $\left(\mathrm{kg} \mathrm{m}^{-3}\right)$. The density of samples was calculated using the sample salinity and room temperature $\left(20^{\circ} \mathrm{C}\right.$, the temperature at which samples were aliquoted) with the SeaWater Library Version $1.2 \mathrm{e}$ released by CSIRO Marine Research, which uses the UNESCO equations of state (Millero and Poisson, 1981; UNESCO, 1983). A second linear regression 
Table 1

${ }^{38} \mathrm{U}$ concentration measurements by ICP-MS. Replicates are $5 \mathrm{~mL}$ aliquots from a single sample collection vial or Standard Seawater vial that have been prepared and analyzed individually.

\begin{tabular}{|c|c|c|c|c|c|c|}
\hline $\begin{array}{l}\text { Collection Location } \\
\text { \& Date }\end{array}$ & $\begin{array}{l}\text { Depth } \\
(\mathrm{m})\end{array}$ & $\begin{array}{l}\text { Temperature } \\
\left({ }^{\circ} \mathrm{C}\right)\end{array}$ & Salinity & $\begin{array}{l}\mathrm{O}_{2} \\
\left(\mu \mathrm{mol} \mathrm{kg} \mathrm{kg}^{-1}\right)\end{array}$ & $\begin{array}{l}{ }^{238} \mathrm{U} \\
\left(\mathrm{ngg}^{-1}\right)\end{array}$ & $\begin{array}{l} \pm \text { Error } \\
\left(\mathrm{ngg}^{-1}\right)\end{array}$ \\
\hline $\begin{array}{l}\text { Subtropical Atlantic (BATS) } 31.665^{\circ} \mathrm{N} \times 64.168^{\circ} \mathrm{W} \\
\text { July } 182007\end{array}$ & $\begin{array}{r}3.9^{\mathrm{b}} \\
3.9^{\mathrm{c}} \\
99.1^{\mathrm{a}} \\
99.1^{\mathrm{b}} \\
99.1^{\mathrm{c}} \\
401.0^{\mathrm{b}} \\
401.0^{\mathrm{c}} \\
500.0^{\mathrm{b}} \\
50000^{\mathrm{c}} \\
600.5^{\mathrm{b}} \\
600.5^{\mathrm{c}} \\
699.3^{\mathrm{b}} \\
699.3^{\mathrm{c}} \\
799.2^{\mathrm{a}} \\
799.2^{\mathrm{b}} \\
799.2^{\mathrm{c}} \\
899.9^{\mathrm{b}} \\
899.9^{\mathrm{c}}\end{array}$ & $\begin{array}{r}27.390 \\
27.390 \\
19.140 \\
19.140 \\
19.140 \\
17.730 \\
17.730 \\
16.800 \\
16.800 \\
15.610 \\
15.010 \\
12.450 \\
12.450 \\
10.160 \\
10.160 \\
10.160 \\
8.280 \\
8.280\end{array}$ & $\begin{array}{l}36.620 \\
36.620 \\
36.646 \\
36.646 \\
36.646 \\
36.531 \\
36.531 \\
36.337 \\
36.337 \\
36.026 \\
36.026 \\
35.622 \\
35.622 \\
35.359 \\
35.359 \\
35.359 \\
35.206 \\
35.206\end{array}$ & $\begin{array}{l}205.4 \\
205.4 \\
211.7 \\
211.7 \\
211.7 \\
212.2 \\
212.2 \\
194.7 \\
194.7 \\
177.9 \\
177.9 \\
162.0 \\
162.0 \\
156.3 \\
156.3 \\
156.3 \\
169.7 \\
169.7\end{array}$ & $\begin{array}{l}3.373 \\
3.387 \\
3.426 \\
3.469 \\
3.386 \\
3.375 \\
3.405 \\
3.402 \\
3.314 \\
2.390 \\
2.385 \\
2.778 \\
2.695 \\
2.712 \\
2.728 \\
2.697 \\
2.372 \\
2.311\end{array}$ & $\begin{array}{l}0.028 \\
0.092 \\
0.028 \\
0.068 \\
0.078 \\
0.028 \\
0.124 \\
0.033 \\
0.083 \\
0.021 \\
0.070 \\
0.033 \\
0.054 \\
0.022 \\
0.025 \\
0.065 \\
0.036 \\
0.058\end{array}$ \\
\hline $\begin{array}{l}\text { Subtropical Atlantic (BATS) } 31.765^{\circ} \mathrm{N} \times 64.311^{\circ} \mathrm{W} \\
\text { June } 272008\end{array}$ & $\begin{array}{r}25.6 \\
56.2 \\
75.1 \\
100.8 \\
126.0 \\
151.2 \\
176.2 \\
201.2 \\
300.6 \\
400.2 \\
600.3 \\
650.3 \\
700.4 \\
749.9 \\
800.9 \\
850.0 \\
901.0 \\
950.4 \\
1000.9 \\
1101.0 \\
3000.0 \\
3000.3 \\
3000.0 \\
3000.6\end{array}$ & $\begin{array}{r}22.953 \\
20.425 \\
19.745 \\
19.329 \\
18.757 \\
18.481 \\
18.306 \\
18.235 \\
17.651 \\
17.013 \\
13.382 \\
12.156 \\
10.848 \\
9.851 \\
8.642 \\
7.825 \\
7.218 \\
6.571 \\
6.239 \\
5.526 \\
2.611 \\
2.611 \\
2.611 \\
2.611\end{array}$ & $\begin{array}{l}36.616 \\
36.640 \\
36.649 \\
36.658 \\
36.615 \\
36.598 \\
36.582 \\
36.581 \\
36.505 \\
36.365 \\
35.729 \\
35.564 \\
35.402 \\
35.298 \\
35.186 \\
35.153 \\
35.153 \\
35.111 \\
35.114 \\
35.081 \\
34.918 \\
34.921 \\
34.942 \\
34.921\end{array}$ & $\begin{array}{l}227.0 \\
230.9 \\
229.5 \\
222.9 \\
212.7 \\
200.8 \\
199.7 \\
201.5 \\
203.3 \\
198.3 \\
171.2 \\
160.1 \\
154.5 \\
152.9 \\
157.9 \\
171.1 \\
186.2 \\
197.2 \\
207.1 \\
223.7 \\
266.3 \\
266.3 \\
266.3 \\
266.3\end{array}$ & $\begin{array}{l}3.320 \\
3.351 \\
3.343 \\
3.339 \\
3.328 \\
3.342 \\
3.342 \\
3.352 \\
3.329 \\
3.288 \\
3.342 \\
3.300 \\
3.215 \\
3.164 \\
3.189 \\
3.221 \\
3.208 \\
3.177 \\
3.173 \\
3.214 \\
3.236 \\
3.223 \\
3.183 \\
3.191\end{array}$ & $\begin{array}{l}0.064 \\
0.028 \\
0.028 \\
0.028 \\
0.027 \\
0.027 \\
0.031 \\
0.027 \\
0.027 \\
0.026 \\
0.027 \\
0.032 \\
0.026 \\
0.038 \\
0.032 \\
0.028 \\
0.026 \\
0.026 \\
0.030 \\
0.027 \\
0.026 \\
0.026 \\
0.027 \\
0.026\end{array}$ \\
\hline $\begin{array}{l}\text { Subtropical Attantic (BATS) }-31.467^{\circ} \mathrm{N} \times-63.900^{\circ} \mathrm{W} \\
\text { Sept } 21-242010\end{array}$ & $\begin{array}{r}21.3 \\
175.7 \\
302.1 \\
402.9 \\
504.8 \\
606.0 \\
657.1 \\
706.1 \\
757.8 \\
906.7 \\
1008.7 \\
1518.0 \\
3043.4\end{array}$ & $\begin{array}{r}27.764 \\
19.345 \\
18.262 \\
17.928 \\
16.977 \\
15.376 \\
13.807 \\
12.611 \\
11.393 \\
7.852 \\
6.376 \\
4.299 \\
2.766\end{array}$ & $\begin{array}{l}36.533 \\
36.646 \\
36.561 \\
36.524 \\
36.355 \\
36.070 \\
35.805 \\
35.621 \\
35.456 \\
35.129 \\
35.072 \\
34.987 \\
34.928\end{array}$ & $\begin{array}{l}197.7 \\
200.0 \\
202.3 \\
197.2 \\
184.8 \\
169.9 \\
158.6 \\
150.0 \\
143.8 \\
167.1 \\
200.2 \\
250.4 \\
267.3\end{array}$ & $\begin{array}{l}3.272 \\
3.299 \\
3.234 \\
3.269 \\
3.252 \\
3.223 \\
3.196 \\
3.241 \\
3.227 \\
3.145 \\
3.148 \\
3.134 \\
3.134\end{array}$ & $\begin{array}{l}0.066 \\
0.066 \\
0.065 \\
0.066 \\
0.067 \\
0.066 \\
0.066 \\
0.066 \\
0.065 \\
0.065 \\
0.066 \\
0.081 \\
0.063\end{array}$ \\
\hline $\begin{array}{l}\text { Tropical Atlantic } 13.071^{\circ} \mathrm{N} \times 40.628^{\circ} \mathrm{W} \\
\text { Aug } 152008\end{array}$ & $\begin{array}{r}58.4 \\
91.3 \\
100.0 \\
110.0 \\
150.4 \\
199.0 \\
250.4 \\
376.4 \\
439.7\end{array}$ & $\begin{array}{r}24.909 \\
23.461 \\
22.181 \\
20.585 \\
17.643 \\
14.872 \\
13.370 \\
10.143 \\
9.233\end{array}$ & $\begin{array}{l}36.969 \\
37.102 \\
36.954 \\
36.831 \\
36.405 \\
35.919 \\
35.666 \\
35.186 \\
35.059\end{array}$ & $\begin{array}{l}196.0 \\
190.2 \\
1.82 .8 \\
162.9 \\
121.7 \\
98.8 \\
30.4 \\
85.4 \\
93.8\end{array}$ & $\begin{array}{l}3.359 \\
3.369 \\
3.355 \\
3.443 \\
3.355 \\
3.264 \\
3.238 \\
3.183 \\
3.167\end{array}$ & $\begin{array}{l}0.037 \\
0.027 \\
0.027 \\
0.028 \\
0.027 \\
0.028 \\
0.027 \\
0.026 \\
0.033\end{array}$ \\
\hline $\begin{array}{l}\text { Tropical Atlantic } 11.715^{\circ} \mathrm{N} \times 28.861^{\circ} \mathrm{W} \\
\text { Aug } 242008\end{array}$ & $\begin{array}{r}5.8 \\
100.7 \\
200.6 \\
300.7 \\
439.3 \\
600.0\end{array}$ & $\begin{array}{r}28.535 \\
13.954 \\
11.592 \\
10.761 \\
9.998 \\
8.253\end{array}$ & $\begin{array}{l}36.106 \\
35.426 \\
35.139 \\
35.074 \\
35.096 \\
34.962\end{array}$ & $\begin{array}{l}196.9 \\
97.9 \\
1.14 .5 \\
87.4 \\
48.4 \\
61.0\end{array}$ & $\begin{array}{l}3.258 \\
3.180 \\
3.154 \\
3.160 \\
3.193 \\
3.174\end{array}$ & $\begin{array}{l}0.026 \\
0.026 \\
0.025 \\
0.026 \\
0.026 \\
0.026\end{array}$ \\
\hline
\end{tabular}




\begin{tabular}{|c|c|c|c|c|c|c|}
\hline $\begin{array}{l}\text { Collection Location } \\
\text { \& Date }\end{array}$ & $\begin{array}{l}\text { Depth } \\
(\mathrm{m})\end{array}$ & $\begin{array}{l}\text { Temperature } \\
\left({ }^{\circ} \mathrm{C}\right)\end{array}$ & Salinity & $\begin{array}{l}\mathrm{O}_{2} \\
(\mu \mathrm{mol} \mathrm{kg}-1)\end{array}$ & $\begin{array}{l}{ }^{238} \mathrm{U} \\
\left(\mathrm{ng} \mathrm{g}^{-1}\right)\end{array}$ & $\begin{array}{l} \pm \text { Error } \\
\left(\mathrm{ng} \mathrm{g}^{-1}\right)\end{array}$ \\
\hline & 850.0 & 6.163 & 34.811 & 104.0 & 3.166 & 0.026 \\
\hline & 1001.8 & 5.473 & 34.809 & 131.3 & 3.125 & 0.033 \\
\hline Southern Ocean $68.252^{\circ} \mathrm{S} \times 69.887^{\circ} \mathrm{W}$ & 1.7 & 1.390 & 33.637 & 346.3 & 3.026 & 0.062 \\
\hline \multirow[t]{6}{*}{ Jan 212009} & 18.4 & 1.070 & 33.641 & 363.3 & 3.106 & 0.062 \\
\hline & 50.4 & -0.003 & 33.862 & 352.1 & 3.326 & 0.068 \\
\hline & 74.7 & -0.520 & 33.977 & 333.1 & 3.321 & 0.071 \\
\hline & 100.3 & -0.540 & 34.174 & 283.2 & 3.062 & 0.062 \\
\hline & 147.2 & 0.490 & 34.433 & 217.9 & 3.100 & 0.063 \\
\hline & 296.2 & 1.430 & 34.671 & 178.6 & 3.175 & 0.064 \\
\hline \multirow{8}{*}{$\begin{array}{l}\text { Southern Ocean } 68.394^{\circ} \mathrm{S} \times 77.920^{\circ} \mathrm{W} \\
\text { Jan } 292009\end{array}$} & 1.5 & 1.210 & 34.022 & 323.3 & 3.085 & 0.063 \\
\hline & 40.1 & 0.460 & 34.043 & 349.9 & 3.223 & 0.087 \\
\hline & 99.2 & -0.120 & 34.318 & 235.6 & 3.205 & 0.091 \\
\hline & 197.8 & 1.860 & 34.638 & 171.0 & 3.192 & 0.108 \\
\hline & 396.2 & 1.880 & 34.705 & 177.1 & 3.129 & 0.063 \\
\hline & 1283.5 & 1.190 & 34.723 & 195.2 & 3.155 & 0.063 \\
\hline & 2557.8 & 0.560 & 34.704 & 207.8 & 3.191 & 0.064 \\
\hline & 3165.4 & 0.420 & 34.701 & 211.8 & 3.185 & 0.064 \\
\hline \multirow{8}{*}{$\begin{array}{l}\text { Southern Ocean } 69.501^{\circ} \mathrm{S} \times 75.506^{\circ} \mathrm{W} \\
\operatorname{Jan} 272010\end{array}$} & 1.8 & -1.250 & 32.752 & 381.2 & 2.880 & 0.058 \\
\hline & 4.1 & -1.370 & 32.688 & 377.0 & 2.865 & 0.058 \\
\hline & 8.0 & -1.250 & 32.827 & 386.7 & 2.913 & 0.058 \\
\hline & 12.4 & -0.650 & 33.100 & 406.1 & 2.955 & 0.059 \\
\hline & 12.3 & -0.670 & 33.111 & 349.4 & 2.950 & 0.059 \\
\hline & 50.4 & -1.170 & 33.524 & 322.0 & 2.999 & 0.060 \\
\hline & 100.3 & -1.540 & 33.822 & 291.7 & 3.010 & 0.060 \\
\hline & 180.8 & -0.950 & 34.047 & 258.9 & 3.067 & 0.061 \\
\hline \multirow{10}{*}{$\begin{array}{l}\text { Southern Ocean } 70.420^{\circ} \mathrm{S} \times 76.421^{\circ} \mathrm{W} \\
\text { March } 292010 \\
\text { IAPSO Standard Seawater OSIL P149 }\end{array}$} & 600.4 & 1.31 & 34.709 & & 3.090 & 0.065 \\
\hline & & & $34.994^{d}$ & & 3.152 & 0.025 \\
\hline & & & $34.994^{\mathrm{d}}$ & & 3.135 & 0.026 \\
\hline & & & $34.994^{d}$ & & 3.113 & 0.042 \\
\hline & & & $34.994^{\mathrm{d}}$ & & 3.103 & 0.031 \\
\hline & & & $34.994^{\mathrm{c}}$ & & 3.132 & 0.063 \\
\hline & & & $34.994^{e}$ & & 3.130 & 0.067 \\
\hline & & & $34.994^{e}$ & & 3.121 & 0.063 \\
\hline & & & $34.994^{\mathrm{f}}$ & & 3.054 & 0.062 \\
\hline & & & $34.994^{\mathrm{f}}$ & & 3.105 & 0.064 \\
\hline
\end{tabular}

${ }^{\mathrm{a}-\mathrm{f}}$ Analysis dates of replicates of BATS samples and IAPSO standard seawater were: ${ }^{\mathrm{a}}$ Dec 21 2007, ${ }^{\mathrm{b}}$ Sept 2 2008, ${ }^{\mathrm{c}}$ May 112009 , ${ }^{\mathrm{d}}$ Dec $172008,{ }^{\mathrm{e}}$ Sept 272010 , and ${ }^{\mathrm{f}}$ Oct 102010.

was performed on the data now in units of $\mathrm{dpm}^{-1}$ and is expressed in Eq. (3).

${ }^{238} \mathrm{U}( \pm 0.047)=(0.0786 \pm 0.00446) \times S-(0.315 \pm 0.158)$

At $\mathrm{S}=35$, this results in a ${ }^{238} \mathrm{U}$ activity of $2.436 \mathrm{dpm} \mathrm{L}^{-1}$ with a $1.9 \%(1 \sigma)$ uncertainty.

The linear regression of the data from this study (without the low concentration BATS samples) yields a $y$-intercept of $-0.326 \pm$ $0.206 \mathrm{ng} \mathrm{g}^{-1}$ or $-1.369 \pm 0.865 \mathrm{nmol} \mathrm{kg}^{-1}$ at zero salinity. The negative intercept implies a loss of uranium between its riverine source and the open ocean, however there is a large uncertainty on this $y$ intercept. From the oceanic uranium budget, we expect a uranium source, rather than sink, from rivers, which globally have a discharge, weighted mean concentration of $1.2 \pm 0.3 \mathrm{nmol} \mathrm{kg}^{-1}$ (Dunk et al., 2002). Submarine groundwater discharge may also account for up to $20 \%$ of uranium input to the oceans, although this value is poorly constrained (Osmond and Cowart, 1992). Both sources and sinks of uranium in fresh water/seawater mixing zones have been noted (Andersen et al, 2007; Carroll and Moore, 1994; Dunk et al., 2002; Feng et al., 2002; McKee et al., 1987) and given the large uncertainty here on the $y$-intercept, it is difficult to resolve the global average impact of these processes. We suggest that the uranium-salinity relationship presented here should only be applied within the salinity range of $\sim 32.7$ to 37.1 and may not hold in lower salinity environments such as estuaries.

\section{Discussion}

This work set out to re-evaluate the conservative relationship between salinity and ${ }^{238} U$ in the open ocean using sensitive mass spectrometric techniques. We have derived a new relationship for ${ }^{238} \mathrm{U}$ and salinity over a wider salinity range and with a larger number of samples than any previous single study (Fig. 1a). While most of the samples analyzed were conservative with salinity, deviations from this behavior were observed in a small number of samples. In the Southern Ocean, two samples lie just above the 95\% prediction line for ${ }^{238} \mathrm{U}$, while in the subtropical Atlantic, anomalously low concentrations of ${ }^{238} \mathrm{U}$ were observed between 500 and $1000 \mathrm{~m}$. These anomalies within this single data set are discussed below but first we compare our results to previous studies to look at the overall trend of ${ }^{238} \mathrm{U}$ vs. salinity.

In Table 2, the salinity-normalized $(S=35)$ average concentration for our data set is compared to previous studies that used alpha spectroscopy or mass spectrometry. Within error, the average for this study is comparable to the averages from previous studies that employed either analytical technique. Similarly, the RSD of all the samples is within the range of those from previous mass spectrometry studies. More informative perhaps is to compare ${ }^{238} \mathrm{U}$ data obtained using the more precise mass spectrometric methods vs. salinity to see if there is a similar trend and anomalies in this relationship as we have found (Fig. 1b). While most measurements from previous studies fall within the 95\% prediction interval of this study, some of the samples do fall outside, including Zheng et al. (2006) which lie near to some of 
Table 2

A comparison of this work to previous studies. Results for alpha spectroscopy and mass spectrometry studies are shown separately. Results for this study were obtained as ng $\mathrm{g}^{-1}$ but have been converted to $\mathrm{dpm} / \mathrm{L}$ (in italics) for comparison to alpha spectroscopy studies. Values in bold are the averages of all the data from each study. For the Atlantic and overall average values from this study, low values from BATS July 2007 are not included. (Andersen et al., 2007; Chen et al., 1986; Delanghe et al., 2002; Gustafsson et al., 1998; Ku et al, 1977; Pates and Muir, 2007; Rengarajan et al., 2003; Robinson et al., 2004; Schmidt, 2006; Schmidt and Reyss, 1991; Zheng et al., 2006).

\begin{tabular}{|c|c|c|c|c|c|c|c|c|c|}
\hline \multicolumn{10}{|c|}{ Alpha spectroscopy studies } \\
\hline \multirow[t]{4}{*}{ Ku } & Atlantic & $34.459-36.140$ & 28 & 2.48 & 0.08 & 3.1 & & & \\
\hline & Pacific & $34.590-35.173$ & 7 & 2.50 & 0.09 & 3.8 & & & \\
\hline & Arctic & $30.300-34.940$ & 13 & 2.54 & 0.03 & 1.1 & & & \\
\hline & Southern Ocean & $33.492-34.732$ & 19 & 2.43 & 0.04 & 1.6 & & & \\
\hline \multirow{2}{*}{ Schmidt \& Reyss } & Mediterranean & 38.14-39.18 & 18 & 2.59 & 0.08 & 3.1 & & & \\
\hline & All & $35.61-39.18$ & 25 & 2.58 & 0.08 & 3.1 & & & \\
\hline Rengarajan & Arabian & 34.892-36.557 & 61 & 2.38 & 0.08 & 3.3 & & & \\
\hline \multirow[t]{3}{*}{ Schmidt } & Atlantic & $35.21-36.46$ & 11 & 2.56 & 0.06 & 2.2 & & & \\
\hline & Mediterranean & $35.98-38.43$ & 2 & 2.64 & 0.10 & 3.6 & & & \\
\hline & All & $35.21-38.43$ & 13 & 2.57 & 0.06 & 2.5 & & & \\
\hline Pates \& Muir & Mediterranean & 36.423-38.633 & 73 & 2.50 & 0.13 & 5.0 & & & \\
\hline \multicolumn{10}{|c|}{ Mass spectrometry studies } \\
\hline Gustafsson & Atlantic & $31.18-31.70$ & 2 & & & & 3.164 & 0.003 & 0.1 \\
\hline \multirow{4}{*}{ Delanghe } & Atlantic & $38.44-38.56$ & 8 & & & & 3.191 & 0.071 & 2.2 \\
\hline & Mediterranean & $34.94-35.92$ & 5 & & & & 3.202 & 0.037 & 1.2 \\
\hline & Indian & $34.72-35.28$ & 8 & & & & 3.283 & 0.039 & 1.2 \\
\hline & All & $34.72-38.56$ & 21 & & & & 3.229 & 0.067 & 2.1 \\
\hline Robinson & Atlantic & $35.400-37.280$ & 12 & & & & 3.334 & 0.013 & 0.4 \\
\hline Zheng & Pacific & 33.034-34.393 & 40 & & & & 3.221 & 0.064 & 2.0 \\
\hline Pates \& Muir & Mediterranean & 37278-39.055 & 68 & & & & 3.268 & 0.045 & 1.4 \\
\hline Andersen & Arctic & $25.90-34.96$ & 20 & & & & 3.25 & 0.03 & 0.9 \\
\hline \multirow[t]{4}{*}{ This study } & Atlantic & 34.809-37.102 & 63 & 2.44 & 0.03 & 1.4 & 3.187 & 0.044 & 1.4 \\
\hline & Southern Ocean & $32.688-34.723$ & 24 & 2.44 & 0.07 & 3.0 & 3.187 & 0.095 & 3.0 \\
\hline & IAPSO & 34.994 & 9 & 2.38 & 0.02 & 0.9 & 3.117 & 0.028 & 0.9 \\
\hline & All & $32.688-37.102$ & 87 & 2.44 & 0.05 & 2.0 & 3.187 & 0.062 & 1.9 \\
\hline
\end{tabular}

our high measurements from the Southern Ocean. Also, the samples from Robinson et al. (2004) all fall along the upper limit of ou prediction interval, suggesting a possible bias (or local ${ }^{238} \mathrm{U}$ source) in their data set. A linear regression of the combined data $(n=271)$ has a strong $\mathrm{R}^{2}$ of 0.92 (in $\mathrm{ng} \mathrm{g}{ }^{-1},{ }^{238} \mathrm{U}( \pm 0.065)=(0.099 \pm 0.002) \times S-$ $(0.238+0.063))$, but we cannot account for analytical bias and uncertainty in other studies so it is difficult to say if these anomalies are real. We focus our discussion on our own samples where the same methods and standards were used throughout

We observed a slight elevation in ${ }^{238} U$ in at least two samples collected in the Southern Ocean, a region where ice melt dynamics could potentially create unique distributions of ${ }^{238} \mathrm{U}$. Ku et al. (1977) is the only study to present results of salinity and alpha-spectroscopy ${ }^{238} \mathrm{U}$ measurements from the Southern Ocean. The salinity normalized average ${ }^{238} \mathrm{U}$ activity measured by $\mathrm{Ku}$ et al. of $2.43 \mathrm{dpm} \mathrm{L}^{-1}$ is comparable to the value of $2.44 \mathrm{dpm} \mathrm{L}^{-1}$ reported here (Table 2 ). In recent work carried out at the ice-edge in the Weddell Sea, Rodriguez y Baena et al. (2008) measured the ${ }^{238} U$ concentration of 26 samples and reported an average relative percent deviation of $1.9 \pm 2.3 \%$ from the value published by Pates and Muir (2007) but generally conservative behavior overall. Unfortunately, paired salinity and uranium measurements were not provided in the publication for direct comparison to this work. Our Southern Ocean samples have large scatter about the mean compared to Atlantic Ocean samples (Table 2) and in particular, samples from the first ( 50 and $75 \mathrm{~m}$ on Jan 212009 ) and second ( 40 and $100 \mathrm{~m}$ on Jan 29 2009) stations deviate from the values predicted by the linear regression by $3-8 \%$ (Fig. 1a). On a T-S plot these four samples did not appear to be part of a unique and distinct water mass that may have suggested a common source of this increased variability such as melt waters, thus we cannot attribute this variability to differences in water mass properties.

The anomalous low ${ }^{238} \mathrm{U}$ concentration values measured at the BATS site in 2007 are the most obvious feature of this data set (Table 1, Fig. 1a) There are three possible explanations for this anomalous feature: (1) collection or measurement error, (2) local removal or (3) removal on the continental shelf/slope and subsequent advection to the study region. In regard to the first hypothesis, it seems unlikely that the low

${ }^{238} \mathrm{U}$ concentrations are a sampling artifact as all samples were collected in a uniform fashion and there is no apparent difference in the 2007 samples. Also, the entire 2007 profile was analyzed in duplicate or triplicate (Table 1, Fig. 2) with good reproducibility. Thus, the low values were not the result of differences in spike equilibration and sample purification or anomalous mass spectrometer behavior on a single day.

The second possibility, that the low uranium signal was generated as the result of a local process, causing uranium to be reduced and removed from the water column, seems unlikely. Firstly, oxygen concentrations in 2008 and 2009 when subsequent samples were collected were the same or lower than in 2007 and no low ${ }^{238} \mathrm{U}$ feature was observed in either year (Fig. 2). Secondly, samples measured at much lower oxygen concentrations in the subtropical Atlantic showed no deviation from salinity-derived values (Table 1). Even in a study of uranium cycling in the Black Sea, an anoxic basin with a long deep-water residence time, there was no evidence of uranium reduction in the water column (Anderson et al., 1989). Uranium occurred as U(VI) throughout the Black Sea even though it was shown to be labile and reducible by a strong reducing agent. The work of Anderson et al. (1989) supported previous results that suggested that at seawater $\mathrm{U}(\mathrm{VI})$ concentrations, an initia adsorption step onto clay particles is required for reduction to occur 


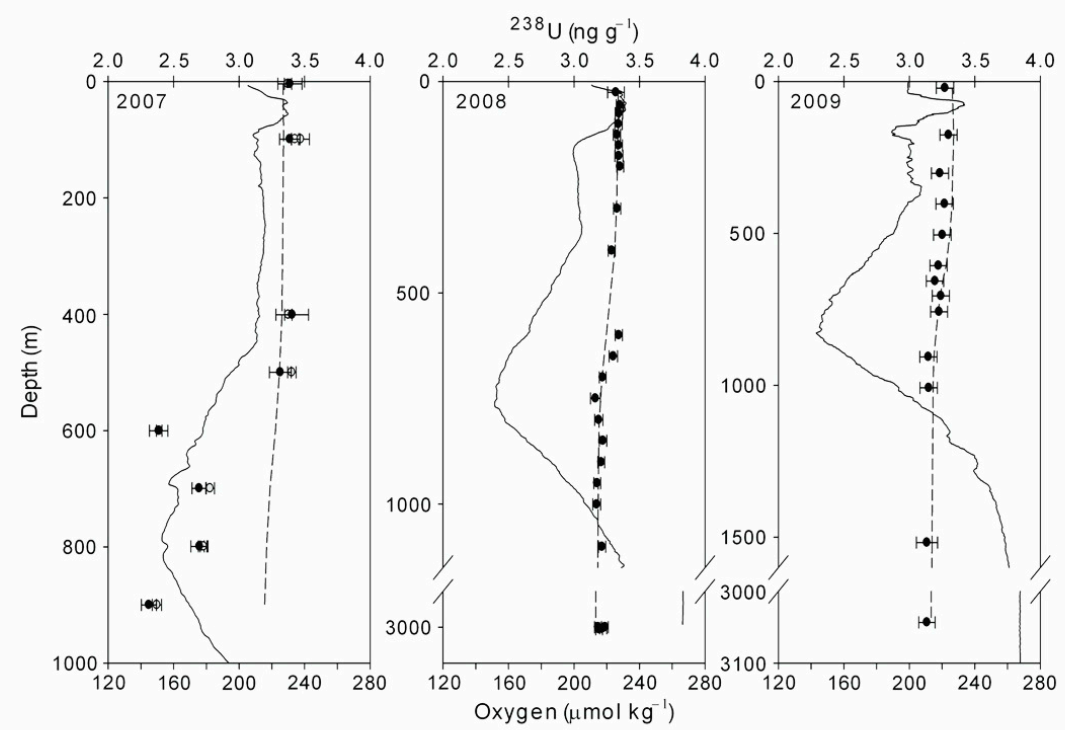

Fig. 2. Measured ${ }^{238} \mathrm{U}$ as a function of depth during three occupations of the Bermuda Atlantic Time-series Study site. Subsamples of the 2007 samples were prepared and measured by ICP-MS at least twice, some three times, and are denoted by white, gray, and black symbols. The dashed line is the ${ }^{238} \mathrm{U}$ concentration estimated from salinity using the regression produced in this study. Dissolved oxygen (solid line) from the CTD is also shown.

(Kochenov et al., 1977; Mohogheghi and Goldhaber, 1982). Thus it is not likely that conditions immediately prior to or during our occupation of the BATS site in June 2007 were conducive to $\mathrm{U}(\mathrm{VI})$ reduction and removal.

The third hypothesis, that we consider most likely, is that uranium was removed from the water prior to its arrival at the BATS site and the resulting signal was maintained during advection. One mechanism for removal of uranium from the water column is the accumulation of uranium in suboxic and anoxic sediments (Dunk et al., 2002; Morford and Emerson, 1999). This accumulation arises when uranium reduction from porewaters to the sediment occurs close to the sediment-water interface, which creates a concentration gradient in the porewater leading to a diffusive flux of uranium from seawater and into the sediments. Uranium accumulation rates are an order of magnitude higher in anoxic sediments compared to suboxic continental shelf and slope sediments. However, the greater spatial coverage of shelf and slope sediments makes these anoxic sediments an equally significant sink of uranium from the ocean (Barnes and Cochran, 1990; Dunk et al., 2002; Klinkhammer and Palmer, 1991).

A second mechanism for uranium removal is the co-precipitation of uranium with iron hydroxide particles. Co-precipitation of uranium with iron hydroxide particles has been documented in the laboratory with solutions of iron and uranium and particulate material from a seasonally anoxic lake and also in hydrothermal vent plumes (Bruno et al., 1995; Edmonds and German, 2004; Liger et al., 1999). Over the continental shelf, a similar co-precipitation process could occur when Fe (II) is remobilized from the sediments and precipitates as iron hydroxide particles (Johnson et al., 1999). These shelf-derived iron particles could then passively sink out of the water column as they are transported from their source to the ocean interior (Lam et al., 2006). To demonstrate the potential of the removal mechanisms proposed in this third hypothesis, a careful study of these redox-sensitive, ocean-margin processes would be needed.

The third hypothesis requires both uranium removal and lateral transport. The importance of lateral transport to the BATS region has been shown in studies of other geochemical tracers. For example, recent work that investigated the source of trace metal fluxes in sediment traps between 500 and $1500 \mathrm{~m}$ near the BATS site, suggested that lateral advection from the continental shelf/slope was a significant source of material (Huang and Conte, 2009). Another study suggested that sediments on the Bermuda rise appeared to have been influenced by advection of material from the Nova Scotia margin based on the presence of anomalously old, but recently deposited, haptophyte-derived alkenones (Ohkouchi et al., 2002).

Anomalies in the ${ }^{234} \mathrm{U} /{ }^{238} \mathrm{U}$ ratios of the 2007 samples may have provided evidence for previous contact of the water with sediments on the ocean margin. Unfortunately, there was not enough sample volume remaining to measure ${ }^{234} \mathrm{U} /{ }^{238} \mathrm{U}$. In revisiting the site in 2008 and 2009, we hoped to recapture this anomalous feature but as shown in Fig. 2, no such feature was observed and without other tracers, its source remains elusive.

The impetus for this study was the observation of unique deficit $\left({ }^{234} \mathrm{Th}<{ }^{238} \mathrm{U}\right)$ features below $500 \mathrm{~m}$ in ${ }^{234} \mathrm{Th}$ profiles taken during the EDDIES study near the BATS site in 2005 (Fig. 3, left panel). Typically,

${ }^{234}$ Th deficits are constrained to the depths of photosynthetic particle formation and export. There have been only a few reported instances of similar deficit features at depth (Benitez-Nelson et al., 2001a; Coppola et al., 2005; Schmidt, 2006). The best resolved example in the open ocean is from the subtropical Pacific in the winter of 1999/2000 (BenitezNelson et al., 2001a). The origin of the intermediate water deficit in ${ }^{234} \mathrm{Th}$ was attributed to particle transformations at depth such as fecal pellet production by zooplankton or aggregation by salps and appendicularians.

The ${ }^{234} \mathrm{Th}$ profiles collected during the EDDIES study that displayed a ${ }^{234}$ Th deficit at depth (Fig. 3, left panel) were all taken from the core of an anticyclonic mode-water eddy. The nutrient and oxygen concentrations at these depths in the eddy were unlike the local, surrounding conditions near the BATS site and together with temperature and salinity anomalies suggest that they were part of a coherent water mass that was held within the eddy and transported laterally from another location (Li and Hansell, 2008; McGillicuddy Jr. 

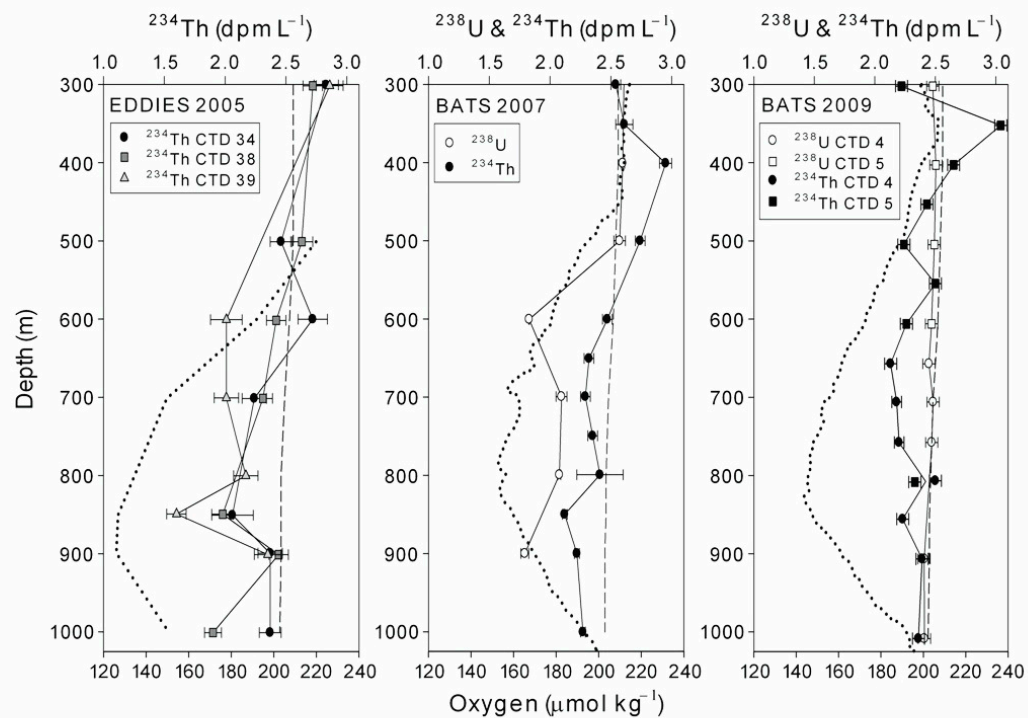

Fig. $3 .{ }^{234} \mathrm{Th}$ profiles from three occupations of the BATS site. ${ }^{238} \mathrm{U}$ derived from salinity (dashed line) and $\mathrm{O}_{2}$ concentrations (dotted line) are shown in all panels. Note that only the 300 to $1000 \mathrm{~m}$ section of these profiles are shown. a) Three ${ }^{234} \mathrm{Th}$ profiles collected during the EDDIES study (solid lines) that have deficit features at depth. b) Salinity-derived ${ }^{238} \mathrm{U}$ (dashed line) compared to measured ${ }^{238} \mathrm{U}$ during June 2007 at the BATS site. The ${ }^{234} \mathrm{Th}$ profile was collected simultaneously and shows evidence of non-equilibrium behavior a depth. c) $\mathrm{A}^{234} \mathrm{Th} /{ }^{238} \mathrm{U}$ profile from the BATS site in September 2009 made up of samples from two casts - CTD 4 (circles) and 5 (squares). ${ }^{238} \mathrm{U}$ (white) is conservative with salinity while ${ }^{234} \mathrm{Th}$ (black) demonstrates non-equilibrium behavior at depth.

et al., 2007). The unique biogeochemical parameters including elevated chlorophyll and low oxygen at depth were constrained to the eddy center, which was estimated, to be on the order of only $10 \mathrm{~km}$ (McGillicuddy Jr. et al., 2007). With this degree of small-scale patchiness, it is not surprising that these profiles of ${ }^{234} \mathrm{Th}$ with deficits at depth are a rare observance.

In 2007, repeat measurements of ${ }^{234} \mathrm{Th}$ were made at the BATS site but, as described above, an anomaly in ${ }^{238} \mathrm{U}$ concentration between 600 and $1000 \mathrm{~m}$ was observed (Fig. 3, middle panel). What appeared to be a deficit in ${ }^{234} \mathrm{Th}$ in 2007 is in fact an excess of ${ }^{234} \mathrm{Th}$ at depth. One factor that could complicate the interpretation of this ${ }^{234} \mathrm{Th}$ profile is that if and when ${ }^{238} \mathrm{U}$ was removed to the sediments, ${ }^{234} \mathrm{Th}$ may also have been removed. However, if the transit time of the water mass from the margin to the BATS site was on the time-scale of 3-6 months, most of the ${ }^{234} \mathrm{Th}$ would have grown back in to secular equilibrium with ${ }^{238} \mathrm{U}$. In 2009, no anomalies in ${ }^{238} U$ concentration were observed yet there was again a deficit of ${ }^{234} \mathrm{Th}$ between 500 and $900 \mathrm{~m}$ indicating a more local, or at least a more recent, scavenging process had taken place in deep waters (Fig. 3, right panel). All ${ }^{234}$ Th measurements have been corrected for low sample recoveries and all measurement uncertainty has been propagated throughout the derivation of ${ }^{234} \mathrm{Th}$ activity so we do not have reason to believe that this is an analytical error. The ${ }^{234} \mathrm{Th}$ deficit appears to be a real feature of the profile. One hypothesis for the formation of a ${ }^{234} \mathrm{Th}$ deficit at depth is the accumulation of small, slowly sinking particles on density gradients that aggregate into larger, fast-sinking particles (Macintyre et al., 1995). We do not believe that this is occurring in the mid-water column (500-1000 m) at BATS because of the lack of a significant density gradient at these depths. A more likely hypothesis for the formation of a ${ }^{234} \mathrm{Th}$ deficit at depth is that filter feeders such as salps are consuming and repackaging small, slow sinking particles into large, very fast sinking fecal pellets (Sutherland et al., 2010). While we canno currently identify the exact source of these ${ }^{234} \mathrm{Th}$ deficits in the mesopelagic, we believe that they warrant further study as potential aggregation or repackaging processes could have an important role in the transfer of carbon to the deep ocean.

\section{Conclusion}

In this work we present a new relationship between salinity and ${ }^{238} \mathrm{U}$ in the open ocean based on a large number of measurements from a single laboratory measured using sensitive isotope dilution mass spectrometry techniques. IAPSO Standard Seawater was used as an internal laboratory standard to establish the reproducibility of our purification and analytical methods. Also, our spike is well calibrated based on a gravimetric standard and years of replicate measurements for equilibrium rock standards.

For a sample with a salinity of 35 , the percent difference between using the Chen et al. (1986) relationship versus using the relationship established here is $1.3 \%$ al though the values agree within error. However, the relationship derived from this data set spans a salinity range twice as large as the Chen et al. data set and is based on 87 sample measurements versus 21 . We therefore recommend the use of the following equations with $1 \sigma$ uncertainty for estimation of ${ }^{238} \mathrm{U}$ from salinity:

$$
\begin{aligned}
& \left(\mathrm{ng} \mathrm{g}^{-1}\right):{ }^{238} \mathrm{U}( \pm 0.061)=0.100 \times S-0.326 \\
& \left(\mathrm{dpmL}{ }^{-1}\right):{ }^{238} \mathrm{U}( \pm 0.047)=0.0786 \times S-0.315 .
\end{aligned}
$$

While most measurements of ${ }^{238} \mathrm{U}$ were conservative with salinity, a few samples from the Southern Ocean exhibited a small positive deviation from this behavior. Another example of departure from conservative behavior was the negative deviation of ${ }^{238} \mathrm{U}$ from salinity between 500 and $1000 \mathrm{~m}$ at the BATS site in 2007. We hypothesize that this feature was neither the result of analytical bias of our measurements nor a local removal event, but rather the advected signal of a remote removal process associated with reducing sediments common at ocean margins. In addition, our observations of ${ }^{234} \mathrm{Th}$ deficits in the mesopelagic hint at processes previously unexplored with this isotope system. We encourage other ${ }^{234} \mathrm{Th}$ studies to expand their sampling efforts into the depths of the 
mesopelagic zone in the hope of gaining a greater understanding of particle cycling and export. Our observation of a ${ }^{238} \mathrm{U}$ anomaly at these depths in 2007 however should be a caveat for future studies. We recommend collecting small, archive seawater samples in conjunction with all ${ }^{234} \mathrm{Th}$ samples that may be analyzed for ${ }^{238} \mathrm{U}$ at a later date should the ${ }^{234} \mathrm{Th}$ data suggest that such an anomalous ${ }^{238} \mathrm{U}$ feature may be present.

\section{Acknowledgments}

Thank you to the captain and crew of the R/V Atlantic Explorer, the R/V Oceanus, the ARSV Laurence M. Gould, and the RVIB Nathaniel B. Palner. Thank you also to Gus Logan and Steve Pike who contributed to sample preparation and analysis. Thanks to Carl Lamborg, Matt Charette, Ed Boyle, Laura Robinson, Bill Jenkins, Paul Morris, Gideon Henderson, Scot Birdwhistel, Jonathan Whitefield, Dave Wellwood, Ruifeng Zhang, and the members of Cafe Thorium and the Sims lab for their array of assistance and advice. This work was supported by a WHOr Summer Student Fellowship and National Science Foundation grants to K.Buesseler from the Chemical Oceanography program. S. Owens is supported by a NASA Earth and Space Science Fellowship. We also thank W.S. Moore and two anonymous reviewers for their recommendations and comments on this manuscript.

\section{References}

Andersen. M.B., et al.. 2007. The tracing of riverine $U$ in Arctic seawater with very precise $171-185$.

Anderson, R.F., Fleisher, M.Q, LeHuray, A.P., 1989. Concentration, oxidation state, and particulate flux of uranium in the Black Sea. Geochimica et Cosmochimica Acta 53, 2215-2224.

Bacon, M.P., Cochran, J.K., Hirschberg, D., Hammar, T.R., Fleer, A.P., 1996. Export flux of carbon at the equator during the EqPac time-series cruises estimated from ${ }^{234} \mathrm{Th}$ carbon at the equator during the EqPac time-series cruises
measurements. Deep-Sea Research II 43 (4-6), 1133-1153.

measurements. Deep-Sea Research If 43 (4-6), 1133-1153.
Barnes, C.E..Cochran, J.K., 1990 . Uranium removal in oceanic sediments and the oceanic U balance Earth and Planetary Science Letters $97,94-101$.

Benitez-Nelson, C., Buesseler, K.O., Karl, D.M., Andrews, J., 2001a. A time-series study of particulate matter export in the North Pacific Subtropical Gyre based on Th-234: of particulate matter export in the North Pacific Subtropical Gyre

Benitez-Nelson, C.R., et al., $2001 \mathrm{~b}$. Testing a new small-volume technique for determining ${ }^{234} \mathrm{Th}$ in seawater. Journal of Radioanalytical and Nuclear Chemistry $248(3), 795-799$

hat, S.G., Krishnaswamy. S., Lal, D., Kama, Moore, W.S., $1969 .{ }^{234} \mathrm{Th} /{ }^{238} \mathrm{U}$ ratios in the ocean. Earth and Planetary Science letters 5, 483 -491 .

Bruno, J.. De Pablo. J., Duro. L., Figuerola, E.. 1.995. Experimental study and modeling of the U(V)-Fe(OH)3 surface precipitation/coprecipitation equilibria. Geochimica et Cosmochimica Acta $59(20), 4113-4123$.

Buesseler, K.O., Bacon, M.P., Cochran, J.K., Livingston, H.D., 1992. Carbon and nitrogen export during the JGOFS North Allantic Bloom Expet ${ }_{2 \geq 2}^{2} \mathrm{Th}:{ }^{238} \mathrm{U}$ disequilibria. Deep-Sea Research I 39 (7-8), 1115-1137.

Buesseler, K.O., et al., 2001. An intercomparison of small- and large-volume techniques for thorium-234 in seawater. Marine Chemistry 74 (1), 15-28.

Buesseler, K.O., et al., 2008a. Particle fiuxes associated with mesoscale eddies in the Sargasso Sea. Deep-Sea Research II 55 (10-13), 1426-1444

Buesseler, K.O., et al., 2008b. Thorium-234 as a tracer of spatial, temporal and vertical variability in particle flux in the North Pacific. Deep-Sea Kesearch Part I-Oceanographic Research Papers 56 (7) 1143-1167.

Carroll, J., Moore, W.S., 1994. Uranium removal during low discharge in the GangesBrahmaputra mising zone. Geochimica et Cosmochimica Acta 58, 4987-4995.

Chen, J.H., Wasserburg. G.J., 1981. Isotopic determination of uranium in picomole and

subpicomole quantities. Analytical Chemistry $53,2060-2067$.
Chen, J.H., Edwards, R.L., Wasserburg, G.J., $1986 .{ }^{238} \mathrm{U},{ }^{234} \mathrm{U}$ and ${ }^{22.2}$ Th in seawater. Earth and Planetary Science Letters 80 (3-4), 241-251

Cochran, J.K.. 1392. The oceanic chemistry of the U- and Th- series nuclides. Book Section: Uranium Series Disequilibrium: Application to Environmental Problems.

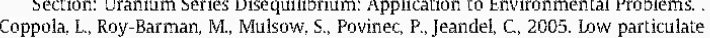
organic carbon export in the frontal zone of the Solthern Ocean (Indian sector) organic carbon export in the frontal zone of the Solth
revealed by ${ }^{234} \mathrm{Th}$. Deep-Sea Research I 52 (1), 51-68.

Delanghe, D., Bard, E., Hamelin, B., 2002. New TIMS constraints on the uranium-238 and uranium-234 in seawaters from the main ocean basins and the Mediteranean Sea. uranium 234 in seawaters from the
Marine Chemistry 80 (1), 79-93.

Djogic, R., Sipos, L., Branica, M., 1.986. Characterization of uranium (VI) in seawater. Limnology and Oceanography 31 (5), 1122-1131.

Dunk, R.M., Mills, R.A., Jenkins, W.J., 2002 . A reevaluation of the oceanic uranium budget for the Holocene. Chemical Geology $190(1-4), 45-67$.

Edmonds, H.N., German, C.R, 2004. Particle geochemistry in the Rainbow hydrothermal plume, Mid-Atlantic Ridge. Geochimica et Cosmochimica Acta 68 (4), 759-772.
Feng, H., Cochran, J.K., Hirschberg, D.J, 2002. Transport and sources of metal contaminants over the course of tidal cycle in the turbidity maximum zone of the Hudson River estuary. Water Research 36 (3), 733-743.

Gustafsson, O., Buesseler, K.O., Geyer, W., Rockwell, Moran, Bradley, S., Gschwend, P.M. 1998. On the relative significance of horizontal and vertical transport of chemicals in the coastal ocean: application of a two-dimensional Th-234 cycling model Continental Shelf Research $18,805-829$.

Huang, S., Conte, M.H., 2009. Source/process apportionment of major and trace elements in sin

Jaffey, A.H. Flynn, K.F, Glendenin, LE, Bentley, W.C., Essling, A.M, 1971. Precision measurement of half-lives and specific activities of U-235 and U-238. Physical Review C 4 (5), 1889-1306.

Johnson, K.S., Chavez, F.P., Friederich, G.E., 1999. Continental-shelf sediment as a primary source of iron for coastal phytoplankton. Nature 398, 697-700

Klinkhammer, G.P., Palmer, M.R., 1991. Uranium in the oceans - where it goes and why Geochimica et Cosmochimica Acta 55, 1799-1806.

Kochenov A. Kornlev, K.G., Dubinchuk V.T., Medvedev Yu, L., 1977. Experimental data on the conditions of precipitation of uranium from acqueous solutions. Geochemistry Intemational $14,82-87$.

Ku, T.L., Knauss, K.G., Mathieu, G.G., 1977 . Uranium in open scean: concentration and isotopic composition. Deep-Sea Research 24 (11), 1005 1017

Lam, P.j., et al., 2006. Wintertime phytoplankton bloom in the subarctic Pacific supported by continental margin iron. Global Biogeochemical Cycles, 20.

i, Q.P., Hansell, D.A., 2008. Nutrient distributions in barodinic eddies of the oligotrophic North Atlantic and inferred impacts on biology. Deep-Sea Research II $55,1291-1299$

Liger, E., Charlet, L., Van Cappellen, P.V., 1999. Surface catalysis of uranium(VI) reduction by iron(II). Geochimica et Cosmochimica Acta 63 (19/20), $2939-2955$

Macintyre, S., Alldredge, AL., Gotschalk, C.., 1995. Accumulation of marine snow at density discontinuities in the water column. Limnology and Oceanography 40 (3). 449-468.

McGillicuddy Jr., D.J., et al., 2007. Eddy-wind interactions stimulate extraordinary mid ocear plankton blooms. Science 316, 1021-1026.

NcKee, B.A. DelMaster. DJ. Nittrouer, CA. 1987 . Uranium geochemistry on the Amazon shelf: evidence for uranium release from bottom sediments. Geochimica et Cosmochimica Acta 51, 2779-2786.

Millero, F.J., Poisson, A., 1981. International one-atmosphere equation of state of seawater. Deep-Sea Research I 28A (6), 625-629.

Mohogheghi, A., Goldhaber, M., 1982. Kinetics of uranyl ion reduction by acqueous sulfide at $35^{\circ} \mathrm{C}$ (abstr.). Geological society of America 568

Morford, J.L., Emerson, S., 1989. The geochemistry of redox sensitive trace metals in sediments. Geochimica et Cosmochimica Acta 63, 1735-1750.

Ohkouchi. N.. Eglinton. TI.. Keigwin, L.D., Hayes, J.M., 2002. Spatial and temporal offsers between proxy records in a sediment drift. Science $298,1224-1227$.

Osmond, J.K., Cowart, J.B., 1992. Ground water. Uranium-Series Disequilibrium: Applications to Earth. Marine and Environmental Sciences. Clarendon Press, oxford.

Pates, J.M., Muir, G.K.P., 2007. U-salinity relationships in the Mediterranean: implications for Th-234/0-238 particle flux studies. Marine Chemistry 106 530-545.

Pike, S.M., Buesseler, K.O., Andrews, J., Savoye, N., 2005. Quantification of ${ }^{234}$ Th recovery in small volume sea water samples by inductively coupled plasma mas spectrometry. Journal of Radioanalytical and Nuclear Chemistry 263 (2), 355-360.

Rengarajan, R., Sarin, M.M., Krishnaswami, S., 2003. Uranium in the Arabian Sea: role of deritrification in controlling its distribution. Oceanologica Acta 26 (5-6), 687-693

Robinson, L.F., Belshaw, N.S., Henderson, G.M., 2004. U and Th concentrations and isotope ratios in modern carbonates and waters from the Bahamas. Geochimica $\varepsilon$ Cosmochimica Acta 68 (8), 1777-1789.

Rodriguez y Baena, A.M., et al., 2008. Th-234-based carbon export during an ice-edge gloom: sea-ice algae as a likely bias in data interpretation. Earth and Planetary Science letters 269, 595-603.

Rutgers van der loeff, M., et al.. 2006. A review of present techniques and methodological advances in analyzing ${ }^{224} \mathrm{Th}$ in aquatic systems. Marine Chemistry $100(3-4), 190-212$.

Santschi, P.H. et al., 2006. Thorium speciation in seawater. Marine Chemistry 100 $250-268$

Schmidt, S. 2006. Impact of the Mediterranean Outfiow Water on the particle dynamics in intermediate waters of the Northeast Atlantic as revealed by Th- 234 and Th- 228 Marine Chemistry 100, 289-298.

Schmidt, S., Reyss. J.L., 1991. Uranium concentrations of Mediterranean seawaters with high salinities. Comptes Rendus de lAcademie des Sciences Serie II 312 (5) $479-484$

Sims, K.W.W., et al., 2008. An inter-laboratory assessment of the thorium isotopic composition of synthetic and rock reference materials. Geostandards and Geoanalytical Research 32 (1), 65--91.

Sutherland, K.R.. Madin, LP.. Stocker, R., 2010. Filtration of submicrometer particles by pelagic tunicates. Proceedings of the National Academy of Sciences 1.07 (34) $15129-15134$

UNESCO, 1983. Algorithms for computation of fundamental properties of seawater UNESCO Technical Papers in Marine Science, 44.

Zheng, J., Yamada, M., Aono, T., Kusakabe, M., 2006. Vertical distribution of uranium concentrations and U-238/U-238 atom ratios in the coastal water off Aomori Japan: a survey prior to the operation of a nuclear fuel reprocessing facility. Journal of Radioanalytical and Nuclear Chemistry 270 (3), 669-675. 


\section{Chapter 3:}

\section{A new time series of particle export from neutrally buoyant sediment traps at the Bermuda Atlantic Time-series Study site}

This chapter was originally published in Deep Sea Research I by Elsevier and is reproduced here with their permission.

A new time series of particle export from neutrally buoyant sediment traps at the Bermuda Atlantic Time-series Study site. Deep Sea Research I. S.A. Owens, K.O. Buesseler, C.H. Lamborg, J. Valdes, M.W. Lomas, R.J. Johnson, D.K. Steinberg, D.A. Siegel, 2012. 72, 34 - 47, http://dx.doi.org/10.1016/j.dsr.2012.10.011. 


\title{
A new time series of particle export from neutrally buoyant sediments traps at the Bermuda Atlantic Time-series Study site
}

\author{
S.A. Owens ${ }^{\mathrm{a}, \mathrm{b}, *}$, K.O. Buesseler ${ }^{\mathrm{a}}$, C.H. Lamborga ${ }^{\mathrm{a}}$, J. Valdes ${ }^{\mathrm{c}}$, M.W. Lomas ${ }^{\mathrm{d}, \mathrm{e}}$, \\ R.J. Johnson ${ }^{\text {, }}$, D.K. Steinbergf, D.A Siegel ${ }^{g}$ \\ a Department of Marine Chemistry and Geochemistry, MS\#25, Woods Hole Oceanographic Institution, 266 Woods Hole Road, Woods Hole, MA 02543, USA \\ ${ }^{\mathrm{b}}$ MTT-WHOI Joint Program in Oceanography/Applied Ocean Science Engineering, 266 Woods Hole Road, Woods Hole, MA 02543, USA \\ 'Department of Physical Oceanography, MS\#25, Woods Hole Oceanographic Institution, 266 Woods Hole Road, Woods Hole, MA 02543, USA \\ ${ }^{d}$ Bermuda Institute of Ocean Sciences, 17 Biological Lane, St George's GE 01, Bermuda \\ ${ }^{e}$ Bigelow Laboratory for Ocean Sciences, 60 Bigelow Drive, P.O. Box 380, East Boothbay, ME 04544, USA \\ ${ }^{\mathrm{I}}$ Virginia Institute of Marine Science, The College of William and Mary, P.O. Box 1346, Gloucester Pt, VA 23062-1346, USA \\ ${ }^{g}$ Earth Research Institute and Department of Geography, University of California, Santa Barbara, CA 93106, USA
}

\section{A R T I C L E I N F O}

Article history:

Received 1 June 2012

Received in revised form

16 October 2012

Accepted 24 October 2012

Available online 10 November 2012

Keywords:

Sediment traps

Particle export

Bermuda Atlantic Time-series Study

\section{A B S T R A C T}

Neutrally buoyant sediment traps (NBSTs) were deployed concurrently with particle interceptor traps (PITs) on monthly cruises of the Bermuda Atlantic Time-series Study (BATS) from June 2007 to July 2010. In most months, particulate organic carbon flux measured by the two sediment trap systems agreed within the range of variability for two separate NBSTs. In three periods of this study however, the PITs collected more than three times the amount of particulate organic carbon (POC) than the NBSTs. One of these periods coincided with two instances when the mixed layer was deeper than the trap deployment depth, which may lead to biased collection. One of the anomalous periods occurred during summer months, for which we were unable to find existing evidence of biogeochemical changes that would lead to such increases in POC flux. The third anomalous period occurred when the POC flux measured by the NBSTs was near zero. We hypothesize that the PITs may have a positive bias at low fluxes relative to the NBSTs. Zooplankton swimmers accounted for $49+20 \%$ of the total measured carbon flux over the three year period and swimmer removal by screening of samples through a $350 \mu \mathrm{m}$ mesh was established as an effective method for this site. Process blank corrections based on sample-identical blanks were important for determining mass and carbon flux from both the NBSTs and the PITs. This new record of particle export from NBSTs suggests that the observed carbon imbalance in this region of the ocean (Michaels et al., 1994) is not due to undersampling by the PITs and that export ratios may be even lower than previously thought.

(c) 2012 Elsevier Ltd. All rights reserved.

\section{Introduction}

Sediment traps are rain gauge-like instruments that are intended to capture sinking particles as they settle through the water column. They are the most direct means of determining the magnitude and composition of export production from the euphotic zone (Eppley, 1989). Though conceptually simple devices, there are several issues that arise when sediment traps are deployed in the complex and dynamic environment of the open ocean. Key problems associated with their use and potential solutions were most recently summarized by a Scientific Committee on Oceanic Research working group, tasked to evaluate methods used to determine upper ocean particle

\footnotetext{
*Corresponding author at: Department of Marine Chemistry and Geochemistry MS\#25, Woods Hole Oceanographic Institution, 266 Woods Hole Road, Wood Hole, MA 02543, USA. Tel.: + 15082893843 ; fax: +1508 4572193
}

E-mail address: sowens@whoi.edu (S.A. Owens). flux including upper ocean sediment traps (Buesseler et al., 2007). Sediment traps have several possible sampling biases. The first issue is referred to as the hydrodynamic issue, which is caused by horizontal flow over the mouth of the trap and trap motion that may lead to under or over sampling of sinking particulate material (Gardner, 1985; Gust et al., 1996). This issue most affects traps in the upper $1000 \mathrm{~m}$ of the water column, where current velocities are highest. The second issue is zooplankton "swimmers" that are inadvertently captured in sediment traps and should not be considered a part of the passively sinking flux (Michaels et al., 1990; Steinberg et al., 1998). The distinction between swimmers that entered the traps alive or passively sinking, deceased zooplankton can be difficult to make and the contribution of swimmers to the measured carbon flux can be large. Therefore, it is important that swimmers are removed from samples prior to analysis in an effective and reproducible manner (Buesseler et al., 2007). Finally, the third issue is solubilization, the problem of sample degradation 
after collection and prior to sample processing (Lee et al., 1992; Antia, 2005; Lamborg et al., 2008). An overarching issue in the use of sediment traps is the lack of standardized methods across the field, ranging from the type of sediment trap used, to the details of sample processing and flux determination. In some cases, such as swimmer removal, different biological systems require different methods to remove swimmers, whereas some procedures, like the preparation of sediment trap process blanks, although unique to a particular processing method, could be standardized and adopted more widely.

Time-series studies have been a key tool in understanding the complexities of the biological carbon pump (Ducklow et al., 2009) and particle flux is one of the critical measurements at the USsupported ocean biogeochemistry time-series sites: the Bermuda Atlantic Time series Study (BATS), the Hawaii Ocean Time series (HOT), and the Carbon Retention in a Colored Ocean (CARIACO) time series. The goal of the present study was to carry out the first long-term comparison of traditional surface-tethered Particle Interceptor Traps (PITs) used at both BATS and HOT (Karl et al., 1996; Knap et al., 1997) and Neutrally Buoyant Sediment Traps (NBSTs) developed at Woods Hole Oceanographic Institution (Valdes and Price, 2000). In performing this work at BATS, we were able to deploy the two sediment trap systems side-by-side on a monthly basis for three years and take advantage of other measurements by the BATS group to aid in the interpretation of our results. Such a long-term study allowed us to compare the two sediment trap systems over a range of seasons and particle flux events. We were also able to carry out longer-term comparisons of sample processing methods such as swimmer removal techniques and sample blank determination. The BATS site was a particularly interesting place to perform this work because of the difficulties in creating a closed carbon budget for this region (Michaels et al., 1994). It has been estimated that the change in carbon stocks over an annual cycle is three times greater than the amount of carbon removed here. This imbalance was hypothesized to be due to either undersampling by the PITs sediment traps and/or unaccounted for horizontal processes. Using the NBSTs for the first time in a time-series capacity, we aimed to shed more light on the characteristics and composition of particle flux at the BATS site.

\section{Methods}

\subsection{Study site and experimental design}

Neutrally buoyant sediment traps (NBSTs) were deployed each month concurrently with a surface-tethered array of particle interceptor traps (PITs) during cruises of the Bermuda Atlantic Time-series Study (BATS) from June 2007 to July 2010. Two NBSTs were deployed at $150 \mathrm{~m}$ each month for replication and in case of failure of one of the traps. In some months only one NBST was deployed at $150 \mathrm{~m}$, usually when the second trap required maintenance or when NBSTs were deployed at multiple depths (150, 300 , and $500 \mathrm{~m}$ ).NBSTs and PITs were deployed near the BATS site, near $31.6^{\circ} \mathrm{N} \times 64.15^{\circ} \mathrm{W}$ within $3 \mathrm{~km}$ of each other on average, for a period of approximately three days.

\subsection{Particle interceptor traps (PITs)}

Deployment and recovery of the PITs array and processing of the samples was carried out according to the BATS Method Manual (Knap et al., 1997), which is based on Knauer et al. (1979). PITs tubes are polycarbonate cylinders (collection area $=0.0039 \mathrm{~m}^{2}$ ) outfitted with plastic baffles at the top of the tube. Three tubes are mounted onto each stainless-steel frame at 150,200 , and $300 \mathrm{~m}$ that are attached to a surface tethered mooring equipped with a bungee and surface/subsurface floats. A current meter is also attached to the array at $165 \mathrm{~m}$. Each PIT tube is filled to the top with a density gradient solution or brine $(1 \mathrm{~L}$ formalin and $2.5 \mathrm{~kg} \mathrm{NaCl}$ in $50 \mathrm{~L}$ of filtered seawater) prior to deployment. Cleaned and pre-weighed polycarbonate filters are mounted in the base of each PIT tube. Upon recovery, entrained seawater at the top of each trap is siphoned off to just above the level of the visible density interface and the remaining brine solution is passed through the filter at the base of the tube. The filters are stored in a refrigerator until the samples are processed further on shore. Once on shore, recognizable zooplankton or swimmers are removed from the filters using forceps under a dissecting microscope. Swimmers are preserved in a formalin solution and archived. Next, material on the filter is scraped towards the center, into a bolus, with a scalpel. The sample is rinsed with a few milliliters of pH 9 Milli-Q water, to remove salts, and dried in an oven. Samples are transferred to a dessicator and weighed periodically until a constant weight is achieved. Mass flux was determined by the difference between post- and pre-deployment filter weights divided by the length of deployment and the area of a PITs tube. To determine particulate carbon and nitrogen flux, the bolus is scraped off the filter with a scalpel into a silver boat, which is weighed to determine the fraction of total weight transferred as the bolus. The silver boats with boluses are fumigated with $\mathrm{HCl}$ for $36 \mathrm{~h}$ to remove inorganic carbon, desiccated overnight, and then analyzed for organic carbon and nitrogen content with a Control Equipment Corporation 9cEC $240 \mathrm{XA}$ elemental analyzer. Carbon and nitrogen flux are calculated by dividing the instrument-blank-corrected $\mathrm{C}$ or $\mathrm{N}$ values by the bolus weight and multiplying by the mass flux $\left(\% \mathrm{C}_{\text {bolus }} \times\right.$ mass flux).

\subsection{Neutrally buoyant sediment traps (NBSTs)}

\subsubsection{Preparation and deployment}

The NBSTs and sample processing techniques employed in this study were similar to those described in Lamborg et al. (2008). NBST tubes are polycarbonate cylinders $(12 \times 70 \mathrm{~cm}$, collection area $=0.0113 \mathrm{~m}^{2}$ ) with HDPE bases and lids, and plastic baffles $2.5 \mathrm{~cm}$ in height with $1 \mathrm{~cm}$ diameter holes. Five tubes are mounted onto the central float of the NBST. The lid of each tube is anchored to the tube itself with amber silicone shock cord and is held open by securing a loop of nylon lanyard onto a retracting pin mechanism in the upper part of the float's pressure casing. The traps descend open and prior to beginning their ascent to the surface, after 3 days deployment, the pin retracts and the lids snap shut. For a typical NBST deployment to $150 \mathrm{~m}$, it takes up to $2 \mathrm{~h}$ for the NBST to reach its deepest depth, between 175 and $400 \mathrm{~m}$, after which it rises to its pre-programmed depth of $150 \mathrm{~m}$. The NBSTs are programmed to maintain their depth within a certain range of depths. No significant difference was found between traps deployed at the same time with $\pm 10,15$, or $25 \mathrm{~m}$ correction windows; $\mathrm{a} \pm 10 \mathrm{~m}$ window was used for most of this study. The number of flux days is taken as the time between when an NBST reaches its deepest depth and when its lids shut. Occasionally, not all of the lids shut correctly; in instances when two or less lids shut, the number of flux days is taken as the time between when an NBST reaches its deepest depth and when it is recovered at the surface. Out of a total of 77 trap deployments, $83 \%$ of the time the traps returned with at least three lids shut. The time correction for two or less lids shutting ranged from 1 to $8 \mathrm{~h}$.

In preparation for deployment, tubes were rinsed three times and then filled to the level of the baffle with filtered seawater that was collected from $150 \mathrm{~m}$ en route to the deployment site. A poisoned, borate-buffered brine solution $(500 \mathrm{~mL}$, salinity $=70$, $3 \mathrm{mM}$ borate, $37 \mathrm{mM}$ formalin), made by freeze-concentrating 
$1.0 \mu \mathrm{m}$ filtered seawater from $400 \mathrm{~m}$ at the BATS site, was added to the base of each tube with acid-cleaned Teflon tubing (Lee et al., 1992; Lamborg et al., 2008). The trap lids were kept shut until immediately before deployment to prevent any sample contamination particularly from the ship's smoke stacks. Four additional tubes for use as blanks of sample processing techniques (hereafter "process blanks") were prepared in the same manner but remained onboard, in the lab, for the duration of the trap deployments.

\subsubsection{Recovery, sample processing and sample analysis}

Upon recovery of the NBSTs, the tubes were removed from the main body and any unclosed lids were closed and noted in the deployment logs. The tubes were allowed to sit for $1-2 \mathrm{~h}$ to allow any material to finish settling into the brine at the base of the tube. The filtered seawater overlying the brine was siphoned off Post-deployment measurements of the salinity of the brine layer suggested minimal mixing or dilution during deployments. Any material remaining on the sides of the tubes was rinsed to the bottom of the tube using filtered seawater. The remaining brine from four of the five tubes was drained through the base of the tubes, passed through an acid-washed $350 \mu \mathrm{m}$ nylon screen to remove zooplankton swimmers, combined in a $4 \mathrm{~L}$ bottle, and stored in a refrigerator until further processing on shore. The screens were rinsed with filtered seawater to remove any particles adsorbed to zooplankton on the screen and these rinses were added to the screened brine. Swimmers from the screen were later rinsed onto silver filters using additional filtered seawater. An alternate swimmer removal technique was tested in which swimmers were picked from the brine and placed on silver filter (discussed further in the Section 3). Material from the fifth tube was drained directly into a separate bottle without removing swimmers and preserved with additional formalin for zooplankton and fecal pellet quantification and classification using microscopy.

From the beginning of the study in June 2007 through October 2008, the NBST sample processing described below was carried out in Bermuda at the Bermuda Institute of Ocean Sciences (BIOS) From November 2008 through February 2009, one sample was processed at BIOS while a second was preserved with an additional $1.2 \mathrm{~mL}$ of formalin and shipped to Woods Hole Oceanographic Institution (WHOI) for processing. Based on agreement over the three-month period between sample processing locations, from March 2009 through July 2010, all samples were subsequently split and filtered at WHOI. The only exceptions to the above are when sample processing occurred at sea as in June and July 2007, June and July 2008, and September 2009.

After swimmer removal, the material from the four combined tubes was split eight ways using the sample splitter set up described in Lamborg et al. (2008). These eight subsamples or "splits" were then filtered onto three Sterlitech silver membrane filters $(1.2 \mu \mathrm{m}$ nominal pore size), three Whatman Nuclepore polycarbonate membrane filters $(1.0 \mu \mathrm{m}$ nominal pore size), and two Whatman quartz microfibre filters. The four blank tubes were screened, combined, split, filtered, and analyzed in the same manner as the samples.

All sample analysis methods were adopted from Lamborg et al. (2008) and we note any deviations from these methods here. The three polycarbonate filters were first used to determine mass flux then two of the three filters were consumed for coulometric particulate inorganic carbon (PIC) analysis (Johnson et al., 1985; Honjo et al., 2000). The three silver filters were dried overnight in an oven at $60^{\circ} \mathrm{C}$ then counted on anti-coincidence beta detector (Risø National Laboratories) for ${ }^{234} \mathrm{Th}$. One of the three silver filters was recounted after $\operatorname{six}$ half-lives $\left(t_{1 / 2}=24.1\right.$ days $)$ to determine the background associated with other isotopes in the sample. All three silver filters were subsampled and a half of each was used for analysis of total particulate carbon (C) and nitrogen $(\mathrm{N})$, a quarter was used to determine biogenic silica (bSi) by inductively coupled plasma emission spectroscopy, and a quarte was kept as an archive. Thus for $\mathrm{C}, \mathrm{N}$, bSi, and ${ }^{234} \mathrm{Th}$ analyses, there were three replicates of each split. Particulate organic carbon flux for the three replicates was determined by subtracting the mean of the two PIC flux values from the total carbon value. The average contribution of PIC to the total carbon signal was $10 \%$. The total carbon content of the swimmer fraction was determined also by CHN analysis. Early in the study, 50\% subsamples of the swimmer filters were analyzed however, for the remainder of the study (May 2008, onward), whole filters were analyzed.

\subsection{June/July 2008 trap inter-comparison experiment}

In June and July 2008, along with the NBSTs and PITs array, an additional surface-tethered, drifting sediment trap array was deployed (McDonnell and Buesseler, 2012). Individual NBST tubes or "CLAP" tubes and PITs tubes were deployed on the sediment trap frame at $150 \mathrm{~m}$. The array included two CLAP tubes with lids, two CLAP tubes without lids, and two PITs tubes. Also, 4 additional PITs tubes were placed on the PITs array to be processed by the WHOI group. The individual tubes were combined and split such that the resulting particle load on silver or polycarbonate filters was similar to that of NBST samples. For example, the two CLAP tubes with lids were combined, split four ways, and filtered onto two silver filter and two polycarbonate filters. Two PITs tubes were combined, split two ways, and filtered onto a silver filter and a polycarbonate filter All samples were passed through $350 \mu \mathrm{m}$ screens to remove swimmers. CLAP tubes were corrected using the NBST blank correction factor. PITs samples processed by our two groups were corrected using PITs blanks measured by the WHOI group $(n=2)$ and the BATS group ( $n=14$ ), respectively.

\section{Results}

\subsection{NBST time-series flux results}

Over the course of three years, NBSTs were successfully deployed 77 times at the BATS site. Only three months were unsampled by the NBSTs because of maintenance requirements or no cruise as in January 2009 and 2010. A consistent seasonal pattern was not apparent in the fluxes of the measured particulate components or their ratios (Figs. 1 and A1). Mass flux was more variable over the three-year period compared to POC flux, which varied little except for a large POC flux event in spring 2010. Split-to-split variability (Table 1) for POC and mass flux was consistent with previous results using the splitting technique (Lamborg et al., 2008).

The mean C: $\mathrm{N}$ of the material collected was $7.0+2.7$, not including values from November 2009 when the $\mathrm{C}: \mathrm{N}$ ratios were abnormally high due to very low $\mathrm{N}$ fluxes (Figs. 1 and $\mathrm{A} 1$ ). There was good agreement between the three splits and two NBSTs for ${ }^{234} \mathrm{Th}$ fluxes, which were highly variable over the study period. Silica fluxes were very low for most of the study period except for a few peaks, most notably in May 2008 and December 2008. Replicate splits and separate NBSTs for biogenic silica also agreed well. PIC fluxes were similarly low except for a small increase in spring 2010. Reproducibility between the two splits and NBSTs was good except in December 2010, when the one NBST collected significantly more PIC. Over the entire study, NBST-to-NBST variability in the same deployment was on the order of $20 \%$ for 
the flux components reported here, consistent with prior NBST deployments (Lamborg et al., 2008).

\subsection{Sample processing methods}

3.2.1. Swimmer removal techniques

During this study, the primary method of swimmer removal from NBST samples was screening of the sediment trap material through a $350 \mu \mathrm{m}$ mesh. On average, swimmer carbon accounted for $49 \pm 20 \%$ of the total carbon flux, ranging from $<1 \%$ to $93 \%$ of the flux (Fig. 2). Early in the study, one of the three screened sample splits on silver filters was examined under a microscope $(n=17)$. Any small swimmers that may have passed through the screen were picked onto a blank silver filter and both fractions were analyzed for their carbon content. The carbon content of
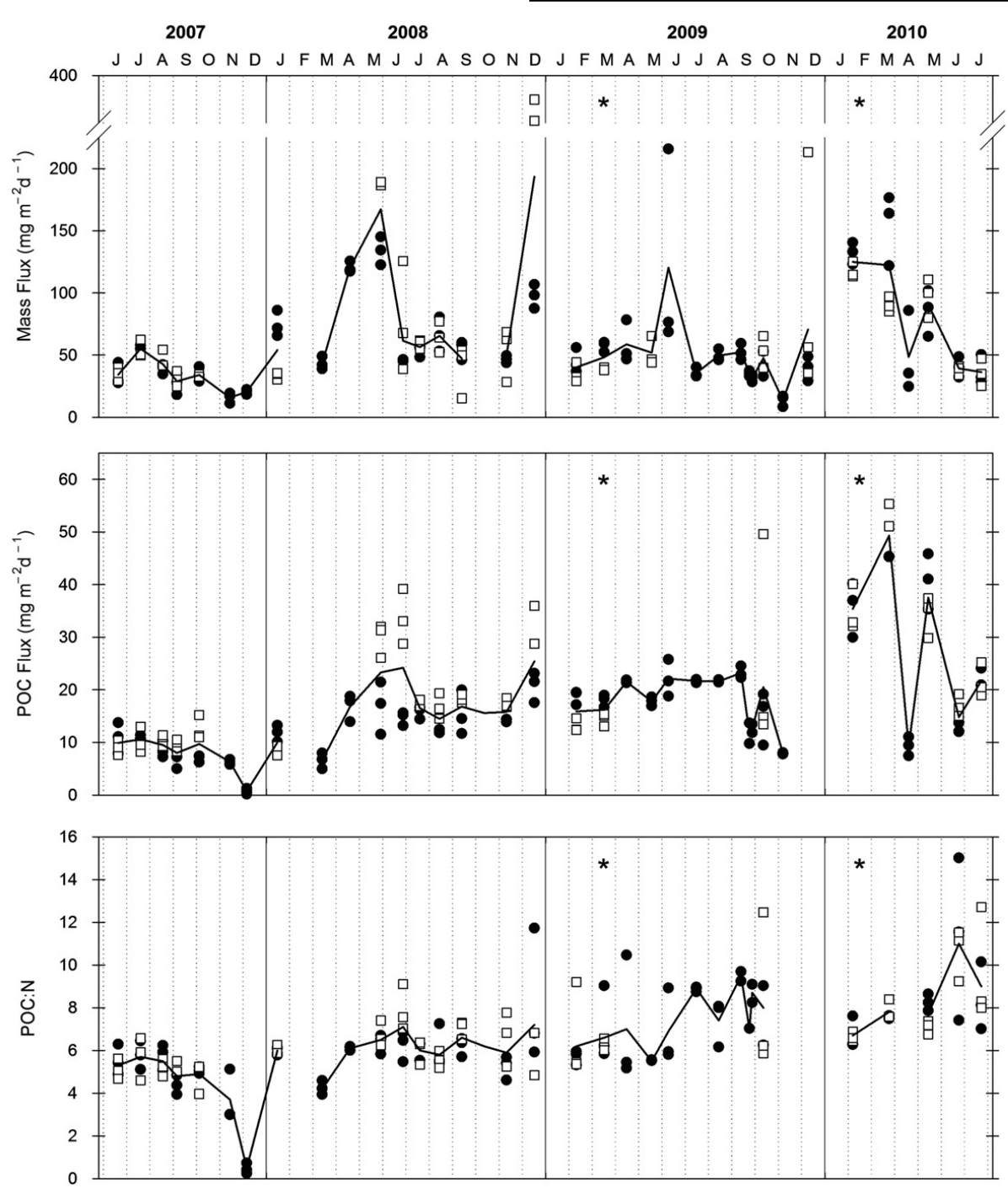

Fig. 1. Mass flux, POC flux, and C:N ratios of sinking material captured by NBSTs at $150 \mathrm{~m}$ at the Bermuda Atlantic Time-series Study site. Two traps were deployed each month (circles and squares) and three replicates of each parameter were obtained (denoted by individual points). The solid black line in each figure is the average of the three replicates in the two traps. Stars above March 2009 and February 2010 denote months when the traps were in the mixed layer. 


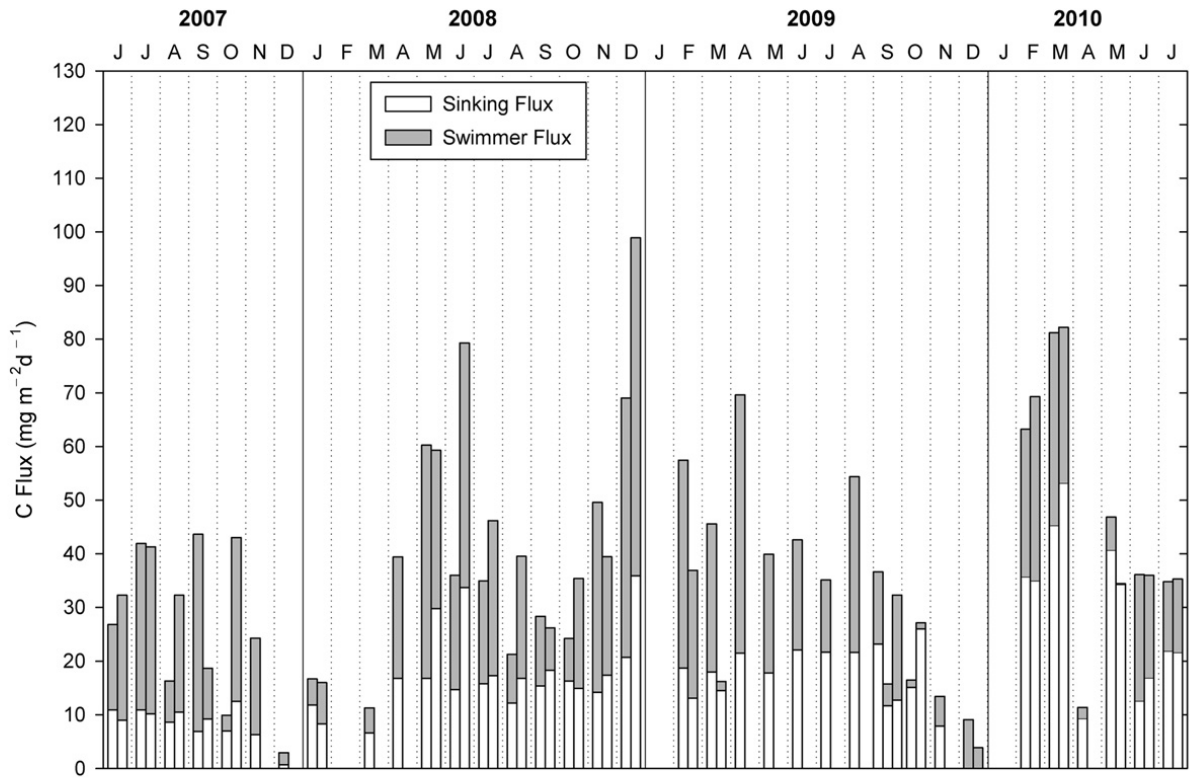

Fig. 2. Comparison of carbon flux associated with the sinking fraction ( $<350 \mu \mathrm{m}$, in white) versus the swimmer fraction ( $>350 \mu \mathrm{m}$, in gray) collected by NBSTs at $150 \mathrm{~m}$. No sinking fraction carbon data was available for December 2009.

screen were a minor or insignificant contribution to the total flux in terms of carbon content

An alternate method of swimmer removal, which we refer to here as "wet-picking," was also tested. For this method, at sea, the brine layer from four tubes was combined in a $4 \mathrm{~L}$ bottle without screening; on shore, the entire sample was examined in smallervolume fractions under a microscope and swimmers were picked directly onto a silver filter. On five separate occasions, screening and wet-picking were carried out on separate NBST samples (Fig. 3). The POC flux of the sinking material, after swimmer removal, was comparable between the two methods (Student's $t$-test with equal variance, $P<0.01$; Fig. 3 , upper panel). The amount of swimmer carbon removed by each method was variable however, with more swimmer carbon from wet-picked samples in three instances and more swimmer carbon from screened samples in two instances (Fig. 3, lower panel). These differences in swimmer carbon content removed are likely attributable to variability between NBSTs, as it may take only one or two large zooplankton to impact the carbon data. In October 2008, for example (Fig. 2), when both NBST samples were screened to remove swimmers, the percent of total carbon from swimmers in the two traps was 34 and $58 \%$, yet the percent difference between the POC fluxes was less than $10 \%$ or approximately $1 \mathrm{mg} \mathrm{C} \mathrm{m}^{-2} \mathrm{~d}^{-1}$. Looking at all instances when two NBSTs were deployed and both sets of samples were screened to remove swimmers $(n=18)$, the absolute difference between percent carbon from swimmers for two NBSTs ranged from 0 to $50 \%$. In the five cases in which screening and wet-picking were compared, the difference in swimmer carbon percentage between two NBSTs ranged from $21 \%$ to $37 \%$, within the lower range for two NBST samples that were both screened.

\subsubsection{NBST process blanks}

NBST process blanks were prepared, processed, and analyzed in an identical manner to NBST samples. The blanks are viewed as "process blanks" in that they account for any background signal inherent to the sampling and processing methodology. Table 2 shows blank "fluxes" for NBSTs from this study at BATS and from the Vertical Transport In the Global Ocean (VERTIGO) program in the subtropical (ALOHA) and subarctic (K2) North Pacific. Blank "fluxes" measured separately by the WHOI and BATS groups are also shown. NBST blank fluxes for most parameters were comparable to those measured in the VERTIGO study (Lamborg et al., 2008). The NBST process blank was most important for total carbon, mass, and biogenic silica (bSi) analyses, where the blank signal was 18,13 , and $40 \%$, on average, of the total measured signal. In contrast, the contribution of the blank for ${ }^{234} \mathrm{Th}$, total $\mathrm{N}$ and PIC was less than 5\% of the total measured amount or below detection. Blank corrections were applied to total C, mass, and bSi analyses before deriving fluxes. Blank corrections were not applied to $^{234} \mathrm{Th}, \mathrm{N}$, and PIC samples because the blank values were low, they were minor contributions to the total measured values, and all had high uncertainties.

\subsection{NBSTs versus PITs POC time series}

The average POC flux collected by the NBSTs was $18.5 \mathrm{mg} \mathrm{C}$ $\mathrm{m}^{-2} \mathrm{~d}^{-1}$ (range $2.0-50.2 \mathrm{mg} \mathrm{C} \mathrm{m}^{-2} \mathrm{~d}^{-1}$ ) compared to an average PITs flux of $27.4 \mathrm{mg} \mathrm{C} \mathrm{m}^{-2} \mathrm{~d}^{-1}$ (range $7.0-69.0 \mathrm{mg} \mathrm{C} \mathrm{m}^{-2} \mathrm{~d}^{-1}$ ) In most months of the time series, POC flux at $150 \mathrm{~m}$ measured by NBSTs and PITs agreed within a factor of two (Fig. 4). In three periods however, the PITs collected more than three times the amount of material than the NBSTs and the highest and lowest individual measurements for the two systems did not overlap (Fig. 5). This variability exceeds the largest variability seen between individual NBSTs, a factor of 2.2. The tube-to-tube variability of POC flux collected by the PITs was greater than the split-to-split variability of the NBSTs (Student's t-test with unequal variance, $P<0.01$; Fig. 4 ; Table 1 ).This trend is not surprising, as the combining and splitting method used on the NBST samples homogenizes any tube-to-tube variability. In the 

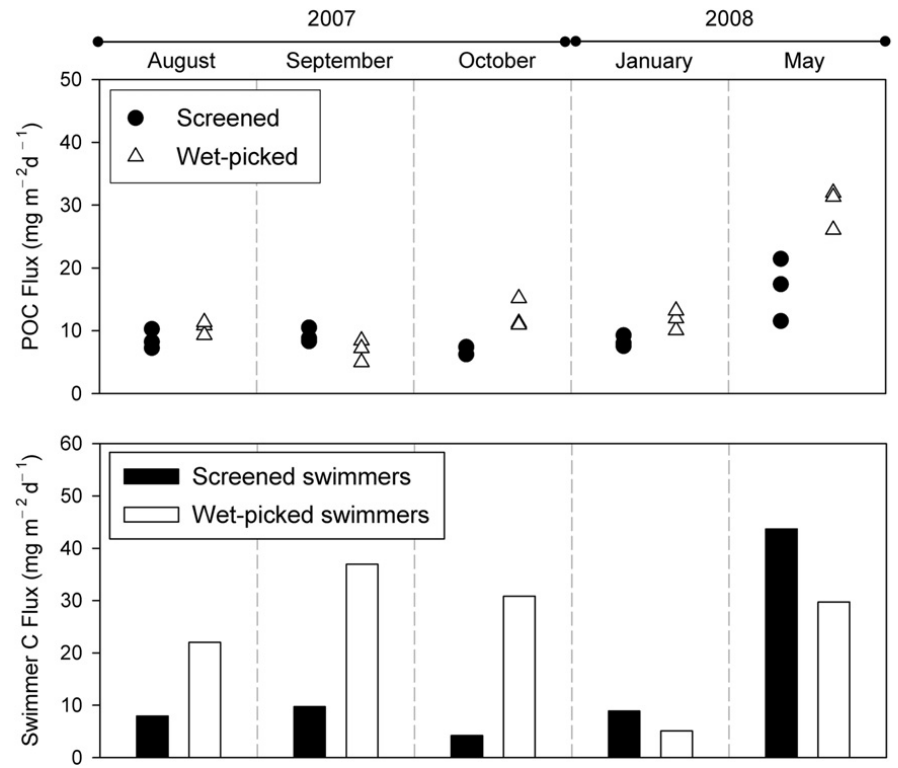

Fig. 3. Two methods for removing swimmers from the NBST samples were tested: screening using a $350 \mu \mathrm{m}$ mesh (black circles and bars) and wet-picking directly from the sample volume (white triangles and bars). The top panel shows the PoC flux measured in the sinking fraction, from which swimmers have been removed by either screening or wet-picking. The bottom panel shows the magnitude of the swimmer carbon removed from each sample by each method. While the magnitude of swimmers removed from by each method varied, the resultant flux of sinking material was comparable for the two methods.

Table 2

NBST Blank fluxes from this study compared to blank measurements during studies in the subtropical (ALOHA) and subarctic (K2) North Pacific. PITs blanks were measured separately by the WHOI and BATS groups. ${ }^{a}$

\begin{tabular}{|c|c|c|c|c|c|c|}
\hline & Total $C\left(m g m^{2} d^{1}\right)$ & $\operatorname{Mass}\left(m g m^{2} d^{1}\right)$ & $b S i\left(m g m^{2} d^{1}\right)$ & ${ }^{234} \mathrm{Th}\left(\mathrm{dpm} \mathrm{m}{ }^{2} \mathrm{~d}^{1}\right)$ & $N\left(\mathrm{mg} \mathrm{m}^{2} \mathrm{~d}^{1}\right)$ & $\operatorname{PIC}\left(m g m^{2} d^{1}\right)$ \\
\hline ALOHA & $1.3 \pm 0.5$ & $8 \pm 2$ & $0.11 \pm 0.06$ & $0 \pm 43$ & $0.07 \pm 0.07$ & $<0.24$ \\
\hline K2 & $4.1 \pm 0.5$ & $28 \pm 14$ & $0.11 \pm 0.06$ & $0 \pm 17$ & $0.35 \pm 0.06$ & $<0.24$ \\
\hline \multicolumn{7}{|l|}{ PITs } \\
\hline $\mathrm{WHOI}^{c}$ & $10.5 \pm 0.3$ & 9 & - & $7 \pm 3$ & $0.77 \pm 0.09$ & $0.01 \pm 0.02$ \\
\hline BATS $^{d}$ & $1.2 \pm 0.7$ & $19 \pm 8$ & - & - & $0.05 \pm 0.04$ & - \\
\hline
\end{tabular}

a Blank "fluxes" were calculated based on the trap area (NBST $0.01143 \mathrm{~m}^{2}$, PITs $0.0039 \mathrm{~m}^{2}$ ) and a three day deployment period.

${ }^{b}$ Four-tube blanks were prepared and analyzed 17 times during this study. For C, mass, bSi, ${ }^{234} \mathrm{Th}$, and $N$ average blank fluxes, $n=51$ and for PIC, $n=34$. Average blank corrections were applied to C, mass, and bSi raw data.

${ }^{c}$ For $\mathrm{C},{ }^{234} \mathrm{Th}, \mathrm{N}$, and PIC, $n=2$; for mass, $n=1$.

${ }^{d}$ For BATS PITs blanks, $n=14$ and the $\mathrm{C}$ blank is for POC, not total C

nine months that NBSTs were deployed at 150, 300, and $500 \mathrm{~m}$, flux measured by the NBSTs and PITs agreed well (Fig. 6). The larger tube-to-tube variability of the PITs is also evident in the flux versus depth profiles. The average mesopelagic transfer efficiency $\left(T_{\text {eff }}=300 \mathrm{~m}\right.$ POC flux $/ 150 \mathrm{~m}$ POC flux) from the NBSTs was $38 \pm 18 \%$ versus $53 \pm 15 \%$ for the PITs.

\subsection{June/July 2008 trap comparison experiment}

In June and July 2008, a more detailed experiment comparing NBST and PITs methodologies was carried out using both systems and an additional drifting array equipped with CLAP (NBST) tubes and PITs tubes (Fig. 7). In June, the flux measured by two NBSTs varied by about a factor of two, while in July, the measured fluxes were almost identical. We had aimed to capture the large discrepancy between the NBST and PITs observed in summer 2007 again (Fig. 5); however, the PITs and NBSTs agreed within the range of NBST-to-NBST variability in June and July 2008. The
CLAP tubes on the drifting array were deployed both with and without lids that closed prior to recovery. In both months, the flux was lower in the tubes without lids, which may suggest that during recovery, as traps are hauled to the surface, there is the potential for material to be washed out of tubes without lids. We are not able to estimate from this work however, the potential for this to occur in the PITs which also do not have lids. These data reinforce the importance of a process blank correction to the NBST/CLAP and PITs data.

\section{Discussion}

\subsection{The swimmer issue}

The significant and variable contribution of swimmer carbon to the total flux collected by the NBSTs in this study reinforces the importance of removing swimmers from sediment trap samples 
to quantify passively sinking particle flux (Fig. 2). The effectiveness of the swimmer removal method used in this study was established in two ways: (1) examination of screened samples for small swimmers and (2) testing an alternate wet-picking method. The contribution to the total carbon flux by swimmers less than $350 \mu \mathrm{m}$ was small, suggesting that for this study at the BATS site, screening was an effective method for removing swimmers from the bulk sample. The wet-picking method for removing swimmers produced sinking flux values that were comparable with

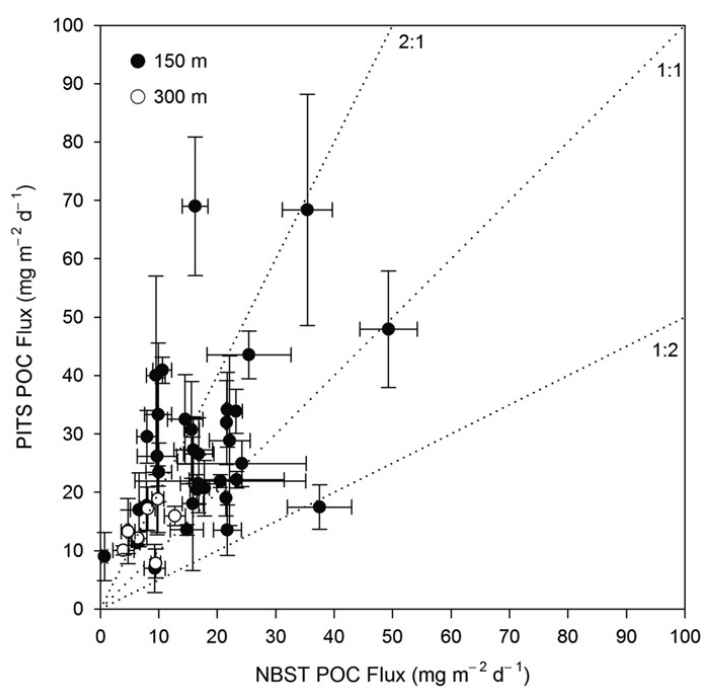

Fig. 4. Average POC flux determined using PITs versus average POC collected by NBSTs at 150 (black) and 300 (white) $\mathrm{m}$. The error bars on the PITs data are the standard deviation of measurements from three PITs tubes while the error bars on the NBST data are the standard deviation of replicates from one or two NBSTs. A single NBST was deployed in November and December 2007, March and April 2008, April to September 2009, November 2009, and April 2010. samples that were screened (Fig. 3). The screens were not examined to determine if they retained any non-swimmer material, however the similarity of POC fluxes determined by the two swimmer removal methods suggest that this was not a significant problem, consistent with previous applications of this method (Lamborg et al., 2008).

While both swimmer removal methods used in this study were effective, the wet-picking technique was time consuming and potentially susceptible to variable swimmer picking skills with changes in personnel. The screening technique was easy to perform at sea and more compatible with our sample-splitting technique. Although no trace metal data is reported in this work it may be easier to maintain trace metal cleanliness for analysis of particulate trace metals using the screening method. It is important to acknowledge that a method that is effective at removing swimmers at one study site may not always be a suitable method at other sites. For example, screening alone may not be as effective in coastal or other environments with high zooplankton biomass and large sinking fecal pellets, such as with krill in the Western Antarctic Peninsula region (Buesseler et al., 2010; Gleiber et al., in press)

In the only comparable study comparing the BATS picking method and screening $(350 \mu \mathrm{m})$ at BATS, the POC flux determined from the picked samples was $40 \%$ lower than the POC flux from the screened samples (Buesseler et al., 2007). In addition, the C:N ratio of the picked samples was lower than the screened samples. These results were used to suggest that the screening method might have missed small swimmers and thus it has not been used at BATS. This is in contrast to our study, where the difference between POC flux from screened and wet-picked NBST samples was indistinguishable (Fig. 3 ) and the $\mathrm{C}: \mathrm{N}$ ratio was the same (not shown; Student's $t$-test with equal variance, $P<0.01$ ). PITs tubes picked for swimmers by the BATS group and PITs tubes screened through a $350 \mu \mathrm{m}$ mesh by the WHOI group during the intercomparison study also produced comparable sinking POC fluxes, within the range of observed tube-to-tube variability (Fig. 7).

It has been hypothesized that surface-tethered traps such as PITs may be more likely to trap swimmers due to hydrodynamic effects around the mouth of the trap that allow the swimmers to

2008

2009

2010

J J ASOND JFMAMJ JASOND J FMAMJ JASOND JFMAMJJ

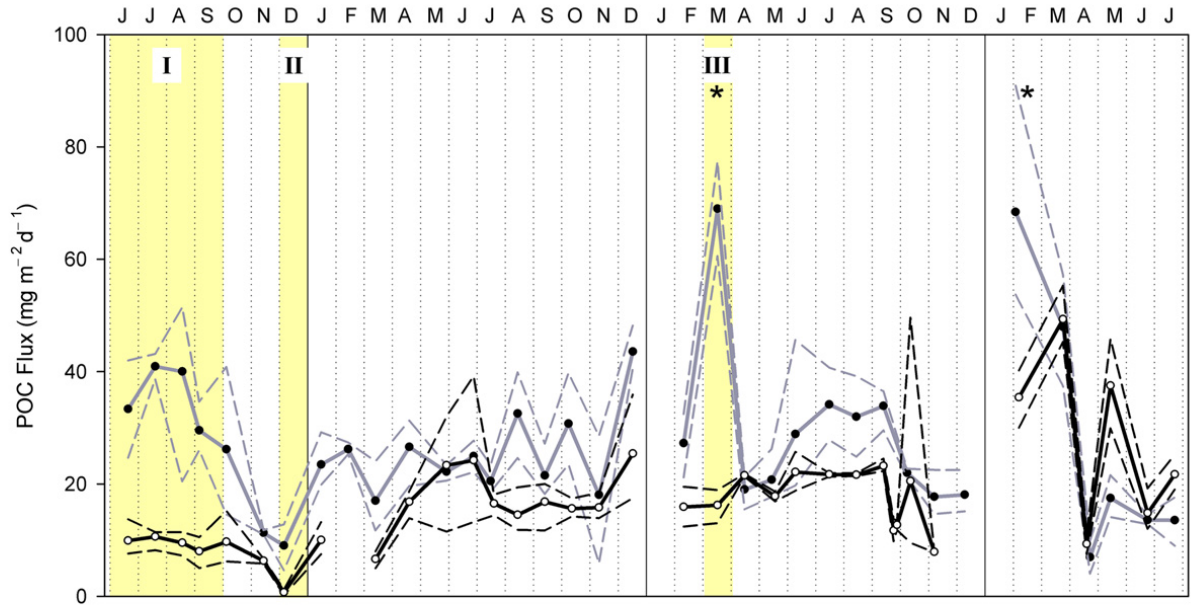

Fig. 5. The average POC flux measured by NBSTs (black solid line) and PITs (grey solid line) at $150 \mathrm{~m}$. The dashed lines denote the highest and lowest fluxes determined for replicates of NBST samples or individual PITs tubes. The three periods of particular interest where the traps differed by more than a factor of three and none of the individual measurements overlapped are highlighted in yellow. Stars above March 2009 and February 2010 denote months when the traps were in the mixed layer. 

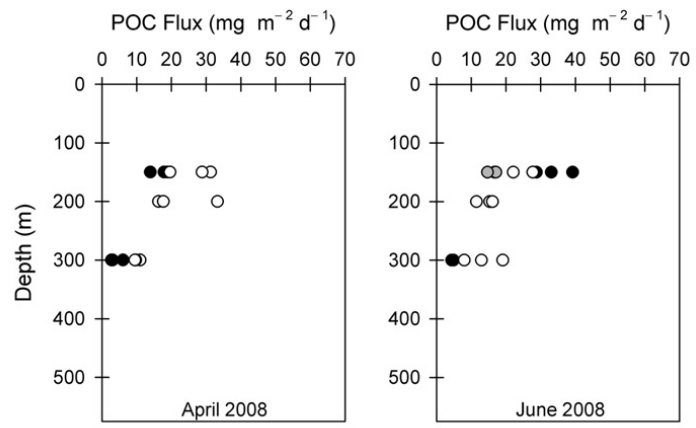

POC Flux (mg m $\left.{ }^{-2} \mathrm{~d}^{-1}\right)$

POC Flux (mg m $\left.{ }^{-2} \mathrm{~d}^{-1}\right)$
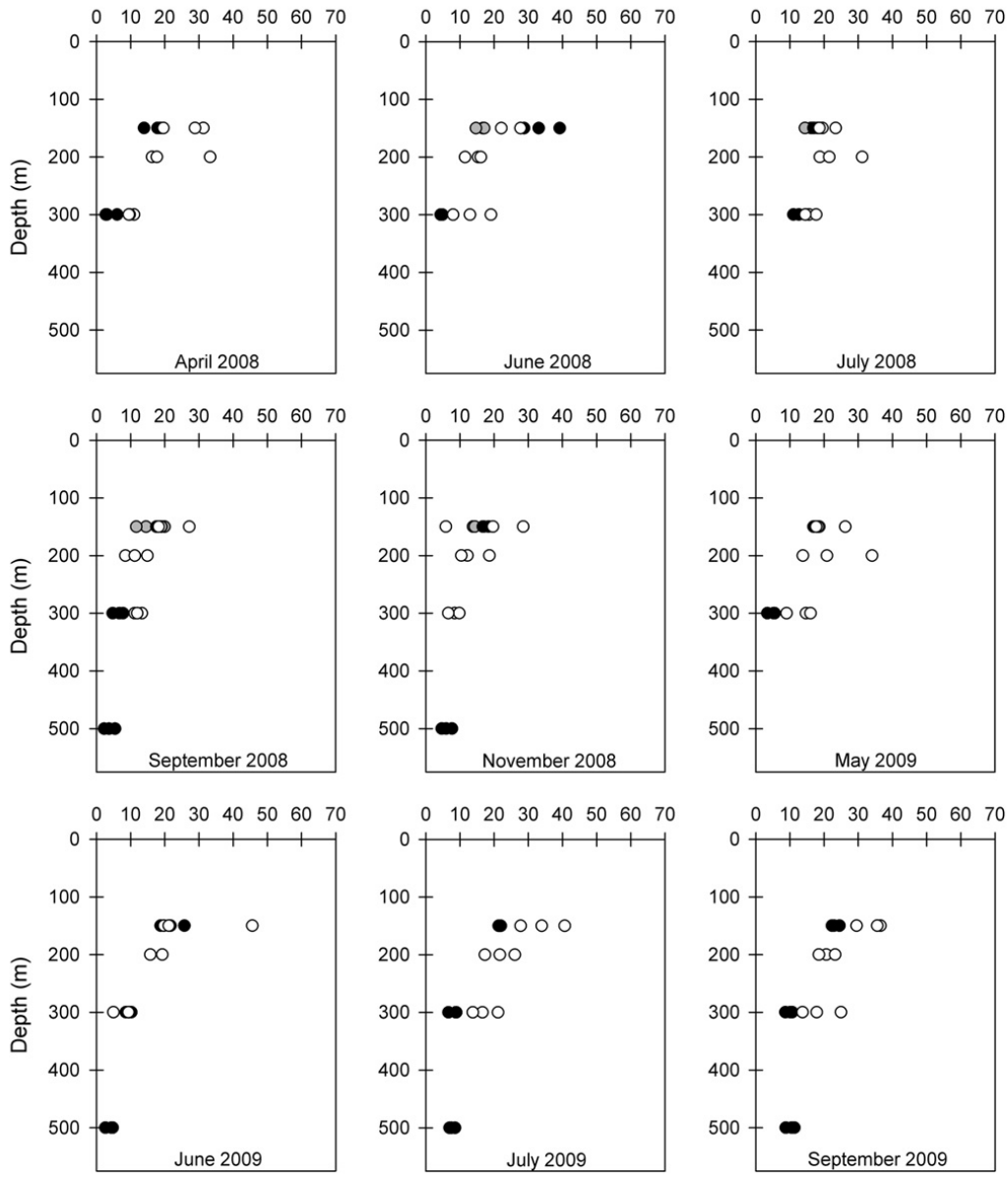

Fig. 6. POC flux versus depth as measured by NBSTs and PITs. Shown are individual NBST replicates (in black, grey for a second $150 \mathrm{~m}$ NBST) from traps at 150 , 300 , and $500 \mathrm{~m}$ and individual PITs tubes at 150,200 , and $300 \mathrm{~m}$ (in white).

"surf" into the device, in addition to swimmers that actively swim into the traps (Buesseler et al., 2007; Lampitt et al., 2008). Thus, traps that experience minimal or no hydrodynamic flow would ensnare fewer unwanted swimmers. Although fewer swimmers were captured in NBSTs than PITs in an early study (Buesseler et al., 2000), more recently, swimmers contributed significantly to the total carbon flux in NBSTs deployed in the Pacific (Lamborg et al., 2008). PELAGRA, another neutrally buoyant sediment trap design, captured very few swimmers in its early deployments (Lampitt et al., 2008), but during deployments in the Southern Ocean, swimmer contribution to the total mass flux ranged from $<1 \%$ to $40 \%$ (Salter et al., 2007). In the study here, swimmer carbon was a significant component of the total carbon flux captured by both the NBSTs and the PITs. In the two-month inter-comparison study, the swimmer carbon flux in the NBSTs ranged from 19 to $46 \mathrm{mg} \mathrm{C} \mathrm{m}^{-2} \mathrm{~d}^{-1}$ while the range of swimmer carbon flux in the PITs was 27 to $72 \mathrm{mg} \mathrm{C} \mathrm{m}^{-2} \mathrm{~d}^{-1}$. If "surfing" swimmers are in fact fewer in neutrally buoyant trap designs, these results suggest that swimmers actively entering or zooplankton passively sinking into the traps are also important.

\subsection{Sediment trap blanks}

Process blank corrections are not common to all sediment trap programs. NBST blanks were implemented during the VERTIGO study primarily to quantify trace metal blanks but were also determined for major particulate components. In the present study, the NBST blank values for C, mass, and Si were significant relative to sample values, particularly as the particle flux at BATS is so low. BATS sediment trap flux measurements take into account analytical blanks but not process blanks (Knap et al., 1997). When measured by the BATS group, the PITs process blank was $28 \%, 9 \%$, and $2 \%$, on average, of the measured values for mass, POC, and N, respectively. To further demonstrate the importance of applying a process blank correction to the PITs data, Fig. 8 shows NBST and PITs POC fluxes as a function of primary production. Applying a correction for the process blank to the PITs data from the period of this study shifts the POC fluxes to lower values, implying lower export efficiency for the biological pump at BATS.

Some issues arose with these preliminary measurements of the PITs blank including how to blank correct for mass and 
carbon/nitrogen on a single filter, the effect of blank corrections on C:N ratios, and what volume of brine to use for measurements for the blanks. For each PITs tube, mass flux is determined from the change in filter weight before and after filtration. After these weight measurements, the sample material is scraped off the filter and this subsample is reweighed to determine the fraction of material recovered off the filter. In some cases, the change in weight of blank and sample PITs filters was similar although the weight of the blank subsample was very small. This led to an overestimation of the blank mass flux and consequently an overestimation of the blank POC flux, which is determined by

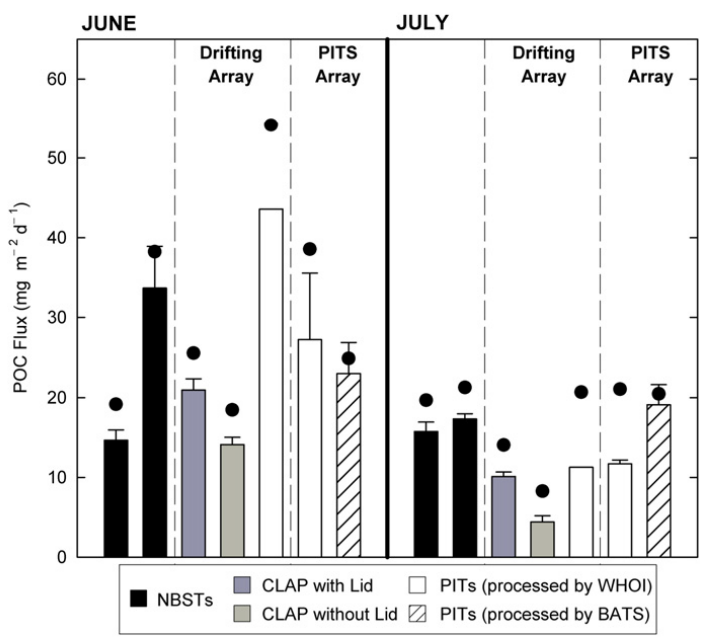

Fig. 7. Results of an experiment comparing sediment trap types in June and July 2008. Average POC flux for two NBSTs is shown (black bars, on left each month) and the error bars represent the standard deviation of three replicates. NBST (CLAP) tubes (with and without lids, dark and light grey) and PITs tubes (white) (CLAP) tubes (with and without lids, dark and light grey) and PITs tubes (white)
were deployed on a surface tethered drifting array (center). Additional PITs tubes were deployed on a surface tethered drifting array (center). Additional PITs tubes
on the PITs array were analyzed by the WHOI group (white bars). The standard PITs tubes analyzed by the BATS group each month are shown to the far right (hashed bars). The black dot above each bar denotes the POC flux before the method-specific process blank correction was applied.

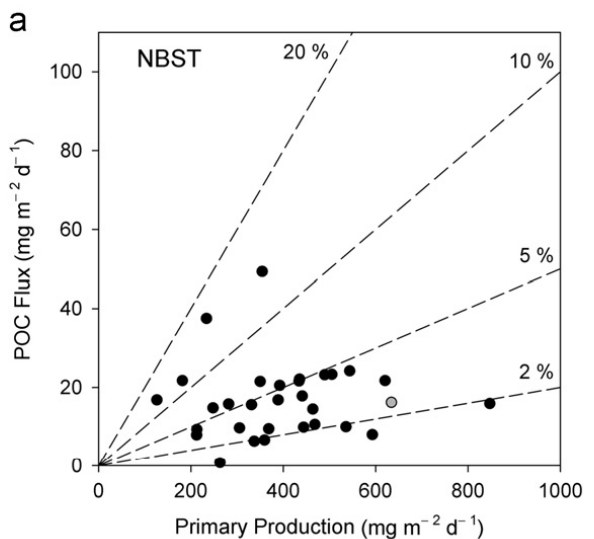

multiplying the percent carbon of the subsample and the mass flux. To avoid this problem, we applied the $C$ blank value to the whole-sample $C$ value rather than the subsample $C$ value. This assumes that the $C$ blank is independent of the calculation that scales from the subsample to the whole sample. The PITs blanks for mass and $C$ were larger when measured on separate filters by the WHOI group in June and July 2008 (Fig. 7). We believe that these analyses by our two groups represent the upper and lower limits of the PITs blank contributions.

A second quandary arose when looking at the effect of $\mathrm{C}$ and $\mathrm{N}$ blank corrections on sample $\mathrm{C}: \mathrm{N}$ ratios of the PITs data. Before blank correction the mean $\mathrm{C}: \mathrm{N}$ of the PITs data was $6.6 \pm 0.9$ and after correcting for both $\mathrm{C}$ and $\mathrm{N}$ blanks, the mean $\mathrm{C}: \mathrm{N}$ was $6.1 \pm 0.9$. Sinking particles tend to have higher $C: N$ values than Redfield values ( $\mathrm{C}: \mathrm{N}=6.625$ ) due to preferential remineralization of nitrogen (Martin et al., 1987; Lamborg et al., 2008). The blankcorrected PITs data are lower than Redfield values, which may suggest that the current $\mathrm{C}$ blank correction is too high or the $\mathrm{N}$ blank is too low; the standard deviations of these mean $\mathrm{C}: \mathrm{N}$ values are too large however to establish this definitively.

A final consideration is how to account for the variable volume of PITs samples when determining process blanks. One third to one half of the brine solution that initially fills the PITs tubes is washed out during deployment. Before filtration, the entrained seawater is siphoned off and only the remaining brine is processed. As a result, individual tubes have different sample volumes. Blank corrections applied in Figs. 7 and 8 are wholetube blanks and do not take this variability into account. Further work is necessary to determine if the volume of the PITs process blanks is important.

Sediment trap process blanks are an important methodological issue that should be considered in existing and future sediment trap studies. A less complex approach to determining PITs blanks would be to deploy additional tubes and measure fluxes and blanks of different components on separate tubes, although this complicates the calculation of elemental ratios due to tube-tovariability. Alternately, samples could combined, split, and filtered onto multiple filters for different analyses, like the NBSTs. To address the problem of variable sample volumes, the height of the brine in each sample tube could be measured then multiple blanks could be prepared based on these volumes. Alternately, if the brine solution was constrained to the bottom of the PITs

b

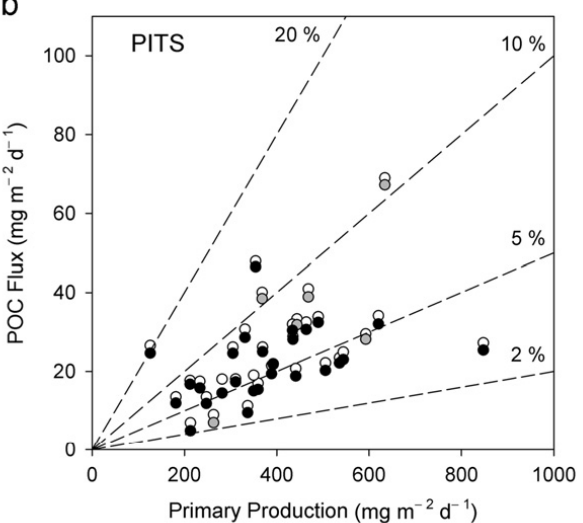

Fig. 8. (a) NBST POC flux versus integrated primary production determined during the BATS cruises from June 2007 to July 2010 with lines of constant export ratios. The grey point corresponds with February 2010 when the NBSTs were within the mixed layer. No primary production data was available for March 2009. (b) For the same time period, PITs POC flux versus integrated primary production before blank corrections are shown in white. In black and grey are the blank-corrected data, using the PITs blank measured by BATS. The grey points are those from the months highlighted in Fig. 5. 
tubes, a more reproducible sample volume might be obtained from each tube. One point however, is that a four-tube NBST blank was not four times as large as a single-tube NBST blank, so determining a process blank may not be as simple as scaling a blank tube measurement with volume. We recognize that there are arguably equal advantages and disadvantages to changing methods used in time-series studies; however this work also has implications for independent studies in which these process blank corrections may be more readily implemented.

\subsection{Differences in NBST and PITs flux measurements}

The purpose of this work was to compare the PITs and NBSTs over the annual productivity and export cycle at BATS. Our aim was not to inter-calibrate the two systems with water-column radionuclide measurements of export. Such an effort would have required multi-week and Lagrangian style sampling during each cruise (Buesseler et al., 1994, 2008b; Cochran et al., 2009), which was beyond the scope of our study. In previous comparisons of earlygeneration NBSTs to PITs at the BATS site, there were few replicates and while mass and POC fluxes agreed well, there were differences in fluxes of minor elements (Buesseler et al., 2000; Stanley et al., 2004). Over the course of the study presented here, flux measured by the two sediment trap systems agreed in most cases within the variability observed for two separate NBSTs, a factor of 2.2. However, we identified three periods, in which the flux collected by the PITs was more than three times higher than the NBST flux (Fig. 5): June to September 2007 (I); December 2007 (II); and March 2009 (III). Thus far, we have addressed methodological issues that should affect the entire time series. Below, we attempt to identify factors that may have caused the large discrepancies between the NBSTs and PITs in the three periods highlighted in Fig. 5.

\subsubsection{Currents}

The purpose of developing the NBSTs was to minimize hydrodynamic biasing experienced by surface-tethered traps like the PITs. As a neutrally buoyant float by design, the NBSTs should have no mooring line, tilt, or other hydrodynamic effects; the current generation of NBSTs however does not have onboard sensors to measure these properties. Flow across the PITs is measured using a current meter located $15 \mathrm{~m}$ below the $150 \mathrm{~m}$ PITs array. In the 33 of 35 months that current meter was available for this study period (Fig. A2), the average current speed was $7 \mathrm{~cm} \mathrm{~s}^{-1}$ and ranged from 3 to $12 \mathrm{~cm} \mathrm{~s}^{-1}$, similar to collection periods in prior NBST-PITs comparisons (Buesseler et al., 2000; Gardner, 2000; Stanley et al., 2004). Peak approach velocities measured during deployments here ranged from 10 to $23 \mathrm{~cm} \mathrm{~s}^{-1}$. There was no direct relationship between mean $\left(r^{2}=0.03, P=0.3\right)$ or maximum $\left(r^{2}=0.05, P=0.2\right)$ current velocities and POC flux measured by the PITs, in agreement with previously published data (Gardner, 2000). Contrary to Gardner (2000) however, when periods of high and low net primary production (NPP) were considered separately, a trend of increasing PITs flux with velocity did not emerge. Also, there was no correspondence between periods of increased current speed and the three periods in which the PITs measured higher values of POC flux. Based on these current meter measurements, hydrodynamic biasing does not appear to be the cause of the discrepancies in these three periods.

\subsubsection{Deep mixed-layer}

Sediment traps used for measuring passively sinking particle flux are typically deployed below the surface mixed layer. Convective mixing in this layer increases the residence time of particles and aggregates (Gardner, 2000) and as a result, particles may have more than one opportunity to sink into a sediment trap, leading to biased sampling (Gardner and Richardson, 1992;
Buesseler et al., 2007). The intensity of stratification can also vary spatially during a sediment trap deployment. Data from sediment traps that are deployed within the mixed layer should therefore be viewed with caution. For example, in a summary of the first decade of BATS data (Steinberg et al., 2001), months in which the mixed layer depth exceeded the PITs depth showed dramatic increases in particle flux, even down to 200 and $300 \mathrm{~m}$, and the data were considered suspect.

The NBSTs and PITs were within deep, winter mixed layers in March 2009 (188 m) and February 2010 (226 m), corresponding with one of the anomalous periods (III; Fig. 5) and the two months of highest POC flux measured by the PITs during this study. The mixed layer was defined using the variable sigma theta criteria and assuming a $0.3^{\circ} \mathrm{C}$ diurnal temperature change (Sprintall and Tomczak, 1992). While the POC flux measured by the PITs in these two months represented significant deviations from the mean flux, a similar change was not observed in the NBST fluxes, particularly in March 2009. The properties used to indicate a deepened mixed layer may persist after the period of actual deep mixing, meaning that during the deployments, the sediment traps may not have been in the zone of active mixing. Nonetheless, until it can be shown that sediment traps of any design can quantitatively capture sinking particle flux in the mixed layer, these data should be regarded with caution. In this work, these data are not considered further and following the convention of Steinberg et al. (2001) are denoted with asterisks in Figs. 1, 5, and A1.

\subsubsection{Spatial variability}

Another factor to consider is differences in deployment locations of the two sediment trap systems resulting in variability in the sinking particle flux. For example, Fig. 9 shows the deployment and recovery positions of the NBSTs and the recovery positions of the PITs each month (\#1-12) of 2008. On average, deployment locations of the PITs and NBSTs were within $3 \mathrm{~km}$ and in 27 of 35 months the recovery locations were within $15 \mathrm{~km}$ of each other. These distances were on the same scale as source funnels calculated for surface-

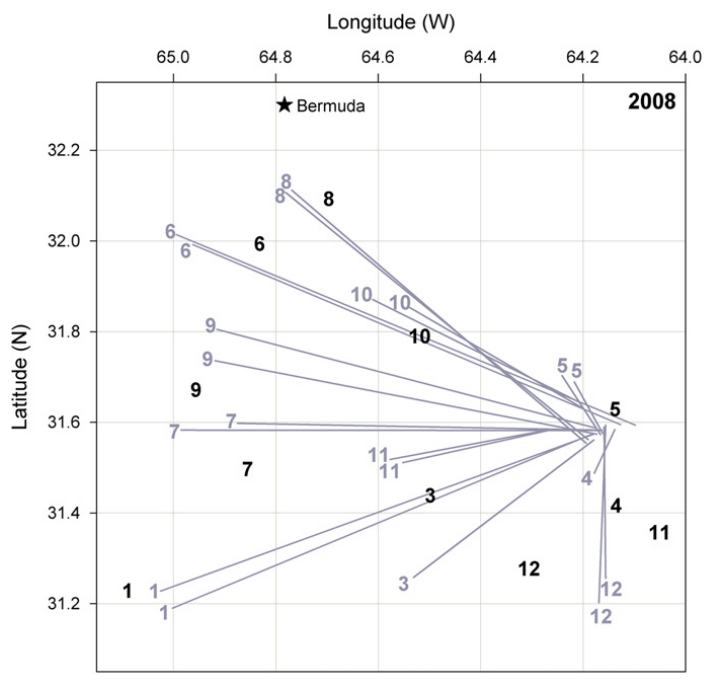

Fig. 9. Deployment and recovery positions for NBSTs in 2008 (in grey). Traps were deployed in the vicinity of $31.6^{\circ} \mathrm{N} \times 64.15^{\circ} \mathrm{W}$ each month and the numbers correspond to the month of the year (e.g. January $=1$, February =2, etc.). The grey lines are not the exact tracks taken by the NBSTs but are the direct paths from the deployment to the recovery positions. PITs were close in time to the NBSTs, in the same general vicinity. Only the recovery positions of the PITs are shown (in black). The island of Bermuda is denoted with a star 
tethered and neutrally buoyant traps in the subtropical North Pacific (Siegel et al., 2008). In the North Pacific, although the spatial extent of the source funnels of the two trap types was similar, the source locations were spatially decoupled. Thus in our study, although the sampling locations of the NBSTs and PITs were similar, the source regions of the particles they collected may have been different. In January 2008, when a factor of 2.3 difference in POC fluxes was observed (Fig. 5), the final separation of the two trap systems was $\sim 7.7 \mathrm{~km}$, a relatively small distance after a 3.9 day deployment (Fig. 9). In contrast, in November 2008, the NBSTs were recovered west-by-south $\left(\sim 255^{\circ}\right)$ of their deployment location while the PITs were recovered $\sim 50 \mathrm{~km}$ away, south-southeast $\left(154^{\circ}\right)$ of their deployment location, yet the POC fluxes measured by the two systems were similar. No simple relationship between separation of recovery locations and difference in POC flux measured by the two systems was observed when all the data were considered.

Data were also examined to determine if mesoscale eddies, which have been shown to affect particle export, might have influenced measurements of export by the PITs and NBSTs during this study (Sweeney et al., 2003; Buesseler et al., 2008a; Goldthwait and Steinberg, 2008). The mean weekly sea surface height (SSH) (Fig A3; from Maps of Absolute Dynamic Topography provided by the Archiving, Validation, and Interpretation of Satellite Data in Oceanography program) for the period of this study was $62 \pm 11 \mathrm{~cm}$. None of the anomalous periods corresponded with significant changes in SSH that would indicate the passage of eddies through the BATS region. Thus, we do not suspect that in-eddy versus out-of-eddy sampling was a cause for the differences between the NBSTs and PITs in any of these periods.

\subsubsection{Particle composition}

Elemental and mass ratios of the sample material from the NBSTs and PITs were compared to assess whether particles of the same composition were collected by each system. On average, the $\mathrm{C}: \mathrm{N}$ ratio measured by the PITs was $6.6 \pm 0.9$ compared to an average $C: N$ measured by the NBSTs of $7.0 \pm 2.7$ (excluding November 2009). The largest difference occurred in November 2009, when the particulate nitrogen flux measured by the NBSTs was very low, which resulted in elevated $\mathrm{C}: \mathrm{N}$ ratios. The mean ratios are not significantly different (Student's $t$-test with equal variance, $P<0.01$ ) and do not suggest any obvious particle sorting differences between the two trap types. The POC:mass ratios also agreed well between the PITs and NBSTs over the time-series (Student's $t$-test with equal variance, $P<0.01$ ). Preserved and unfiltered PITs and NBST samples from the three periods in question were examined with microscopy but there were no obvious differences in bulk composition of the samples.

\subsubsection{Summer flux peaks}

Large differences in the PITs and NBSTs were observed from June to September 2007 (I), a period during the seasonal carbon cycle at BATS not typically thought to be associated with significant increases in particle flux. The highest values (40$105 \mathrm{mg} \mathrm{C} \mathrm{m}^{-2} \mathrm{~d}^{-1}$ ) of POC flux measured at BATS by the PITs are associated with a bloom that occurs in the February to April period, caused by entrainment of nutrient-rich water by a deep winter mixed layer and subsequent shoaling of the mixed layer in the spring. The average PITs POC flux at $150 \mathrm{~m}$ in June to September from 1989 to 2009 was $25.1 \pm 5.6 \mathrm{mg} \mathrm{C} \mathrm{m}^{-2} \mathrm{~d}^{-1}$ compared to 2007 when it was $35.9 \pm 5.5 \mathrm{mg} \mathrm{C} \mathrm{m}^{-2} \mathrm{~d}^{-1}$ in the PITs, the highest value ever recorded for this period at BATS. Though 2007 has the highest mean flux for this four-month period, higher POC fluxes were observed in July $1989\left(42.7 \mathrm{mg} \mathrm{C} \mathrm{m}^{-2} \mathrm{~d}^{-1}\right)$ and August 1998 (42.9 $\mathrm{mg} \mathrm{C} \mathrm{m}^{-2} \mathrm{~d}^{-1}$ ) compared to July and August 2007 (40.9 $\mathrm{mg} \mathrm{C} \mathrm{m}^{-2} \mathrm{~d}^{-1}$ and $40.0 \mathrm{mg} \mathrm{C} \mathrm{m}^{-2} \mathrm{~d}^{-1}$, respectively). Nutrient concentrations are typically below detection limits of conventional methods in the summer at BATS (Steinberg et al.,
2001) and this holds true for 2007 to 2010 . Diatom blooms have occurred in the late spring or summer at BATS (Steinberg et al. 2001), though not in the years with increased summer fluxes (1989, 1998,or 2007). These blooms were associated with increases in the diatom pigment, fucoxanthin, and enhanced biogenic silica fluxes but not with increases in POC flux (Brzezinski and Nelson, 1995; Nelson and Brzezinski, 1997). There were no significant changes in euphotic-zone integrated fucoxanthin stocks or biogenic silica flux in the NBSTs (Fig. A1) in the summer of 2007 to suggest the occurrence of a diatom bloom. Though the 2007 summer period is not unique in its elevated POC flux, there is no evidence of a bloom nor a clear physical or biogeochemical explanation for why the NBSTs would collect less POC flux than the PITs during this period.
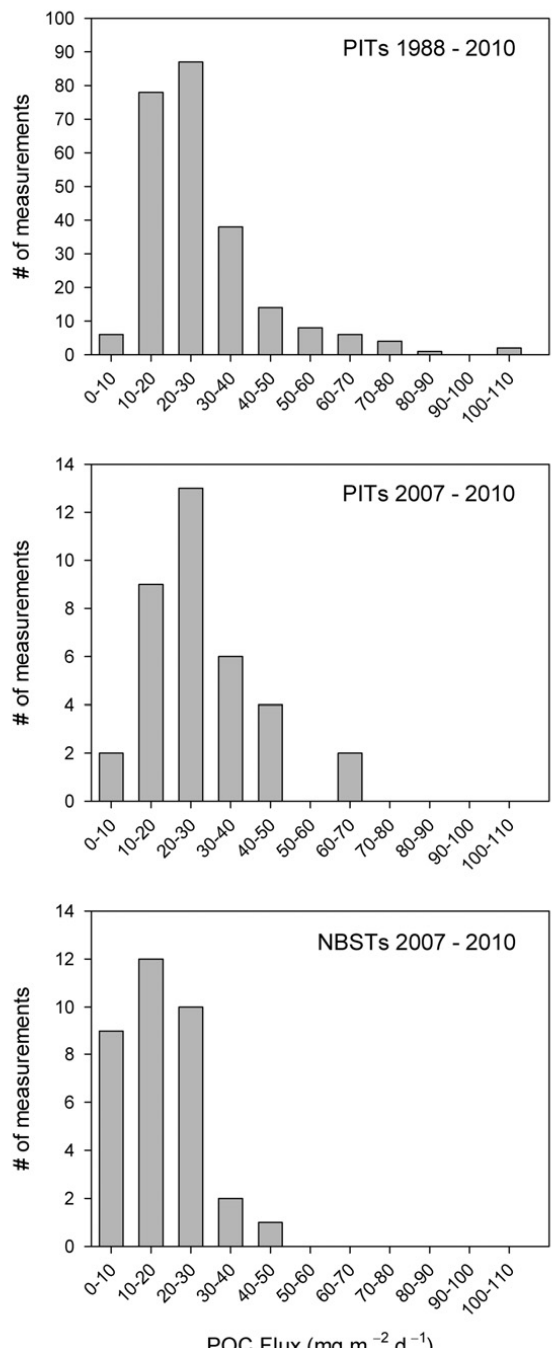

Fig. 10. The frequency of POC flux values measured by the PITs from 1988 to 2010 ( $n=244$; top panel), during the period of this study ( $n=36$; middle panel), and by the NBSTs during this study ( $n=34$; bottom panel). 
4.3.6. Near-zero fluxes

In period II, the POC flux collected by the NBSTs was very close to zero $\left(0.7 \pm 0.5 \mathrm{mg} \mathrm{C} \mathrm{m}^{-2} \mathrm{~d}^{-1}\right)$ compared to the PITs, which measured a POC flux of $9.0 \pm 4.1 \mathrm{mg} \mathrm{C} \mathrm{m}^{-2} \mathrm{~d}^{-1}$. Over the entire BATS PITs record, there are only six periods in which the mean POC flux at $150 \mathrm{~m}$ is less than $10 \mathrm{mg} \mathrm{C} \mathrm{m}^{-2} \mathrm{~d}^{-1}$, two instances of which were during our study in December 2007 (I) and April 2010. From 2007 to 2010 however, the NBSTs collected mean POC fluxes less than $10 \mathrm{mg} \mathrm{C} \mathrm{m}^{-2} \mathrm{~d}^{-1}$ on nine occasions (Fig. 10). One of the conclusions of a calibration exercise of PITs at BATS was that PITs over-collected during low flux periods (Buesseler et al., 1994). That study calculated that over a 4-day deployment, the PITs were flushed with approximately $6000 \mathrm{~L}$ of seawater and particles. Only a minimal amount of sheer-induced aggregation of small particles into sinking particles would have to take place during the trap deployment to cause a positive bias in the flux measurements. Thus it may not be surprising that measured flux is rarely less than $10 \mathrm{mg} \mathrm{C} \mathrm{m}^{-2} \mathrm{~d}^{-1}$. As neutrally buoyant devices, the NBSTs should experience little shear over the mouth of the traps, in theory minimizing this hypothesized bias, and allowing for the measurement of near-zero fluxes.

\subsection{Consequences for the BATS carbon cycle}

A one-dimensional carbon budget for BATS, constructed using data from the first five years of the time-series, revealed that the decrease in carbon stocks from spring to autumn were three times greater than the fluxes out of the system (Michaels et al., 1994). This imbalance was attributed to two factors: failure to include horizontal advection of carbon and/or underestimation of the sinking particle flux. Additional measurements of carbon transport by migrating zooplankton reduced the imbalance to a factor of 2.4 (Steinberg et al., 2000). With respect to under sampling of the POC flux, hydrodynamic biases on the traps were suspected to be the most significant problem, rather than swimmers or sample preservation. The comparison of NBSTs and PITs presented in this work does not support the hypothesis in Michaels et al. (1994) of undercollection of sinking material by sediment traps at BATS. Adopting the notation used by Michaels et al. (1994), of $\mathrm{mol} \mathrm{C} \mathrm{m}^{-2}$ period ${ }^{-1}$ (April to December), the NBST data reduces the sinking flux from $0.55 \mathrm{~mol} \mathrm{C} \mathrm{m}^{-2}$ period $^{-1}$ to $0.40 \mathrm{~mol} \mathrm{C} \mathrm{m}^{-2}$ period $^{-1}$. The POC flux measured by the PITs during the period of this study was $0.56 \mathrm{~mol} \mathrm{POC}^{-2}$ period $^{-1}$. PIC data for the PITs was not available for this period, so using the NBST PIC value of $0.03 \mathrm{~mol} \mathrm{C} \mathrm{m}^{-2}$ period $^{-1}$, the PITs $C$ flux value becomes $0.59 \mathrm{~mol} \mathrm{C} \mathrm{m}^{-2}$ period $^{-1}$ or as low as $0.52 \mathrm{~mol} \mathrm{C} \mathrm{m}^{-2}$ period $^{-1}$ if we apply a blank correction as in Fig. 8b. The NBST and PITs data together suggest that the observed carbon imbalance at BATS cannot be accounted for by undersampling of sinking carbon flux by these sediment traps.

The differences in the PITs and NBST data also have consequences for the export ratios (e-ratios) measured at BATS. For the NBST data set, e-ratios cluster between $2 \%$ and $5 \%$ (mean $4.9 \pm 3.8 \%$ ) except for April 2008 and March, May, and July 2010 when the e-ratios are greater than $10 \%$ (Fig. 8a). To compare, the average e-ratio based on the PITS data (Fig. 8b, white and grey) was $7.7 \pm 3.5 \%$ before blank correction and $6.2 \pm 3.4 \%$ afterwards (Fig. 8b, black). The only remaining months in the PITs data with export ratios higher than 10\% are April 2008 and March 2010, in agreement in with the NBST data. Three of the four highest export ratios were measured by the NBSTs in spring 2010, which was preceded by a winter of particularly deep mixing (Fig. 11). These increased e-ratios do not appear to be related to changes in particulate mineral composition (Fig. 11), consistent with Salter et al. (2010), and suggest that there is some unknown driver other than ballast for these highly efficient flux events.

\section{Summary and conclusions}

This study represents the first successful use of neutrally buoyant sediment trap technology in a time-series capacity, with 77 deployments of NBSTs at the BATS site between 2007 and 2010. NBST deployment and recovery operations were swift and less time was spent with wires under tension compared to surface-tethered trap operations. The sample processing regime of screening, combining tubes, and splitting the samples allowed for elucidation of multiple parameters with replication, thus providing details on the

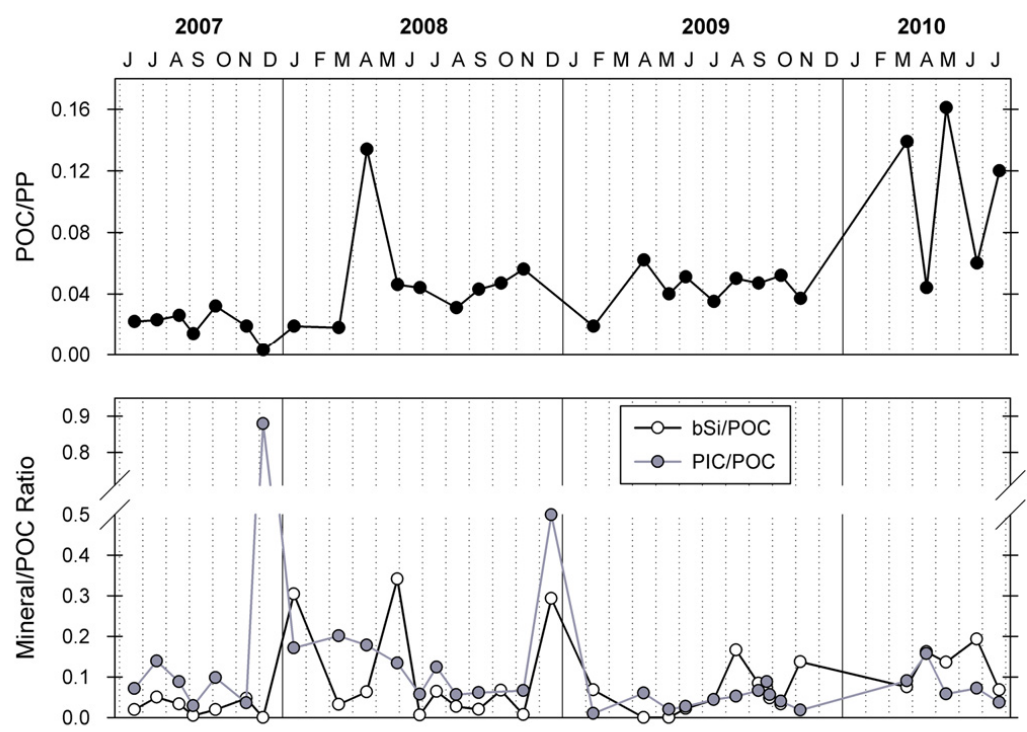

Fig. 11. Export ratio (POC flux at $150 \mathrm{~m} /$ integrated primary production, $0-140 \mathrm{~m}$ ) versus time (top panel) and mineral (inorganic carbon or biogenic silica) to POC ratios versus time for NBSTs at BATS. Changes in export ratio were not associated with changes in mineral composition of the sinking particles. 
composition of the sinking particle flux each month. Swimmer removal from trap samples was an important sample-processing step, as swimmers contributed significantly to the total collected flux. Screening and wet-picking methods were found to be comparable, however screening was adopted as the preferred method as it was less time consuming and conducive to the splitting approach. Blank corrections of mass, silica, and carbon measurements with a sample-identical set of blank tubes were important, particularly at this site where the ambient particle flux is very low.

In most months, the NBSTs were comparable to the surfacetethered PITs within the range of variability for two NBSTs $(\leq 2.2)$. In three periods during the time-series however, the difference in POC flux collected by the two systems was greater than a factor of three. Based on available data, these large differences were not attributable to hydrodynamic biasing, differences in trap sampling locations, or particle composition. In two months of the study, one corresponding to higher fluxes in the PITs than NBSTs, the sediment traps were deployed within deep winter mixed layers. Collection by traps in these regimes may be biased, thus data from these periods should be viewed with caution, as their inclusion would bias analyses of POC export in the BATS record. A second period of higher fluxes in the PITs than the NBSTs spanned four summer months in 2007. Though similarly high fluxes were measured in July 1989 and August 1998 , there was no evidence of a bloom, which occurs at BATS after periods of deep mixing that enhance nutrient concentrations in the surface, or a community shift that may have led to increased POC flux. Finally, one period of large discrepancy between the PITs and NBSTs occurred when the POC flux measured by the NBSTs was very close to zero, lower than any flux measurement by PITs in the entire BATS record. More frequent sampling of very low POC fluxes by the NBSTs in this study than by the PITs is consistent with earlier studies that suggested that the PITs might have a positive bias during low flux periods due to shear-induced aggregation in the mouth of the traps.

This new examination does not support the hypothesis that the carbon imbalance in the Sargasso Sea is due to undersampling by the PITs. The NBST data set confirms that carbon export is low over the annual cycle and there can be years with little flux seasonal variability, as was observed in 2008 and 2009. Export ratios for the NBSTs $(4.9 \pm 3.8 \%)$ were lower than for the PITs $(7.7 \pm 3.5 \%)$, implying even lower efficiency of the biological pump.

Sediment traps are critical tools for directly sampling sinking particle flux and trap design has been shown to be important Previous studies have detailed the advances of neutrally buoyan traps and we encourage further development of these devices including the incorporation of physical and biochemical sensors As shown in this work however, methods used to process sediment trap samples are as important as trap design and deserve equal attention.

\section{Acknowledgments}

We are grateful to the captain and crew of the R/V Atlantic Explorer who became adept at deploying and recovering NBSTs during this study. Many thanks to those who assisted in this work both at sea and on land, including Amanda Burke, John Casey, Brad Issler, Helen Dröst, and Doug Bell at BIOS, Steve Pike, Andrew McDonnell, Steve Manganini, Paul Henderson, and Paul Morris at WHOI, Erik Fields at UCSB, and Joe Cope at VIMS. Finally, we thank the three anonymous reviewers and the editor for their constructive responses and advice. This work was supported by a grant from the NSF Carbon and Water Program, the MIT Scurlock Fund, and a NASA Earth and Space Science Fellowship.

\section{Appendix. Supporting information}

Supplementary data associated with this article can be found in the online version at http://dx.doi.org/10.1016/j.dsr.2012.10.011.

\section{References}

Antia, A.N., 2005. Particle-associated dissolved elemental fluxes, revising the stoichiometry of mixed layer export. Biogeosci. Discuss. 2, 275-302.

Brzezinski, M.A., Nelson, D.M., 1995. The annual silica cycle in the Sargasso Sea near Bermuda. Deep-Sea Res. I 42 (7), 1215-1237.

Buesseler, K.O., Antia, A.N., Chen, M., Fowler, S.W., Gardner, W.D., Gustafsson, O., Harada, K., Michaels, A.F., van der Loeffo, M.R., Sarin, M., Steinberg, D.K., Trull, T., 2007. An assessment of the use of sediment traps for estimating upper ocean particle fluxes. J. Mar. Res. 65 (3), 345-416.

Buesseler, K.O., Lamborg, C., Cai, P., Escoube, R., Johnson, R., Pike, S., Masque, P. McGillicuddy, D., Verdeny, E., 2008a. Particle fluxes associated with mesoscale McGillicuddy, D., Verdeny, E., 2008a. Particle fluxes associated with meso
eddies in the Sargasso Sea. Deep-Sea Res. II 55 (10-13), 1426-1444.

Buesseler, K.O. McDonnell, A.M.P., Schofield, O.M.E., Steinberg, D.K., Ducklow, H.W., 2010. High particle export over the continental shelf of the west Antarctic Peninsula. Geophys. Res. Lett. 37 (L22606).

Buesseler, K.., Michaels, A.F., Siegel, D.A., Knap, A.H., 1994. A three dimensional time-dependent approach to calibrating sediment trap fluxes. Global Biogeochem. Cycles 8 (2), 179-193.

Buesseler, K.O., Pike, S., Maiti, K., Lamborg, C.H., Siegel, D.A., Trull, T.W., 2008b. Thorium-234 as a tracer of spatial, temporal and vertical variability in particle flux in the North Pacific. Deep-Sea Res. I 56 (7), 1143-1167.

Buesseler, K.O., Steinberg, D.K., Michaels, A.F., Johnson, RJ., Andrews, J.E., Valdes, J.R, Price, J.F., 2000. A comparison of the quantity and composition of material caught in a neutrally buoyant versus surface-tethered sediment trap. Deep-Sea Res. I 47 (2), 277-294

Cochran, J.K., Miquel, J.C., Armstrong, R, Fowler, S.W., Masqué, P., Gasser, B., Hirschberg, D., Szlosek, J., Rodriguez y Baena, A.M., Verdeny, E., Stewart, G. 2009. Time-series measurements of Th-234 in water column and sediment trap samples from the northwestern Mediterranean Sea. Deep-Sea Res. II 56 (18), 1487-1501.

Ducklow, H.W., Doney, S.C., Steinberg, D.K., 2009. Contributions of long-term research and time-series observations to marine ecology and biogeochemistry. Annu. Rev. Mar. Sci. 1, 279-302.

Eppley, RW., 1989. New production: history, methods, and problems. In: Berger W.H., Smetacek, V.S., Wefer, G. (Eds.), Productivity of the Ocean: Present and Past. Wiley \& Sons, New York, pp. 85-97.

Gardner, W.D., 1985. The effect of tilt on sediment trap efficiency. Deep Sea Res. 32, 349-361.

Gardner, W.D. 2000. Sediment trap sampling in surface waters. In: Hanson, R.B. Ducklow, H.W., Field, J.G. (Eds.), The Changing Ocean Carbon Cycle: A midterm Ducklow, H.W., Field, J.G. (Eds.), The Changing Ocean Carbon Cycle: A midterm
synthesis of the Joint Global Ocean Flux Study. Cambridge University Press, Synthesis of the Joint Global

Gardner, W.D., Richardson, M.J., 1992. Particle export and resuspension fluxes in the western North Atlantic. In: Rowe, G.T., Pariente, V. (Eds.), Deep-Sea Food Chains and the Global Carbon Cycle. Kluwer Academic Publishers, Netherlands, pp. 339-364

Gleiber, M.R., Steinberg, D.K., Ducklow, H.W. Time series of vertical flux of zooplankton fecal pellets on the continental shelf of the West Antarctic Peninsula. Mar. Ecol. Prog. Ser., http://dx.doi.org/10.3354/meps10021, in press.

Goldthwait, S.A., Steinberg, D.K., 2008. Elevated biomass of mesozooplankton and enhanced fecal pellet flux in cyclonic and mode-water eddies in the Sargass Sea. Deep-Sea Res. II 55, 1360-1377.

Gust, G., Bowles, W., Giordano, S., Huettel, M., 1996. Particle accumulation in a cylindrical sediment trap under laminar and turbulent steady flow, An experimental approach. Aquat. Sci. 58, 297-326.

Honjo, S., Francois, R., Manganini, S., Dymond, J., Collier, R, 2000. Particle fluxes to the interior of the Southern Ocean in the Western Pacific sector along $170^{\circ} \mathrm{W}$ Deep-Sea Res. II 47, 3521-3548.

Johnson, K.M., King, A.E., Sieburth, J.M., 1985. Coulometric $\mathrm{TCO}_{2}$ analyses for marine studies an introduction. Mar. Chem. 16, 61-82.

Karl, D.M., Christian, J.R., Dore, J.E., Hebel, D.V., Letelier, R.M., Tupas, L.M., Winn C.D., 1996. Seasonal and interannual variability in primary production and particle flux at Station ALOHA. Deep-Sea Res. II 43 (2-3), 539-568.

Knap, A.H., Michaels, A.F., Steinberg, D.K., Bahr, F., Bates, N.R., Bell, S., Countway, P. Close, A., Doyle, A., Howse, F., Gundersen, K., Johnson, R.J., Little, R., Orcutt, K., Parsons, R., Rathbun, C., Sanderson, M., Stone, S., 1997. BATS Methods Manual. Parsons, R., Rathbun, C., Sanderson, M., Sto

Knauer, G.A., Martin, J.H., Bruland, K.W., 1979. Fluxes of particulate carbon, nitrogen, and phosphorus in the upper water column of the northeast Pacific. nitrogen, and phosphorus in the
Deep-Sea Res. 26 (1), 97-108.

Lamborg, C.H., Buesseler, K.O. Valdes, J., Bertrand, C.H., Bidigare, R, Manganini, S. Pike, S., Steinberg, D., Trull, T., Wilson, S., 2008. The flux of bio- and lithogenic material associated with sinking particles in the mesopelagic "twilight zone" of the northwest and North Central Pacific Ocean. Deep-Sea Res. II 55 (14-15) $1540-1563$. 
Lampitt, R.S., Boorman, B., Brown, L, Lucas, M., Salter, I., Sanders, R., Saw, K., Seeyave, S. Thomalla, SJ. Turnewitsch, R, 2008. Particle export from the euphotic zone: estimates using a novel drifting sediment trap, Th-234 and new production. Deep-Sea Res. I 55 (11), 1484-1502

Lee, C., Hedges, J.I., Wakeham, S.G., Zhu, N., 1992. Effectiveness of various treatments in retarding microbial activity in sediment trap material and their effects on the collection of swimmers. Limnol. Oceanogr. 37 (1), 117-130

Martin, J.H., Knauer, G.A., Karl, D.M., Broenkow, W.W., 1987. VERTEX: carbon cycling in the northeast Pacific. Deep-Sea Res. Pt. A 34 (2), 267-285.

McDonnell, A.M.P., Buesseler, K.O. 2012. A new method for the estimation of sinking particle fluxes from measurements of particle size distribution, sinking velocity, and carbon density. Limnol. Oceanogr. Methods, 10, 329-346.

Michaels, A.F., R., B.N., Buesseler, K.O., Carlson, C.A., Knap, A.H., 1994. Carbon-cycle imbalances in the Sargasso Sea. Nature 372, 537-540.

Michaels, A.F., Silver, M.W., Gowing, M.M., Knauer, G.A., 1990. Cryptic zooplankton "swimmers" in upper ocean sediment traps. Deep-Sea Res. I 37 (8A), 1285-1296. Nelson, D.M., Brzezinski, M.A., 1997. Diatom growth and productivity in an oligotrophic midocean gyre: a 3 -yr record from the Sargasso Sea near Bermuda. Limnol. Oceanogr. 42 (3), 473-486.

Salter, I., Kemp, A.E.S., Lampitt, R.S., Gledhill, M., 2010. The association between biogenic and inorganic materials and the amino acid composition of settling particles. Limnol. Oceanogr. 55 (5), 2207-2218.

Salter, I., Lampitt, R.S., Sanders, R, Poulton, A., Kemp, A.E.S., Boorman, B., Saw, K., Pearce, R., 2007. Estimating carbon, silica and diatom export from a naturally fertilised phytoplankton bloom in the Southern Ocean using PELAGRA: a novel drifting sediment trap. Deep-Sea Res. II 54 (18-20), 2233-2259.

Siegel, D.A. Fields, E., Buesseler, KO., 2008. A bottom-up view of the biological pump: modeling source funnels above ocean sediment traps. Deep-Sea Res. I
p.ofical pump: modeling

Sprintall, J., Tomczak, M., 1992. Evidence of the barrier layer in the surface layer of the tropics. J. Geophys. Res. 97, 7305-7316.

Stanley, R.H.R., Buesseler, K.O., Manganini, S.J., Steinberg, D.K., Valdes, J.R., 2004. A comparison of major and minor elemental fluxes collected in neutrally buoy ant and surface-tethered sediment traps. Deep-Sea Res. I $51(10), 1387-1395$.

Steinberg, D.K., Carlson, C., Bates, N.R., Goldthwait, S.A., Madin, L.P., Michaels, A.F. 2000. Zooplankton vertical migration and the active transport of dissolve organic and inorganic carbon in the Sargasso Sea. Deep-Sea Res. I 47, 137-158.

Steinberg, D.K., Carlson, C.A., Bates, N.R., Johnson, R.j., Michaels, A.F., Knap, A.H., 2001. Overview of the US JGOFS Bermuda Atlantic Time-series Study (BATS): decade-scale look at ocean biology and biogeochemistry. Deep-Sea Res. II 48, 1405-1447.

Steinberg, D.K., Pilskaln, C.H., Silver, M.W., 1998. Contribution of zooplankton associated with detritus to sediment trap "swimmer" carbon in Monterey Bay, CA. Mar. Ecol. Prog. Ser. 164, 157-166.

Sweeney, E.N., McGillicuddy Jr., D.J., Buesseler, K.O., 2003. Biogeochemical impacts due to mesoscale eddy activity in the Sargasso Sea as measured at the Bermuda Atlantic Time-series Study (BATS). Deep-Sea Res. II 50, 3017-3039.

Valdes, J.R., Price, J.F., 2000. A neutrally buoyant, upper ocean sediment trap. J. Atmos. Ocean Technol. 17 (1), 62-68. 


\section{Supplemental Material}
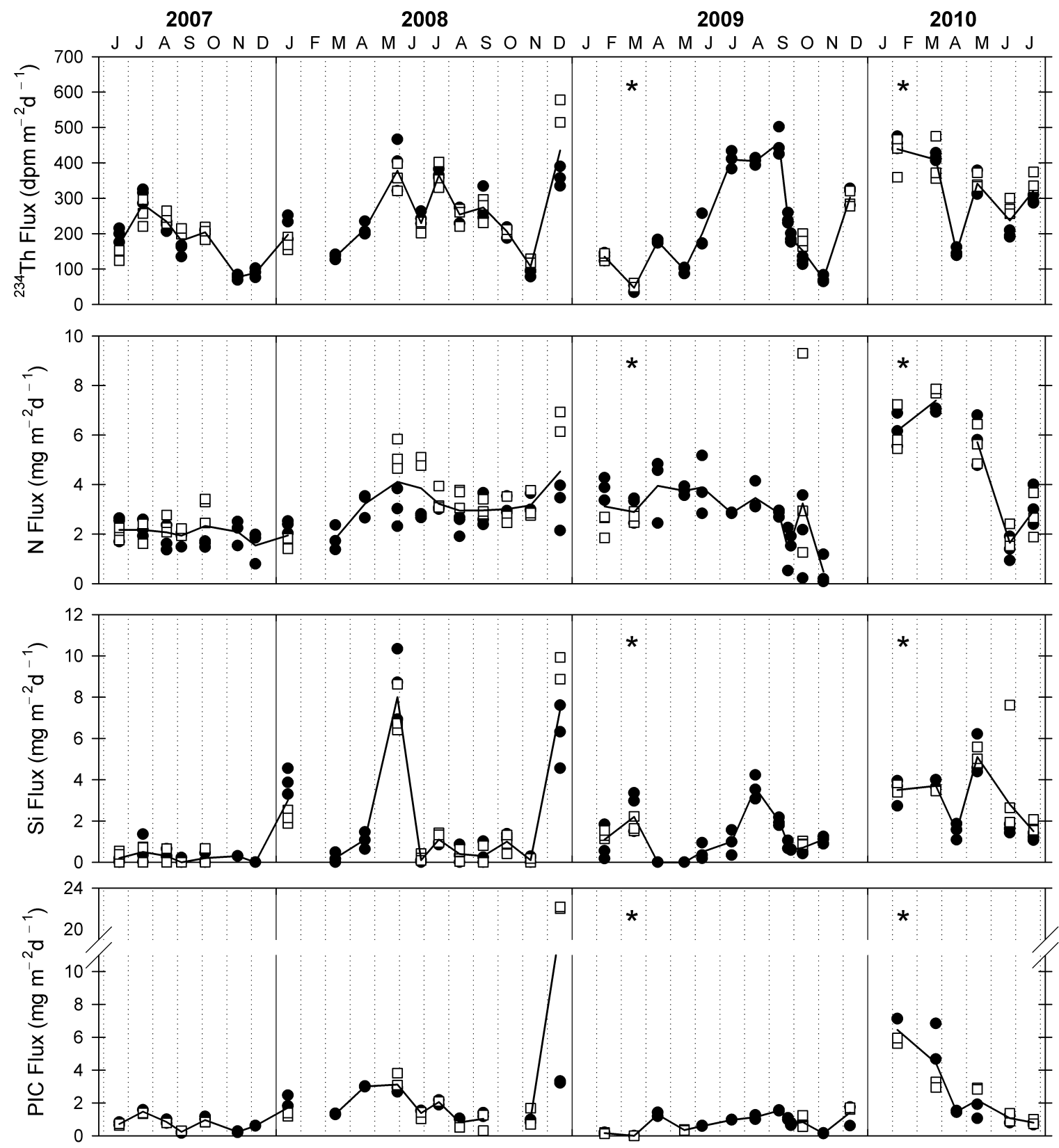

Figure A.1 - Th-234 flux, N flux, biogenic Si flux, and PIC flux captured by NBSTs at $150 \mathrm{~m}$ at the Bermuda Atlantic Time-series Study site. Two traps were deployed each month (circles and squares) and three replicates of each parameter were obtained (denoted by individual points). The solid black line in each figure is the average of the three replicates in the two traps. Stars above March 2009 and February 2010 denote months when the traps were in the mixed layer. 


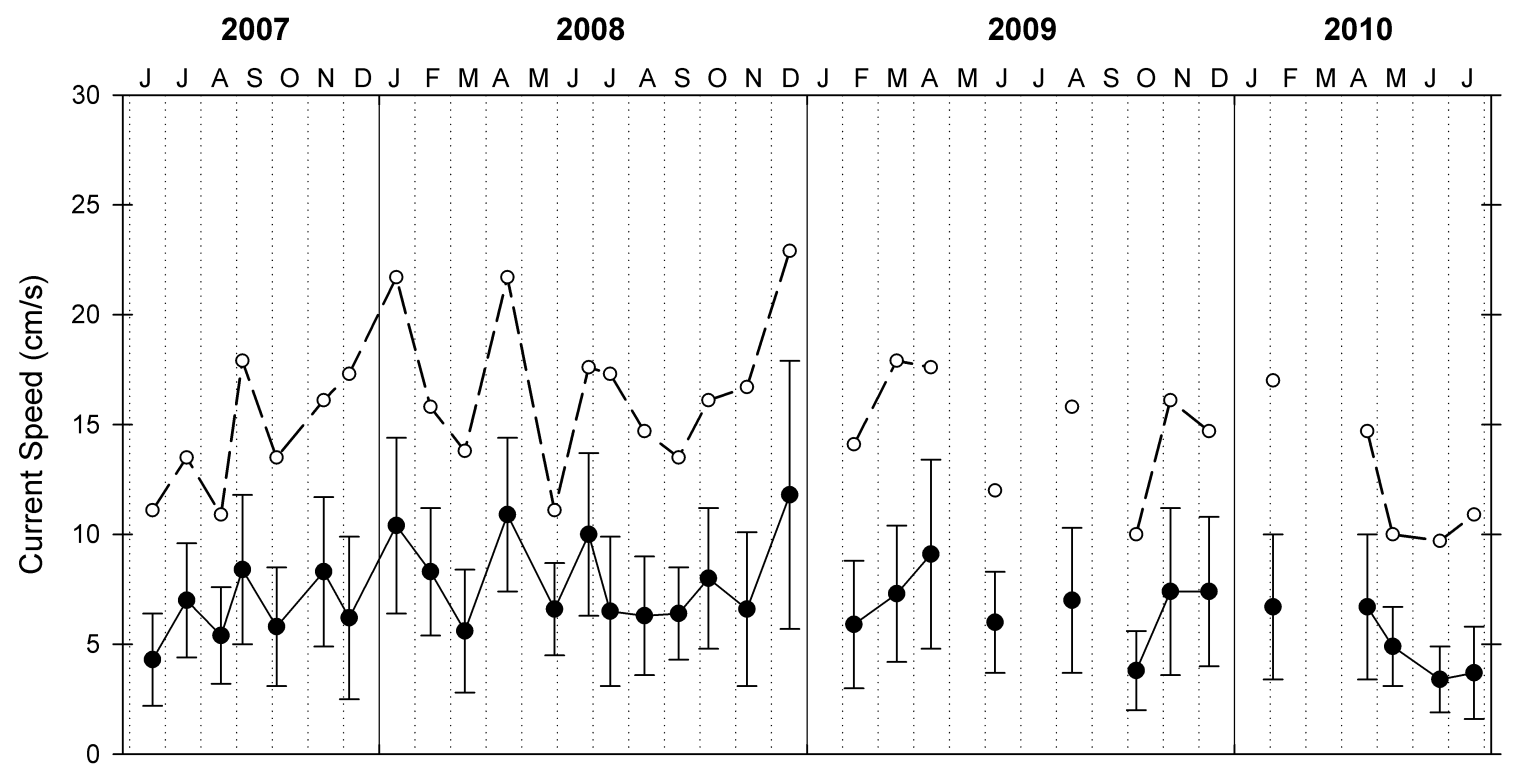

Figure A.2 - Average current speed from a current meter $15 \mathrm{~m}$ below the $150 \mathrm{~m}$ tubes on the PITs array (in black). The maximum current speed measured during deployment is also shown (in white).

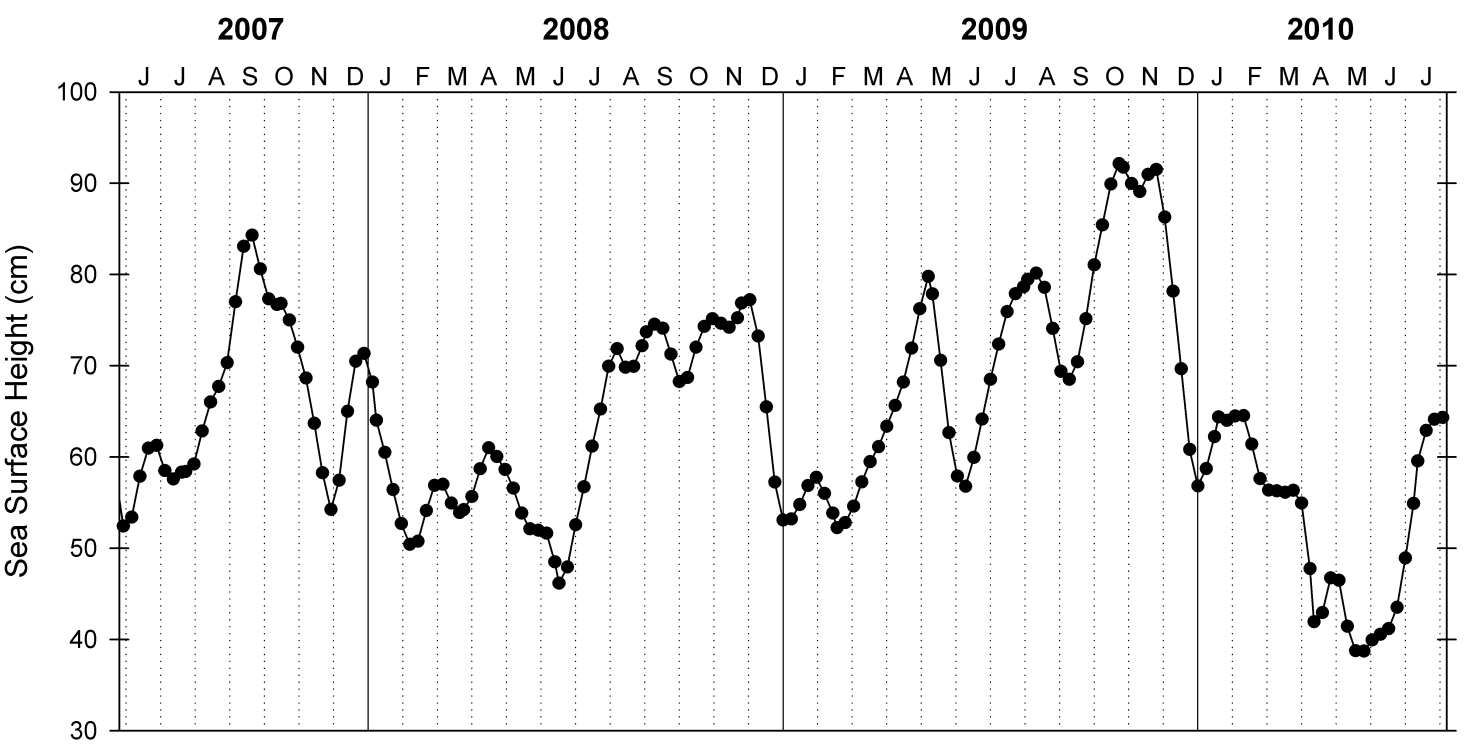

Figure A.3 - Weekly sea surface height at the BATS site during the course of this study. 


\section{Chapter 4:}

Temporal and spatial variability of particle export off the West Antarctic Peninsula 


\section{Introduction}

The flux of organic carbon from the upper sunlit ocean via passively sinking particles, or carbon export, is an important component of the global carbon cycle. Key processes that determine the extent of carbon export are known (Ducklow et al., 2001). However, still unknown is the relative importance of these processes in determining the magnitude and efficiency of carbon export at a specific place and time in the ocean (Boyd and Trull, 2007). A complicating factor in understanding the links between these particle production/consumption processes and the resultant particle flux is the highly variable nature of these processes in time and space. While little is known about the spatial variability of particle export, satellite and field observations have provided insight into the variability of phytoplankton and zooplankton (Mackas and Boyd, 1979; Yoder et al., 1993; Garçon et al., 2001; Mahadevan and Campbell, 2002; Martin, 2003). The scales of zooplankton variability are smaller than phytoplankton (more spatially variable), which are subsequently smaller than the scale of variability of physical properties driven by mixing (Abraham, 1998). Since particle export is a result of these complex processes, that the scales of variability of particle export may be even smaller.

Modeling studies have been important to understanding the role of mesoscale and submesoscale variability in the ocean on the distribution of dissolved species and phytoplankton production (Lévy and Klein, 2004; Lévy, 2008). Few modeling studies have considered the impact of patchiness on particle flux however. Martinez \& Richards (2010) demonstrated that particle export is indeed affected by temporal and spatial variability in the euphotic zone. In Resplandy et al. (2012), a 3-D biogeochemical model was used to evaluate the effect of small-scale variability on carbon export in further detail. This work also included a discussion of the consequences of small-scale variability on measurements of particle export using the ${ }^{238} \mathrm{U}^{234} \mathrm{Th}$ disequilibrium method.

While models are useful in probing the impact of small-scale variability on particle export, field measurements of this variability are difficult. The most direct way of measuring particulate organic carbon (POC) flux is with sediment traps, "rain gauge- 
like" instruments that collect the passively sinking particles (Buesseler et al., 2007). Sediment traps are not ideal tools for capturing spatial variability of particle export however due to their short (3-5 day) deployment periods and the effort to required to deploy just one sediment trap array or instrument. In recent years, underwater cameras have begun to reveal the temporal and spatial variability of particle abundance and sizedistribution (Guidi et al., 2007; Guidi et al., 2008; McDonnell and Buesseler, 2010). Another approach is to use geochemical tracers of particle export like ${ }^{234} \mathrm{Th}$. This tracer was used in a detailed study of two sites in the Pacific Ocean to assess the variability and controls on carbon export (Buesseler et al., 2008). The spatial variability in ${ }^{234} \mathrm{Th}-$ derived POC flux exceeded method uncertainty and supported the idea that the spatial scales of POC export were smaller than phytoplankton biomass or production. The highest resolution ${ }^{234}$ Th sampling to date was carried out on the GEOTRACES "Zero and Drake" expedition (Rutgers van der Loeff et al., 2011). Vertical profiles of ${ }^{234}$ Th were sampled every 100 to $200 \mathrm{~km}\left(1\right.$ to $\left.2^{\circ}\right)$ and surface samples were collected every 4 hours $(\sim 35$ to $50 \mathrm{~km})$. The surface sampling of this transect across the Southern Ocean revealed features that were missed at the discrete vertical profile stations.

The study presented here focuses on the continental shelf region off the West Antarctic Peninsula (WAP) and combines estimates of carbon export derived from CTD and underway measurements of ${ }^{234} \mathrm{Th}$ across the entire WAP region and sediment trap measurements from three process stations. The aim of this study was to measure particle export using ${ }^{234} \mathrm{Th}$ at high spatial resolution to evaluate the importance of spatial variability in characterizing regional particle fluxes. An understanding of this small-scale variability may be important for future experimental design and parameterizing biogeochemical models. Additionally, this work is the first to present measurements of particle export over a large extent of the WAP region, from 64 to $70^{\circ} \mathrm{S}$. 


\section{Methods}

\subsection{Study area}

Sampling was carried out on two cruises to the West Antarctic Peninsula (WAP) in January 2010 on the ARSV L.M. Gould and in March-April 2010 on the RVIB N.B. Palmer. The region of focus lies over the western continental margin of Antarctica, with an average water depth of $\sim 450 \mathrm{~m}$ and a cross-shelf width of $\sim 200 \mathrm{~km}$ (Ducklow, 2008). Upper Circumpolar Deep Water (UCDW) that originates in the Antarctic Circumpolar Current (ACC) is upwelled onto the shelf, supplying heat and nutrients (Martinson et al., 2008; Savidge and Amft, 2009). The summer phytoplankton bloom is generally initiated $200-400 \mathrm{~km}$ offshore near the southern end of the peninsula and migrates shoreward and northward as it progresses. The export flux is strongly seasonal with very low fluxes during the ice-covered winter and intense peak fluxes during the summer after the ice cover has retreated (Ducklow et al., 2008).

\subsection{Sample collection}

The austral summer cruise on the Gould was carried out in conjunction with the Palmer Long Term Ecological Research (LTER) group. Sampling was carried out along the LTER grid over approximately a $700 \mathrm{~km} \times 200 \mathrm{~km}$ area (Figure 1). Twenty-nine

depth profiles of ${ }^{234} \mathrm{Th}$, a particle flux proxy, were collected at discrete stations 40 to 100 $\mathrm{km}$ apart (Figure 2). Measurements made by the LTER group that are utilized in this work include particulate organic carbon concentrations, primary production, and zooplankton abundance. This data has been made publicly available for research purposes through the Scripps Institution of Oceanography database "Datazoo." The austral autumn cruise on the Palmer was more limited in scope because we were not a part of a larger biogeochemistry group, as on the Gould. Eighteen profiles of ${ }^{234} \mathrm{Th}$ were collected along the WAP region, with most effort focused at process stations; however, some profiles were collected between these stations (Figure 2).

In addition to water-column samples, surface samples of ${ }^{234} \mathrm{Th}$ were collected at higher spatial resolution using the ships' underway systems. On the Gould, the primary 
intake was located at $5.5 \mathrm{~m}$ below the surface and on the Palmer intake was $6.8 \mathrm{~m}$ below the surface. Both ships had underway sensors for temperature, salinity, fluorescence, carbon dioxide partial pressure, and light transmission. On the austral summer cruises, 74 underway stations were sampled every $10-20 \mathrm{~km}$ and 47 underway samples were collected on the austral autumn cruise.

Three process stations were occupied along the Peninsula (Figure 1) on the summer and autumn cruises where sediment traps and in situ pumps were deployed to gather more information about the magnitude and composition of the sinking particle flux. On the summer cruise all three process stations were occupied in the north (PS 1; near CTD 7), in Marguerite Bay (PS 2; near CTD 24), and in the south (PS 3 ) near and in the sea-ice (near CTDs 43 and 40, respectively). On the autumn cruise, the northern station was occupied twice, four weeks apart and the Marguerite Bay station was occupied once. At these sites, neutrally buoyant sediment traps (NBST) were deployed at a single depth and drifting arrays with collection tubes at three depths were deployed for about three days. In-situ pumps were deployed at three depths in the upper $300 \mathrm{~m}$ on the summer cruise to sample sinking and suspended particles; approximately $1000 \mathrm{~L}$ of water was filtered subsequently through 90, 53, and 10 um mesh filters. On the autumn cruise, the in situ pumps were deployed at six depths per station with 53 and 10 um mesh filters.

\subsection{Sample processing and analyses}

\section{Thorium-234}

Total ${ }^{234} \mathrm{Th}$ was analyzed using the small-volume method (Benitez-Nelson et al., 2001; Buesseler et al., 2001); all initial beta counting was done at sea using low background coincidence counters (Risø National Laboratories). Thorium-234 activities were corrected for sample loss using a modified version of the ${ }^{230} \mathrm{Th}^{229} \mathrm{Th}$ double-spike method (Pike et al., 2005). Briefly, samples were dissolved with $10 \mathrm{~mL}$ of a $50 \%$ nitric acid $/ 10 \%$ hydrogen peroxide solution. Thorium- 229 was added quantitatively to the samples, which were then sonicated for 20 minutes. Samples were left to sit overnight, after which $0.5 \mathrm{~mL}$ of the dissolved sample were filtered through a 0.2 um filter and 
diluted with a $10 \%$ nitric acid/ $1 \%$ hydrofluoric acid solution. Samples were analyzed for ${ }^{230} \mathrm{Th}$ and ${ }^{229} \mathrm{Th}$ and the ratio was used to correct the initial ${ }^{234} \mathrm{Th}$ measurements based on the known amount of ${ }^{230} \mathrm{Th}$ added to the samples at sea using a calibrated electronic repeater pipette. Uranium-238 activity was calculated from its conservative relationship with salinity using the equation derived in Owens et al. (2011), which includes some samples collected from the WAP in 2009. Particulate ${ }^{234} \mathrm{Th}$ was determined for the sediment trap and pump samples on silver filters that were dried prior to analysis. The efficiency and backgrounds of the beta counters were determined at the beginning and end of each cruise and appeared to be stable and reliable throughout both cruises.

\section{Sediment traps and in situ pumps}

The sediment trap preparation and sample processing procedures are similar to those used in previous studies (Lamborg et al., 2008; Buesseler et al., 2010; McDonnell and Buesseler, 2010; Owens et al., 2012) with some minor changes and adaptations specific to this study site. All drifting array and neutrally buoyant collection tubes were filled with filtered seawater with a buffered and poisoned brine layer in the base $(20 \mathrm{ml}$ of pH 8 150mM Borate buffer/L, $3 \mathrm{~mL}$ formalin/L, and $35 \mathrm{~g} \mathrm{NaCl} / \mathrm{L}$ ). Two tubes from each depth of the tethered array (six in total) were analyzed for ${ }^{234} \mathrm{Th}$ and particulate carbon on Ag filters. Two NBST tubes were filtered onto separate Ag filters for ${ }^{234} \mathrm{Th}$ and $\mathrm{C}$, two were filtered onto pre-weighed polycarbonate filters for mass, and the remaining tube was preserved with additional formalin for archive. All of the sediment trap samples were filtered through a $350 \mu \mathrm{m}$ mesh screen. Zooplankton swimmers were picked off the $350 \mu \mathrm{m}$ screen onto a Ag filter. The $<350 \mu \mathrm{m}$ and $>350 \mu \mathrm{m}$ sinking flux samples were then filtered onto Ag or polycarbonate filters. The analytical techniques used for determining ${ }^{234} \mathrm{Th}, \mathrm{C}$, mass, particulate inorganic carbon (PIC), and POC flux are the same as those described in Owens et al. (2012).

In-situ pump samples were rinsed off the respective 90,53 , or $10 \mu \mathrm{m}$ screens onto Ag filters using $1.0 \mu \mathrm{m}$ filtered seawater. Samples were analyzed for ${ }^{234} \mathrm{Th}$ and particulate carbon in the same way as the sediment trap samples above. 


\subsection{Data processing and analyses}

Determination of key water column depths

Mixed layer depth was defined as the depth where the absolute difference in potential temperature from the surface was $0.2^{\circ} \mathrm{C}$ (Huang et al., 2012). The euphotic zone was defined as where photosynthetically available radiation (PAR) was $1 \%$ of the surface value (Huang et al., 2012). Here, we also define a zone of primary production, based on the depth where the fluorescence (minus background) reaches $10 \%$ its maximum value. Figure 3 illustrates the effectiveness of these definitions in constraining the mixed layer (left panel) and the euphotic zone and primary production zone (PPZ, middle panel) for a sample CTD cast (22). The PPZ depth is also below the zone of maximum light attenuation by particles in the surface (right panel).

\section{Thorium-234 flux model}

${ }^{234} \mathrm{Th}$ export on sinking particles can be determined using a model that describes the evolution of ${ }^{234} \mathrm{Th}$ activity with time $\left(\delta^{234} T h / \delta t\right)$ :

$$
\delta^{234} T h / \delta t=\left({ }^{238} U-{ }^{234} T h\right) \lambda-P+V
$$

where ${ }^{238} \mathrm{U}$ is the activity of uranium determined from Owens et al. (2011), ${ }^{234} \mathrm{Th}$ is the measured activity of total ${ }^{234} \mathrm{Th}, \lambda$ is the decay constant of ${ }^{234} \mathrm{Th}\left(0.0288\right.$ day $\left.^{-1}\right), \mathrm{P}$ is the export of ${ }^{234} \mathrm{Th}$ on sinking particles, and $\mathrm{V}$ is the sum of advective and vertical diffusive fluxes of ${ }^{234} \mathrm{Th}$. Most studies assume steady state (SS; $\left.\delta^{234} T h / \delta t=0\right)$ because of sampling limitations and ignore the contribution of physical processes $(\mathrm{V} \approx 0)$ because of their usually minor contribution to calculated fluxes in relation to the flux uncertainty.

An assumption of non-steady state (NSS) requires that the same water mass be occupied repeatedly within the half-life of ${ }^{234} \mathrm{Th}$. Our occupation of sites along the peninsula in the summer and autumn were on average 80 days apart, more than three times longer than the half-life of ${ }^{234} \mathrm{Th}$. This time difference and our non-Lagrangian sampling, preclude our ability to calculate NSS fluxes. We can estimate, however, the effect of the SS assumption on the calculated fluxes. The mean fluxes of ${ }^{234} \mathrm{Th}$ at $100 \mathrm{~m}$ 
measured on the summer and autumn cruises were $1404 \pm 537$ and $585 \pm 287 \mathrm{dpm} \mathrm{m}^{-2}$ $\mathrm{d}^{-1}$, respectively. Taking the difference between the mean ${ }^{234}$ Th activity $(0-100 \mathrm{~m})$ between the two cruises and dividing by the number of days between two cruises, results in $\delta^{234} \mathrm{Th} / \delta t=412 \mathrm{dpm} \mathrm{m}^{-2} \mathrm{~d}^{-1}$. As ${ }^{234} \mathrm{Th}$ activities in the upper $100 \mathrm{~m}$ were increasing from cruise 1 to cruise 2, the assumption of SS may therefore result in an overestimation of the fluxes on the second cruise, by $\sim 400 \mathrm{dpm} \mathrm{m}^{-2} \mathrm{~d}^{-1}$ or $40-100 \%$ of the mean flux in March/April. Results from a model study by Resplandy et al. (2012) suggest, however, that the use of NSS may mask the effects of spatial variability as temporal changes and also introduce larger errors into the flux estimates.

Neglecting the physical transport term " $\mathrm{V}$ " is often a reasonable assumption in open ocean studies because of minimal advection and diffusion combined with small gradients in ${ }^{234}$ Th (Savoye et al., 2006). The WAP study area is more complex, however, due to its proximity to the ACC and its coastal nature. In general, at scales of hundreds of kilometers, for horizontal transport of ${ }^{234} \mathrm{Th}$, advection will dominate over diffusion (Buesseler, 1994). On the West Antarctic Peninsula, we can calculate 1-D gradients for three modes of advection of $\left.{ }^{234} \mathrm{Th}: 1\right)$ northeastward transport along the shelf-edge, 2) southwestward coastal transport, and 3) along or cross-shelf transport. Along the shelfedge, there is northeastward flow, attributed to the southern ACC front (Savidge and Amft, 2009). ${ }^{234}$ Th profiles were collected along the shelf edge only on the summer cruise; from the 200 to the 600 line (northeast) there was a gradient of $0.0002 \mathrm{dpm} \mathrm{L}^{-1}$ $\mathrm{km}^{-1}$ for the upper $100 \mathrm{~m}\left(\mathrm{r}^{2}=0.52\right)$. Assuming a mean, northeastward velocity of $0.1 \mathrm{~m}$ $\mathrm{s}^{-1}$ (Savidge and Amft, 2009), the change in flux as a result of advection for the upper $100 \mathrm{~m}$ was $173 \mathrm{dpm} \mathrm{m}^{-2} \mathrm{~d}^{-1}$. This is $\leq 10 \%$ of the mean shelf-edge ${ }^{234} \mathrm{Th}$ flux and thus neglected in our flux calculations. Meanwhile, the most coastal stations may be influenced by the southwestward flowing Antarctic Peninsula Coastal Current (Moffat et

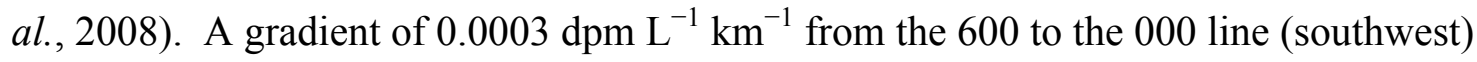
was measured on the summer cruise. Assuming a mean velocity of $0.2 \mathrm{~m} \mathrm{~s}^{-1}$ (Moffat et al., 2008), the change in ${ }^{234} \mathrm{Th}$ flux as a result of horizontal advection would be on the order of $500 \mathrm{dpm} \mathrm{m}^{-2} \mathrm{~d}^{-1}$ across the upper $100 \mathrm{~m}$. Despite this possibly significant ${ }^{234} \mathrm{Th}$ 
flux, the linearity of this gradient is poor $\left(r^{2}=0.12\right)$, thus this advective flux likely represents an upper limit and is not considered in calculating downward ${ }^{234} \mathrm{Th}$ fluxes. The ${ }^{234} \mathrm{Th}$ gradients across and along the shelf in the summer were very small and/or poorly linear, thus this mode of advection is not considered further. From the autumn cruise, too few ${ }^{234} \mathrm{Th}$ profiles were collected to determine gradients due to different advection pathways so horizontal advection is not included in the derivation of ${ }^{234} \mathrm{Th}$ fluxes from this cruise.

In the vertical dimension, the gradients in ${ }^{234} \mathrm{Th}$ activity across $100 \mathrm{~m}$ were highly variable ( -0.0076 to $0.0254 \mathrm{dpm} \mathrm{L}^{-1} \mathrm{~m}^{-1}$ ), making it difficult to estimate the influence of upward advection or diffusion of deep high-activity water. If not included in flux calculations, these vertical processes typically lead to an underestimation of particle export, but is often a small fraction of the measured downward flux, except in locations of wind-driven upwelling like the Equatorial Pacific (Savoye et al., 2006). Resplandy et al. (2012) concluded that the error associated with neglecting physical processes was smaller than the uncertainty due to using SS versus NSS or undersampling. In this work,

${ }^{234}$ Th fluxes have been calculated by integrating to the depth of the PPZ, assuming steady state, and neglecting the influence of physical processes.

\section{Results}

\subsection{Water-column measurements of ${ }^{234}$ Th}

Relative to the autumn, in the summer, chlorophyll concentrations were higher and light transmission was lower in the surface (Figure 4), which may suggest greater production by phytoplankton and larger quantities of particulate material available for export. Deficits of ${ }^{234} \mathrm{Th}$ relative to ${ }^{238} \mathrm{U}$ were larger and deeper in the summer. Error bars are not shown for the ${ }^{234} \mathrm{Th} /{ }^{238} \mathrm{U}$ ratios in Figure 4, however the mean uncertainty on these ratios is small $( \pm 0.04$; Table 1$)$.

One-dimensional, steady state fluxes of ${ }^{234}$ Th were calculated at all CTD stations at the calculated depth of the primary production zone (PPZ; Table 2). In Figure 3, the depths of the euphotic zone and the PPZ are similar, at 40 and $49 \mathrm{~m}$, respectively. At 
other sites however, for example, CTD 17 on the summer cruise, the extent of the PPZ was $68 \mathrm{~m}$ deeper than the euphotic zone depth (Table 2). In both the summer and autumn, the mean euphotic zone depth ( $41 \pm 15 \mathrm{~m}$ in summer, $44 \pm 14$ in autumn) was shallower than the mean PPZ depth $(75 \pm 27 \mathrm{~m}$ in summer, $85 \pm 18$ in autumn). The PPZ depth also matches better the depth at which ${ }^{238} \mathrm{U}$ and ${ }^{234} \mathrm{Th}$ come into equilibrium. For this region off West Antarctic Peninsula therefore, the PPZ boundary seems to better capture the surface layer of particle formation.

The seasonal change in ${ }^{234} \mathrm{Th}$ fluxes from the summer to the autumn can be seen in Figure 5. The mean ${ }^{234} \mathrm{Th}$ flux at the PPZ during the summer was $1250 \pm 495 \mathrm{dpm} \mathrm{m}^{-2}$ $\mathrm{d}^{-1}\left(202-2042 \mathrm{dpm} \mathrm{m}^{-2} \mathrm{~d}^{-1}\right)$ compared to $594 \pm 235 \mathrm{dpm} \mathrm{m}^{-2} \mathrm{~d}^{-1}\left(225-1010 \mathrm{dpm} \mathrm{m} \mathrm{m}^{-2}\right.$ $\mathrm{d}^{-1}$ ) in the autumn. The mean uncertainty across both cruises on ${ }^{234} \mathrm{Th}$ fluxes from the PPZ was $12.6 \%$. The three process stations were occupied on both the summer and autumn cruises. Process station 1 near the northern part of the LTER grid had a mean flux of $1673 \pm 113 \mathrm{dpm} \mathrm{m}^{-2} \mathrm{~d}^{-1}(\mathrm{n}=3)$ during the summer and decreased to $317 \pm 105$ $\mathrm{dpm} \mathrm{m}{ }^{-2} \mathrm{~d}^{-1}(\mathrm{n}=5)$ in the autumn (Figure 5). ${ }^{234}$ Th fluxes in Marguerite Bay, at process station 2, did not change dramatically from summer to fall, $622 \pm 97(\mathrm{n}=3)$ and $598 \pm 98$ $\mathrm{dpm} \mathrm{m} \mathrm{m}^{-2} \mathrm{~d}^{-1}(\mathrm{n}=3)$, respectively. Fluxes near Charcot Island were higher in the autumn $\left(771 \pm 53 \mathrm{dpm} \mathrm{m}^{-2} \mathrm{~d}^{-1}\right)$ than the summer $\left(292 \pm 117 \mathrm{dpm} \mathrm{m}^{-2} \mathrm{~d}^{-1}\right)$.

In the summer, ${ }^{234} \mathrm{Th}$ fluxes along the WAP were highest in the region north of Marguerite Bay. In the autumn however, the highest fluxes were measured in the southern portion of the sampling region, south of Marguerite Bay. From the coast to the continental slope, fluxes were either constant or increased slightly in the summer. In the autumn, these cross shelf gradients were not well sampled, as sampling was limited to coastal stations and PS 1 on the shelf.

\subsection{Surface measurements of ${ }^{234}$ Th}

Underway (UW) surface samples were collected at CTD stations and additional points in between stations every 10 to $20 \mathrm{~km}$. UW samples were collected while the ship was moving, thus the samples inherently average over a small area. Samples for all 
parameters were collected, on average, in 6.5 minutes or over $1.8 \mathrm{~km}$ (assuming a speed of 9 knots). On the summer cruise, the majority of the underway samples were collected in a ten-day period from January 6 to $16^{\text {th }}$. Additional samples were collected after this time, but only at sites with CTD casts. On the autumn cruise, samples were collected in four groups, first around PS 1, then along the transect from PS 1 to PS 3, along a transect from PS 3 to PS 2, and finally, four samples were collected on the northern tip of the WAP (not shown).

There was good agreement between ${ }^{234} \mathrm{Th} /{ }^{238} \mathrm{U}$ ratios measured on samples from the ships' underway systems and CTD surface samples collected at the same sites in the upper $10 \mathrm{~m}$ (Figure $6 ; \mathrm{r}^{2}=0.55, \mathrm{y}=(1.1450 \pm 0.2338) * \mathrm{x}-(0.0936 \pm 0.1940)$ for summer and $\mathrm{r}^{2}=0.88, \mathrm{y}=(1.1837 \pm 0.1340)^{*} \mathrm{x}-(0.0719 \pm 0.1230)$ for autumn $)$. Neither of these slopes is significantly different from one (Student's t-test, 95\% confidence), although the underway system from the summer cruise appeared to be noisier. The differences between the underway and CTD ratios are most pronounced when the ${ }^{234} \mathrm{Th}$ deficits are small or particle export is low. There does not appear to be evidence however that thorium loss to the walls of the underway system or thorium addition from biological matter in the systems was a significant problem. Slopes significantly larger or less than one, respectively, could be indicative of these processes.

Water-column derived ${ }^{234} \mathrm{Th}$ fluxes were compared to ${ }^{234} \mathrm{Th} /{ }^{238} \mathrm{U}$ ratios measured from the underway system (Figure 7). Only ${ }^{234} \mathrm{Th} /{ }^{238} \mathrm{U}$ ratios $<1.0$ were included in the regression with ${ }^{234} \mathrm{Th}$ flux $\left(\mathrm{n}=28, \mathrm{r}^{2}=0.75, \mathrm{p}<0.0001\right)$ :

Estimated ${ }^{234} \mathrm{Th}$ flux $\left(\mathrm{dpm} \mathrm{m}{ }^{-2} \mathrm{~d}^{-1}\right)=(3600 \pm 272)-(3224 \pm 362)\left({ }^{234} \mathrm{Th} /{ }^{238} \mathrm{U}\right)$ This relationship was then used to derive ${ }^{234} \mathrm{Th}$ PPZ fluxes at sites with only surface measurements of ${ }^{234} \mathrm{Th}$ (when ${ }^{234} \mathrm{Th} /{ }^{238} \mathrm{U}<1.0$; Figure 8, Table 3). The mean fluxes derived from surface measurements in the summer and autumn, were $1395 \pm 278$ and 826 $\pm 315 \mathrm{dpm} \mathrm{m}^{-2} \mathrm{~d}^{-1}$, respectively. These values are comparable to those reported above, from CTD measurements alone. The mean error of the estimates based on the 95\% confidence intervals was $128 \mathrm{dpm} \mathrm{m}^{-2} \mathrm{~d}^{-1}$. Uncertainties on the estimated flux values were derived from the uncertainties on the slope, intercept, and the covariance: 


$$
\sigma_{\text {Estimated flux }}^{2}=\sigma_{\text {Intercept }}^{2}+\sigma_{\text {Slope }}^{2} *\left({ }^{234} \mathrm{Th} /{ }^{238} \mathrm{U}\right){ }^{2}+2 \sigma_{\text {Covariance }}^{2}\left({ }^{234} \mathrm{Th} /{ }^{238} \mathrm{U}\right)
$$

Relative uncertainties on flux values ranged from 3.5 to $25 \%$ of the estimated flux.

\section{$3.3 C^{234}$ Th ratios and carbon fluxes}

$\mathrm{C}{ }^{234} \mathrm{Th}$ ratios were measured on particles larger than $53 \mu \mathrm{m}$ from the in situ pumps and on the sediment trap samples (Figure 9). Particulate inorganic carbon (PIC) measurements from the sediment trap samples suggested that PIC accounted for less than $0.1 \mathrm{mmol} / \mathrm{m} 2 / \mathrm{d}$ of sinking flux or $\leq 10 \%$. We assume therefore that the PIC contribution to the sinking flux is insignificant and from this point forward, equate measurements of total carbon with organic carbon. In January, at the northern and central process stations, the $\mathrm{C} /{ }^{234} \mathrm{Th}$ ratios were relatively constant with depth and agreed well between the pumps and the sediment traps. At the southern station, the pumps and NBST were deployed outside the ice line while the surface-tethered trap was deployed within the ice. In the ice, the $\mathrm{C}^{234} \mathrm{Th}$ increased with depth from 100 to $150 \mathrm{~m}$. Outside the ice however, the $\mathrm{C} /{ }^{234} \mathrm{Th}$ ratios from the pumps decreased with depth. In the autumn, during the first occupation of the northern station and the only occupation of the central station, $\mathrm{C} /{ }^{234} \mathrm{Th}$ ratios decreased with depth. During the second occupation of the northern station, $\mathrm{C} /{ }^{234} \mathrm{Th}$ were constant with depth as in January. $\mathrm{C} /{ }^{234} \mathrm{Th}$ ratios from the three devices agreed well during all of the autumn occupations. From summer to autumn, $\mathrm{C} /{ }^{234} \mathrm{Th}$ at the northern and central sites increased two to five-fold.

The $\mathrm{C} /{ }^{234} \mathrm{Th}$ ratios from the in situ pumps were used to derive estimates of sinking C flux at the PPZ from water-column profiles and underway samples of ${ }^{234} \mathrm{Th}$. When the calculated PPZ depth was within the depths sampled by the pumps, the $\mathrm{C} /{ }^{234} \mathrm{Th}$ at the PPZ was determined by linear interpolation between points. When the PPZ was shallower than the first pump, $\mathrm{C} /{ }^{234} \mathrm{Th}$ ratios at the PPZ were determined from power and exponential fits extrapolated upwards. The mean of the $\mathrm{C} /{ }^{234} \mathrm{Th}$ ratios estimated from the two fits and the standard deviation were used (Table 2). At underway sampling points, for which no water-column data was available, thus for which no PPZ could be calculated, the mean PPZ for the northern, central, and southern regions was assumed. 
Then, the $\mathrm{C}^{234} \mathrm{Th}$ at the mean PPZ in the northern, central, and southern regions was applied to the estimated ${ }^{234} \mathrm{Th}$ fluxes (Table 3). The increase in $\mathrm{C}^{234} \mathrm{Th}$ ratios from summer to autumn resulted in higher estimated carbon fluxes in March/April, with the highest $\mathrm{C}$ fluxes occurring around and south of Marguerite Bay (Figure 10).

\subsection{Sediment trap fluxes}

Particle fluxes using sediment traps were measured at each of the three process stations. Process station 1 is the site of the LTER program's bottom-moored sediment trap that samples the sinking flux at $175 \mathrm{~m}$. This site was occupied three times during the course of our study, in January, March, and April 2010. Particulate ${ }^{234} \mathrm{Th}$ and carbon fluxes were measured on two tubes from a surface-tethered (ST) sediment trap and a neutrally buoyant sediment trap (NBST; Figure 11). In January, the NBST was lost, so only data from the ST trap is available. Trap tubes were not combined, thus the difference in values includes tube-to-tube variability of the devices. For ${ }^{234} \mathrm{Th}$, fluxes increased with depth in January, were relatively constant with depth in March, and then increased slightly with depth in April. The particulate carbon data was more variable, particularly in April, perhaps due to incomplete removal of swimmers, which are carbon rich, from the samples. The flux of particulate carbon increased slightly with depth in January, decreased with depth in March, and reverted to increasing with depth in April. The trends in particulate ${ }^{234} \mathrm{Th}$ fluxes were consistent with the trends of the water-column ${ }^{234} \mathrm{Th}$ fluxes. In January, the water-column flux estimates of ${ }^{234} \mathrm{Th}$ were higher than the measured sediment trap fluxes, but agreed better in March and April when fluxes were lower. In both March and April, the NBST fluxes of ${ }^{234} \mathrm{Th}$ and carbon appeared to be consistent with measurements from the ST trap. While ${ }^{234} \mathrm{Th}$ fluxes were highest in January and consistently lower in the autumn, the range and magnitude of carbon export values were less variable, on the order of $2-8 \mathrm{mmol} \mathrm{m}^{-2} \mathrm{~d}^{-1}$.

Fluxes in Marguerite Bay were measured once in the summer and once in the autumn (Figure 12). In January, ${ }^{234} \mathrm{Th}$ fluxes measured in the ST trap were higher than the water-column and NBST fluxes and were relatively constant with depth. Similarly, 
the particulate $\mathrm{C}$ fluxes in January were higher in the ST trap compared to the NBST but instead decreased with depth. The NBST and ST traps agreed better in the autumn deployment. In April, the ${ }^{234} \mathrm{Th}$ fluxes in the surface tethered trap were five-fold lower than January. The shallowest $\mathrm{C}$ fluxes in the autumn were comparable to the summer fluxes, but decreased to a lower value at depth. The shift to lower ${ }^{234} \mathrm{Th}$ fluxes but less change in the $\mathrm{C}$ fluxes from January to March/April is similar to the seasonal change observed at the northern process station.

While ${ }^{234}$ Th profiles were collected on both cruises near Charcot Island, in the southern region of the study area, export was only measured with sediment traps on the summer cruise (Figure 13). The ST trap was deployed in the ice while the NBST was deployed a few miles beyond the ice line to minimize the possibility that it would surface underneath ice. In the ice, carbon export was lowest in the shallow trap and increased with depth. Carbon flux outside the ice, determined by the NBST, was lower for carbon and more variable for ${ }^{234} \mathrm{Th}$ relative to the in-ice measurements. ${ }^{234} \mathrm{Th}$ flux in surface tethered trap was significantly higher compared to the water-column estimate while outside the ice, the ${ }^{234}$ Th NBST fluxes bracketed the water-column estimate.

\section{Discussion}

\subsection{Integration depth for particle flux calculations}

Early studies of ${ }^{234} \mathrm{Th}$ often used a fixed integration depth for flux calculations. Reasons for using a single integration depth may have included convenience, limited depth resolution of samples, or because a single depth defined the depth at which ${ }^{234} \mathrm{Th}$ and ${ }^{238} \mathrm{U}$ came into equilibrium relatively well. Recently however, Buesseler and Boyd (2009) advocated for normalizing export fluxes to a biologically relevant depth rather than a single fixed depth. The necessity for this change arose when attempting to compare the magnitude of particle fluxes and remineralization efficiencies across different study areas. They found that comparing fluxes from different locations using a single depth led to misinterpretation of these biological pump characteristics. Rather, they compared fluxes integrated to the depth of the euphotic zone (1\% light level) at each 
site. Thus fluxes only from the region of particle formation were compared to one another.

In keeping with this technique, we have chosen to calculate particle fluxes off the WAP at a biologically relevant depth rather than a fixed single depth. The goal in defining the primary production zone (PPZ) based on fluorescence was to capture the zone in which primary production is taking place in the upper ocean. While fluorescence or chlorophyll is not linearly related to primary production due to adaptive change of cell/chlorophyll ratios to variable light levels, where fluorescence is increased, chlorophyll is increased, and some production is taking place. The $10 \%$-of-themaximum definition seems to constrain this region well and can be systematically calculated across stations and sampling locations (Figure 3). Another reason for defining the PPZ using fluorescence rather than a light-availability based definition is that the photosynthetically available radiation (PAR) sensor on the CTD package was less reliable than the fluorometer. Thus, at several stations we were unable to calculate a euphotic zone depth. Our definition of the PPZ also appears to define the region of net particle removal, the ${ }^{234}$ Th deficit, well across both cruises (Figures 14 and 15). Although the transmissometer could have been used to define a particle-rich zone in the surface too, we did not choose to define the PPZ this way because processes other than primary production, such as lateral input of particulate material, can change this measurement.

If the PPZ is an effective definition of production in the surface ocean, then it should fall within the range of light levels typically used to define the euphotic zone, from 0.1 to $1 \%$. The mean euphotic zone depths in the summer and autumn were $41 \pm$ $15 \mathrm{~m}$ and $44 \pm 14 \mathrm{~m}$ ( $1 \%$ light level, for stations where PAR data was available). In comparison, the mean fluorocline depths during these time periods were $75 \pm 27 \mathrm{~m}$ and $85 \pm 18 \mathrm{~m}$. In the summer, ${ }^{234} \mathrm{Th}$ and $\mathrm{C}$ fluxes at the base of the euphotic zone were approximately two-thirds of the flux calculated the fluorocline. In these months, the mean light level at the PPZ was $0.3 \%$ and ranged from $<0.01$ to $1.4 \%$. In the autumn, euphotic zone fluxes increased to $\sim 80 \%$ of the flux measured at the fluorocline. In 
March/April, the mean light level at the PPZ was $0.6 \%$ and ranged from 0.03 to $1.7 \%$. While the fluorocline does not always perfectly define the ${ }^{234} \mathrm{Th}$ deficit, it is an improvement over using a fixed integration depth, in that its definition is biologically relevant rather than chosen for convenience. In addition, the PPZ falls within relevant light-level ranges, which suggests the $10 \%$ definition is an appropriate constraint on the region of primary production.

A recent study off the WAP used $\mathrm{O}_{2} / \mathrm{Ar}$ ratios to derive estimates of net community production (NCP), which can be equated to export production over large temporal and spatial scales (Huang et al., 2012). That study, carried out in January 2008, also on the annual LTER cruise, used these measurements to examine controls on export production off the WAP. $\mathrm{O}_{2} / \mathrm{Ar}$ measurements are made on samples from the mixed layer and integrate over a time period of $\sim 1$ week. Our measurements of export production from ${ }^{234} \mathrm{Th}$ fluxes integrate over the depth defined by the PPZ and a time period of $\sim 3$ weeks. In the $\mathrm{O}_{2} / \mathrm{Ar}$ study, the mean mixed layer depth was $24 \pm 10 \mathrm{~m}$ and the mean euphotic zone depth was $37 \pm 16$. They calculated that the absorbed PAR in the mixed layer accounted for 51 to $91 \%$ (mean $80 \%$ ) of the PAR in the entire euphotic zone and concluded that their $\mathrm{O}_{2} / \mathrm{Ar}$ measurements accounted for a major fraction of total productivity in the upper water column. In summer 2010, the mean mixed layer and euphotic zone depths were similar ( $39 \pm 16 \mathrm{~m}$ versus $41 \pm 15 \mathrm{~m}$ ), however the mean PPZ depth was approximately $35 \mathrm{~m}$ deeper. ${ }^{234} \mathrm{Th}$ and $\mathrm{C}$ fluxes at the base of the mixed layer accounted for 62 and $65 \%$ of the fluxes measured at the depth of the fluorocline. Thus, had $\mathrm{O}_{2} / \mathrm{Ar}$ ratios and ${ }^{234} \mathrm{Th}$ fluxes been measured simultaneously on the 2010 cruise, the two methods would likely have resulted in different values for new and export production, in part due to their different time-integration scales, but also due to their different depth-integration scales. Other differences between the two methods could arise depending on where in the water column zooplankton feed and defecate. If these processes were to predominantly take place below the mixed layer, particularly if the mixed layer is shallow $(<10 \mathrm{~m})$, then the $\mathrm{O}_{2} / \mathrm{Ar}$ method may neglect both zooplankton 
respiration and particle repackaging, which could change the magnitude of measured new or export production.

\subsection{Carbon fluxes from water-column ${ }^{234}$ Th and sediment traps}

There is a long history of water column radionuclides being used to calibrate sediment trap fluxes (Knauer et al., 1979; Bacon et al., 1985; Coale and Bruland, 1985; Buesseler, 1991). Many studies that have compared ${ }^{234}$ Th fluxes from water column profiles and collected in upper ocean sediment traps and have concluded that single profiles of ${ }^{234}$ Th cannot be used calibrate sediment traps (Buesseler, 1994; Buesseler et al., 2008; Lampitt et al., 2008; Cochran et al., 2009). Calibration efforts require Lagrangian sampling and multi-week studies. Another caveat is that the calibration factor for one particulate component, such as ${ }^{234} \mathrm{Th}$, may not be the same for other particulate phases like POC, silica, or inorganic carbon (Buesseler et al., 2008). One take on the water-column versus sediment trap issue is that the two techniques offer complementary views of the particle export. Water-column radionuclide profiles integrate over longer temporal scales compared to sediment traps, which capture the export flux occurring at the time of sampling. Sediment traps also provide information about the composition of the sinking flux. However, multiple profiles of ${ }^{234} \mathrm{Th}$ can be measured for the same amount of effort required to deploy and process a single sediment trap.

One reason to compare ${ }^{234} \mathrm{Th}$ fluxes from the water-column and sediment traps here is that a single sediment trap at the northern process station, operated by the LTER program, has been the sole source of information about particle export off the WAP, until recently. One may ask then, how does what we know from this single sediment trap fit with the new information about particle export off the WAP presented here? For more than a decade, a bottom-moored sediment trap has collected sinking particle fluxes at 170 $m$ on an annual basis (Ducklow et al., 2008). From this trap, it has been shown that the annual cycle of particle flux is marked by an intense period of high flux in the austral spring and summer, ranging from 1 to $10 \mathrm{mmol} \mathrm{C} \mathrm{m}^{-2} \mathrm{~d}^{-1}$ and very low flux in the 
winter, $<0.0001 \mathrm{mmol} \mathrm{C} \mathrm{m} \mathrm{C}^{-2}$. Recently, fluxes from this moored trap were compared to fluxes measured by a surface-tethered drifting trap and ${ }^{234} \mathrm{Th}$ water-column measurements (Buesseler et al., 2010). At the time of the study, January 2009, fluxes determined from these additional methods were up to thirty times higher, suggesting that the moored sediment trap significantly underestimates the magnitude of sinking fluxes. Unfortunately, for the period of our study, there is no data available from the bottommoored trap because it was not successfully recovered in 2010 or 2011.

We can however compare fluxes measured in our surface-tethered and neutrally buoyant sediment traps to water-column derived fluxes at process stations and at regional scales to assess how well sediment traps reflect water-column derived fluxes off the WAP. Table 4 shows sediment trap and water column derived fluxes of ${ }^{234} \mathrm{Th}$ and $\mathrm{C}$ at $100 \mathrm{~m}$. This table should not be used to compare fluxes from summer to autumn for reasons discussed above, specifically, changes in the depth of the PPZ between seasons. Comparing different measurements at a fixed depth rather than at the base of the PPZ is convenient however because sediment traps were often deployed at or near $100 \mathrm{~m}$. At the northern site, water-column estimates of ${ }^{234} \mathrm{Th}$ and $\mathrm{C}$ flux at $100 \mathrm{~m}$ were either the same or higher than measurements from the surface-tethered trap (STT) array. In January, there was significant variability between the two STT tubes at $100 \mathrm{~m}$, thus the ratio of sediment trap ${ }^{234} \mathrm{Th}$ flux to ${ }^{234} \mathrm{Th}$ flux from water column samples ranged from $10-75 \%$. The mean ${ }^{234} \mathrm{Th}$ flux from profiles around the process station site was similar to the mean ${ }^{234} \mathrm{Th}$ flux for the entire northern region. Thus the sediment trap measurements alone are not representative of the larger region during this period. No NBST data was available from January, but in March and April, the STT and NBST agreed well (Figure 11). At the central station in Marguerite Bay, ${ }^{234} \mathrm{Th}$ and $\mathrm{C}$ fluxes in the surface tethered trap were more than double the water column derived fluxes in January, but the two measurements agreed better in April. The NBST measurement of ${ }^{234}$ Th flux in January at this site was more in line with two of the three water column measurements than the STT, possibly indicating that STT oversampled during this period (Figure 11). 
Sediment traps were only deployed at the southern process station in January, with the STT being deployed inside the ice line and the NBST and in situ pumps being deployed outside the ice line. ${ }^{234} \mathrm{Th}$ profiles were collected at both sediment trap sites. Inside the ice, the sediment trap fluxes of ${ }^{234} \mathrm{Th}$ and $\mathrm{C}$ greatly exceeded the fluxes estimated from water-column ${ }^{234} \mathrm{Th}$ measurements. A previous study demonstrated the potential for ${ }^{234} \mathrm{Th}$-rich sea-ice algae to lead to underestimation of ${ }^{234} \mathrm{Th}$ fluxes by up to $75 \%$ (Rodriguez y Baena et al., 2008). The difference between the sediment trap and water-column measurements here however is much larger. Unfortunately, we do not have additional ${ }^{234} \mathrm{Th}$ profiles at this site to determine if this difference is robust. The two NBST samples from outside the ice have very different ${ }^{234} \mathrm{Th}$ flux values but very similar $\mathrm{C}$ flux values (Figure 13). While the water-column ${ }^{234} \mathrm{Th}$ flux measurement falls between the trap-flux values, the water-column estimate of $\mathrm{C}$ export is three times larger than the trap measurements (Table 4). This difference may be due to the temporal mismatch between the two methods, with the traps recording the "instantaneous" flux at the time of sampling and ${ }^{234}$ Th integrating over $\sim 3$ weeks.

Sediment trap deployments at multiple sites along the WAP are useful for looking at simple spatial trends and as a second measurement to confirm the approximate magnitude of particle flux. In addition, they can serve as platforms for other experiments to investigate flux composition and other properties of the sinking material (McDonnell and Buesseler, 2010; McDonnell, 2011). In this study however ${ }^{234} \mathrm{Th}$ measurements, both from CTDs and underway sampling, were important for providing more information about the spatial variability of particle export across and along the shelf of the WAP (see section 4.3).

\subsection{Spatial variability of particle export}

An obvious feature of this dataset is the dramatic increase in spatial resolution of measurements of particle flux using combined water column and underway sampling of ${ }^{234} \mathrm{Th}$ (Figures $8 \& 10$ ). Underway sampling every $20 \mathrm{~km}$ supplemented the limited CTD samples taken along the coast to slope gridlines in January 2010 (Figure 16). As 
expected, the surface and water column-derived estimates of $\mathrm{C}$ flux along these lines agree well. While export appears to be relatively constant along the 600 and 300 lines, the additional measurements from surface samples on the 400 line reveal variability in the flux that otherwise would not have been discerned. When the data are binned into slope, shelf, and coastal stations for each cruise, the increase in sampling resolution is apparent, particularly along the shelf in the autumn when water column sampling was very limited (Figure 17). In the summer, the mean flux, from CTD \& UW samples, is highest on the slope $\left(9.5 \pm 1.4 \mathrm{mmol} \mathrm{m}^{-2} \mathrm{~d}^{-1}\right)$ and decreases across the shelf $(8.3 \pm 1.8$ mmol m $\left.\mathrm{d}^{-1}\right)$ and towards the coast $\left(6.9 \pm 2.0 \mathrm{mmol} \mathrm{m}^{-2} \mathrm{~d}^{-1}\right)$. In the autumn, the opposite is true, with the highest fluxes observed in the coastal region $(24.3 \pm 8.2 \mathrm{mmol}$ $\left.\mathrm{m}^{-2} \mathrm{~d}^{-1}\right)$ compared to lower fluxes over the shelf $\left(9.1 \pm 6.9 \mathrm{mmol} \mathrm{m}^{-2} \mathrm{~d}^{-1}\right)$. This trend may be skewed by along-shelf differences, however; the shelf stations were in the northern part of the study area while the coastal stations were in the vicinity of Marguerite Bay and Charcot Island to the south. In the summer there was a small decrease from the north to the central and southern regions in $\mathrm{C}$ export $(9.7 \pm 1.5,5.9 \pm$ 2.2, and $5.9 \pm 1.7 \mathrm{mmol} \mathrm{m}^{-2} \mathrm{~d}^{-1}$ from north to south). In contrast, in the autumn fluxes in the northern region of the peninsula are significantly lower $\left(7.1 \pm 2.8 \mathrm{mmol} \mathrm{m}^{-2} \mathrm{~d}^{-1}\right)$ than fluxes in the central $\left(25.0 \pm 8.3 \mathrm{mmol} \mathrm{m}^{-2} \mathrm{~d}^{-1}\right)$ and southern $\left(23.0 \pm 6.8 \mathrm{mmol} \mathrm{m}^{-2} \mathrm{~d}^{-1}\right)$ regions. This difference is due to a combination of higher ${ }^{234} \mathrm{Th}$ fluxes and higher $\mathrm{C} /{ }^{234} \mathrm{Th}$ ratios in the central and southern regions (Table 2).

The moored sediment trap discussed previously has provided a wealth of information on the temporal variability of particle export off the WAP, however it provided no information about spatial variability of export because it was limited to a single site. Two recent studies have expanded our view of particle dynamics and export across the entire region of the WAP. In the first study, particle concentrations were measured using an underwater camera system in the summer and autumn of 2009 and 2010 (McDonnell, 2011). Using a calibration derived from sediment trap measurements, particle abundances were converted to particle fluxes. The second study, discussed early, carried out in 2008, evaluated along and cross-shelf trends in NCP or export production 
using $\mathrm{O}_{2} /$ Ar ratios (Huang et al., 2012). Both studies produced carbon flux estimates similar in magnitude to those reported in this work. From sediment traps at the three process stations in 2009, carbon fluxes were higher in January compared to February/March and ranged from 2 to $26 \mathrm{mmol} \mathrm{m}^{-2} \mathrm{~d}^{-1}$, with higher fluxes in January compared to February and March (McDonnell, 2011). NCP values in January 2008 ranged from -2.1 to $54 \mathrm{mmol} \mathrm{C} \mathrm{m}^{-2} \mathrm{~d}^{-1}$ (Huang et al., 2012).

Across the shelf, NCP was highest and most variable in the shelf area, lower and less variable in the coastal regions, and consistently low over the slope. In our study, ${ }^{234}$ Th and C fluxes in January 2010 were highest over the slope and decreased in magnitude over the shelf and coastal regions. Along the shelf, NCP in January 2008 was highest in the northern region and lower in the southern region. In January 2009, flux measured in sediment traps was highest in Marguerite Bay (McDonnell, 2011) yet profiles of particle abundance were generally the same shape and magnitude over the entire WAP. In 2010 however, particle abundances were higher in the south than the north. The variability within the northern and southern regions themselves was very low. From our data, there was only a small decrease in $\mathrm{C}$ export form north to south in the summer, but in the autumn, flux was significantly higher in the central and southern regions. This change likely reflects the effects of a phytoplankton bloom across Marguerite Bay and the southern region of the WAP that was becoming stronger in January and peaked in February (Figure 18). The camera and ${ }^{234}$ Th data combined suggest that the build up in stocks observed in January did not translate into increased particle export until later in the season.

Relative to the single moored sediment trap at PS 1, the dataset presented here has dramatically broadened our view of particle export in the WAP region, particularly in relation to along and cross-shelf gradients. In this region where gradients in export seem to be large, on the scale of hundreds of kilometers, sampling resolution is important to capture shifts from region to region. Our CTD-based sampling in January 2010, could represent a minimum amount of sampling required in order to see the north to south decrease and the offshore increase in export as seen in Figure 10. Certainly, we could 
have benefitted from additional CTDs in March/April 2010 to better resolve these along and across shelf trends. In a model study of the effect of spatial variability on ${ }^{234} \mathrm{Th}$ of particle export measurements, Resplandy et al. (2012) concluded that undersampling can contribute significantly to uncertainty in trying to characterize the magnitude of the particle export in a specific region. In their model, when sampling resolution was $\sim 25$ samples per $5^{\circ} \times 5^{\circ}$ region $(\sim 100 \mathrm{~km}$ resolution), bias due to undersampling was greatly reduced. Our minimum sample set of CTD sampling fits this criterion. The additional underway sampling bridged the gap between the CTD sites and provide additional information about the variability of fluxes. The underway sampling in March/April 2010 was particularly important as our wire time for CTD sampling was very limited. It is important to note however that the CTD sampling was a necessary component of this project in order to calibrate the underway samples and derive a relationship between surface ${ }^{234} \mathrm{Th}$ and ${ }^{234} \mathrm{Th}$ fluxes. Also, this technique required a range of surface ${ }^{234} \mathrm{Th} /{ }^{238} \mathrm{U}$ values in order to obtain a robust relationship. Grid-like sampling on the first cruise and high depth resolution of the water column profiles to define the ${ }^{234} \mathrm{Th}$ deficits well were also important experimental factors that aided in this work. We hypothesize that this technique may be more difficult to apply in some subtropical regions where surface deficits and derived fluxes can be very small. In coastal settings, obtaining measurements of along and across shelf variability would be important in order to capture the full range of export fluxes.

\subsection{Controlling factors of particle export off the WAP}

Sampling of particle export off the WAP has been very limited to date, so little is known about the major processes controlling the magnitude and timing of export. Results from the moored sediment trap in the northern region of the WAP indicate that the peak in particle export occurs between mid-December and mid March (Ducklow et al., 2008). However, this peak can occur at the same time as the peak of the phytoplankton bloom or as late as 2 to 4 months afterwards. Thus, primary production and related properties are likely a poor predictor of particle export, when the two 
measurements are made simultaneously. Using a combination of sediment trap and underwater camera technology, great strides have been made in characterizing particles off the WAP. Sinking particles in this region primarily fall into two groups: 1) small particles that include diatom aggregates, detritus, radiolarians, and their fecal pellets and 2) large fecal pellets, predominantly from the krill E. superba (McDonnell and Buesseler, 2010). In general, these particles are characterized by high sinking rates and low microbial degradation rates (McDonnell, 2011). Based on these results, we hypothesize that phytoplankton and zooplankton community structure play a key role in regulating export off the WAP.

The only extensive effort to date that attempted to understand the controls on export off the WAP is the survey of $\mathrm{O}_{2} / \mathrm{Ar}$ to determine NCP undertaken in January 2008 (Huang et al., 2012). The authors of that study cite the concept that over sufficiently large spatial and temporal scales that NCP should be equivalent to export production (Eppley and Peterson, 1979). However, over the period of their study, the carbon cycling within the biological pump is not likely to be in steady state due to the dynamic changes taking place in the spring to autumn months off the WAP. In other words, NCP is not equal to particle export at the point in time that the NCP measurements are made. This is also supported by the long delay of export following the peak of the spring bloom observed in the northern sediment trap (Ducklow et al., 2008) and low particle flux values despite the build-up of particulate stocks in the south in 2010 (McDonnell, 2011). Huang et al. (2012) also reported that a tight relationship existed between surface chlorophyll and NCP, which they equated with export production.

Various properties of the WAP have been plotted against $\mathrm{C}$ export at the fluorocline in Figure 19. As predicted above, primary production is a poor predictor of export when the two are measured concurrently. Contrary to the Huang et al. (2012) study, where a positive relationship between NCP and surface chlorophyll was observed, there is a weak, inverse relationship between export and surface chlorophyll during our cruise. POC stocks were also a poor predictor of instantaneous particle export. These parameters might become more significant if a time lag was imposed on the export 
values. For example, in Figure 19, primary production and surface chlorophyll were highest in the coastal region in January, then in March/April this was the region of highest carbon flux (Figure 10). One reason for the differences between the results of this study and Huang et al. (2012) may be the timing of our measurements in relation to the bloom. Huang et al. (2012) reported that during their study period, the southern and offshore regions were in a declining bloom phase while the northern and inshore regions were in the growth or peak stage of the bloom. Based on satellite images of chlorophyll, in 2010 the phytoplankton bloom developed in Marguerite Bay in January, but did not peak until February when it also spread southwestward towards Charcot Island (Figure 18). Thus, our January flux measurements were made in the growth stages of the bloom and our March/April measurements were made after the peak of the phytoplankton bloom.

Increased PP has been observed where nutrient concentrations are high due to intrusions of UCDW and also where the water column is well stratified as a result of seaice and glacial melting (Vernet et al., 2008). Stratification or mixed layer depth was considered to be a key factor controlling NCP in January 2008 in the inner shelf and coastal regions (Huang et al., 2012). Shoaling of the mixed layer was associated with increases in NCP. There is a poor correlation between carbon export and MLD in our study, although the shallowest mixed layers are associated with the regions of highest export later in the season. Huang et al. (2012) also suggested that iron limitation was important over the slope and along shelf trends in NCP were due to a shift in phytoplankton communication structure. Unfortunately, information on dissolved iron and phytoplankton community structure from pigments are not available at this point in time for our study period, but they will be pursued as avenues for further study.

One important factor not considered explicitly by Huang et al. (2012) was the role of zooplankton in controlling export flux off the WAP. Abundance and biovolume of five major zooplankton species including three krill species (E. superba, T. macrura, and E. crystallorophias), a pteropods species (L. helicina), and a salp species (S. thompsoni) were measured at each CTD site in January 2010 (Bernard et al., 2012). The highest total 
abundance and biovolume of these five species was observed offshore and in the north, driven primarily by a large salp bloom there. Low zooplankton abundances during January, in general, were attributed to the early stage of the bloom during the study, which is corroborated by the satellite chlorophyll evidence (Figure 18). Salps were the primary grazers in the northern region and E. superba were the key grazers to the south. There does not appear to be a significant relationship between $C$ export and the abundance of E. superba however (Figure 19e). The salps offshore in the north had the most significant grazing impact in terms of percent of standing stock or primary production grazed, suggesting they could dramatically alter the result export flux. Additionally, salps can produce large, rapidly sinking fecal pellets (Bruland and Silver, 1983). In Figure19f at least the two highest flux values were areas with increased salp abundance. Due to their potentially important role in controlling carbon export, through particle consumption and repackaging, zooplankton abundances and grazing rates would be valuable measurements to obtain over the course of an entire WAP seasonal bloom.

\section{Conclusions}

In this study, water-column measurements of ${ }^{234} \mathrm{Th}$ were combined with underway sampling of surface ${ }^{234} \mathrm{Th}$ in an attempt to assess the spatial variability of particle export off the West Antarctic Peninsula (WAP). ${ }^{234}$ Th fluxes were calculated at the base of the primary production zone (PPZ), defined here as the depth where fluorescence equaled $10 \%$ of its maximum value. A relationship was derived between depth-integrated estimates of ${ }^{234} \mathrm{Th}$ flux and surface ${ }^{234} \mathrm{Th} /{ }^{238} \mathrm{U}$ ratios at sites where the two were measured concurrently. This relationship was used to estimate ${ }^{234} \mathrm{Th}$ fluxes at sites where only surface measurements were made. Whereas water column measurements were made 40 to $100 \mathrm{~km}$ apart, these underway measurement increased the sampling resolution of particle export to $10-20 \mathrm{~km}$. This work demonstrates the potential utility of surface measurements of ${ }^{234} \mathrm{Th}$ in combination with water column sampling of ${ }^{234} \mathrm{Th}$. The technique is likely best suited to a region or period of time that is characterized by a gradient in ${ }^{234} \mathrm{Th} /{ }^{238} \mathrm{U}$ ratios. This approach may be more difficult in 
subtropical regions where export is often very low and surface ${ }^{234} \mathrm{Th} /{ }^{238} \mathrm{U}$ ratios can be near unity.

This is the most extensive survey of particle export off this region of the WAP from 64 to $70^{\circ} \mathrm{S}$. Prior measurements of particle flux were limited to a single sediment trap in the northern, shelf region of the WAP. In January 2010, carbon fluxes were highest offshore to the north, potentially driven by a bloom of salps, which are known to produce large, fast-sinking fecal pellets. Although ${ }^{234} \mathrm{Th}$ fluxes were higher in January, the highest carbon fluxes observed during the study period were in Marguerite Bay in March and April 2010, due to high $\mathrm{C} /{ }^{234} \mathrm{Th}$ ratios. These results are consistent with the timing of the seasonal phytoplankton bloom, which peaked in February, in between the two sampling periods, and spread from Marguerite Bay southwestward towards Charcot Island. While increases in in chlorophyll and primary production were already evident in these regions in January, the carbon export was not yet as high in January as it would be in March and April. These results highlight the importance of the sampling time period in understanding the controls on particle export off the WAP. By sampling this region only in January, it can be difficult to draw relationships between factors controlling carbon export and the resulting flux. Our results suggest that the relationships derived between surface chlorophyll and export production in 2008 (Huang et al., 2012) may not be applicable in years when the relative timing of the peaks in the phytoplankton bloom and carbon export differ from the pattern in 2008. Future work with this data set will include working with other colleagues to look at the role of iron availability (R. Sherrell) and phytoplankton community composition (O. Schofield) in controlling carbon export off the WAP.

\section{Acknowledgements}

Thank you to the captains and crews of the $A R S V$ L.M. Gould and the RVIB N.B. Palmer and the staff of Raytheon Polar Services for facilitating this work. This work was supported by an NSF grant to K.O. Buesseler from the NSF Office of Polar Programs. 


\section{References}

Abraham, E.R., 1998. The generation of plankton patchiness by turbulent stirring. Nature $391,577-580$.

Bacon, M.P., Huh, C.A., Fleer, A.P., Deuser, W.G., 1985. Seasonality in the flux of natural radionuclides and plutonium in the deep Sargasso Sea. Deep Sea Research 32, 273-286.

Benitez-Nelson, C.R., Buesseler, K.O., van der Loeff, M.R., Andrews, J., Ball, L., Crossin, G., Charette, M.A., 2001. Testing a new small-volume technique for determining ${ }^{234} \mathrm{Th}$ in seawater. Journal of Radioanalytical and Nuclear Chemistry $248(3), 795-799$.

Bernard, K.S., Steinberg, D.K., Schofield, O.M.E., 2012. Summertime grazing impact of the dominant macrozooplankton off teh Western Antarctic Peninsula. Deep-Sea Research I 62, 111-122.

Boyd, P.W., Trull, T.W., 2007. Understanding the export of biogenic particles in oceanic waters: Is there consensus? Progress in Oceanography 72 (4), 276-312.

Bruland, K.W., Silver, M.W., 1983. Sinking rates of fecal pellets from gelatinous zooplankton (salps, pteropods, doliolids). Marine Biology 63, 295-300.

Buesseler, K.O., 1991. Do upper-ocean sediment traps provide an accurate record of particle flux? Nature 353, 420-423.

Buesseler, K.O., Antia, A.N., Chen, M., Fowler, S.W., Gardner, W.D., Gustafsson, O., Harada, K., Michaels, A.F., van der Loeffo, M.R., Sarin, M., Steinberg, D.K., Trull, T., 2007. An assessment of the use of sediment traps for estimating upper ocean particle fluxes. Journal of Marine Research 65 (3), 345-416.

Buesseler, K.O., Benitez-Nelson, C.R., Rutgers van der Loeff, M., Andrews, J., Ball, L., Crossin, G., Charette, M.A., 2001. An intercomparison of small- and largevolume techniques for thorium-234 in seawater. Marine Chemistry 74 (1), 15-28.

Buesseler, K.O., Boyd, P.W., 2009. Shedding light on processes that control particle export and flux attenuation in the twilight zone of the open ocean. Limnology and Oceanography 54 (4), 1210-1232.

Buesseler, K.O., McDonnell, A.M.P., Schofield, O.M.E., Steinberg, D.K., Ducklow, H.W., 2010. High particle export over the continental shelf of the west Antarctic Peninsula. Geophysical Research Letters 37 (L22606). 
Buesseler, K.O., Michaels, A.F., Siegel, D.A., Knap, A.H., 1994. A three dimensional time-dependent approach to calibrating sediment trap fluxes. Global Biogeochemical Cycles 8 (2), 179-193.

Buesseler, K.O., Pike, S., Maiti, K., Lamborg, C.H., Siegel, D.A., Trull, T.W., 2008. Thorium-234 as a tracer of spatial, temporal and vertical variability in particle flux in the North Pacific. Deep-Sea Research Part I-Oceanographic Research Papers 56 (7), 1143-1167.

Coale, K.H., Bruland, K.W., 1985. ${ }^{234} \mathrm{Th}:{ }^{238} \mathrm{U}$ disequilibria within the California Current. Limnology and Oceanography 30 (1), 22-33.

Cochran, J.K., Miquel, J.C., Armstrong, R., Fowler, S.W., Masqué, P., Gasser, B., Hirschberg, D., Szlosek, J., Rodriguez y Baena, A.M., Verdeny, E., Stewart, G., 2009. Time-series measurements of Th-234 in water column and sediment trap samples from the northwestern Mediterranean Sea. Deep-Sea Research II 56 (18), 1487-1501.

Ducklow, H.W., 2008. Preface: Long-term studies of the marine ecosystem along the west Antarctic Peninsula. Deep-Sea Research II 55 (1945-1948).

Ducklow, H.W., Erickson, M., Kelly, J., Montes-Hugo, M., Ribic, C.A., Smith, R.C., Stammerjohn, S.E., Karl, D.M., 2008. Particle export from the upper ocean over the continental shelf of the west Antarctic Peninsula: A long-term record, 19922007. Deep-Sea Research II 55, 2118-2131.

Ducklow, H.W., Steinberg, D.K., Buesseler, K.O., 2001. Upper Ocean Carbon Export and the Biological Pump. Oceanography 14 (4), 50-58.

Eppley, R.W., Peterson, B.J., 1979. Particulate organic matter flux and planktonic new production in the deep ocean. Nature 282 (5740), 677-680.

Garçon, V.C., Oschlies, A., Doney, S.C., McGillicuddy Jr., D.J., Waniek, J., 2001. The role of mesoscale variability on plankton dynamics in the North Atlantic. DeepSea Research II 48, 2199-2226.

Guidi, L., Jackson, G.A., Stemmann, L., Miquel, J.C., Picheral, M., Gorsky, G., 2008. Relationship between particle size distribution and flux in the mesopelagic zone. Deep-Sea Research I 55 (1364-1374).

Guidi, L., Stemmann, L., Legendre, L., Picheral, M., Prieur, L., Gorsky, G., 2007. Vertical distribution of aggregrates $(>110 \mu \mathrm{m})$ and mesoscale activity in the northeastern Atlantic: Effects on the deep vertical export of surface carbon. Limnology \& Oceanography 52, 7-18. 
Huang, K., Ducklow, H.W., Vernet, M., Cassar, N., Bender, M.L., 2012. Export production and its regulating factors in the West Antarctic Peninsula region of the Southern Ocean. Global Biogeochemical Cycles 26.

Knauer, G.A., Martin, J.H., Bruland, K.W., 1979. Fluxes of particulate carbon, nitrogen, and phosphorus in the upper water column of the northeast Pacific. Deep-Sea Research 26 (1), 97-108.

Lamborg, C.H., Buesseler, K.O., Valdes, J., Bertrand, C.H., Bidigare, R., Manganini, S., Pike, S., Steinberg, D., Trull, T., Wilson, S., 2008. The flux of bio- and lithogenic material associated with sinking particles in the mesopelagic "twilight zone" of the northwest and North Central Pacific Ocean. Deep-Sea Research Part IiTopical Studies in Oceanography 55 (14-15), 1540-1563.

Lampitt, R.S., Boorman, B., Brown, L., Lucas, M., Salter, I., Sanders, R., Saw, K., Seeyave, S., Thomalla, S.J., Turnewitsch, R., 2008. Particle export from the euphotic zone: Estimates using a novel drifting sediment trap, Th-234 and new production. Deep-Sea Research Part I-Oceanographic Research Papers 55 (11), 1484-1502.

Lévy, M., 2008. The modulation of biological production by oceanic mesoscale turbulence. In: Weiss, J.B., Provenzale, A. (Eds.), Transport in geophysical flow: Ten years after. Springer, pp. 219-261.

Lévy, M., Klein, P., 2004. Does the low frequency of the mesoscale dynamics explain a part of the phytoplankton and zooplankton spectral variability? Proceedings of the Royal Society of London A 460, 1673-1687.

Mackas, D.L., Boyd, C.M., 1979. Spectral analysis of zooplankton spatial heterogeneity. Science 204, 62-64.

Mahadevan, A., Campbell, J., 2002. Biogeochemical patchiness at the sea surface. Geophysical Research Letters 29 (19), 1926.

Martin, A.P., 2003. Phytoplankton patchines: the role of lateral stirring and mixing. Progress in Oceanography 57, 125-174.

Martinez, E., Richards, K.J., 2010. Impact of spatio-temporal heterogeneities and lateral stirring and mixing on mid-water biotic interactions. Journal of Marine Systems $82,122-134$.

Martinson, D.G., Stammerjohn, S.E., Iannuzzi, R.A., Smith, R.C., Vernet, M., 2008. Western Antarctic Peninsula physical oceanography and spatio-temporal variability. Deep-Sea Research II 55 (1964-1987). 
McDonnell, A.M.P., 2011. Marine particle dynamics: sinking velocities, size distributions, and microbial degradation rates, Massachusetts Institute of Technology \& Woods Hole Oceanographic Institution.

McDonnell, A.M.P., Buesseler, K.O., 2010. Variability in the average sinking velocity of marine particles. Limnology \& Oceanography 55 (5), 2085-2096.

Moffat, C., Beardsley, R.C., Owens, B., van Lipzig, N., 2008. A first description of the Antarctic Peninsula coastal current. Deep-Sea Research II 55, 277-293.

Owens, S.A., Buesseler, K.O., Lamborg, C.H., Valdes, J., Lomas, M.W., Johnson, R.J., Steinberg, D.K., Siegel, D.A., 2012. A new time series of particle export from neutrally buoyant sediment traps at the Bermuda Atlantic Time-series Study site. Deep-Sea Research I, submitted.

Owens, S.A., Buesseler, K.O., Sims, K.W.W., 2011. Re-evaluating the U-238-salinity relationship in seawater: Implications for the U-238/Th-234 disequilibrium method. Marine Chemistry 127, 31-39.

Pike, S.M., Buesseler, K.O., Andrews, J., Savoye, N., 2005. Quantification of ${ }^{234}$ Th recovery in small volume sea water samples by inductively coupled plasma mass spectrometry. Journal of Radioanalytical and Nuclear Chemistry 263 (2), 355360 .

Resplandy, L., Martin, A.P., Le Moigne, F., Martin, P., Aquilina, A., Mémery, M., Lévy, M., Sanders, R., 2012. How does dynamical spatial variability impact Th-234 derived estimates of organic export? Deep-Sea Research I.

Rodriguez y Baena, A.M., Boudjenoun, R., Fowler, S.W., Miquel, J.C., Masqué, P., Sanchez-Cabeza, J.-A., Warnau, M., 2008. Th-234-based carbon export during an ice-edge bloom: Sea-ice algae as a likely bias in data interpretation. Earth and Planetary Science Letters 269, 595-603.

Rutgers van der Loeff, M., Cai, P.H., Stimac, I., Bracher, A., Middag, R., Klunder, M.B., van Heuven, S.M.A.C., 2011. Th-234 in surface waters: Distribution of particle export flux across the Antarctic Circumpolar Current and in the Weddell Sea during the GEOTRACES expedition ZERO and DRAKE. Deep Sea Research Part II: Topical Studies in Oceanography 58 (25-26), 2749-2766.

Savidge, D.K., Amft, J.A., 2009. Circulation on the West Antarctic Peninsula derived from 6 years of shipboard ADCP transects. Deep-Sea Research I 56, 1633-1655.

Savoye, N., Benitez-Nelson, C., Burd, A.B., Cochran, J.K., Charette, M., Buesseler, K.O., Jackson, G.A., Roy-Barman, M., Schmidt, S., Elskens, M., 2006. ${ }^{234} \mathrm{Th}$ 
sorption and export models in the water column: A review. Marine Chemistry 100 (3-4), 234-249.

Vernet, M., Martinson, D.G., Iannuzzi, R.A., Stammerjohn, S.E., Kozlowski, W., Sines, K., Smith, R., Garibotti, I., 2008. Primary production within the sea-ice zone west of the Antarctic Peninsula: I - Sea ice, summer mixed layer, and irradiance. DeepSea Research II 55, 2068-2085.

Yoder, J.A., Aiken, J., Swift, R.N., Hoge, F.E., Stegmann, P.M., 1993. Spatial variability in near-surface chlorophyll a fluorescence measured by airborne oceanographic lidar (AOL). Deep-Sea Research II 40, 37-53. 
Table 1

${ }^{238} \mathrm{U}$, total ${ }^{234} \mathrm{Th}$ activities, and ${ }^{234} \mathrm{Th} /{ }^{238} \mathrm{U}$ ratios from water-column profiles off the WAP

\begin{tabular}{|c|c|c|c|c|c|c|c|c|}
\hline CTD \# & $\begin{array}{c}\text { Date } \\
\mathrm{mm} / \mathrm{dd} / \mathrm{yy}\end{array}$ & $\begin{array}{c}\text { Depth } \\
\text { m }\end{array}$ & $\begin{array}{c}{ }^{238} \mathrm{U}^{-1} \\
\mathrm{dpm} \mathrm{L} \mathrm{L}^{-1}\end{array}$ & err & $\begin{array}{c}\text { Total }{ }^{234} \mathrm{Th} \\
\mathrm{dpm} \mathrm{L} \mathrm{L}^{-1}\end{array}$ & err & ${ }^{234} \mathrm{Th} /{ }^{238} \mathrm{U}$ & err \\
\hline \multicolumn{9}{|c|}{ Summer cruise } \\
\hline \multirow[t]{10}{*}{1} & $1 / 5 / 10$ & 5 & 2.35 & 0.05 & 1.63 & 0.05 & 0.69 & 0.02 \\
\hline & & 10 & 2.35 & 0.05 & 1.70 & 0.06 & 0.73 & 0.03 \\
\hline & & 20 & 2.35 & 0.05 & 1.59 & 0.04 & 0.68 & 0.02 \\
\hline & & 50 & 2.35 & 0.05 & 1.80 & 0.05 & 0.76 & 0.02 \\
\hline & & 61 & 2.36 & 0.05 & 2.13 & 0.06 & 0.90 & 0.03 \\
\hline & & 81 & 2.37 & 0.05 & 2.29 & 0.06 & 0.97 & 0.03 \\
\hline & & 101 & 2.38 & 0.05 & 2.25 & 0.06 & 0.94 & 0.03 \\
\hline & & 301 & 2.40 & 0.05 & 2.29 & 0.06 & 0.95 & 0.03 \\
\hline & & 500 & 2.41 & 0.05 & 2.42 & 0.07 & 1.01 & 0.04 \\
\hline & & 1100 & 2.41 & 0.05 & 2.58 & 0.06 & 1.07 & 0.03 \\
\hline \multirow[t]{10}{*}{2} & $1 / 6 / 10$ & 5 & 2.35 & 0.05 & 1.72 & 0.06 & 0.73 & 0.03 \\
\hline & & 10 & 2.35 & 0.05 & 1.87 & 0.05 & 0.80 & 0.03 \\
\hline & & 30 & 2.35 & 0.05 & 1.74 & 0.06 & 0.74 & 0.03 \\
\hline & & 51 & 2.35 & 0.05 & 1.82 & 0.06 & 0.77 & 0.03 \\
\hline & & 61 & 2.35 & 0.05 & 1.73 & 0.05 & 0.74 & 0.03 \\
\hline & & 79 & 2.35 & 0.05 & 1.59 & 0.06 & 0.68 & 0.03 \\
\hline & & 104 & 2.37 & 0.05 & 2.19 & 0.05 & 0.92 & 0.03 \\
\hline & & 204 & 2.40 & 0.05 & 2.53 & 0.07 & 1.06 & 0.04 \\
\hline & & 303 & 2.40 & 0.05 & 2.51 & 0.07 & 1.04 & 0.04 \\
\hline & & 501 & 2.41 & 0.05 & 2.67 & 0.08 & 1.11 & 0.04 \\
\hline \multirow[t]{9}{*}{3} & $1 / 7 / 10$ & 4 & 2.34 & 0.05 & 1.39 & 0.04 & 0.59 & 0.02 \\
\hline & & 10 & 2.34 & 0.05 & 1.21 & 0.05 & 0.52 & 0.02 \\
\hline & & 19 & 2.34 & 0.05 & 1.78 & 0.06 & 0.76 & 0.03 \\
\hline & & 40 & 2.34 & 0.05 & 1.33 & 0.05 & 0.57 & 0.02 \\
\hline & & 60 & 2.36 & 0.05 & 2.09 & 0.28 & 0.89 & 0.12 \\
\hline & & 99 & 2.37 & 0.05 & 2.37 & 0.07 & 1.00 & 0.04 \\
\hline & & 250 & 2.40 & 0.05 & 2.46 & 0.07 & 1.02 & 0.04 \\
\hline & & 401 & 2.41 & 0.05 & 2.52 & 0.07 & 1.04 & 0.04 \\
\hline & & 1999 & 2.41 & 0.05 & 2.45 & 0.06 & 1.01 & 0.03 \\
\hline \multirow[t]{10}{*}{4} & $1 / 7 / 10$ & 4 & 2.34 & 0.05 & 1.53 & 0.05 & 0.65 & 0.02 \\
\hline & & 5 & 2.34 & 0.05 & 1.46 & 0.05 & 0.63 & 0.02 \\
\hline & & 10 & 2.34 & 0.05 & 1.64 & 0.05 & 0.70 & 0.03 \\
\hline & & 21 & 2.34 & 0.05 & 1.64 & 0.06 & 0.70 & 0.03 \\
\hline & & 46 & 2.34 & 0.05 & 1.59 & 0.05 & 0.68 & 0.03 \\
\hline & & 60 & 2.35 & 0.05 & 2.11 & 0.07 & 0.90 & 0.03 \\
\hline & & 71 & 2.36 & 0.05 & 1.99 & 0.05 & 0.84 & 0.03 \\
\hline & & 101 & 2.37 & 0.05 & 2.14 & 0.06 & 0.90 & 0.03 \\
\hline & & 415 & 2.41 & 0.05 & 2.45 & 0.06 & 1.01 & 0.03 \\
\hline & & 1002 & 2.41 & 0.05 & 2.46 & 0.09 & 1.02 & 0.04 \\
\hline \multirow[t]{9}{*}{7} & $1 / 9 / 10$ & 2 & 2.34 & 0.05 & 1.69 & 0.06 & 0.72 & 0.03 \\
\hline & & 10 & 2.34 & 0.05 & 1.70 & 0.06 & 0.73 & 0.03 \\
\hline & & 25 & 2.35 & 0.05 & 1.72 & 0.06 & 0.73 & 0.03 \\
\hline & & 45 & 2.35 & 0.05 & 1.54 & 0.06 & 0.66 & 0.03 \\
\hline & & 70 & 2.35 & 0.05 & 1.63 & 0.06 & 0.69 & 0.03 \\
\hline & & 81 & 2.36 & 0.05 & 2.21 & 0.06 & 0.93 & 0.03 \\
\hline & & 90 & 2.37 & 0.05 & 2.16 & 0.06 & 0.91 & 0.03 \\
\hline & & 99 & 2.38 & 0.05 & 2.24 & 0.06 & 0.94 & 0.03 \\
\hline & & 225 & 2.41 & 0.05 & 2.21 & 0.07 & 0.92 & 0.04 \\
\hline
\end{tabular}




\begin{tabular}{|c|c|c|c|c|c|c|c|c|}
\hline CTD \# & $\begin{array}{c}\text { Date } \\
\mathrm{mm} / \mathrm{dd} / \mathrm{yy}\end{array}$ & $\begin{array}{c}\text { Depth } \\
\text { m }\end{array}$ & $\begin{array}{c}{ }^{238} \mathrm{U}^{-1} \\
\mathrm{dpm} \mathrm{L} \mathrm{L}^{-1}\end{array}$ & err & $\begin{array}{c}\text { Total }{ }^{234} \mathrm{Th} \\
\text { dpm L L }\end{array}$ & err & ${ }^{234} \mathrm{Th} /{ }^{238} \mathrm{U}$ & err \\
\hline & & 380 & 2.41 & 0.05 & 2.35 & 0.07 & 0.97 & 0.03 \\
\hline \multirow[t]{10}{*}{9} & $1 / 10 / 10$ & 3 & 2.34 & 0.05 & 1.54 & 0.06 & 0.66 & 0.03 \\
\hline & & 10 & 2.34 & 0.05 & 1.58 & 0.06 & 0.67 & 0.03 \\
\hline & & 26 & 2.34 & 0.05 & 1.59 & 0.04 & 0.68 & 0.02 \\
\hline & & 40 & 2.34 & 0.05 & 1.64 & 0.05 & 0.70 & 0.02 \\
\hline & & 51 & 2.34 & 0.05 & 1.49 & 0.04 & 0.64 & 0.02 \\
\hline & & 60 & 2.34 & 0.05 & 1.71 & 0.05 & 0.73 & 0.03 \\
\hline & & 80 & 2.36 & 0.05 & 2.14 & 0.05 & 0.91 & 0.03 \\
\hline & & 100 & 2.37 & 0.05 & 2.11 & 0.06 & 0.89 & 0.03 \\
\hline & & 200 & 2.40 & 0.05 & 2.36 & 0.07 & 0.98 & 0.03 \\
\hline & & 300 & 2.41 & 0.05 & 2.39 & 0.06 & 0.99 & 0.03 \\
\hline \multirow[t]{10}{*}{10} & $1 / 11 / 10$ & 3 & 2.34 & 0.05 & 1.66 & 0.06 & 0.71 & 0.03 \\
\hline & & 9 & 2.34 & 0.05 & 1.44 & 0.05 & 0.61 & 0.02 \\
\hline & & 24 & 2.34 & 0.05 & 1.59 & 0.05 & 0.68 & 0.03 \\
\hline & & 34 & 2.35 & 0.05 & 1.61 & 0.05 & 0.69 & 0.03 \\
\hline & & 49 & 2.35 & 0.05 & 1.59 & 0.05 & 0.68 & 0.03 \\
\hline & & 75 & 2.36 & 0.05 & 1.98 & 0.06 & 0.84 & 0.03 \\
\hline & & 99 & 2.37 & 0.05 & 2.14 & 0.06 & 0.90 & 0.03 \\
\hline & & 150 & 2.39 & 0.05 & 2.39 & 0.07 & 1.00 & 0.03 \\
\hline & & 207 & 2.40 & 0.05 & 2.33 & 0.08 & 0.97 & 0.04 \\
\hline & & 305 & 2.41 & 0.05 & 2.02 & 0.06 & 0.84 & 0.03 \\
\hline \multirow[t]{9}{*}{11} & $1 / 11 / 10$ & 3 & 2.34 & 0.05 & 1.60 & 0.07 & 0.68 & 0.03 \\
\hline & & 11 & 2.34 & 0.05 & 1.56 & 0.08 & 0.67 & 0.03 \\
\hline & & 30 & 2.34 & 0.05 & 1.55 & 0.07 & 0.66 & 0.03 \\
\hline & & 52 & 2.34 & 0.05 & 1.82 & 0.09 & 0.78 & 0.04 \\
\hline & & 75 & 2.36 & 0.05 & 1.84 & 0.08 & 0.78 & 0.04 \\
\hline & & 100 & 2.37 & 0.05 & 1.52 & 0.05 & 0.64 & 0.03 \\
\hline & & 124 & 2.38 & 0.05 & 2.12 & 0.09 & 0.89 & 0.04 \\
\hline & & 151 & 2.39 & 0.05 & 1.92 & 0.06 & 0.81 & 0.03 \\
\hline & & 179 & 2.40 & 0.05 & 2.03 & 0.07 & 0.85 & 0.03 \\
\hline \multirow[t]{10}{*}{12} & $1 / 12 / 10$ & 4 & 2.33 & 0.05 & 1.39 & 0.05 & 0.60 & 0.03 \\
\hline & & 10 & 2.33 & 0.05 & 1.37 & 0.05 & 0.59 & 0.03 \\
\hline & & 20 & 2.33 & 0.05 & 1.31 & 0.05 & 0.56 & 0.03 \\
\hline & & 39 & 2.33 & 0.05 & 1.33 & 0.05 & 0.57 & 0.03 \\
\hline & & 65 & 2.36 & 0.05 & 2.14 & 0.06 & 0.91 & 0.03 \\
\hline & & 80 & 2.37 & 0.05 & 2.06 & 0.06 & 0.87 & 0.03 \\
\hline & & 100 & 2.38 & 0.05 & 2.03 & 0.06 & 0.85 & 0.03 \\
\hline & & 150 & 2.40 & 0.05 & 2.18 & 0.07 & 0.91 & 0.03 \\
\hline & & 194 & 2.41 & 0.05 & 2.14 & 0.07 & 0.89 & 0.03 \\
\hline & & 275 & 2.41 & 0.05 & 2.27 & 0.07 & 0.94 & 0.03 \\
\hline \multirow[t]{10}{*}{13} & $1 / 12 / 10$ & 3 & 2.34 & 0.05 & 1.36 & 0.05 & 0.58 & 0.03 \\
\hline & & 9 & 2.34 & 0.05 & 1.61 & 0.07 & 0.69 & 0.03 \\
\hline & & 28 & 2.34 & 0.05 & 1.36 & 0.05 & 0.58 & 0.02 \\
\hline & & 35 & 2.34 & 0.05 & 1.32 & 0.06 & 0.56 & 0.03 \\
\hline & & 50 & 2.34 & 0.05 & 1.65 & 0.07 & 0.71 & 0.03 \\
\hline & & 75 & 2.36 & 0.05 & 2.07 & 0.07 & 0.88 & 0.03 \\
\hline & & 100 & 2.37 & 0.05 & 1.88 & 0.07 & 0.79 & 0.03 \\
\hline & & 149 & 2.39 & 0.05 & 2.33 & 0.08 & 0.98 & 0.04 \\
\hline & & 200 & 2.40 & 0.05 & 2.28 & 0.07 & 0.95 & 0.03 \\
\hline & & 249 & 2.41 & 0.05 & 2.15 & 0.08 & 0.89 & 0.04 \\
\hline 14 & $1 / 12 / 10$ & 3 & 2.33 & 0.05 & 1.36 & 0.07 & 0.58 & 0.03 \\
\hline
\end{tabular}




\begin{tabular}{|c|c|c|c|c|c|c|c|c|}
\hline CTD \# & $\begin{array}{c}\text { Date } \\
\mathrm{mm} / \mathrm{dd} / \mathrm{yy}\end{array}$ & $\begin{array}{c}\text { Depth } \\
\mathrm{m}\end{array}$ & $\begin{array}{c}{ }^{238} \mathrm{U} \\
\mathrm{dpm} \mathrm{L} \mathrm{L}^{-1}\end{array}$ & err & $\begin{array}{c}\text { Total }^{234} \mathrm{Th} \\
\mathrm{dpm} \mathrm{L} \mathrm{L}^{-1}\end{array}$ & err & ${ }^{234} \mathrm{Th} /{ }^{238} \mathrm{U}$ & err \\
\hline & & 10 & 2.33 & 0.05 & 1.37 & 0.07 & 0.59 & 0.03 \\
\hline & & 20 & 2.33 & 0.05 & 1.34 & 0.13 & 0.57 & 0.06 \\
\hline & & 45 & 2.34 & 0.05 & 1.32 & 0.06 & 0.57 & 0.03 \\
\hline & & 81 & 2.36 & 0.05 & 2.07 & 0.10 & 0.87 & 0.05 \\
\hline & & 100 & 2.37 & 0.05 & 2.38 & 0.13 & 1.00 & 0.06 \\
\hline & & 149 & 2.39 & 0.05 & 2.43 & 0.12 & 1.02 & 0.06 \\
\hline & & 201 & 2.40 & 0.05 & 2.39 & 0.11 & 1.00 & 0.05 \\
\hline & & 301 & 2.41 & 0.05 & 2.41 & 0.13 & 1.00 & 0.06 \\
\hline & & 400 & 2.41 & 0.05 & 2.47 & 0.12 & 1.02 & 0.05 \\
\hline \multirow[t]{10}{*}{15} & $1 / 13 / 10$ & 3 & 2.34 & 0.05 & 1.34 & 0.07 & 0.57 & 0.03 \\
\hline & & 9 & 2.34 & 0.05 & 1.38 & 0.08 & 0.59 & 0.04 \\
\hline & & 30 & 2.34 & 0.05 & 1.60 & 0.09 & 0.69 & 0.04 \\
\hline & & 39 & 2.34 & 0.05 & 2.27 & 0.11 & 0.97 & 0.05 \\
\hline & & 56 & 2.35 & 0.05 & 2.03 & 0.11 & 0.86 & 0.05 \\
\hline & & 84 & 2.36 & 0.05 & 1.43 & 0.09 & 0.61 & 0.04 \\
\hline & & 98 & 2.37 & 0.05 & 2.09 & 0.13 & 0.88 & 0.06 \\
\hline & & 125 & 2.38 & 0.05 & 2.06 & 0.10 & 0.87 & 0.05 \\
\hline & & 227 & 2.41 & 0.05 & 2.00 & 0.11 & 0.83 & 0.05 \\
\hline & & 299 & 2.41 & 0.05 & 2.09 & 0.12 & 0.87 & 0.05 \\
\hline \multirow[t]{10}{*}{17} & $1 / 13 / 10$ & 3 & 2.33 & 0.05 & 1.59 & 0.10 & 0.68 & 0.05 \\
\hline & & 21 & 2.33 & 0.05 & 1.55 & 0.09 & 0.66 & 0.04 \\
\hline & & 41 & 2.33 & 0.05 & 1.67 & 0.09 & 0.72 & 0.04 \\
\hline & & 76 & 2.36 & 0.05 & 1.94 & 0.10 & 0.82 & 0.05 \\
\hline & & 102 & 2.36 & 0.05 & 2.00 & 0.09 & 0.85 & 0.04 \\
\hline & & 152 & 2.38 & 0.05 & 2.24 & 0.15 & 0.94 & 0.07 \\
\hline & & 251 & 2.41 & 0.05 & 2.18 & 0.13 & 0.91 & 0.06 \\
\hline & & 380 & 2.41 & 0.05 & 2.04 & 0.11 & 0.85 & 0.05 \\
\hline & & 500 & 2.41 & 0.05 & 1.99 & 0.10 & 0.83 & 0.04 \\
\hline & & 658 & 2.41 & 0.05 & 2.16 & 0.15 & 0.89 & 0.07 \\
\hline \multirow[t]{10}{*}{18} & $1 / 14 / 10$ & 3 & 2.33 & 0.05 & 1.61 & 0.10 & 0.69 & 0.05 \\
\hline & & 11 & 2.33 & 0.05 & 1.59 & 0.10 & 0.68 & 0.04 \\
\hline & & 25 & 2.34 & 0.05 & 1.69 & 0.09 & 0.72 & 0.04 \\
\hline & & 35 & 2.33 & 0.05 & 1.73 & 0.08 & 0.74 & 0.04 \\
\hline & & 50 & 2.34 & 0.05 & 1.73 & 0.09 & 0.74 & 0.04 \\
\hline & & 70 & 2.36 & 0.05 & 1.93 & 0.09 & 0.82 & 0.04 \\
\hline & & 99 & 2.36 & 0.05 & 1.87 & 0.10 & 0.79 & 0.04 \\
\hline & & 149 & 2.38 & 0.05 & 2.22 & 0.12 & 0.93 & 0.05 \\
\hline & & 300 & 2.41 & 0.05 & 2.00 & 0.10 & 0.83 & 0.04 \\
\hline & & 449 & 2.41 & 0.05 & 2.28 & 0.11 & 0.94 & 0.05 \\
\hline \multirow[t]{10}{*}{19} & $1 / 14 / 10$ & 3 & 2.34 & 0.05 & 1.69 & 0.11 & 0.72 & 0.05 \\
\hline & & 9 & 2.34 & 0.05 & 1.61 & 0.09 & 0.69 & 0.04 \\
\hline & & 20 & 2.34 & 0.05 & 1.58 & 0.09 & 0.67 & 0.04 \\
\hline & & 34 & 2.34 & 0.05 & 1.59 & 0.08 & 0.68 & 0.04 \\
\hline & & 49 & 2.34 & 0.05 & 1.66 & 0.10 & 0.71 & 0.05 \\
\hline & & 74 & 2.36 & 0.05 & 2.04 & 0.11 & 0.86 & 0.05 \\
\hline & & 100 & 2.37 & 0.05 & 2.22 & 0.10 & 0.94 & 0.05 \\
\hline & & 151 & 2.40 & 0.05 & 2.27 & 0.11 & 0.95 & 0.05 \\
\hline & & 200 & 2.41 & 0.05 & 2.20 & 0.12 & 0.92 & 0.05 \\
\hline & & 301 & 2.41 & 0.05 & 2.23 & 0.11 & 0.92 & 0.05 \\
\hline \multirow[t]{3}{*}{20} & $1 / 16 / 10$ & 3 & 2.33 & 0.05 & 1.44 & 0.07 & 0.62 & 0.03 \\
\hline & & 10 & 2.33 & 0.05 & 1.42 & 0.09 & 0.61 & 0.04 \\
\hline & & 19 & 2.33 & 0.05 & 1.52 & 0.11 & 0.65 & 0.05 \\
\hline
\end{tabular}




\begin{tabular}{|c|c|c|c|c|c|c|c|c|}
\hline CTD \# & $\begin{array}{c}\text { Date } \\
\mathrm{mm} / \mathrm{dd} / \mathrm{yy}\end{array}$ & $\begin{array}{c}\text { Depth } \\
\text { m }\end{array}$ & $\begin{array}{c}{ }^{238} \mathrm{U}^{-1} \\
\mathrm{dpm} \mathrm{L} \mathrm{L}^{-1}\end{array}$ & err & $\begin{array}{c}\text { Total }{ }^{234} \mathrm{Th} \\
\text { dpm L L }\end{array}$ & err & ${ }^{234} \mathrm{Th} /{ }^{238} \mathrm{U}$ & err \\
\hline & & 40 & 2.33 & 0.05 & 1.46 & 0.08 & 0.62 & 0.04 \\
\hline & & 59 & 2.33 & 0.05 & 1.41 & 0.07 & 0.61 & 0.03 \\
\hline & & 79 & 2.36 & 0.05 & 1.95 & 0.12 & 0.83 & 0.05 \\
\hline & & 100 & 2.37 & 0.05 & 2.21 & 0.11 & 0.93 & 0.05 \\
\hline & & 378 & 2.41 & 0.05 & 2.37 & 0.13 & 0.98 & 0.06 \\
\hline & & 1500 & 2.41 & 0.05 & 2.70 & 0.15 & 1.12 & 0.07 \\
\hline & & 3293 & 2.41 & 0.05 & 2.40 & 0.14 & 0.99 & 0.06 \\
\hline \multirow[t]{10}{*}{21} & $1 / 16 / 10$ & 4 & 2.34 & 0.05 & 1.53 & 0.10 & 0.66 & 0.05 \\
\hline & & 9 & 2.34 & 0.05 & 1.66 & 0.11 & 0.71 & 0.05 \\
\hline & & 19 & 2.34 & 0.05 & 1.71 & 0.12 & 0.73 & 0.05 \\
\hline & & 35 & 2.34 & 0.05 & 1.52 & 0.09 & 0.65 & 0.04 \\
\hline & & 55 & 2.35 & 0.05 & 2.15 & 0.12 & 0.91 & 0.06 \\
\hline & & 76 & 2.36 & 0.05 & 2.44 & 0.15 & 1.03 & 0.07 \\
\hline & & 98 & 2.36 & 0.05 & 2.50 & 0.14 & 1.06 & 0.06 \\
\hline & & 149 & 2.38 & 0.05 & 2.28 & 0.12 & 0.96 & 0.05 \\
\hline & & 199 & 2.40 & 0.05 & 2.48 & 0.15 & 1.03 & 0.06 \\
\hline & & 250 & 2.41 & 0.05 & 2.40 & 0.13 & 1.00 & 0.06 \\
\hline \multirow[t]{8}{*}{22} & $1 / 16 / 10$ & 4 & 2.34 & 0.05 & 2.01 & 0.11 & 0.86 & 0.05 \\
\hline & & 12 & 2.34 & 0.05 & 2.14 & 0.13 & 0.91 & 0.06 \\
\hline & & 21 & 2.34 & 0.05 & 1.89 & 0.10 & 0.81 & 0.05 \\
\hline & & 76 & 2.36 & 0.05 & 2.58 & 0.13 & 1.09 & 0.06 \\
\hline & & 99 & 2.36 & 0.05 & 2.58 & 0.13 & 1.09 & 0.06 \\
\hline & & 100 & 2.36 & 0.05 & 2.47 & 0.14 & 1.04 & 0.06 \\
\hline & & 200 & 2.40 & 0.05 & 2.70 & 0.14 & 1.13 & 0.06 \\
\hline & & 300 & 2.41 & 0.05 & 2.50 & 0.13 & 1.04 & 0.06 \\
\hline \multirow[t]{10}{*}{24} & $1 / 18 / 10$ & 3 & 2.33 & 0.05 & 1.87 & 0.11 & 0.80 & 0.05 \\
\hline & & 15 & 2.33 & 0.05 & 1.82 & 0.12 & 0.78 & 0.05 \\
\hline & & 30 & 2.33 & 0.05 & 2.01 & 0.13 & 0.86 & 0.06 \\
\hline & & 60 & 2.35 & 0.05 & 2.50 & 0.15 & 1.07 & 0.07 \\
\hline & & 80 & 2.36 & 0.05 & 2.37 & 0.13 & 1.00 & 0.06 \\
\hline & & 100 & 2.36 & 0.05 & 2.73 & 0.16 & 1.16 & 0.07 \\
\hline & & 200 & 2.39 & 0.05 & 2.61 & 0.14 & 1.09 & 0.06 \\
\hline & & 350 & 2.41 & 0.05 & 2.80 & 0.16 & 1.16 & 0.07 \\
\hline & & 476 & 2.41 & 0.05 & 2.70 & 0.14 & 1.12 & 0.06 \\
\hline & & 592 & 2.41 & 0.05 & 2.83 & 0.20 & 1.17 & 0.09 \\
\hline \multirow[t]{10}{*}{27} & $1 / 19 / 10$ & 2 & 2.33 & 0.05 & 1.80 & 0.12 & 0.77 & 0.05 \\
\hline & & 11 & 2.33 & 0.05 & 1.69 & 0.11 & 0.72 & 0.05 \\
\hline & & 21 & 2.33 & 0.05 & 1.60 & 0.10 & 0.68 & 0.05 \\
\hline & & 40 & 2.35 & 0.05 & 1.97 & 0.13 & 0.84 & 0.06 \\
\hline & & 60 & 2.35 & 0.05 & 2.33 & 0.15 & 0.99 & 0.07 \\
\hline & & 80 & 2.36 & 0.05 & 2.01 & 0.13 & 0.85 & 0.06 \\
\hline & & 100 & 2.36 & 0.05 & 2.35 & 0.17 & 1.00 & 0.08 \\
\hline & & 200 & 2.39 & 0.05 & 2.45 & 0.17 & 1.02 & 0.07 \\
\hline & & 400 & 2.41 & 0.05 & 2.40 & 0.13 & 0.99 & 0.06 \\
\hline & & 611 & 2.41 & 0.05 & 2.54 & 0.12 & 1.05 & 0.05 \\
\hline \multirow[t]{7}{*}{29} & $1 / 20 / 10$ & 3 & 2.33 & 0.05 & 1.66 & 0.16 & 0.71 & 0.07 \\
\hline & & 15 & 2.33 & 0.05 & 1.54 & 0.10 & 0.66 & 0.04 \\
\hline & & 22 & 2.33 & 0.05 & 1.84 & 0.19 & 0.79 & 0.08 \\
\hline & & 30 & 2.33 & 0.05 & 2.01 & 0.16 & 0.86 & 0.07 \\
\hline & & 60 & 2.35 & 0.05 & 2.16 & 0.19 & 0.92 & 0.08 \\
\hline & & 75 & 2.35 & 0.05 & 2.28 & 0.16 & 0.97 & 0.07 \\
\hline & & 100 & 2.36 & 0.05 & 2.54 & 0.13 & 1.08 & 0.06 \\
\hline
\end{tabular}




\begin{tabular}{|c|c|c|c|c|c|c|c|c|}
\hline CTD \# & $\begin{array}{c}\text { Date } \\
\mathrm{mm} / \mathrm{dd} / \mathrm{yy}\end{array}$ & $\begin{array}{l}\text { Depth } \\
\text { m }\end{array}$ & $\begin{array}{c}{ }^{238} \mathrm{U}^{-1} \\
\mathrm{dpm} \mathrm{L} \mathrm{L}^{-1}\end{array}$ & err & $\begin{array}{c}\text { Total }{ }^{234} \mathrm{Th} \\
\text { dpm L } \mathrm{L}^{-1}\end{array}$ & err & ${ }^{234} \mathrm{Th} /{ }^{238} \mathrm{U}$ & err \\
\hline & & 150 & 2.37 & 0.05 & 2.33 & 0.16 & 0.98 & 0.07 \\
\hline & & 280 & 2.41 & 0.05 & 2.45 & 0.15 & 1.02 & 0.06 \\
\hline & & 351 & 2.41 & 0.05 & 2.15 & 0.15 & 0.89 & 0.07 \\
\hline \multirow[t]{8}{*}{31} & $1 / 21 / 10$ & 11 & 2.34 & 0.05 & 1.41 & 0.13 & 0.60 & 0.06 \\
\hline & & 25 & 2.34 & 0.05 & 1.31 & 0.08 & 0.56 & 0.04 \\
\hline & & 35 & 2.34 & 0.05 & 1.59 & 0.12 & 0.68 & 0.05 \\
\hline & & 47 & 2.34 & 0.05 & 1.54 & 0.12 & 0.66 & 0.05 \\
\hline & & 59 & 2.35 & 0.05 & 1.78 & 0.12 & 0.76 & 0.05 \\
\hline & & 100 & 2.36 & 0.05 & 2.21 & 0.14 & 0.93 & 0.06 \\
\hline & & 499 & 2.41 & 0.05 & 2.41 & 0.15 & 1.00 & 0.06 \\
\hline & & 999 & 2.41 & 0.05 & 2.30 & 0.15 & 0.95 & 0.06 \\
\hline \multirow[t]{10}{*}{32} & $1 / 21 / 10$ & 3 & 2.33 & 0.05 & 2.01 & 0.11 & 0.86 & 0.05 \\
\hline & & 15 & 2.33 & 0.05 & 1.73 & 0.11 & 0.74 & 0.05 \\
\hline & & 25 & 2.33 & 0.05 & 1.91 & 0.12 & 0.82 & 0.05 \\
\hline & & 50 & 2.34 & 0.05 & 1.92 & 0.13 & 0.82 & 0.06 \\
\hline & & 70 & 2.34 & 0.05 & 1.81 & 0.15 & 0.77 & 0.06 \\
\hline & & 100 & 2.36 & 0.05 & 2.22 & 0.15 & 0.94 & 0.07 \\
\hline & & 150 & 2.37 & 0.05 & 2.17 & 0.16 & 0.92 & 0.07 \\
\hline & & 201 & 2.38 & 0.05 & 2.13 & 0.15 & 0.89 & 0.06 \\
\hline & & 249 & 2.40 & 0.05 & 2.17 & 0.11 & 0.91 & 0.05 \\
\hline & & 350 & 2.41 & 0.05 & 2.34 & 0.11 & 0.97 & 0.05 \\
\hline \multirow[t]{10}{*}{33} & $1 / 21 / 10$ & 3 & 2.30 & 0.05 & 1.81 & 0.17 & 0.79 & 0.08 \\
\hline & & 13 & 2.30 & 0.05 & 1.66 & 0.13 & 0.72 & 0.06 \\
\hline & & 21 & 2.30 & 0.05 & 1.61 & 0.10 & 0.70 & 0.05 \\
\hline & & 25 & 2.30 & 0.05 & 1.67 & 0.14 & 0.72 & 0.06 \\
\hline & & 34 & 2.31 & 0.05 & 1.94 & 0.11 & 0.84 & 0.05 \\
\hline & & 50 & 2.32 & 0.05 & 1.89 & 0.12 & 0.82 & 0.05 \\
\hline & & 70 & 2.33 & 0.05 & 1.99 & 0.10 & 0.85 & 0.05 \\
\hline & & 100 & 2.34 & 0.05 & 1.93 & 0.14 & 0.82 & 0.06 \\
\hline & & 124 & 2.35 & 0.05 & 2.29 & 0.12 & 0.98 & 0.05 \\
\hline & & 149 & 2.35 & 0.05 & 2.19 & 0.13 & 0.93 & 0.06 \\
\hline \multirow[t]{10}{*}{34} & $1 / 22 / 10$ & 2 & 2.33 & 0.05 & 1.79 & 0.12 & 0.77 & 0.05 \\
\hline & & 5 & 2.33 & 0.05 & 1.57 & 0.12 & 0.67 & 0.05 \\
\hline & & 10 & 2.33 & 0.05 & 1.71 & 0.14 & 0.74 & 0.06 \\
\hline & & 18 & 2.33 & 0.05 & 1.60 & 0.11 & 0.69 & 0.05 \\
\hline & & 30 & 2.33 & 0.05 & 1.64 & 0.13 & 0.70 & 0.06 \\
\hline & & 41 & 2.33 & 0.05 & 1.84 & 0.11 & 0.79 & 0.05 \\
\hline & & 50 & 2.34 & 0.05 & 1.94 & 0.13 & 0.83 & 0.06 \\
\hline & & 60 & 2.35 & 0.05 & 1.84 & 0.11 & 0.79 & 0.05 \\
\hline & & 72 & 2.36 & 0.05 & 1.83 & 0.14 & 0.78 & 0.06 \\
\hline & & 95 & 2.36 & 0.05 & 2.16 & 0.12 & 0.91 & 0.06 \\
\hline \multirow[t]{10}{*}{38} & $1 / 24 / 10$ & 2 & 2.33 & 0.05 & 1.63 & 0.09 & 0.70 & 0.04 \\
\hline & & 10 & 2.33 & 0.05 & 1.73 & 0.12 & 0.74 & 0.05 \\
\hline & & 20 & 2.33 & 0.05 & 1.41 & 0.10 & 0.60 & 0.04 \\
\hline & & 42 & 2.33 & 0.05 & 1.83 & 0.11 & 0.79 & 0.05 \\
\hline & & 59 & 2.34 & 0.05 & 2.02 & 0.15 & 0.87 & 0.07 \\
\hline & & 75 & 2.34 & 0.05 & 2.02 & 0.13 & 0.86 & 0.06 \\
\hline & & 99 & 2.36 & 0.05 & 2.25 & 0.14 & 0.95 & 0.06 \\
\hline & & 150 & 2.38 & 0.05 & 2.51 & 0.16 & 1.05 & 0.07 \\
\hline & & 199 & 2.40 & 0.05 & 2.51 & 0.16 & 1.05 & 0.07 \\
\hline & & 299 & 2.41 & 0.05 & 2.67 & 0.18 & 1.11 & 0.08 \\
\hline
\end{tabular}




\begin{tabular}{|c|c|c|c|c|c|c|c|c|}
\hline CTD \# & $\begin{array}{c}\text { Date } \\
\mathrm{mm} / \mathrm{dd} / \mathrm{yy}\end{array}$ & $\begin{array}{c}\text { Depth } \\
\mathrm{m}\end{array}$ & $\begin{array}{c}{ }^{238} \mathrm{U} \\
\mathrm{dpm} \mathrm{L} \mathrm{L}^{-1}\end{array}$ & err & $\begin{array}{c}\text { Total }^{234} \mathrm{Th} \\
\mathrm{dpm} \mathrm{L} \mathrm{L}^{-1}\end{array}$ & err & ${ }^{234} \mathrm{Th} /{ }^{238} \mathrm{U}$ & err \\
\hline \multirow[t]{12}{*}{40} & $1 / 26 / 10$ & 2 & 2.28 & 0.05 & 1.59 & 0.10 & 0.70 & 0.05 \\
\hline & & 5 & 2.29 & 0.05 & 2.05 & 0.15 & 0.90 & 0.07 \\
\hline & & 9 & 2.29 & 0.05 & 1.81 & 0.13 & 0.79 & 0.06 \\
\hline & & 20 & 2.30 & 0.05 & 2.04 & 0.11 & 0.89 & 0.05 \\
\hline & & 34 & 2.32 & 0.05 & 2.05 & 0.13 & 0.89 & 0.06 \\
\hline & & 50 & 2.33 & 0.05 & 2.49 & 0.15 & 1.07 & 0.07 \\
\hline & & 75 & 2.34 & 0.05 & 2.39 & 0.16 & 1.02 & 0.07 \\
\hline & & 99 & 2.34 & 0.05 & 2.55 & 0.15 & 1.09 & 0.07 \\
\hline & & 199 & 2.37 & 0.05 & 2.39 & 0.16 & 1.01 & 0.07 \\
\hline & & 300 & 2.41 & 0.05 & 2.77 & 0.19 & 1.15 & 0.08 \\
\hline & & 449 & 2.41 & 0.05 & 2.62 & 0.18 & 1.08 & 0.08 \\
\hline & & 579 & 2.41 & 0.05 & 3.02 & 0.16 & 1.25 & 0.07 \\
\hline \multirow[t]{9}{*}{43} & $1 / 27 / 10$ & 2 & 2.26 & 0.05 & 1.56 & 0.08 & 0.69 & 0.04 \\
\hline & & 4 & 2.25 & 0.05 & 1.69 & 0.10 & 0.75 & 0.05 \\
\hline & & 8 & 2.27 & 0.05 & 1.91 & 0.13 & 0.84 & 0.06 \\
\hline & & 12 & 2.29 & 0.05 & 1.87 & 0.11 & 0.82 & 0.05 \\
\hline & & 50 & 2.32 & 0.05 & 2.00 & 0.11 & 0.86 & 0.05 \\
\hline & & 74 & 2.33 & 0.05 & 2.17 & 0.13 & 0.93 & 0.06 \\
\hline & & 100 & 2.34 & 0.05 & 2.29 & 0.15 & 0.98 & 0.07 \\
\hline & & 150 & 2.36 & 0.05 & 2.29 & 0.16 & 0.97 & 0.07 \\
\hline & & 181 & 2.36 & 0.05 & 2.30 & 0.14 & 0.97 & 0.06 \\
\hline \multirow[t]{16}{*}{47} & $1 / 31 / 10$ & 2 & 2.34 & 0.05 & 1.48 & 0.08 & 0.63 & 0.04 \\
\hline & & 10 & 2.34 & 0.05 & 1.44 & 0.09 & 0.61 & 0.04 \\
\hline & & 24 & 2.35 & 0.05 & 1.60 & 0.12 & 0.68 & 0.05 \\
\hline & & 40 & 2.34 & 0.05 & 1.48 & 0.14 & 0.63 & 0.06 \\
\hline & & 50 & 2.35 & 0.05 & 1.54 & 0.09 & 0.65 & 0.04 \\
\hline & & 59 & 2.35 & 0.05 & 1.74 & 0.10 & 0.74 & 0.05 \\
\hline & & 80 & 2.36 & 0.05 & 1.94 & 0.13 & 0.82 & 0.06 \\
\hline & & 100 & 2.37 & 0.05 & 2.19 & 0.13 & 0.93 & 0.06 \\
\hline & & 125 & 2.38 & 0.05 & 2.13 & 0.13 & 0.90 & 0.06 \\
\hline & & 151 & 2.39 & 0.05 & 2.26 & 0.11 & 0.95 & 0.05 \\
\hline & & 175 & 2.39 & 0.05 & 2.30 & 0.14 & 0.96 & 0.06 \\
\hline & & 200 & 2.40 & 0.05 & 2.19 & 0.12 & 0.91 & 0.05 \\
\hline & & 225 & 2.40 & 0.05 & 2.10 & 0.11 & 0.88 & 0.05 \\
\hline & & 249 & 2.40 & 0.05 & 2.07 & 0.12 & 0.86 & 0.05 \\
\hline & & 300 & 2.41 & 0.05 & 2.17 & 0.11 & 0.90 & 0.05 \\
\hline & & 328 & 2.41 & 0.05 & 2.16 & 0.14 & 0.89 & 0.06 \\
\hline \multicolumn{9}{|c|}{ Autumn cruise } \\
\hline \multirow[t]{10}{*}{2} & $3 / 21 / 10$ & 11 & 2.35 & 0.05 & 2.03 & 0.05 & 0.86 & 0.03 \\
\hline & & 24 & 2.35 & 0.05 & 2.07 & 0.04 & 0.88 & 0.02 \\
\hline & & 52 & 2.35 & 0.05 & 2.29 & 0.04 & 0.97 & 0.03 \\
\hline & & 59 & 2.35 & 0.05 & 2.01 & 0.07 & 0.85 & 0.03 \\
\hline & & 75 & 2.36 & 0.05 & 2.25 & 0.04 & 0.96 & 0.03 \\
\hline & & 103 & 2.38 & 0.05 & 2.60 & 0.05 & 1.09 & 0.03 \\
\hline & & 125 & 2.38 & 0.05 & 2.13 & 0.06 & 0.90 & 0.03 \\
\hline & & 153 & 2.39 & 0.05 & 2.63 & 0.05 & 1.10 & 0.03 \\
\hline & & 175 & 2.39 & 0.05 & 2.35 & 0.04 & 0.98 & 0.03 \\
\hline & & 280 & 2.41 & 0.05 & 2.52 & 0.05 & 1.05 & 0.03 \\
\hline \multirow[t]{7}{*}{4} & $3 / 23 / 10$ & 12 & 2.35 & 0.05 & 1.94 & 0.04 & 0.83 & 0.03 \\
\hline & & 27 & 2.35 & 0.05 & 2.21 & 0.04 & 0.94 & 0.03 \\
\hline & & 43 & 2.35 & 0.05 & 2.25 & 0.04 & 0.96 & 0.03 \\
\hline & & 51 & 2.35 & 0.05 & 2.52 & 0.05 & 1.07 & 0.03 \\
\hline & & 62 & 2.35 & 0.05 & 2.48 & 0.05 & 1.05 & 0.03 \\
\hline & & 71 & 2.35 & 0.05 & 2.39 & 0.04 & 1.02 & 0.03 \\
\hline & & 82 & 2.36 & 0.05 & 2.43 & 0.05 & 1.03 & 0.03 \\
\hline
\end{tabular}




\begin{tabular}{|c|c|c|c|c|c|c|c|c|}
\hline CTD \# & $\begin{array}{c}\text { Date } \\
\mathrm{mm} / \mathrm{dd} / \mathrm{yy}\end{array}$ & $\begin{array}{c}\text { Depth } \\
\mathrm{m}\end{array}$ & $\begin{array}{c}{ }^{238} \mathrm{U} \\
\mathrm{dpm} \mathrm{L} \mathrm{L}^{-1}\end{array}$ & err & $\begin{array}{c}\text { Total }^{234} \mathrm{Th} \\
\mathrm{dpm} \mathrm{L} \mathrm{L}^{-1}\end{array}$ & err & ${ }^{234} \mathrm{Th} /{ }^{238} \mathrm{U}$ & err \\
\hline & & 91 & 2.37 & 0.05 & 2.23 & 0.04 & 0.94 & 0.03 \\
\hline & & 99 & 2.37 & 0.05 & 2.40 & 0.05 & 1.01 & 0.03 \\
\hline & & 110 & 2.37 & 0.05 & 2.64 & 0.05 & 1.11 & 0.03 \\
\hline & & 129 & 2.38 & 0.05 & 2.56 & 0.05 & 1.08 & 0.03 \\
\hline & & 152 & 2.39 & 0.05 & 2.52 & 0.04 & 1.05 & 0.03 \\
\hline & & 178 & 2.39 & 0.05 & 2.76 & 0.05 & 1.15 & 0.03 \\
\hline & & 201 & 2.40 & 0.05 & 2.67 & 0.05 & 1.11 & 0.03 \\
\hline & & 277 & 2.41 & 0.05 & 2.57 & 0.05 & 1.07 & 0.03 \\
\hline \multirow[t]{10}{*}{6} & $3 / 24 / 10$ & 10 & 2.35 & 0.05 & 2.26 & 0.04 & 0.96 & 0.03 \\
\hline & & 25 & 2.35 & 0.05 & 2.23 & 0.04 & 0.95 & 0.03 \\
\hline & & 51 & 2.35 & 0.05 & 2.33 & 0.05 & 0.99 & 0.03 \\
\hline & & 76 & 2.35 & 0.05 & 2.30 & 0.05 & 0.98 & 0.03 \\
\hline & & 101 & 2.36 & 0.05 & 2.25 & 0.06 & 0.95 & 0.03 \\
\hline & & 127 & 2.38 & 0.05 & 2.68 & 0.05 & 1.13 & 0.03 \\
\hline & & 152 & 2.38 & 0.05 & 2.42 & 0.05 & 1.02 & 0.03 \\
\hline & & 177 & 2.39 & 0.05 & 2.68 & 0.07 & 1.12 & 0.04 \\
\hline & & 229 & 2.40 & 0.05 & 2.55 & 0.04 & 1.06 & 0.03 \\
\hline & & 278 & 2.41 & 0.05 & 2.68 & 0.05 & 1.11 & 0.03 \\
\hline \multirow[t]{15}{*}{7} & $3 / 26 / 10$ & 10 & 2.29 & 0.05 & 1.89 & 0.04 & 0.83 & 0.02 \\
\hline & & 25 & 2.29 & 0.05 & 1.77 & 0.03 & 0.77 & 0.02 \\
\hline & & 51 & 2.31 & 0.05 & 1.92 & 0.03 & 0.83 & 0.02 \\
\hline & & 76 & 2.33 & 0.05 & 2.37 & 0.04 & 1.02 & 0.03 \\
\hline & & 100 & 2.34 & 0.05 & 2.38 & 0.04 & 1.02 & 0.03 \\
\hline & & 118 & 2.34 & 0.05 & 2.51 & 0.04 & 1.07 & 0.03 \\
\hline & & 152 & 2.35 & 0.05 & 2.62 & 0.06 & 1.12 & 0.03 \\
\hline & & 176 & 2.36 & 0.05 & 2.71 & 0.05 & 1.15 & 0.03 \\
\hline & & 202 & 2.37 & 0.05 & 2.50 & 0.05 & 1.06 & 0.03 \\
\hline & & 303 & 2.40 & 0.05 & 2.55 & 0.04 & 1.06 & 0.03 \\
\hline & & 404 & 2.41 & 0.05 & 2.51 & 0.04 & 1.04 & 0.03 \\
\hline & & 505 & 2.41 & 0.05 & 2.60 & 0.05 & 1.08 & 0.03 \\
\hline & & 556 & 2.41 & 0.05 & 2.67 & 0.05 & 1.11 & 0.03 \\
\hline & & 586 & 2.41 & 0.05 & 2.50 & 0.04 & 1.04 & 0.03 \\
\hline & & 615 & 2.41 & 0.05 & 2.28 & 0.04 & 0.94 & 0.02 \\
\hline \multirow[t]{15}{*}{9} & $3 / 29 / 10$ & 5 & 2.28 & 0.05 & 1.64 & 0.05 & 0.72 & 0.03 \\
\hline & & 12 & 2.28 & 0.05 & 1.69 & 0.05 & 0.74 & 0.03 \\
\hline & & 30 & 2.31 & 0.05 & 1.78 & 0.04 & 0.77 & 0.02 \\
\hline & & 61 & 2.33 & 0.05 & 2.24 & 0.05 & 0.96 & 0.03 \\
\hline & & 76 & 2.34 & 0.05 & 2.33 & 0.05 & 1.00 & 0.03 \\
\hline & & 91 & 2.34 & 0.05 & 2.26 & 0.05 & 0.96 & 0.03 \\
\hline & & 127 & 2.35 & 0.05 & 2.33 & 0.04 & 0.99 & 0.03 \\
\hline & & 152 & 2.36 & 0.05 & 2.29 & 0.05 & 0.97 & 0.03 \\
\hline & & 176 & 2.36 & 0.05 & 2.22 & 0.04 & 0.94 & 0.03 \\
\hline & & 202 & 2.37 & 0.05 & 2.27 & 0.04 & 0.96 & 0.03 \\
\hline & & 606 & 2.41 & 0.05 & 2.30 & 0.04 & 0.95 & 0.03 \\
\hline & & 605 & 2.41 & 0.05 & 2.49 & 0.05 & 1.03 & 0.03 \\
\hline & & 605 & 2.41 & 0.05 & 2.43 & 0.04 & 1.01 & 0.03 \\
\hline & & 605 & 2.41 & 0.05 & 2.33 & 0.05 & 0.97 & 0.03 \\
\hline & & 605 & 2.41 & 0.05 & 2.50 & 0.04 & 1.04 & 0.03 \\
\hline \multirow[t]{5}{*}{11} & $4 / 1 / 10$ & 10 & 2.33 & 0.05 & 1.93 & 0.04 & 0.83 & 0.02 \\
\hline & & 20 & 2.33 & 0.05 & 1.84 & 0.03 & 0.79 & 0.02 \\
\hline & & 40 & 2.34 & 0.05 & 1.89 & 0.08 & 0.81 & 0.04 \\
\hline & & 60 & 2.35 & 0.05 & 2.34 & 0.04 & 0.99 & 0.03 \\
\hline & & 81 & 2.36 & 0.05 & 2.46 & 0.05 & 1.04 & 0.03 \\
\hline
\end{tabular}




\begin{tabular}{|c|c|c|c|c|c|c|c|c|}
\hline CTD \# & $\begin{array}{c}\text { Date } \\
\mathrm{mm} / \mathrm{dd} / \mathrm{yy}\end{array}$ & $\begin{array}{c}\text { Depth } \\
\mathrm{m}\end{array}$ & $\begin{array}{c}{ }^{238} \mathrm{U} \\
\mathrm{dpm} \mathrm{L} \mathrm{L}^{-1}\end{array}$ & err & $\begin{array}{c}\text { Total }^{234} \mathrm{Th} \\
\mathrm{dpm} \mathrm{L} \mathrm{L}^{-1}\end{array}$ & err & ${ }^{234} \mathrm{Th} /{ }^{238} \mathrm{U}$ & err \\
\hline & & 105 & 2.36 & 0.05 & 2.50 & 0.04 & 1.06 & 0.03 \\
\hline & & 125 & 2.37 & 0.05 & 2.29 & 0.04 & 0.97 & 0.03 \\
\hline & & 151 & 2.38 & 0.05 & 2.55 & 0.04 & 1.07 & 0.03 \\
\hline & & 203 & 2.39 & 0.05 & 2.39 & 0.04 & 1.00 & 0.03 \\
\hline & & 252 & 2.40 & 0.05 & 2.52 & 0.05 & 1.05 & 0.03 \\
\hline \multirow[t]{10}{*}{12} & $4 / 1 / 10$ & 10 & 2.34 & 0.05 & 1.74 & 0.04 & 0.75 & 0.02 \\
\hline & & 20 & 2.34 & 0.05 & 1.70 & 0.04 & 0.73 & 0.02 \\
\hline & & 39 & 2.34 & 0.05 & 1.89 & 0.04 & 0.81 & 0.02 \\
\hline & & 60 & 2.35 & 0.05 & 2.19 & 0.04 & 0.93 & 0.03 \\
\hline & & 81 & 2.36 & 0.05 & 2.44 & 0.05 & 1.03 & 0.03 \\
\hline & & 101 & 2.36 & 0.05 & 2.46 & 0.05 & 1.04 & 0.03 \\
\hline & & 126 & 2.37 & 0.05 & 2.46 & 0.05 & 1.04 & 0.03 \\
\hline & & 151 & 2.38 & 0.05 & 2.51 & 0.05 & 1.06 & 0.03 \\
\hline & & 202 & 2.40 & 0.05 & 2.36 & 0.04 & 0.98 & 0.03 \\
\hline & & 254 & 2.40 & 0.05 & 2.55 & 0.05 & 1.06 & 0.03 \\
\hline \multirow[t]{10}{*}{13} & $4 / 2 / 10$ & 10 & 2.34 & 0.05 & 1.92 & 0.04 & 0.82 & 0.02 \\
\hline & & 20 & 2.34 & 0.05 & 2.03 & 0.04 & 0.87 & 0.03 \\
\hline & & 41 & 2.34 & 0.05 & 2.16 & 0.05 & 0.92 & 0.03 \\
\hline & & 60 & 2.35 & 0.05 & 2.18 & 0.04 & 0.93 & 0.03 \\
\hline & & 81 & 2.36 & 0.05 & 2.63 & 0.05 & 1.11 & 0.03 \\
\hline & & 101 & 2.36 & 0.05 & 2.64 & 0.05 & 1.12 & 0.03 \\
\hline & & 151 & 2.37 & 0.05 & 2.36 & 0.05 & 0.99 & 0.03 \\
\hline & & 202 & 2.39 & 0.05 & 2.60 & 0.05 & 1.08 & 0.03 \\
\hline & & 279 & 2.41 & 0.05 & 2.42 & 0.05 & 1.01 & 0.03 \\
\hline & & 328 & 2.41 & 0.05 & 2.50 & 0.05 & 1.04 & 0.03 \\
\hline \multirow[t]{10}{*}{14} & $4 / 2 / 10$ & 10 & 2.30 & 0.05 & 1.58 & 0.04 & 0.69 & 0.02 \\
\hline & & 20 & 2.32 & 0.05 & 1.79 & 0.04 & 0.77 & 0.02 \\
\hline & & 40 & 2.33 & 0.05 & 2.00 & 0.04 & 0.86 & 0.03 \\
\hline & & 60 & 2.35 & 0.05 & 2.32 & 0.05 & 0.99 & 0.03 \\
\hline & & 82 & 2.36 & 0.05 & 2.46 & 0.05 & 1.04 & 0.03 \\
\hline & & 96 & 2.36 & 0.05 & 2.31 & 0.05 & 0.98 & 0.03 \\
\hline & & 126 & 2.37 & 0.05 & 2.33 & 0.05 & 0.98 & 0.03 \\
\hline & & 151 & 2.38 & 0.05 & 2.23 & 0.05 & 0.94 & 0.03 \\
\hline & & 202 & 2.40 & 0.05 & 2.36 & 0.05 & 0.99 & 0.03 \\
\hline & & 252 & 2.41 & 0.05 & 2.44 & 0.05 & 1.01 & 0.03 \\
\hline \multirow[t]{10}{*}{15} & $4 / 2 / 10$ & 5 & 2.32 & 0.05 & 1.76 & 0.04 & 0.76 & 0.02 \\
\hline & & 20 & 2.32 & 0.05 & 1.67 & 0.04 & 0.72 & 0.02 \\
\hline & & 41 & 2.33 & 0.05 & 1.83 & 0.04 & 0.78 & 0.02 \\
\hline & & 63 & 2.34 & 0.05 & 2.03 & 0.05 & 0.87 & 0.03 \\
\hline & & 82 & 2.36 & 0.05 & 2.28 & 0.05 & 0.97 & 0.03 \\
\hline & & 96 & 2.36 & 0.05 & 2.21 & 0.04 & 0.94 & 0.03 \\
\hline & & 126 & 2.37 & 0.05 & 2.37 & 0.05 & 1.00 & 0.03 \\
\hline & & 152 & 2.39 & 0.05 & 2.27 & 0.05 & 0.95 & 0.03 \\
\hline & & 227 & 2.40 & 0.05 & 2.57 & 0.05 & 1.07 & 0.03 \\
\hline & & 292 & 2.41 & 0.05 & 2.50 & 0.05 & 1.04 & 0.03 \\
\hline \multirow[t]{7}{*}{16} & $4 / 2 / 10$ & 10 & 2.32 & 0.05 & 1.87 & 0.04 & 0.80 & 0.02 \\
\hline & & 25 & 2.32 & 0.05 & 1.78 & 0.04 & 0.77 & 0.02 \\
\hline & & 51 & 2.32 & 0.05 & 1.63 & 0.04 & 0.70 & 0.02 \\
\hline & & 67 & 2.34 & 0.05 & 2.12 & 0.07 & 0.91 & 0.03 \\
\hline & & 81 & 2.35 & 0.05 & 2.38 & 0.05 & 1.01 & 0.03 \\
\hline & & 101 & 2.36 & 0.05 & 2.17 & 0.05 & 0.92 & 0.03 \\
\hline & & 152 & 2.37 & 0.05 & 2.33 & 0.05 & 0.98 & 0.03 \\
\hline
\end{tabular}




\begin{tabular}{|c|c|c|c|c|c|c|c|c|}
\hline CTD \# & $\begin{array}{c}\text { Date } \\
\mathrm{mm} / \mathrm{dd} / \mathrm{yy}\end{array}$ & $\begin{array}{c}\text { Depth } \\
\mathrm{m}\end{array}$ & $\begin{array}{c}{ }^{238} \mathrm{U} \\
\mathrm{dpm} \mathrm{L} \mathrm{L}^{-1}\end{array}$ & err & $\begin{array}{c}\text { Total }^{234} \mathrm{Th} \\
\mathrm{dpm} \mathrm{L} \mathrm{L}^{-1}\end{array}$ & err & ${ }^{234} \mathrm{Th} /{ }^{238} \mathrm{U}$ & err \\
\hline & & 253 & 2.40 & 0.05 & 2.33 & 0.05 & 0.97 & 0.03 \\
\hline & & 354 & 2.41 & 0.05 & 2.49 & 0.05 & 1.03 & 0.03 \\
\hline & & 448 & 2.41 & 0.05 & 2.41 & 0.05 & 1.00 & 0.03 \\
\hline \multirow[t]{10}{*}{18} & $4 / 7 / 10$ & 5 & 2.33 & 0.05 & 2.03 & 0.04 & 0.87 & 0.03 \\
\hline & & 25 & 2.33 & 0.05 & 1.90 & 0.04 & 0.81 & 0.02 \\
\hline & & 50 & 2.33 & 0.05 & 1.96 & 0.04 & 0.84 & 0.02 \\
\hline & & 81 & 2.35 & 0.05 & 2.39 & 0.05 & 1.02 & 0.03 \\
\hline & & 101 & 2.36 & 0.05 & 2.41 & 0.04 & 1.02 & 0.03 \\
\hline & & 127 & 2.38 & 0.05 & 2.52 & 0.05 & 1.06 & 0.03 \\
\hline & & 153 & 2.39 & 0.05 & 2.60 & 0.05 & 1.09 & 0.03 \\
\hline & & 178 & 2.39 & 0.05 & 2.33 & 0.05 & 0.97 & 0.03 \\
\hline & & 228 & 2.40 & 0.05 & 2.52 & 0.04 & 1.05 & 0.03 \\
\hline & & 280 & 2.41 & 0.05 & 2.30 & 0.04 & 0.95 & 0.03 \\
\hline \multirow[t]{14}{*}{20} & $4 / 9 / 10$ & 5 & 2.32 & 0.05 & 2.05 & 0.04 & 0.88 & 0.02 \\
\hline & & 20 & 2.32 & 0.05 & 2.14 & 0.04 & 0.92 & 0.03 \\
\hline & & 40 & 2.33 & 0.05 & 2.02 & 0.04 & 0.87 & 0.02 \\
\hline & & 50 & 2.33 & 0.05 & 1.93 & 0.04 & 0.83 & 0.02 \\
\hline & & 60 & 2.34 & 0.05 & 2.18 & 0.04 & 0.93 & 0.03 \\
\hline & & 71 & 2.35 & 0.05 & 2.33 & 0.04 & 0.99 & 0.03 \\
\hline & & 81 & 2.36 & 0.05 & 2.22 & 0.04 & 0.94 & 0.03 \\
\hline & & 91 & 2.36 & 0.05 & 2.28 & 0.05 & 0.96 & 0.03 \\
\hline & & 101 & 2.37 & 0.05 & 2.43 & 0.04 & 1.03 & 0.03 \\
\hline & & 127 & 2.37 & 0.05 & 2.34 & 0.04 & 0.98 & 0.03 \\
\hline & & 152 & 2.39 & 0.05 & 2.67 & 0.05 & 1.12 & 0.03 \\
\hline & & 177 & 2.40 & 0.05 & 2.48 & 0.04 & 1.04 & 0.03 \\
\hline & & 228 & 2.41 & 0.05 & 2.70 & 0.05 & 1.12 & 0.03 \\
\hline & & 278 & 2.41 & 0.05 & 2.55 & 0.05 & 1.06 & 0.03 \\
\hline \multirow[t]{10}{*}{21} & $4 / 10 / 10$ & 10 & 2.32 & 0.05 & 2.24 & 0.04 & 0.96 & 0.03 \\
\hline & & 20 & 2.32 & 0.05 & 2.05 & 0.04 & 0.88 & 0.03 \\
\hline & & 41 & 2.33 & 0.05 & 1.98 & 0.04 & 0.85 & 0.02 \\
\hline & & 61 & 2.34 & 0.05 & 2.00 & 0.04 & 0.86 & 0.02 \\
\hline & & 76 & 2.35 & 0.05 & 2.20 & 0.04 & 0.94 & 0.03 \\
\hline & & 100 & 2.37 & 0.05 & 2.63 & 0.05 & 1.11 & 0.03 \\
\hline & & 126 & 2.38 & 0.05 & 2.44 & 0.05 & 1.03 & 0.03 \\
\hline & & 177 & 2.40 & 0.05 & 2.55 & 0.05 & 1.06 & 0.03 \\
\hline & & 227 & 2.41 & 0.05 & 2.40 & 0.05 & 1.00 & 0.03 \\
\hline & & 279 & 2.41 & 0.05 & 2.58 & 0.05 & 1.07 & 0.03 \\
\hline \multirow[t]{10}{*}{27} & $4 / 19 / 10$ & 5 & 2.34 & 0.05 & 2.27 & 0.05 & 0.97 & 0.03 \\
\hline & & 25 & 2.34 & 0.05 & 2.22 & 0.04 & 0.95 & 0.03 \\
\hline & & 51 & 2.34 & 0.05 & 2.03 & 0.07 & 0.87 & 0.03 \\
\hline & & 82 & 2.35 & 0.05 & 2.34 & 0.04 & 1.00 & 0.03 \\
\hline & & 101 & 2.37 & 0.05 & 2.34 & 0.05 & 0.99 & 0.03 \\
\hline & & 120 & 2.38 & 0.05 & 2.19 & 0.05 & 0.92 & 0.03 \\
\hline & & 153 & 2.39 & 0.05 & 2.16 & 0.05 & 0.90 & 0.03 \\
\hline & & 203 & 2.40 & 0.05 & 2.44 & 0.05 & 1.02 & 0.03 \\
\hline & & 253 & 2.40 & 0.05 & 2.15 & 0.04 & 0.89 & 0.03 \\
\hline & & 303 & 2.41 & 0.05 & 2.32 & 0.05 & 0.96 & 0.03 \\
\hline \multirow[t]{5}{*}{29} & $4 / 21 / 10$ & 6 & 2.34 & 0.05 & 2.46 & 0.05 & 1.05 & 0.03 \\
\hline & & 10 & 2.34 & 0.05 & 2.05 & 0.04 & 0.87 & 0.03 \\
\hline & & 20 & 2.34 & 0.05 & 2.15 & 0.05 & 0.92 & 0.03 \\
\hline & & 40 & 2.34 & 0.05 & 2.19 & 0.04 & 0.93 & 0.03 \\
\hline & & 51 & 2.34 & 0.05 & 1.90 & 0.04 & 0.81 & 0.03 \\
\hline
\end{tabular}




\begin{tabular}{|c|c|c|c|c|c|c|c|c|}
\hline CTD \# & $\begin{array}{c}\text { Date } \\
\mathrm{mm} / \mathrm{dd} / \mathrm{yy}\end{array}$ & $\begin{array}{c}\text { Depth } \\
\text { m }\end{array}$ & $\begin{array}{c}{ }^{238} \mathrm{U}^{-1} \\
\mathrm{dpm} \mathrm{L} \mathrm{L}^{-1}\end{array}$ & err & $\begin{array}{c}\text { Total }{ }^{234} \mathrm{Th} \\
\text { dpm L L }\end{array}$ & err & ${ }^{234} \mathrm{Th} /{ }^{238} \mathrm{U}$ & err \\
\hline & & 61 & 2.35 & 0.05 & 2.42 & 0.05 & 1.03 & 0.03 \\
\hline & & 72 & 2.35 & 0.05 & 2.34 & 0.05 & 1.00 & 0.03 \\
\hline & & 81 & 2.36 & 0.05 & 2.43 & 0.05 & 1.03 & 0.03 \\
\hline & & 91 & 2.37 & 0.05 & 2.29 & 0.05 & 0.96 & 0.03 \\
\hline & & 101 & 2.38 & 0.05 & 2.25 & 0.05 & 0.95 & 0.03 \\
\hline & & 112 & 2.38 & 0.05 & 2.44 & 0.05 & 1.02 & 0.03 \\
\hline & & 121 & 2.38 & 0.05 & 2.22 & 0.05 & 0.93 & 0.03 \\
\hline & & 131 & 2.39 & 0.05 & 2.29 & 0.05 & 0.96 & 0.03 \\
\hline & & 142 & 2.39 & 0.05 & 2.42 & 0.05 & 1.01 & 0.03 \\
\hline & & 153 & 2.39 & 0.05 & 2.52 & 0.05 & 1.05 & 0.03 \\
\hline & & 203 & 2.40 & 0.05 & 2.45 & 0.06 & 1.02 & 0.03 \\
\hline & & 252 & 2.41 & 0.05 & 2.43 & 0.05 & 1.01 & 0.03 \\
\hline & & 303 & 2.41 & 0.05 & 2.45 & 0.06 & 1.02 & 0.03 \\
\hline & & 343 & 2.41 & 0.05 & 2.40 & 0.05 & 1.00 & 0.03 \\
\hline
\end{tabular}


Table 2

Depths of the mixed layer (ML), euphotic zone (EZ), and primary production zone (PPZ) and fluxes of ${ }^{234} \mathrm{Th}$ at the PPZ. C fluxes at the PPZ were calculated using $\mathrm{C} /{ }^{234} \mathrm{Th}$ ratios from in situ pumps. Along shelf positions are denoted by $\mathrm{N}$ (North), C (Central), and S (South). Across shelf positions are denoted by C (Coastal), Sh (Shelf), and $\mathrm{Sl}$ (Slope). Also indicated is the process station number (see Figure 1).

\begin{tabular}{|c|c|c|c|c|c|c|c|c|c|c|c|c|}
\hline$\#$ & Date & Lat. & Long & ML & EZ & PPZ & $\begin{array}{c}{ }^{234} \text { Th Flux } \\
\text { @PPZ }\end{array}$ & err & $\mathrm{C} / \mathrm{Th}$ & $\begin{array}{l}\text { C Flux } \\
\text { (a)PPZ }\end{array}$ & $\begin{array}{l}\text { Along } \\
\text { Shelf }\end{array}$ & $\begin{array}{c}\text { Across } \\
\text { Shelf }\end{array}$ \\
\hline & & ${ }^{\circ} \mathrm{S}$ & ${ }^{\circ} \mathrm{W}$ & $\mathrm{m}$ & $\mathrm{m}$ & $\mathrm{m}$ & $\mathrm{dpm} \mathrm{m} \mathrm{m}^{-2} \mathrm{~d}^{-1}$ & & $\begin{array}{l}\mu \mathrm{mol} \\
\mathrm{dpm}^{-1}\end{array}$ & $\begin{array}{l}\text { mmol } \\
\mathrm{m}^{-2} \mathrm{~d}^{-1}\end{array}$ & $\mathrm{~N} / \mathrm{C} / \mathrm{S}$ & $\mathrm{C} / \mathrm{Sh} / \mathrm{Sl}$ \\
\hline
\end{tabular}

\begin{tabular}{|c|c|c|c|c|c|c|c|c|c|c|c|c|c|}
\hline \multicolumn{14}{|c|}{ Summer cruise } \\
\hline 1 & $1 / 5 / 10$ & 64.93 & 64.40 & 25 & 42 & 63 & 1111 & 62 & 7.1 & 7.9 & $\mathrm{~N}$ & $\mathrm{C}$ & \\
\hline 2 & $1 / 6 / 10$ & 64.58 & 65.34 & 76 & 23 & 79 & 1353 & 76 & 6.3 & 8.6 & $\mathrm{~N}$ & $\mathrm{Sh}$ & \\
\hline 3 & $1 / 7 / 10$ & 63.97 & 66.86 & 46 & - & 134 & 1479 & 302 & 4.3 & 6.4 & $\mathrm{~N}$ & $\mathrm{~S} 1$ & \\
\hline 4 & $1 / 7 / 10$ & 64.61 & 68.29 & 48 & - & 122 & 1676 & 141 & 4.9 & 8.2 & $\mathrm{~N}$ & $\mathrm{~S} 1$ & \\
\hline 7 & $1 / 9 / 10$ & 64.50 & 66.20 & 33 & 45 & 79 & 1548 & 80 & 6.3 & 9.8 & $\mathrm{~N}$ & $\mathrm{Sh}$ & 1 \\
\hline 9 & $1 / 10 / 10$ & 64.47 & 66.19 & 38 & 58 & 110 & 1767 & 97 & 5.5 & 9.7 & $\mathrm{~N}$ & $\mathrm{Sh}$ & 1 \\
\hline 10 & $1 / 11 / 10$ & 65.23 & 66.77 & 28 & 46 & 62 & 1380 & 61 & 7.2 & 9.9 & $\mathrm{~N}$ & $\mathrm{Sh}$ & \\
\hline 11 & $1 / 11 / 10$ & 66.26 & 67.34 & 37 & 57 & 56 & 1144 & 82 & 7.6 & 8.7 & $\mathrm{~N}$ & $\mathrm{C}$ & \\
\hline 12 & $1 / 12 / 10$ & 65.88 & 68.28 & 44 & 38 & 63 & 1562 & 67 & 7.1 & 11.2 & $\mathrm{~N}$ & $\mathrm{Sh}$ & \\
\hline 13 & $1 / 12 / 10$ & 65.50 & 69.20 & 46 & 60 & 67 & 1544 & 74 & 6.9 & 10.7 & $\mathrm{~N}$ & $\mathrm{~S} 1$ & \\
\hline 14 & $1 / 12 / 10$ & 66.12 & 70.77 & 44 & 61 & 97 & 2042 & 145 & 5.9 & 12.0 & $\mathrm{~N}$ & $\mathrm{~S} 1$ & \\
\hline 15 & $1 / 13 / 10$ & 66.37 & 70.17 & 39 & - & 102 & 1749 & 137 & 5.9 & 10.3 & $\mathrm{~N}$ & $\mathrm{Sh}$ & \\
\hline 17 & $1 / 13 / 10$ & 66.89 & 68.92 & 47 & 37 & 105 & 1741 & 161 & 5.7 & 9.9 & $\mathrm{~N}$ & $\mathrm{C}$ & \\
\hline 18 & $1 / 14 / 10$ & 67.51 & 70.59 & 19 & 66 & 58 & 1101 & 79 & 6.1 & 6.7 & $\mathrm{C}$ & $\mathrm{C}$ & \\
\hline 19 & $1 / 14 / 10$ & 67.10 & 71.55 & 49 & 39 & 85 & 1491 & 123 & 5.6 & 8.4 & $\mathrm{C}$ & $\mathrm{Sh}$ & \\
\hline 20 & $1 / 16 / 10$ & 66.73 & 72.52 & 59 & - & 82 & 1894 & 109 & 6.2 & 11.7 & $\mathrm{~N}$ & $\mathrm{~S} 1$ & \\
\hline 21 & $1 / 16 / 10$ & 67.70 & 73.27 & 40 & 59 & 108 & 947 & 188 & 5.6 & 5.3 & $\mathrm{C}$ & $\mathrm{Sh}$ & \\
\hline 22 & $1 / 16 / 10$ & 68.11 & 72.34 & 42 & 40 & 49 & 535 & 113 & 6.3 & 3.4 & $\mathrm{C}$ & $\mathrm{C}$ & \\
\hline 24 & $1 / 18 / 10$ & 68.17 & 70.00 & 38 & 33 & 49 & 510 & 114 & 6.3 & 3.2 & $\mathrm{C}$ & $\mathrm{C}$ & 2 \\
\hline 27 & $1 / 19 / 10$ & 68.18 & 69.97 & 6 & 27 & 40 & 682 & 80 & 6.6 & 4.5 & $\mathrm{C}$ & $\mathrm{C}$ & 2 \\
\hline 29 & $1 / 20 / 10$ & 68.14 & 70.22 & 16 & 19 & 45 & 675 & 115 & 6.4 & 4.3 & $\mathrm{C}$ & $\mathrm{C}$ & 2 \\
\hline 31 & $1 / 21 / 10$ & 68.14 & 75.42 & 32 & 63 & 99 & 1871 & 208 & 5.6 & 10.5 & $\mathrm{C}$ & $\mathrm{Sh}$ & \\
\hline 32 & $1 / 21 / 10$ & 68.69 & 74.19 & 61 & 27 & 76 & 1000 & 148 & 5.8 & 5.8 & $\mathrm{C}$ & $\mathrm{C}$ & \\
\hline 33 & $1 / 21 / 10$ & 68.97 & 73.56 & 45 & 16 & 79 & 1062 & 123 & 5.7 & 6.1 & $\mathrm{C}$ & $\mathrm{C}$ & \\
\hline 34 & $1 / 22 / 10$ & 68.38 & 71.70 & 33 & 52 & 62 & 1042 & 90 & 6.0 & 6.3 & $\mathrm{C}$ & $\mathrm{C}$ & \\
\hline 38 & $1 / 24 / 10$ & 68.03 & 69.28 & 21 & 26 & 57 & 1042 & 102 & 6.1 & 6.4 & $\mathrm{C}$ & $\mathrm{C}$ & \\
\hline 40 & $1 / 26 / 10$ & 69.82 & 75.54 & 12 & 37 & 49 & 374 & 96 & 20.2 & 7.6 & $\mathrm{~S}$ & $\mathrm{C}$ & 3 \\
\hline 43 & $1 / 27 / 10$ & 69.50 & 75.51 & 74 & 17 & 15 & 209 & 33 & 20.2 & 4.2 & $\mathrm{~S}$ & $\mathrm{C}$ & 3 \\
\hline 47 & $1 / 31 / 10$ & 64.49 & 66.03 & 32 & 47 & 81 & 1705 & 119 & 6.2 & 10.6 & $\mathrm{~N}$ & $\mathrm{Sh}$ & 1 \\
\hline \multicolumn{14}{|c|}{ Autumn cruise } \\
\hline 2 & $3 / 21 / 10$ & 64.47 & 65.97 & 64 & 37 & 100 & 468 & 82 & 14.9 & 7.0 & $\mathrm{~N}$ & $\mathrm{Sh}$ & 1 \\
\hline 4 & $3 / 23 / 10$ & 64.35 & 65.94 & 72 & - & 104 & 234 & 67 & 14.3 & 3.3 & $\mathrm{~N}$ & $\mathrm{Sh}$ & 1 \\
\hline 6 & $3 / 24 / 10$ & 64.37 & 65.84 & 99 & 24 & 116 & 225 & 102 & 12.6 & 2.8 & $\mathrm{~N}$ & $\mathrm{Sh}$ & 1 \\
\hline 7 & $3 / 26 / 10$ & 69.82 & 75.55 & 14 & 44 & 111 & 734 & 85 & 20 & 14.7 & $\mathrm{~S}$ & $\mathrm{C}$ & 3 \\
\hline 9 & $3 / 29 / 10$ & 70.42 & 76.42 & 17 & 37 & 87 & 809 & 75 & 25.1 & 20.3 & $\mathrm{~S}$ & $\mathrm{C}$ & 3 \\
\hline 11 & $4 / 1 / 10$ & 68.69 & 74.20 & 54 & 78 & 62 & 652 & 72 & 28.1 & 18.3 & $\mathrm{C}$ & $\mathrm{C}$ & \\
\hline 12 & $4 / 1 / 10$ & 68.50 & 73.58 & 62 & 67 & 69 & 870 & 63 & 28.6 & 24.9 & $\mathrm{C}$ & $\mathrm{C}$ & \\
\hline 13 & $4 / 2 / 10$ & 68.31 & 72.97 & 59 & 36 & 70 & 516 & 66 & 28.7 & 14.8 & $\mathrm{C}$ & $\mathrm{C}$ & \\
\hline 14 & $4 / 2 / 10$ & 68.11 & 72.35 & 19 & 37 & 71 & 742 & 65 & 28.5 & 21.1 & $\mathrm{C}$ & $\mathrm{C}$ & \\
\hline 15 & $4 / 2 / 10$ & 67.91 & 71.76 & 64 & 42 & 62 & 940 & 61 & 28.1 & 26.4 & $\mathrm{C}$ & $\mathrm{C}$ & \\
\hline 16 & $4 / 2 / 10$ & 67.72 & 71.19 & 72 & 37 & 66 & 1010 & 64 & 28.4 & 28.7 & $\mathrm{C}$ & $\mathrm{C}$ & \\
\hline
\end{tabular}




\begin{tabular}{|c|c|c|c|c|c|c|c|c|c|c|c|c|c|}
\hline$\#$ & Date & $\begin{array}{l}\text { Lat. } \\
{ }^{\circ} \mathrm{S}\end{array}$ & $\begin{array}{l}\text { Long } \\
{ }^{\circ} \mathrm{W}\end{array}$ & $\begin{array}{c}\mathrm{ML} \\
\mathrm{m}\end{array}$ & EZ & $\begin{array}{c}\text { PPZ } \\
\text { m }\end{array}$ & 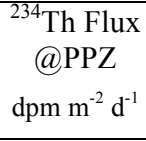 & err & $\begin{array}{l}\mathrm{C} / \mathrm{Th} \\
\mu \mathrm{mol}^{-1} \\
\mathrm{dpm}^{-1}\end{array}$ & $\begin{array}{l}\text { C Flux } \\
@ \text { PPZ } \\
\mathrm{mmol} \\
\mathrm{m}^{-2} \mathrm{~d}^{-1} \\
\end{array}$ & $\begin{array}{l}\text { Along } \\
\text { Shelf } \\
\text { N/C/S }\end{array}$ & $\begin{array}{c}\text { Across } \\
\text { Shelf } \\
\mathrm{C} / \mathrm{Sh} / \mathrm{Sl}\end{array}$ & \\
\hline 18 & $4 / 7 / 10$ & 68.15 & 69.99 & 76 & - & 86 & 693 & 80 & 25.3 & 17.5 & $\mathrm{C}$ & $\mathrm{C}$ & 2 \\
\hline 20 & $4 / 9 / 10$ & 68.15 & 69.99 & 67 & 42 & 77 & 498 & 57 & 27.2 & 13.5 & $\mathrm{C}$ & $\mathrm{C}$ & 2 \\
\hline 21 & $4 / 10 / 10$ & 68.21 & 70.02 & 74 & 45 & 85 & 603 & 71 & 25.5 & 15.4 & $\mathrm{C}$ & $\mathrm{C}$ & 2 \\
\hline 27 & $4 / 19 / 10$ & 64.45 & 65.97 & 117 & - & 100 & 383 & 99 & 9.2 & 3.5 & $\mathrm{~N}$ & Sh & 1 \\
\hline 29 & $4 / 21 / 10$ & 64.34 & 66.06 & 100 & - & 99 & 276 & 59 & 9.3 & 2.6 & $\mathrm{~N}$ & $\mathrm{Sh}$ & 1 \\
\hline
\end{tabular}


Table 3

Results of ${ }^{234} \mathrm{Th}$ underway sampling. ${ }^{238} \mathrm{U}$ was derived from salinity using Owens et al. (2011). ${ }^{234}$ Th fluxes were determined using the relationship between fluxes and surface $\mathrm{Th} / \mathrm{U}$ ratios. $\mathrm{C} /{ }^{234} \mathrm{Th}$ ratios determined on in situ pump samples were use to estimate $\mathrm{C}$ fluxes at each underway sampling site.

\begin{tabular}{|c|c|c|c|c|c|c|c|c|c|c|c|}
\hline $\begin{array}{c}\text { Julian } \\
\text { Day }\end{array}$ & $\begin{array}{l}\text { Lat. } \\
{ }^{\circ} \mathrm{S}\end{array}$ & $\begin{array}{c}\text { Long } \\
{ }^{\circ} \mathrm{W}\end{array}$ & $\begin{array}{c}{ }^{234} \mathrm{Th} \\
\mathrm{dpm} \mathrm{L} \mathrm{L}^{-1}\end{array}$ & err & $\begin{array}{c}{ }^{238} \mathrm{U} \\
\mathrm{dpm} \mathrm{L}^{-1}\end{array}$ & err & $\mathrm{Th} / \mathrm{U}$ & err & $\begin{array}{l}\text { Est. }{ }^{234} \mathrm{Th} \\
\text { Flux } \\
\text { dpm } \mathrm{m}^{-2} \mathrm{~d}^{-1}\end{array}$ & $\begin{array}{c}\mathrm{C} / \mathrm{Th} \\
\mu \mathrm{mol} \mathrm{dpm}{ }^{-1}\end{array}$ & $\begin{array}{c}\text { Est. C } \\
\text { Flux } \\
\text { mmol m }^{-2} \mathrm{~d}^{-1}\end{array}$ \\
\hline \multicolumn{12}{|c|}{ Summer cruise } \\
\hline 6 & 64.90 & 64.48 & 1.86 & 0.07 & 2.33 & 0.05 & 0.80 & 0.03 & 1031 & 6.0 & 6.2 \\
\hline 6 & 64.80 & 64.76 & 1.60 & 0.05 & 2.35 & 0.05 & 0.68 & 0.03 & 1406 & 6.0 & 8.4 \\
\hline 6 & 64.69 & 65.05 & 1.53 & 0.05 & 2.35 & 0.05 & 0.65 & 0.03 & 1502 & 6.0 & 9.0 \\
\hline 6 & 64.58 & 65.33 & 1.63 & 0.05 & 2.35 & 0.05 & 0.69 & 0.03 & 1365 & 6.0 & 8.2 \\
\hline 6 & 64.45 & 65.66 & 1.68 & 0.05 & 2.35 & 0.05 & 0.72 & 0.03 & 1294 & 6.0 & 7.8 \\
\hline 7 & 64.34 & 65.94 & 1.73 & 0.05 & 2.34 & 0.05 & 0.74 & 0.03 & 1222 & 6.0 & 7.3 \\
\hline 7 & 64.22 & 66.23 & 1.69 & 0.05 & 2.34 & 0.05 & 0.72 & 0.03 & 1273 & 6.0 & 7.6 \\
\hline 7 & 64.10 & 66.54 & 1.68 & 0.05 & 2.34 & 0.05 & 0.72 & 0.03 & 1285 & 6.0 & 7.7 \\
\hline 7 & 63.99 & 66.81 & 1.40 & 0.04 & 2.33 & 0.05 & 0.60 & 0.02 & 1667 & 6.0 & 10.0 \\
\hline 7 & 64.29 & 67.57 & 1.57 & 0.05 & 2.34 & 0.05 & 0.67 & 0.03 & 1438 & 6.0 & 8.6 \\
\hline 7 & 64.60 & 68.27 & 1.56 & 0.05 & 2.34 & 0.05 & 0.67 & 0.03 & 1450 & 6.0 & 8.7 \\
\hline 8 & 64.55 & 67.20 & 1.42 & 0.06 & 2.34 & 0.05 & 0.61 & 0.03 & 1646 & 6.0 & 9.9 \\
\hline 8 & 64.50 & 66.18 & 1.64 & 0.06 & 2.34 & 0.05 & 0.70 & 0.03 & 1344 & 6.0 & 8.1 \\
\hline 11 & 64.87 & 66.49 & 1.80 & 0.06 & 2.35 & 0.05 & 0.77 & 0.03 & 1130 & 6.0 & 6.8 \\
\hline 11 & 65.20 & 66.75 & 1.69 & 0.06 & 2.34 & 0.05 & 0.72 & 0.03 & 1274 & 6.0 & 7.6 \\
\hline 11 & 65.19 & 66.68 & 1.83 & 0.06 & 2.34 & 0.05 & 0.78 & 0.03 & 1083 & 6.0 & 6.5 \\
\hline 11 & 65.29 & 66.77 & 1.75 & 0.06 & 2.34 & 0.05 & 0.75 & 0.03 & 1192 & 6.0 & 7.1 \\
\hline 11 & 65.37 & 66.85 & 1.78 & 0.07 & 2.34 & 0.05 & 0.76 & 0.03 & 1152 & 6.0 & 6.9 \\
\hline 11 & 65.46 & 66.90 & 1.37 & 0.05 & 2.34 & 0.05 & 0.58 & 0.02 & 1716 & 6.0 & 10.3 \\
\hline 11 & 65.55 & 66.95 & 1.60 & 0.06 & 2.34 & 0.05 & 0.68 & 0.03 & 1400 & 6.0 & 8.4 \\
\hline 11 & 65.64 & 67.00 & 1.53 & 0.06 & 2.34 & 0.05 & 0.65 & 0.03 & 1490 & 6.0 & 8.9 \\
\hline 11 & 65.73 & 67.04 & 1.94 & 0.07 & 2.34 & 0.05 & 0.83 & 0.03 & 923 & 6.0 & 5.5 \\
\hline 11 & 65.81 & 67.09 & 1.56 & 0.06 & 2.34 & 0.05 & 0.67 & 0.03 & 1447 & 6.0 & 8.7 \\
\hline 11 & 65.91 & 67.14 & 1.36 & 0.05 & 2.34 & 0.05 & 0.58 & 0.02 & 1724 & 6.0 & 10.3 \\
\hline 11 & 66.00 & 67.19 & 1.66 & 0.06 & 2.34 & 0.05 & 0.71 & 0.03 & 1313 & 6.0 & 7.9 \\
\hline 11 & 66.09 & 67.24 & 1.60 & 0.05 & 2.34 & 0.05 & 0.68 & 0.03 & 1397 & 6.0 & 8.4 \\
\hline 11 & 66.18 & 67.29 & 1.70 & 0.05 & 2.34 & 0.05 & 0.73 & 0.03 & 1260 & 6.0 & 7.6 \\
\hline 11 & 66.14 & 67.62 & 1.55 & 0.06 & 2.34 & 0.05 & 0.66 & 0.03 & 1462 & 6.0 & 8.8 \\
\hline 11 & 66.00 & 67.97 & 1.27 & 0.05 & 2.33 & 0.05 & 0.54 & 0.02 & 1846 & 6.0 & 11.1 \\
\hline 11 & 65.93 & 68.25 & 1.28 & 0.05 & 2.33 & 0.05 & 0.55 & 0.02 & 1833 & 6.0 & 11.0 \\
\hline 12 & 65.75 & 68.60 & 1.55 & 0.06 & 2.34 & 0.05 & 0.66 & 0.03 & 1463 & 6.0 & 8.8 \\
\hline 12 & 65.62 & 68.91 & 1.85 & 0.07 & 2.34 & 0.05 & 0.79 & 0.03 & 1049 & 6.0 & 6.3 \\
\hline 12 & 65.50 & 69.19 & 1.53 & 0.06 & 2.33 & 0.05 & 0.66 & 0.03 & 1487 & 6.0 & 8.9 \\
\hline 12 & 65.51 & 69.25 & 1.31 & 0.07 & 2.33 & 0.05 & 0.56 & 0.03 & 1791 & 6.0 & 10.7 \\
\hline 12 & 65.58 & 69.41 & 1.38 & 0.08 & 2.33 & 0.05 & 0.59 & 0.04 & 1695 & 6.0 & 10.2 \\
\hline 12 & 65.64 & 69.56 & 1.54 & 0.10 & 2.34 & 0.05 & 0.66 & 0.05 & 1475 & 6.0 & 8.9 \\
\hline 12 & 65.70 & 69.73 & 1.20 & 0.07 & 2.33 & 0.05 & 0.51 & 0.03 & 1944 & 6.0 & 11.7 \\
\hline 12 & 65.76 & 69.87 & 1.50 & 0.09 & 2.34 & 0.05 & 0.64 & 0.04 & 1530 & 6.0 & 9.2 \\
\hline 12 & 65.83 & 70.04 & 1.57 & 0.08 & 2.34 & 0.05 & 0.67 & 0.04 & 1434 & 6.0 & 8.6 \\
\hline 12 & 65.89 & 70.20 & 1.52 & 0.08 & 2.34 & 0.05 & 0.65 & 0.04 & 1503 & 6.0 & 9.0 \\
\hline 12 & 65.95 & 70.37 & 1.31 & 0.07 & 2.33 & 0.05 & 0.56 & 0.03 & 1791 & 6.0 & 10.7 \\
\hline 12 & 66.01 & 70.53 & 1.31 & 0.07 & 2.33 & 0.05 & 0.56 & 0.03 & 1791 & 6.0 & 10.7 \\
\hline 12 & 66.07 & 70.67 & 1.56 & 0.08 & 2.33 & 0.05 & 0.67 & 0.04 & 1446 & 6.0 & 8.7 \\
\hline 13 & 66.13 & 70.75 & 1.31 & 0.09 & 2.33 & 0.05 & 0.56 & 0.04 & 1791 & 6.0 & 10.7 \\
\hline 13 & 66.26 & 70.45 & 1.50 & 0.09 & 2.34 & 0.05 & 0.64 & 0.04 & 1530 & 6.0 & 9.2 \\
\hline
\end{tabular}




\begin{tabular}{|c|c|c|c|c|c|c|c|c|c|c|c|}
\hline $\begin{array}{c}\text { Julian } \\
\text { Day }\end{array}$ & $\begin{array}{l}\text { Lat. } \\
{ }^{\circ} \mathrm{S}\end{array}$ & $\begin{array}{c}\text { Long } \\
{ }^{\circ} \mathrm{W}\end{array}$ & $\begin{array}{c}{ }^{234} \mathrm{Th} \\
\mathrm{dpm} \mathrm{L} \mathrm{L}^{-1}\end{array}$ & err & $\begin{array}{c}{ }^{238} \mathrm{U} \\
\mathrm{dpm} \mathrm{L}^{-1}\end{array}$ & err & $\mathrm{Th} / \mathrm{U}$ & err & 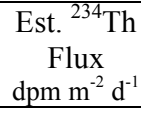 & $\begin{array}{c}\mathrm{C} / \mathrm{Th} \\
\mu \mathrm{mol} \mathrm{dpm}{ }^{-1}\end{array}$ & $\begin{array}{c}\text { Est. C } \\
\text { Flux } \\
\text { mmol m}^{-2} \mathrm{~d}^{-1}\end{array}$ \\
\hline 13 & 66.38 & 70.18 & 1.49 & 0.09 & 2.34 & 0.05 & 0.64 & 0.04 & 1544 & 6.0 & 9.3 \\
\hline 13 & 66.49 & 69.84 & 1.42 & 0.09 & 2.34 & 0.05 & 0.61 & 0.04 & 1642 & 6.0 & 9.9 \\
\hline 13 & 66.64 & 69.54 & 1.51 & 0.09 & 2.34 & 0.05 & 0.65 & 0.04 & 1517 & 6.0 & 9.1 \\
\hline 13 & 66.78 & 69.21 & 1.55 & 0.10 & 2.33 & 0.05 & 0.67 & 0.05 & 1457 & 6.0 & 8.7 \\
\hline 13 & 66.89 & 68.92 & 1.44 & 0.07 & 2.33 & 0.05 & 0.62 & 0.03 & 1609 & 6.0 & 9.7 \\
\hline 13 & 67.01 & 69.23 & 1.49 & 0.09 & 2.33 & 0.05 & 0.64 & 0.04 & 1542 & 5.9 & 9.1 \\
\hline 13 & 67.13 & 69.57 & 1.52 & 0.10 & 2.34 & 0.05 & 0.65 & 0.04 & 1504 & 5.9 & 8.9 \\
\hline 14 & 67.26 & 69.90 & 1.46 & 0.08 & 2.33 & 0.05 & 0.63 & 0.04 & 1585 & 5.9 & 9.4 \\
\hline 14 & 67.38 & 70.25 & 1.52 & 0.09 & 2.33 & 0.05 & 0.65 & 0.04 & 1501 & 5.9 & 8.9 \\
\hline 14 & 67.51 & 70.58 & 1.85 & 0.12 & 2.33 & 0.05 & 0.79 & 0.05 & 1045 & 5.9 & 6.2 \\
\hline 14 & 67.24 & 71.24 & 1.65 & 0.10 & 2.34 & 0.05 & 0.71 & 0.05 & 1327 & 5.9 & 7.8 \\
\hline 14 & 67.08 & 71.45 & 1.78 & 0.11 & 2.34 & 0.05 & 0.76 & 0.05 & 1147 & 5.9 & 6.8 \\
\hline 14 & 66.98 & 71.84 & 1.33 & 0.08 & 2.33 & 0.05 & 0.57 & 0.04 & 1764 & 6.0 & 10.6 \\
\hline 14 & 66.84 & 72.16 & 1.76 & 0.12 & 2.33 & 0.05 & 0.76 & 0.05 & 1166 & 6.0 & 7.0 \\
\hline 16 & 66.74 & 72.42 & 1.52 & 0.11 & 2.33 & 0.05 & 0.65 & 0.05 & 1498 & 6.0 & 9.0 \\
\hline 16 & 66.91 & 72.57 & 1.81 & 0.09 & 2.33 & 0.05 & 0.78 & 0.04 & 1096 & 6.0 & 6.6 \\
\hline 16 & 67.06 & 72.73 & 2.10 & 0.12 & 2.33 & 0.05 & 0.90 & 0.05 & 697 & 5.9 & 4.1 \\
\hline 16 & 67.24 & 72.88 & 1.63 & 0.09 & 2.33 & 0.05 & 0.70 & 0.04 & 1349 & 5.9 & 8.0 \\
\hline 16 & 67.41 & 73.02 & 1.95 & 0.14 & 2.34 & 0.05 & 0.83 & 0.06 & 914 & 5.9 & 5.4 \\
\hline 16 & 67.56 & 73.16 & 1.61 & 0.10 & 2.34 & 0.05 & 0.69 & 0.05 & 1381 & 5.9 & 8.2 \\
\hline 16 & 67.70 & 73.28 & 1.85 & 0.12 & 2.34 & 0.05 & 0.79 & 0.05 & 1048 & 5.9 & 6.2 \\
\hline 16 & 67.85 & 72.96 & 1.97 & 0.12 & 2.34 & 0.05 & 0.84 & 0.05 & 891 & 5.9 & 5.3 \\
\hline 16 & 67.99 & 72.64 & 1.87 & 0.11 & 2.34 & 0.05 & 0.80 & 0.05 & 1029 & 5.9 & 6.1 \\
\hline 16 & 68.11 & 72.34 & 2.08 & 0.13 & 2.34 & 0.05 & 0.89 & 0.06 & 738 & 5.9 & 4.4 \\
\hline 20 & 68.16 & 70.42 & 1.62 & 0.12 & 2.33 & 0.05 & 0.69 & 0.05 & 1362 & 5.9 & 8.0 \\
\hline 21 & 68.14 & 75.42 & 1.24 & 0.10 & 2.34 & 0.05 & 0.53 & 0.04 & 1891 & 5.9 & 11.2 \\
\hline 21 & 68.69 & 74.19 & 1.96 & 0.11 & 2.33 & 0.05 & 0.84 & 0.05 & 889 & 5.9 & 5.2 \\
\hline 21 & 68.97 & 73.56 & 1.69 & 0.12 & 2.30 & 0.05 & 0.73 & 0.05 & 1232 & 5.9 & 7.3 \\
\hline 22 & 68.38 & 71.70 & 1.46 & 0.09 & 2.33 & 0.05 & 0.63 & 0.04 & 1578 & 5.9 & 9.3 \\
\hline \multicolumn{12}{|c|}{ Autumn cruise } \\
\hline 80 & 64.89 & 64.29 & 2.43 & 0.05 & 2.34 & 0.05 & 1.04 & 0.03 & - & - & - \\
\hline 80 & 64.84 & 65.14 & 2.32 & 0.06 & 2.34 & 0.05 & 0.99 & 0.03 & 400 & 13.9 & 5.6 \\
\hline 80 & 64.73 & 65.45 & 2.38 & 0.05 & 2.34 & 0.05 & 1.02 & 0.03 & - & - & - \\
\hline 80 & 64.62 & 65.77 & 2.31 & 0.06 & 2.34 & 0.05 & 0.99 & 0.03 & 424 & 13.9 & 5.9 \\
\hline 80 & 64.47 & 65.97 & 2.24 & 0.04 & 2.35 & 0.05 & 0.95 & 0.03 & 523 & 13.9 & 7.3 \\
\hline 80 & 64.45 & 65.56 & 2.35 & 0.08 & 2.34 & 0.05 & 1.00 & 0.04 & - & - & - \\
\hline 80 & 64.44 & 65.17 & 2.60 & 0.05 & 2.34 & 0.05 & 1.11 & 0.03 & - & - & - \\
\hline 82 & 64.82 & 65.12 & 2.14 & 0.05 & 2.33 & 0.05 & 0.92 & 0.03 & 641 & 13.9 & 8.9 \\
\hline 82 & 64.67 & 65.36 & 2.29 & 0.06 & 2.34 & 0.05 & 0.98 & 0.03 & 442 & 13.9 & 6.1 \\
\hline 83 & 64.52 & 65.61 & 2.26 & 0.05 & 2.34 & 0.05 & 0.96 & 0.03 & 494 & 13.9 & 6.9 \\
\hline 83 & 64.37 & 65.80 & 2.51 & 0.05 & 2.35 & 0.05 & 1.07 & 0.03 & - & - & - \\
\hline 83 & 64.82 & 66.20 & 2.11 & 0.05 & 2.34 & 0.05 & 0.90 & 0.03 & 695 & 13.9 & 9.7 \\
\hline 83 & 65.28 & 66.59 & 2.18 & 0.05 & 2.34 & 0.05 & 0.93 & 0.03 & 598 & 13.9 & 8.3 \\
\hline 83 & 65.71 & 67.20 & 2.18 & 0.05 & 2.34 & 0.05 & 0.93 & 0.03 & 593 & 13.9 & 8.2 \\
\hline 83 & 65.90 & 67.61 & 2.12 & 0.05 & 2.33 & 0.05 & 0.91 & 0.03 & 666 & 13.9 & 9.3 \\
\hline 83 & 66.08 & 67.98 & 2.01 & 0.06 & 2.33 & 0.05 & 0.86 & 0.03 & 817 & 13.9 & 11.4 \\
\hline 83 & 66.26 & 68.38 & 2.27 & 0.05 & 2.33 & 0.05 & 0.98 & 0.03 & 454 & 13.9 & 6.3 \\
\hline 83 & 66.43 & 68.75 & 1.92 & 0.05 & 2.33 & 0.05 & 0.82 & 0.03 & 949 & 13.9 & 13.2 \\
\hline 84 & 66.62 & 69.15 & 2.13 & 0.05 & 2.33 & 0.05 & 0.91 & 0.03 & 654 & 13.9 & 9.1 \\
\hline 84 & 66.96 & 69.92 & 2.21 & 0.04 & 2.33 & 0.05 & 0.95 & 0.03 & 549 & 13.9 & 7.6 \\
\hline 84 & 67.32 & 70.72 & 1.85 & 0.04 & 2.33 & 0.05 & 0.79 & 0.02 & 1041 & 28.2 & 29.4 \\
\hline 84 & 67.61 & 71.39 & 1.88 & 0.06 & 2.33 & 0.05 & 0.81 & 0.03 & 1003 & 28.2 & 28.3 \\
\hline 84 & 67.88 & 72.00 & 1.66 & 0.04 & 2.33 & 0.05 & 0.71 & 0.02 & 1300 & 28.2 & 36.7 \\
\hline 84 & 68.12 & 72.57 & 1.47 & 0.04 & 2.30 & 0.05 & 0.64 & 0.02 & 1537 & 28.2 & 43.3 \\
\hline 84 & 68.37 & 73.15 & 1.85 & 0.04 & 2.34 & 0.05 & 0.79 & 0.02 & 1050 & 28.2 & 29.6 \\
\hline 84 & 68.62 & 73.73 & 1.80 & 0.04 & 2.34 & 0.05 & 0.77 & 0.02 & 1117 & 28.2 & 31.5 \\
\hline
\end{tabular}




\begin{tabular}{cccccccccccc}
\hline $\begin{array}{c}\text { Julian } \\
\text { Day }\end{array}$ & $\begin{array}{c}\text { Lat. } \\
{ }^{\circ} \mathrm{S}\end{array}$ & $\begin{array}{c}\text { Long } \\
{ }^{\circ} \mathrm{W}\end{array}$ & $\begin{array}{c}{ }^{234} \mathrm{Th} \\
\mathrm{dpm} \mathrm{L} \mathrm{L}^{-1}\end{array}$ & err & $\begin{array}{c}{ }^{238} \mathrm{U} \\
\mathrm{dpm} \mathrm{L} \mathrm{L}^{-1}\end{array}$ & err & $\mathrm{Th} / \mathrm{U}$ & err & $\begin{array}{c}\text { Est. }{ }^{234} \mathrm{Th} \\
\text { Flux } \\
\mathrm{dpm} \mathrm{m}^{-2} \mathrm{~d}^{-1}\end{array}$ & $\begin{array}{c}\mathrm{C} / \mathrm{Th} \\
\mu \mathrm{mol} \mathrm{dpm}^{-1}\end{array}$ & $\begin{array}{c}\text { Est. C } \\
\text { Flux } \\
\mathrm{mmol} \mathrm{m}^{-2} \mathrm{~d}^{-1}\end{array}$ \\
\hline 84 & 68.86 & 74.33 & 1.60 & 0.04 & 2.31 & 0.05 & 0.69 & 0.02 & 1367 & 28.2 & 38.6 \\
84 & 69.14 & 75.02 & 1.66 & 0.04 & 2.30 & 0.05 & 0.72 & 0.02 & 1270 & 22.6 & 28.7 \\
85 & 69.39 & 75.38 & 1.66 & 0.03 & 2.29 & 0.05 & 0.73 & 0.02 & 1259 & 22.6 & 28.5 \\
91 & 68.69 & 74.19 & 2.09 & 0.04 & 2.33 & 0.05 & 0.90 & 0.03 & 707 & 28.2 & 19.9 \\
91 & 68.56 & 73.77 & 2.16 & 0.05 & 2.33 & 0.05 & 0.93 & 0.03 & 610 & 28.2 & 17.2 \\
91 & 68.50 & 73.58 & 2.11 & 0.05 & 2.33 & 0.05 & 0.91 & 0.03 & 680 & 28.2 & 19.2 \\
92 & 68.40 & 73.26 & 1.99 & 0.05 & 2.32 & 0.05 & 0.86 & 0.03 & 832 & 28.2 & 23.5 \\
92 & 68.31 & 72.96 & 2.03 & 0.05 & 2.33 & 0.05 & 0.87 & 0.03 & 792 & 28.2 & 22.3 \\
92 & 68.20 & 72.63 & 1.55 & 0.04 & 2.29 & 0.05 & 0.68 & 0.02 & 1419 & 28.2 & 40.0 \\
92 & 68.11 & 72.39 & 1.61 & 0.04 & 2.29 & 0.05 & 0.70 & 0.02 & 1333 & 28.2 & 37.6 \\
92 & 68.00 & 72.07 & 2.04 & 0.05 & 2.32 & 0.05 & 0.88 & 0.03 & 765 & 28.2 & 21.6 \\
92 & 67.91 & 71.76 & 1.99 & 0.05 & 2.31 & 0.05 & 0.86 & 0.03 & 828 & 28.2 & 23.3 \\
92 & 67.80 & 71.42 & 2.02 & 0.05 & 2.32 & 0.05 & 0.87 & 0.03 & 793 & 28.2 & 22.4 \\
92 & 67.72 & 71.19 & 2.02 & 0.04 & 2.31 & 0.05 & 0.87 & 0.03 & 788 & 28.2 & 22.2 \\
92 & 67.90 & 70.70 & 1.89 & 0.04 & 2.31 & 0.05 & 0.82 & 0.02 & 961 & 28.2 & 27.1 \\
93 & 68.17 & 70.00 & 2.21 & 0.05 & 2.32 & 0.05 & 0.95 & 0.03 & 528 & 28.2 & 14.9 \\
99 & 68.14 & 69.99 & 2.23 & 0.05 & 2.31 & 0.05 & 0.96 & 0.03 & 495 & 28.2 & 14.0 \\
\hline
\end{tabular}




\section{Table 4}

Comparison of sediment trap (STT or NBST) and water column (WC) fluxes of ${ }^{234} \mathrm{Th}$ and $\mathrm{C}$ at $100 \mathrm{~m}$ off the WAP in 2010 . Mean fluxes at $100 \mathrm{~m}$ are shown with either the propagated uncertainty of the fluxes or the standard deviation whichever was largest. When sediment traps were not deployed at $100 \mathrm{~m}$, the flux values have been linearly interpolated from the traps above and below $100 \mathrm{~m}$. Multiple flux values are shown when the difference between the values was large. $\mathrm{C} /{ }^{234} \mathrm{Th}$ ratios at $100 \mathrm{~m}$ were used to convert water-column derived ${ }^{234}$ Th fluxes to $\mathrm{C}$ fluxes (North site: 5.9, 14.9, 9.2 in Jan., Mar., Apr.; Central site: 5.7, 22.3 in Jan., Apr.; and Southern site: 10.4 out of ice in Jan.).

\begin{tabular}{|c|c|c|c|c|c|c|}
\hline & \multicolumn{3}{|c|}{ 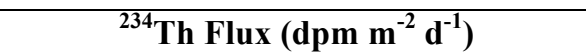 } & \multicolumn{3}{|c|}{ C Flux $\left(\mathrm{mmol} \mathrm{m}^{-2} \mathrm{~d}^{-1}\right)$} \\
\hline & Jan. & Mar. & Apr. & Jan. & Mar. & Apr. \\
\hline \multicolumn{7}{|l|}{ North } \\
\hline STT & $\begin{array}{c}1249 \pm 12 \\
168 \pm 5\end{array}$ & $200 \pm 22$ & $160 \pm 6$ & $\begin{array}{l}6.3 \\
2.0\end{array}$ & $4.5 \pm 1.8$ & 1.3 \\
\hline WC - Near trap & $1672 \pm 62$ & $302 \pm 146$ & $331 \pm 73$ & $9.9 \pm 0.4$ & $4.5 \pm 2.2$ & $3.0 \pm 0.7$ \\
\hline $\begin{array}{r}\mathrm{WC}-\text { Whole } \\
\text { region }\end{array}$ & $1737 \pm 214$ & - & - & $10.2 \pm 1.3$ & - & - \\
\hline \multicolumn{7}{|l|}{ Central } \\
\hline STT & $2169 \pm 293$ & - & $377 \pm 38$ & $10.2 \pm 0.3$ & - & $8.0 \pm 0.4$ \\
\hline WC - Near trap & $\begin{array}{c}304 \pm 202 \\
1006 \pm 190 \\
771 \pm 214\end{array}$ & - & $584 \pm 84$ & $\begin{array}{l}1.7 \\
4.4 \\
5.7\end{array}$ & - & $13.0 \pm 1.9$ \\
\hline $\begin{array}{r}\mathrm{WC}-\text { Whole } \\
\text { region }\end{array}$ & $1088 \pm 523$ & - & $703 \pm 270$ & $6.2 \pm 3.0$ & - & $15.7 \pm 6.0$ \\
\hline \multicolumn{7}{|l|}{ South } \\
\hline STT & $2427 \pm 91$ & - & - & $30.6 \pm 1.5$ & - & - \\
\hline WC & $202 \pm 205$ & - & - & $2.1 \pm 2.1$ & - & - \\
\hline \multicolumn{7}{|l|}{ Out of ice } \\
\hline NBST & $\begin{array}{c}244 \pm 6 \\
1985 \pm 24\end{array}$ & - & - & $3.0 \pm 0.1$ & - & - \\
\hline $\mathrm{WC}$ & $913 \pm 285$ & - & - & $9.5 \pm 3.0$ & - & - \\
\hline
\end{tabular}




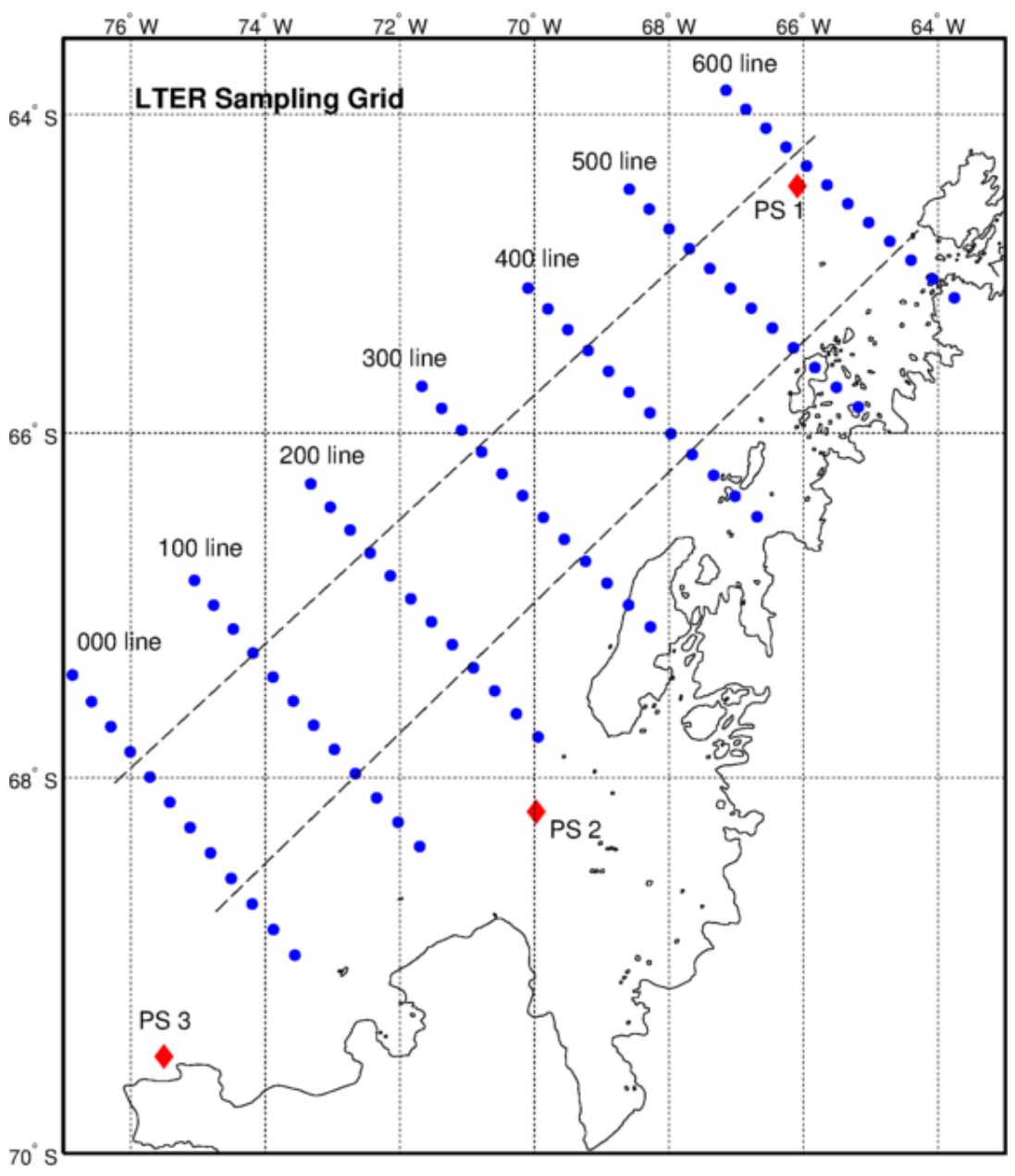

Figure 1 Sampling grid of the Palmer Long Term Ecological Research (LTER) study. Discrete sampling stations (blue circles) are denoted by a north-south values (lines 0 to 600 , every $100 \mathrm{~km}$ ) and coastal-offshore values ( 0 to 220 , every $20 \mathrm{~km}$ ). In addition, more intense studies are carried out at process study sites (red diamonds) at a northern site (1), in Marguerite Bay (2), and at a southern site near Charcot Island (3). The dashed lines denote the coastal, shelf, and slope regions of the study area. 

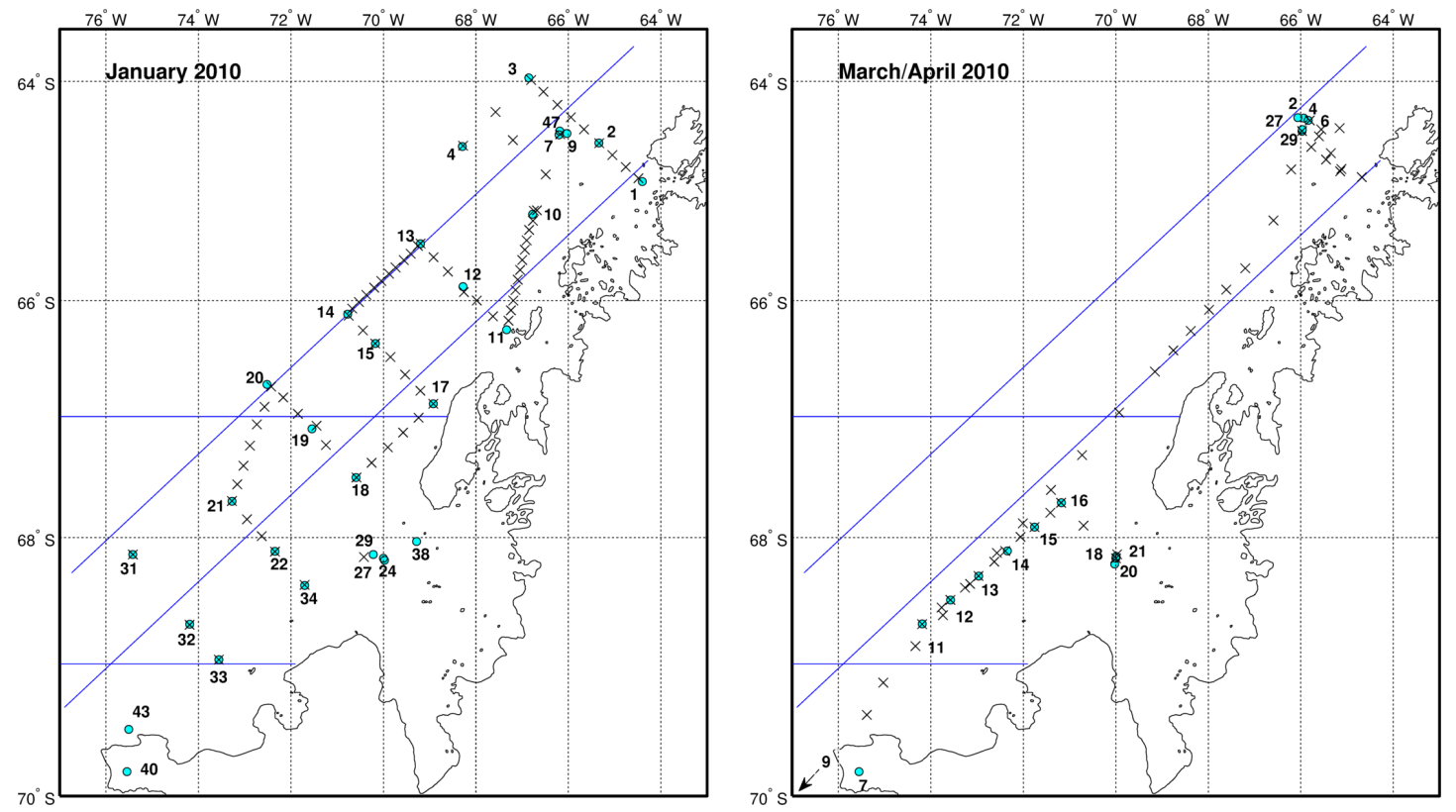

Figure 2 Sampling locations on two cruises to the West Antarctic Peninsula in 2010. Blue circles and corresponding CTD numbers denote the location of CTD casts and crosses denote underway-sampling locations. Stations in the Charcot Island area appear on land on the map because the exact location of this island is not well constrained. The blue lines denote the northern, central, and southern regions of the study region and the coastal, shelf, and slope areas. 

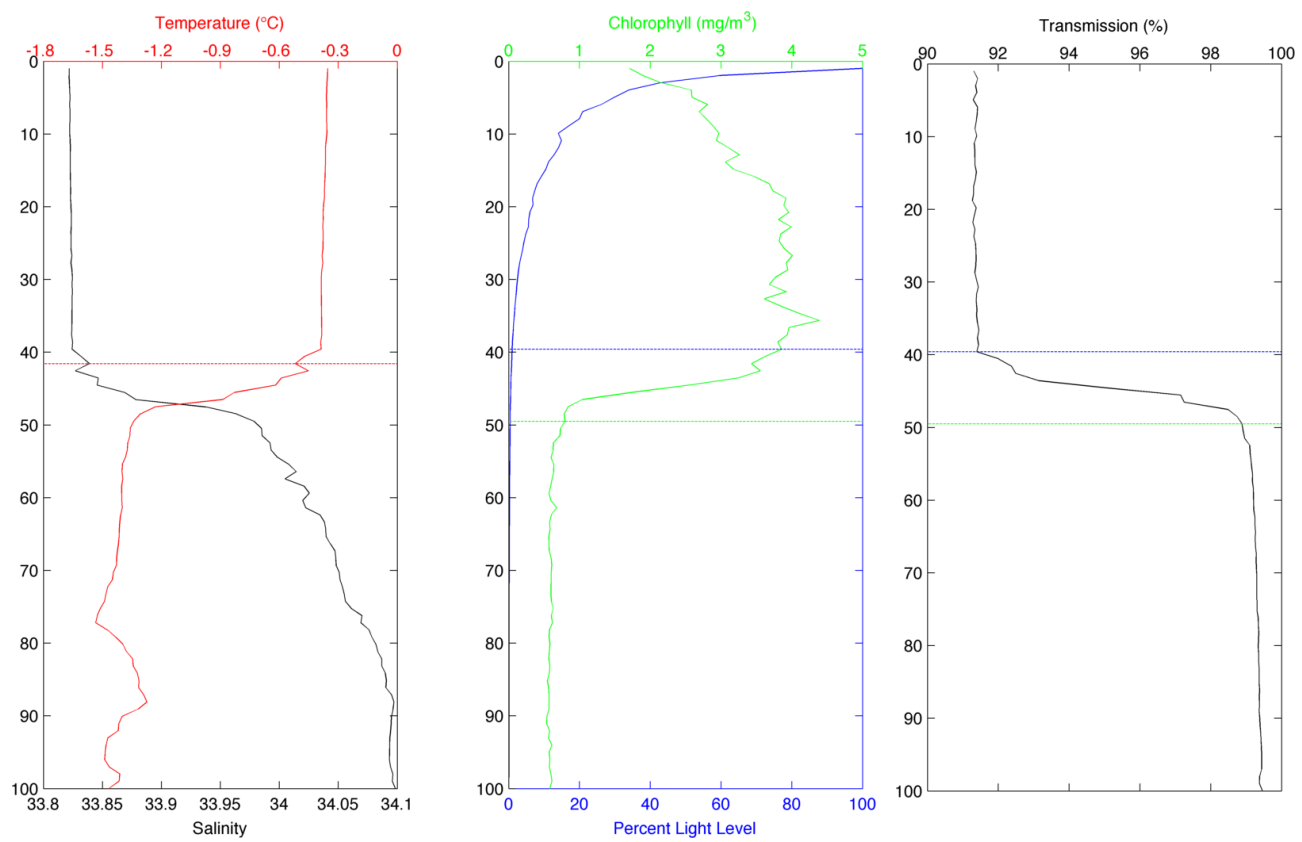

Figure 3 Example CTD profile from the upper $200 \mathrm{~m}$ at CTD 22. Shown on the left are temperature (red) and salinity (black) where the red line marks the depth of the mixed layer, the depth at which the absolute difference in potential temperature from the surface was $0.2^{\circ} \mathrm{C}$. Shown in the middle are the fluorescence (green) and percent light level (in blue, from the PAR sensor); the 1\% light level is denoted by the dashed blue line and the PPZ depth is in green. On the right is the light transmission profile, shown with the euphotic zone and PPZ depths. 

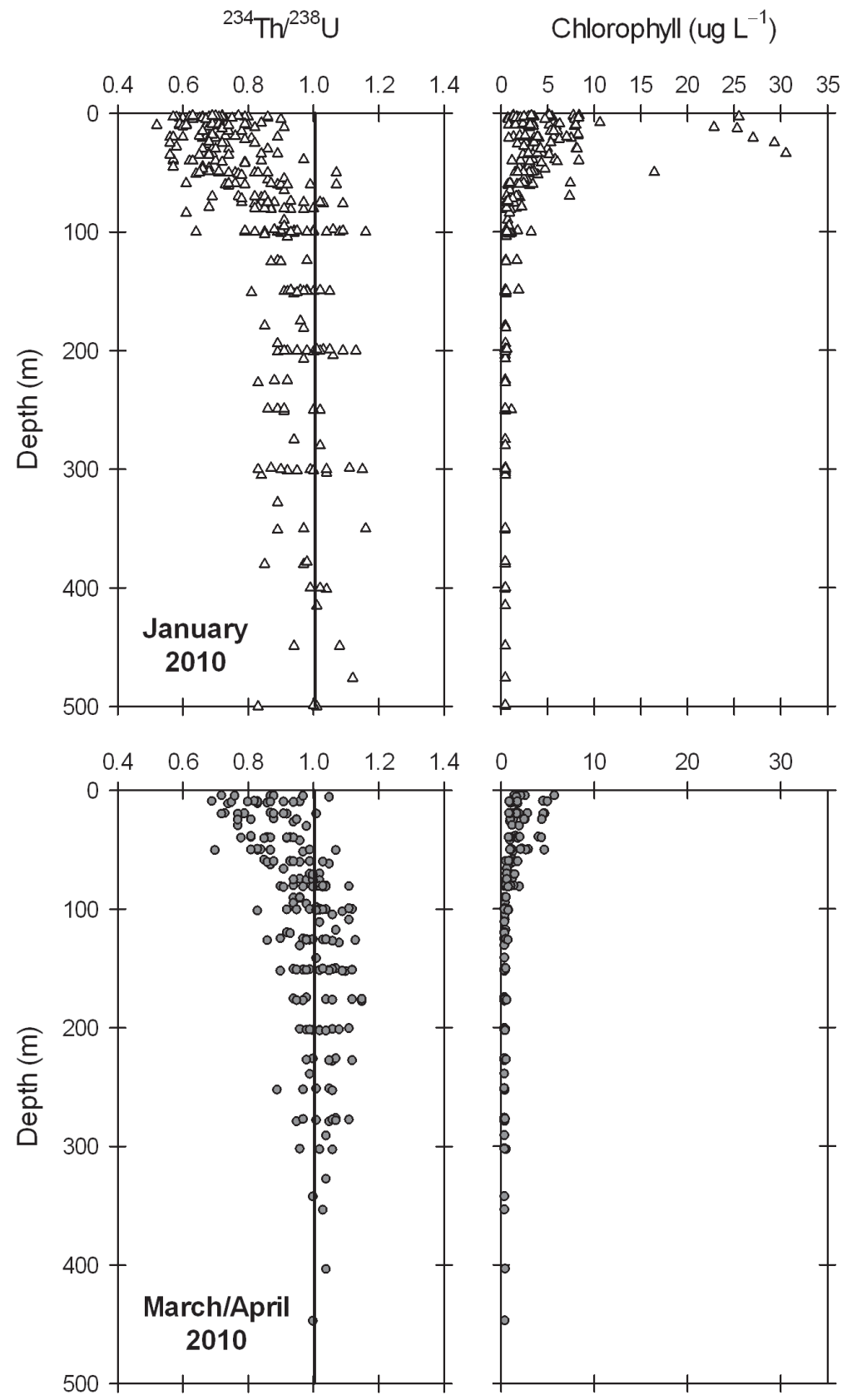

Light Transmission (\%)
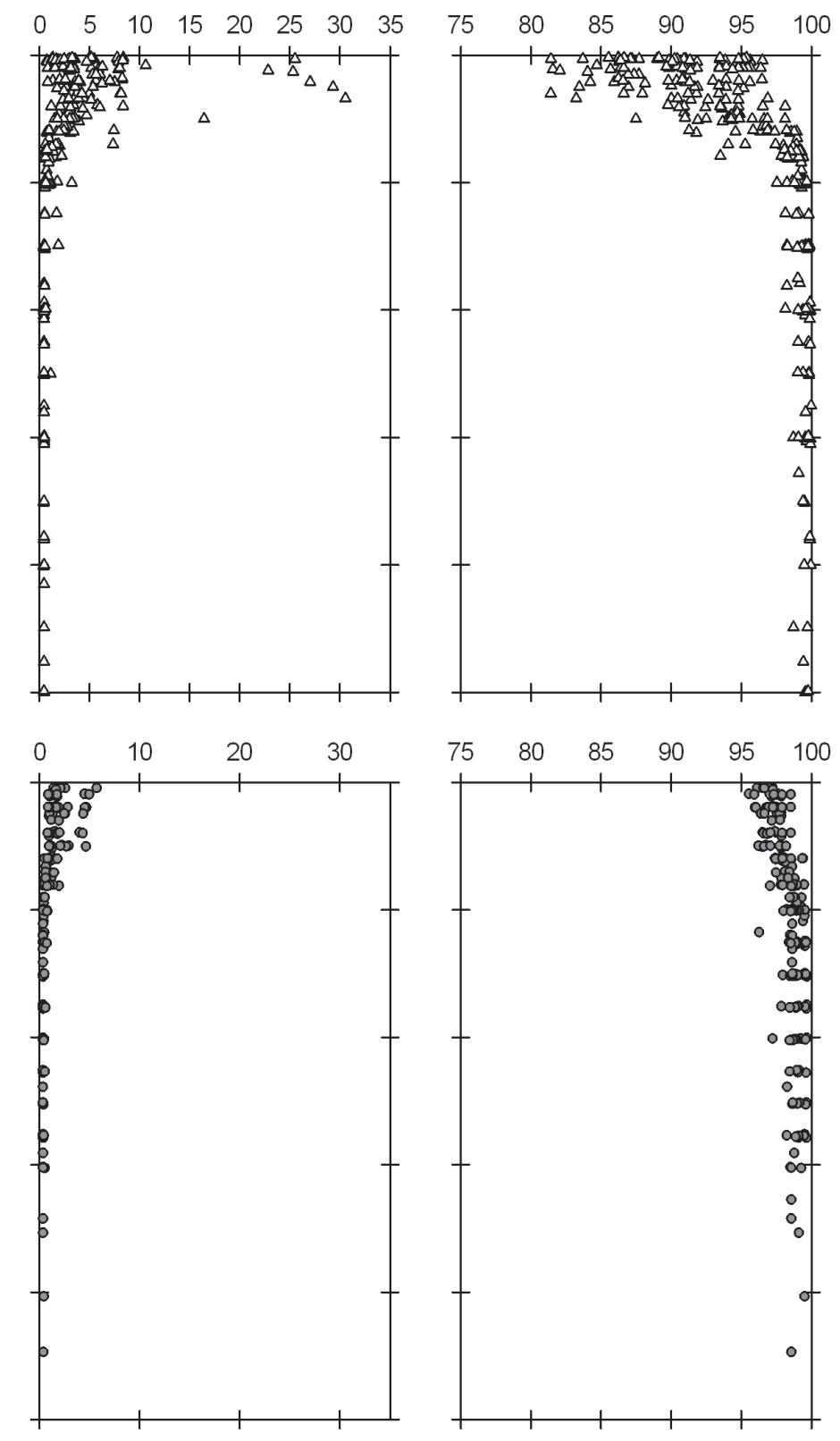

Figure $4{ }^{234} \mathrm{Th} /{ }^{238} \mathrm{U}$ ratios, chlorophyll, and light transmission measured at sites along the WAP on two cruises in January and March/April $2010 .{ }^{234} \mathrm{Th} /{ }^{238} \mathrm{U}$ ratios of less than one imply particle export, ratios greater than one suggest remineralization and ratios equal one when ${ }^{234} \mathrm{Th}$ and ${ }^{238} \mathrm{U}$ are in equilibrium. 


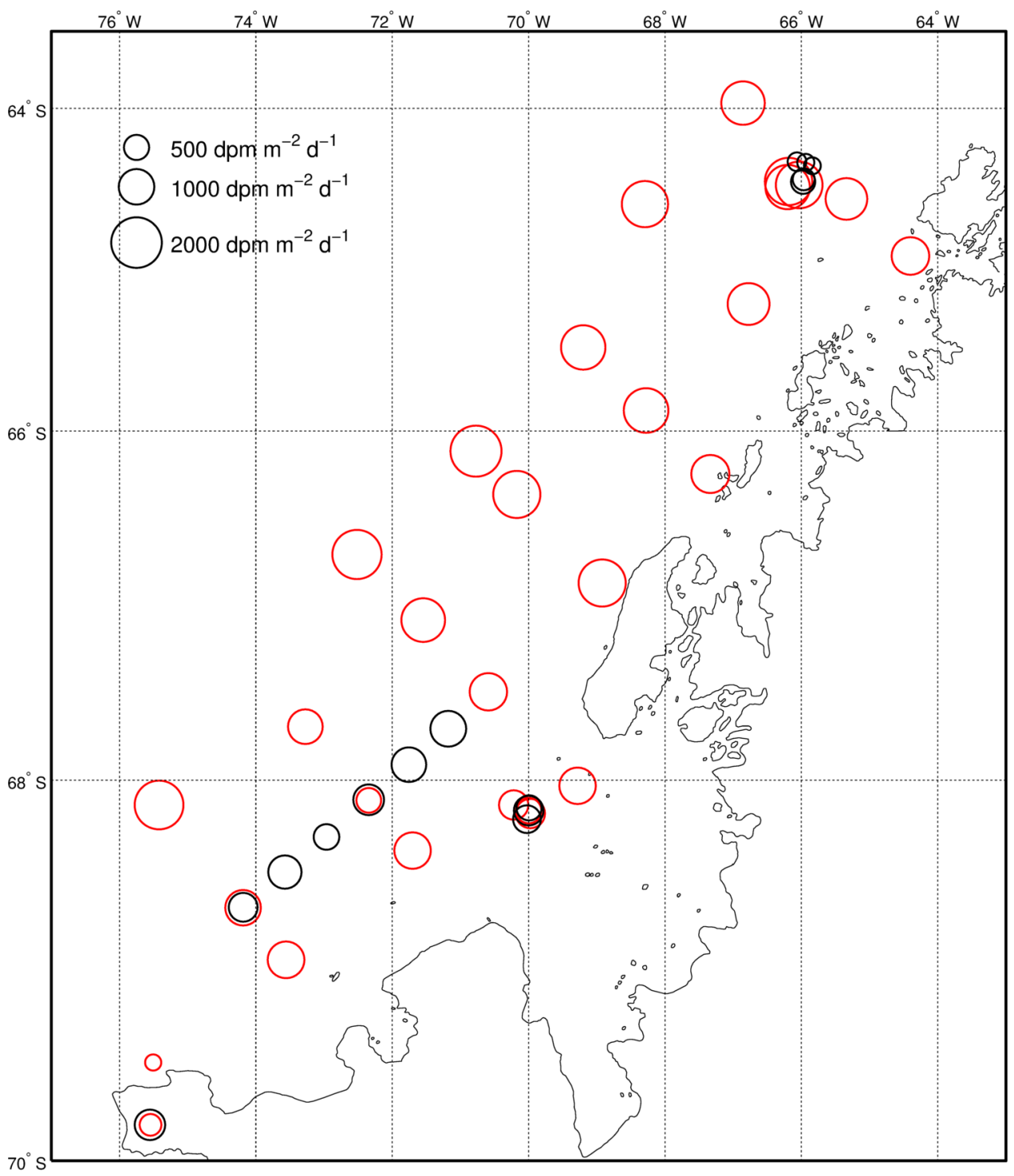

Figure $5{ }^{234} \mathrm{Th}$ fluxes at the PPZ in the summer (red) and autumn (black) off the WAP. 


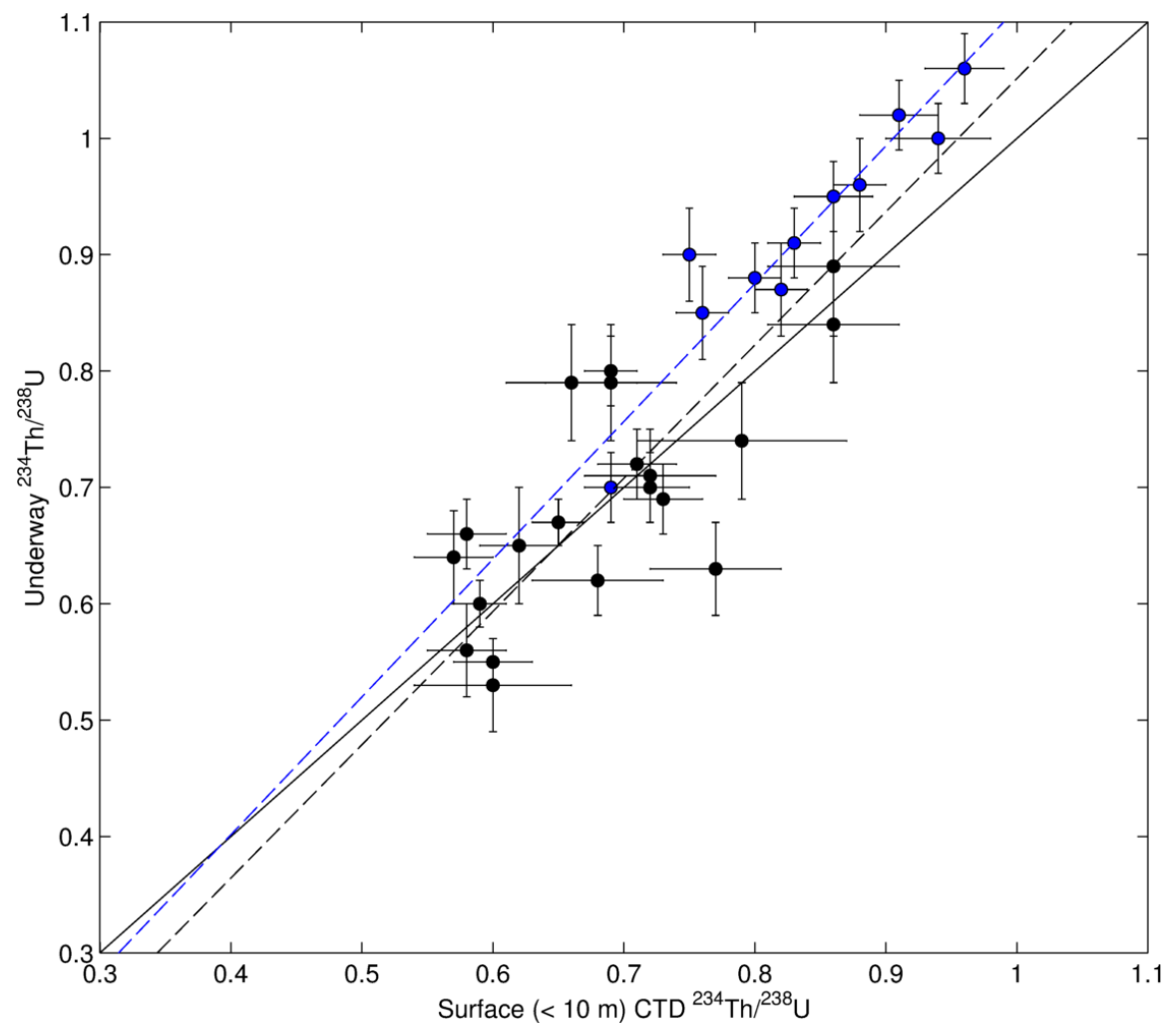

Figure $6{ }^{234} \mathrm{Th} /{ }^{238} \mathrm{U}$ ratio of samples collected from the ships' underway systems versus samples collected from the upper $10 \mathrm{~m}$ with the CTD in summer (black) and autumn (blue) 2010. The solid black line denotes a 1:1 line. The dashed black and blue lines are the best fit lines from Type II regressions of the summer and autumn data, respectively. 


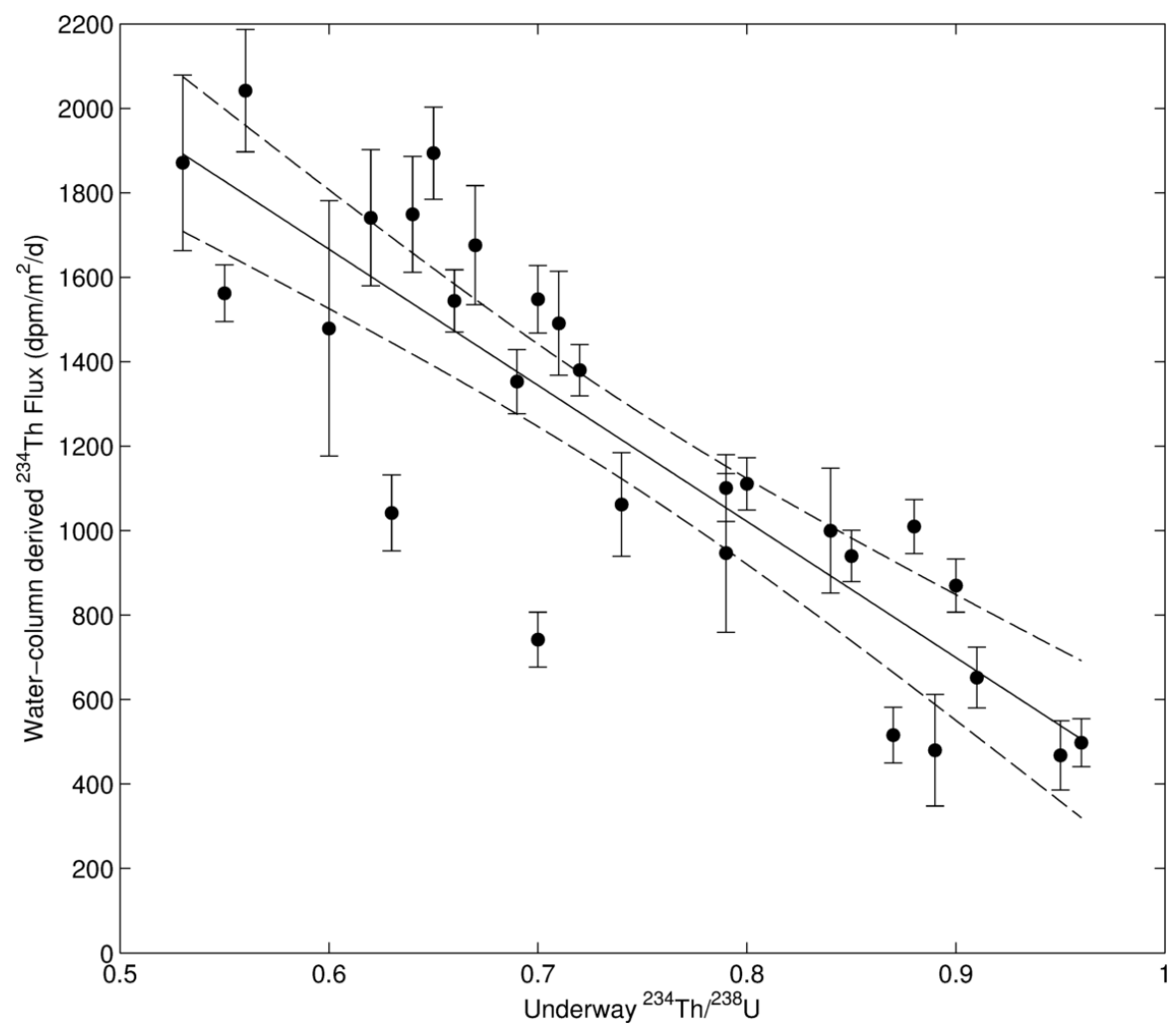

Figure $7{ }^{234} \mathrm{Th}$ flux at the fluorocline calculated from water-column profiles of ${ }^{234} \mathrm{Th}$ versus surface ${ }^{234} \mathrm{Th} /{ }^{238} \mathrm{U}$ ratios determined on underway samples at the same sites. The best fit line (solid) and 95\% confidence intervals (dashed) are shown $\left(\mathrm{r}^{2}=0.75, \mathrm{p}<\right.$ $0.0001, \mathrm{n}=28)$. 

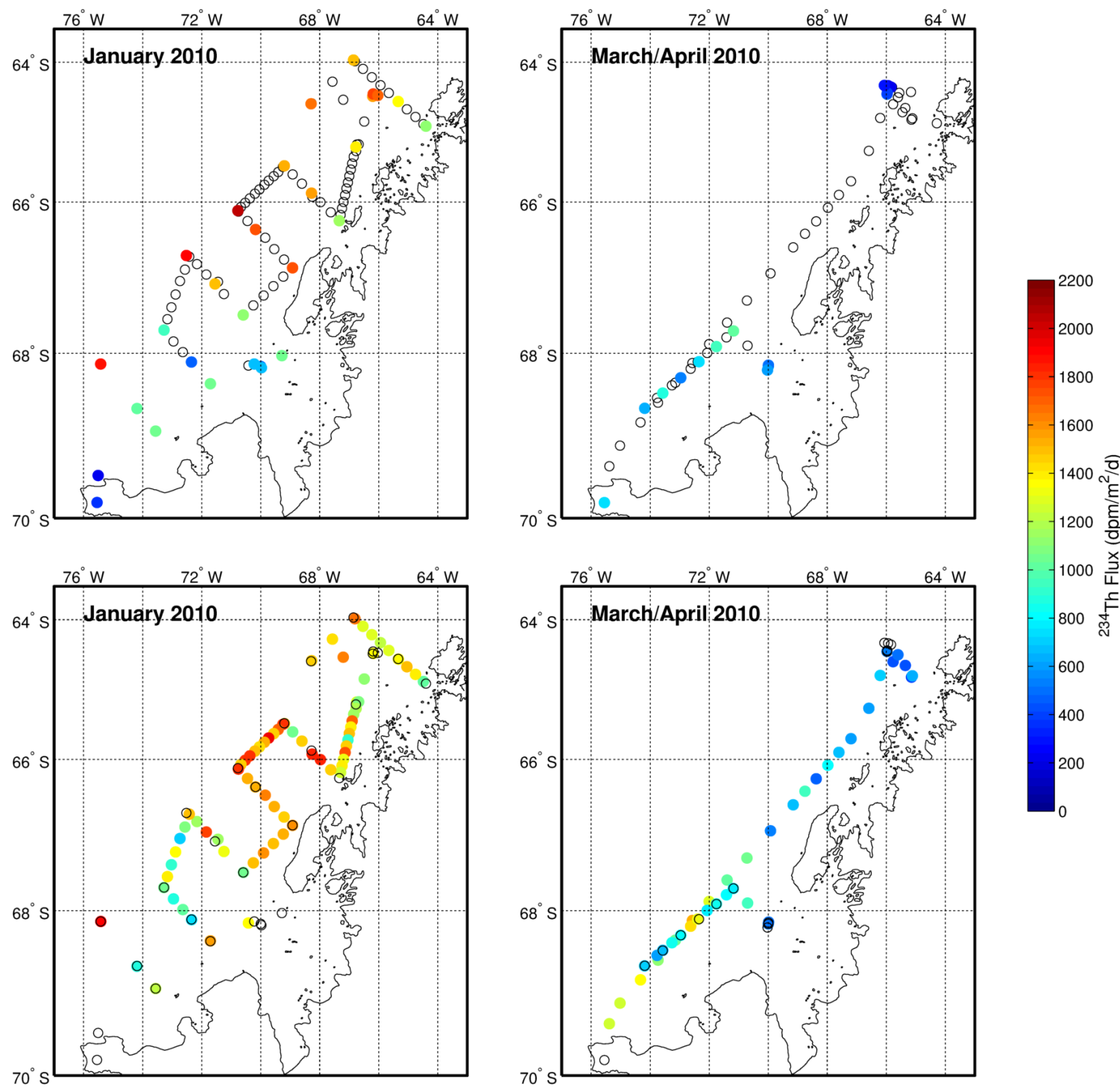

Figure $8{ }^{234} \mathrm{Th}$ fluxes from water-column profiles of ${ }^{234} \mathrm{Th}$ at CTD sites (top panels) and ${ }^{234} \mathrm{Th}$ fluxes calculated at underway sample sites (bottom panels) from the regression shown in Figure 7. In the top panels, open circles denote underway sample sites and in the bottom panels, sites of CTDs are denoted in the same way. 


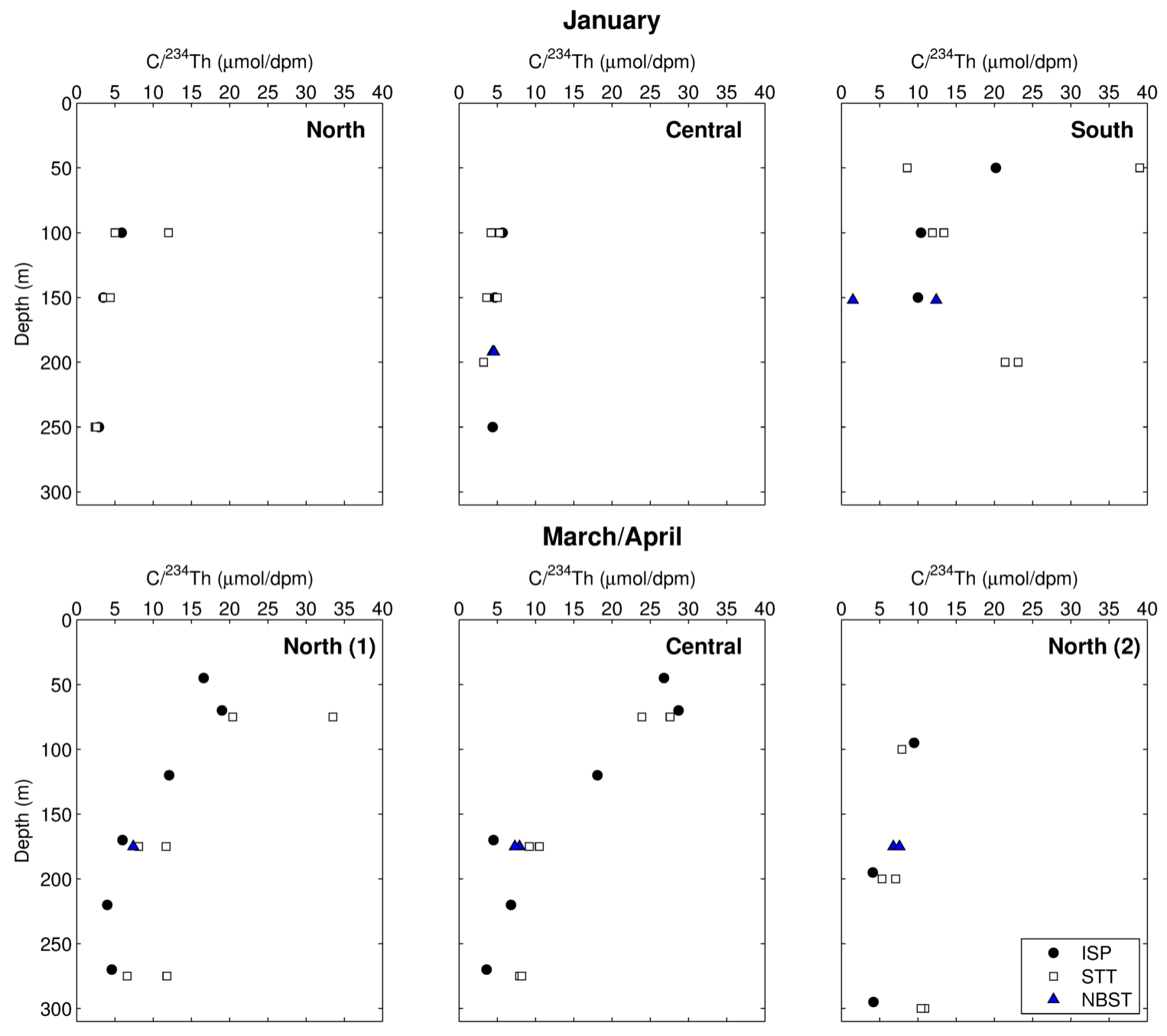

Figure 9 Carbon: ${ }^{234} \mathrm{Th}$ ratios for particles $>53 \mu \mathrm{m}$ collected by in situ pumps. On the first cruise, pumps were deployed at the three process stations in the study area, off Anvers Island in the northern region, in Marguerite Bay in the central region, and off Charcot Island in the southern region. On the second cruise, samples were collected twice at the northern station and once at the central region station in Marguerite Bay. Measurements from in situ pumps (ISP), surface-tethered traps (STT), and neutrally buoyant sediment traps (NBST) are shown; $\mathrm{C} /{ }^{234} \mathrm{Th}$ ratios from the ISP were used to derive $\mathrm{C}$ fluxes. 

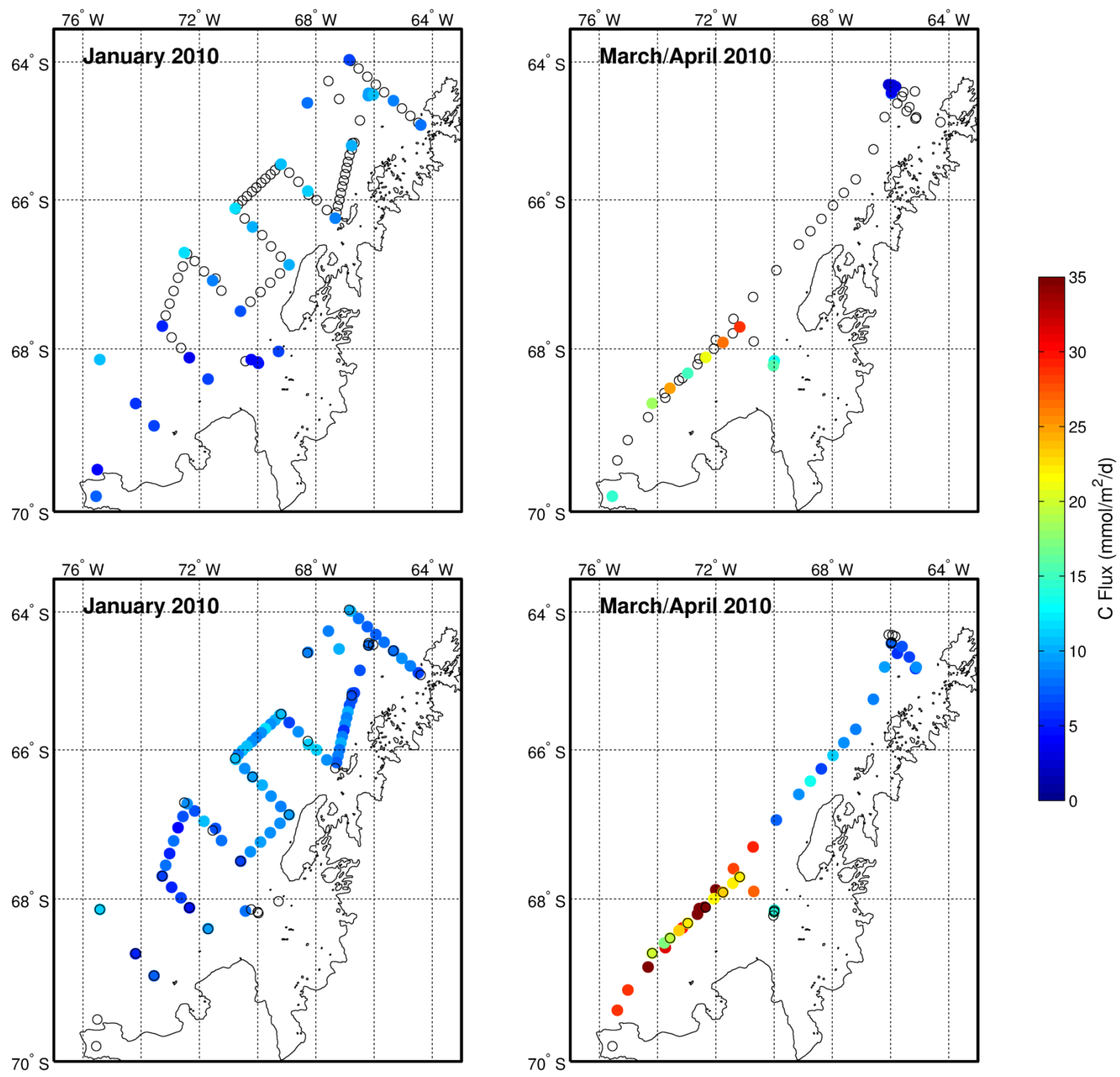

Figure 10 Carbon fluxes derived from ${ }^{234} \mathrm{Th}$ data shown in Figure 8 using $\mathrm{C} /{ }^{234} \mathrm{Th}$ ratios shown in Figure 9. 

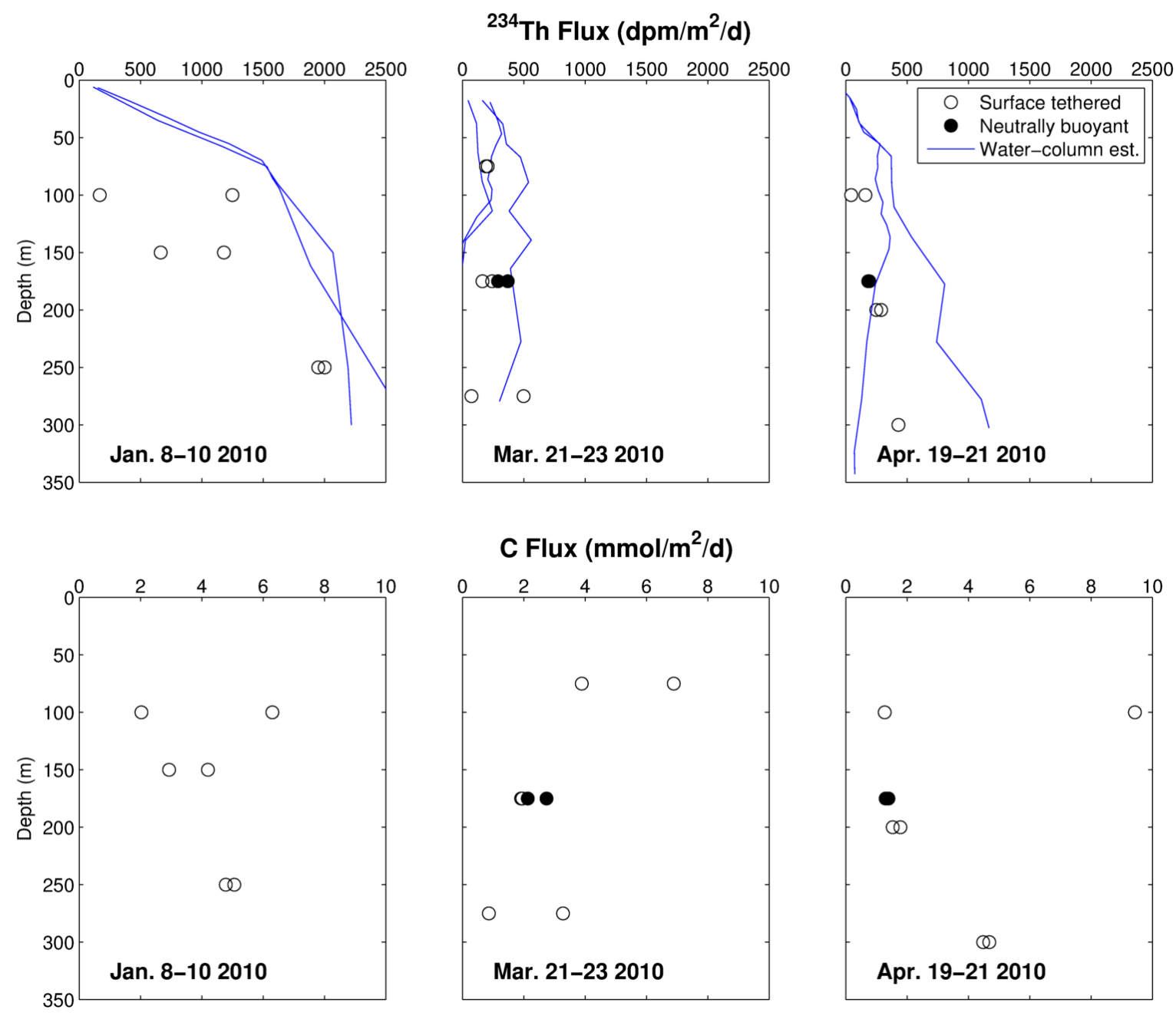

Figure 11 Results from sediment trap sampling at the northern end of the study region over four months in 2010. The top panel shows ${ }^{234} \mathrm{Th}$ fluxes from surface tethered (white) and neutrally buoyant sediment traps which are compared to water-column derived fluxes. The bottom panel shows total particulate carbon fluxes determined on the same samples. 

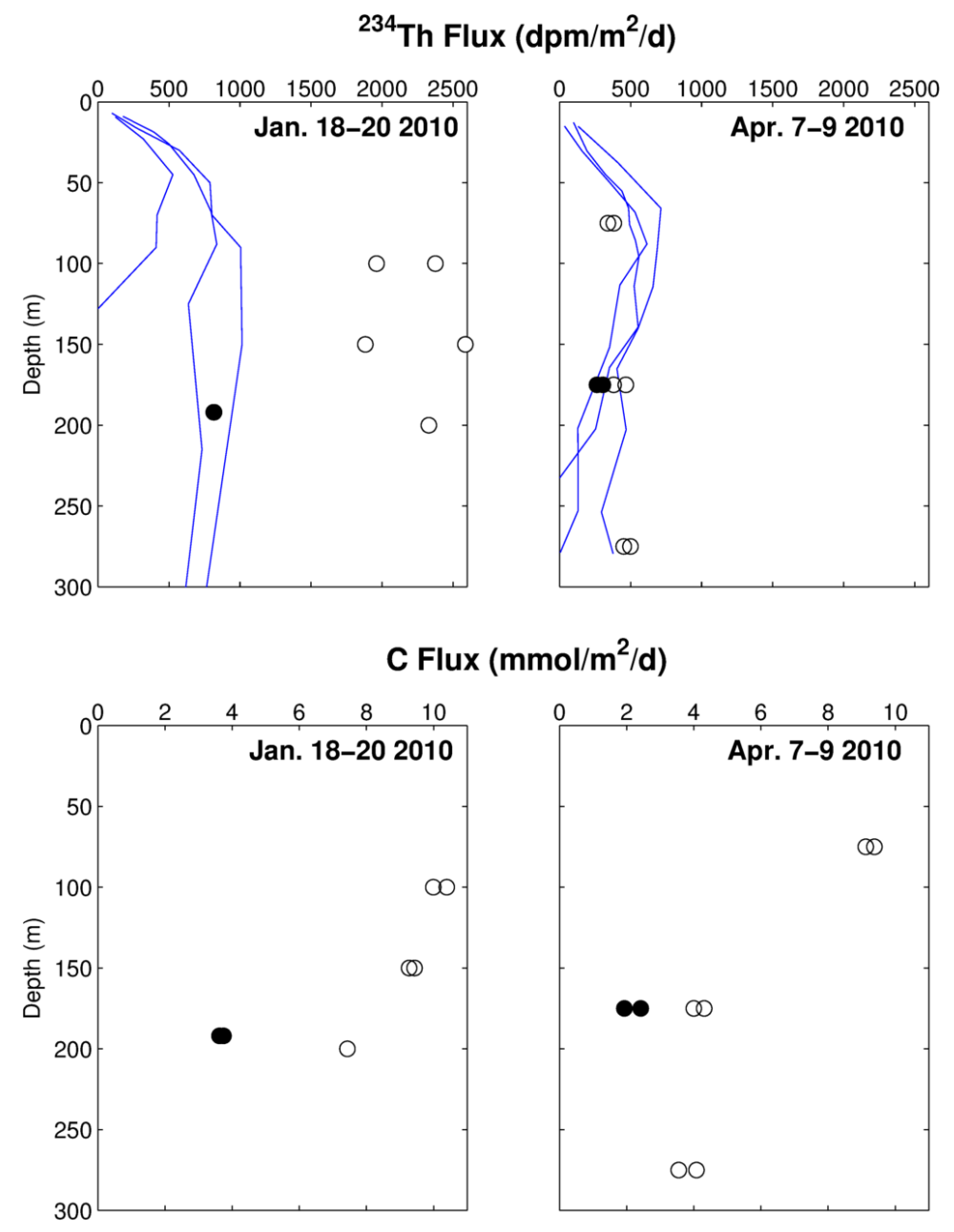

Figure 12 Results from sediment trap sampling in Marguerite Bay in 2010. Symbols are the same as in Figure 11. 

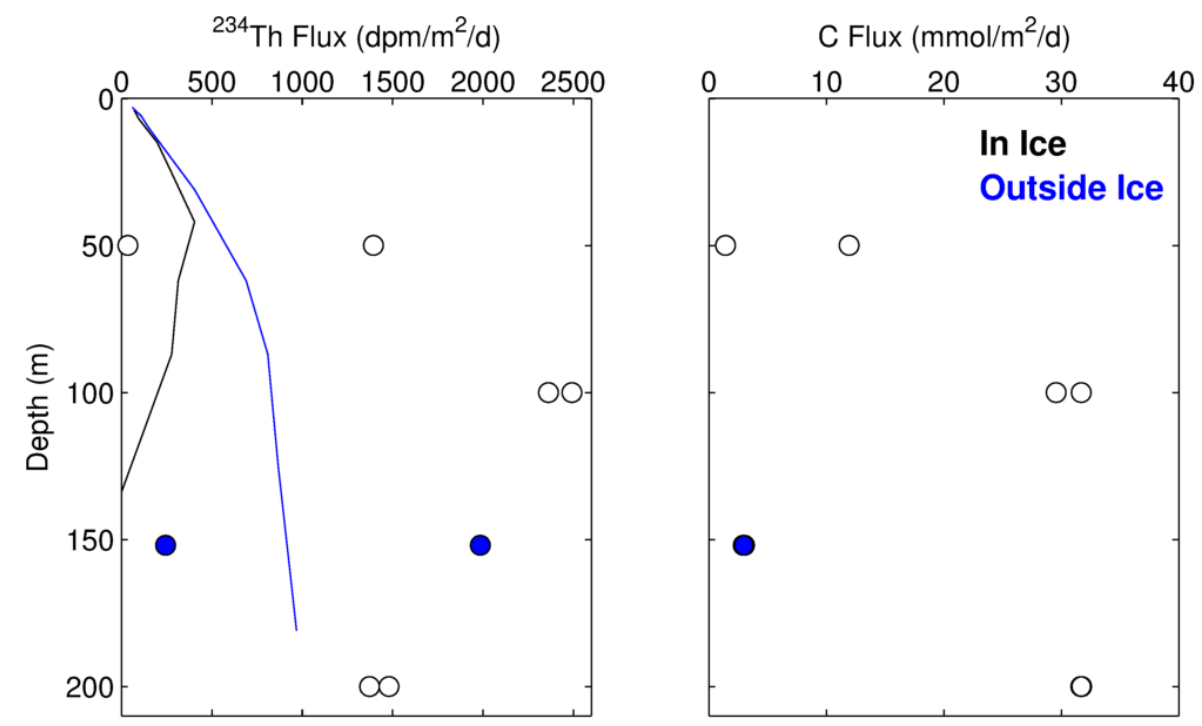

Figure 13 Results from sediment trap sampling near Charcot Island in January 2010. A surface tethered sediment trap was deployed in the ice (white circles) and a neutrally buoyant sediment trap was deployed outside the ice line (blue circles). ${ }^{234} \mathrm{Th}$ fluxes derived from water column measurements are also shown. 

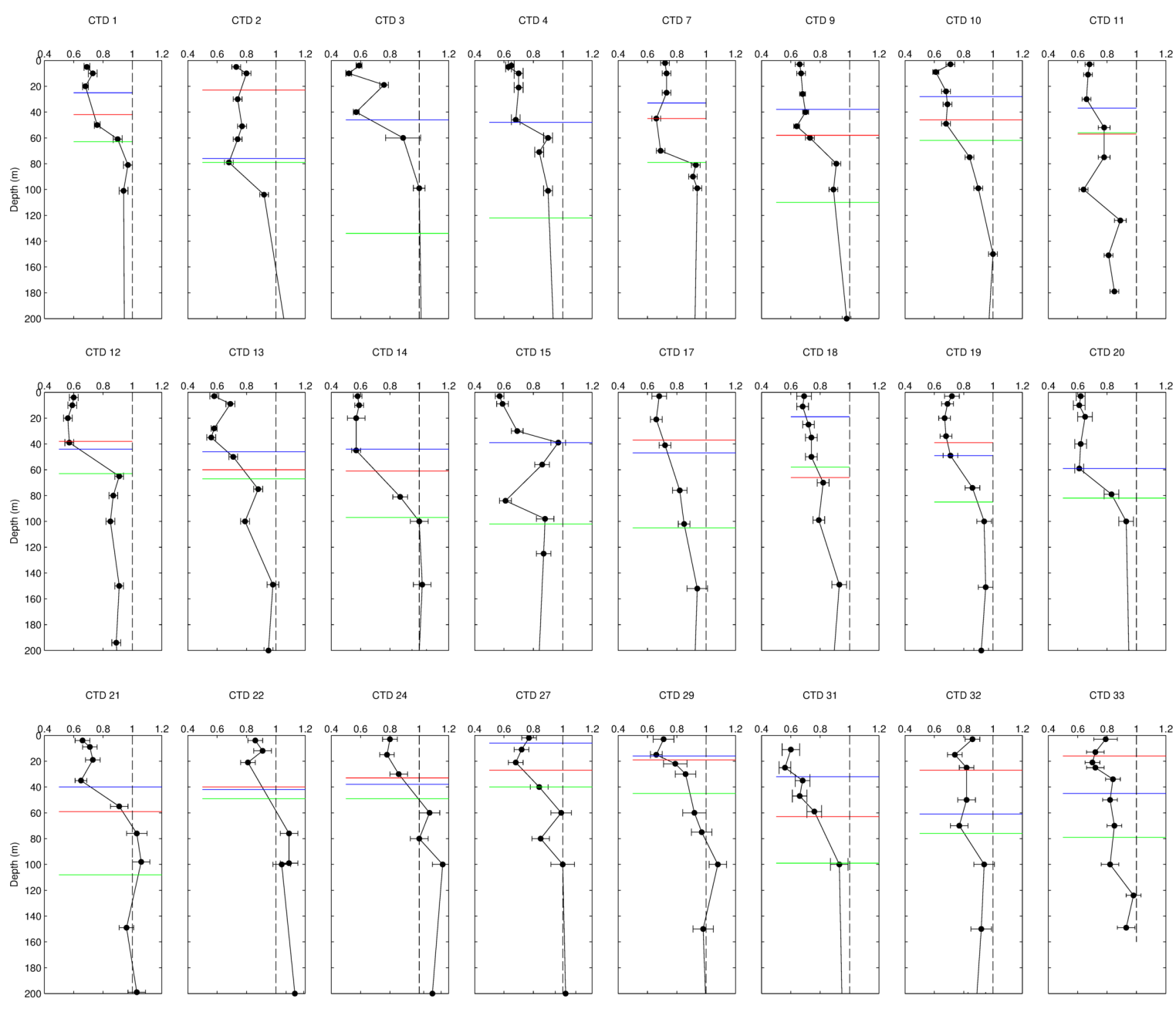

CTD 24

CTD 29

CTD $31 \quad$ CTD 32

CTD 33
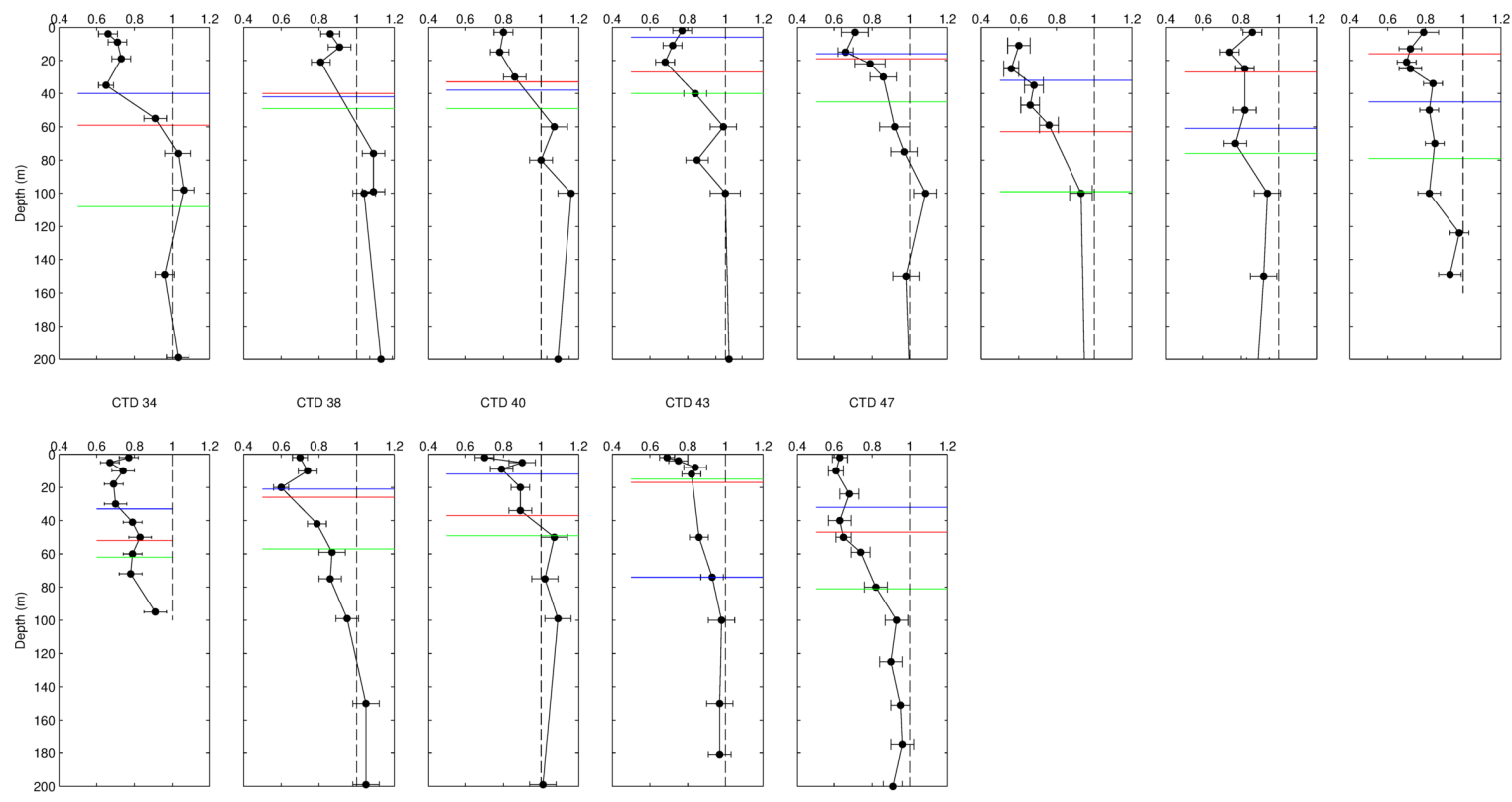

Figure 14 Profiles of ${ }^{234} \mathrm{Th} /{ }^{238} \mathrm{U}$ ratios off the West Antarctic Peninsula in January 2010. Refer to Figure 2 for sample locations. Solid, horizontal lines represent the depth of the mixed layer (in blue), the depth of the euphotic zone (1\% light level, in red), and the fluorocline (in green). 

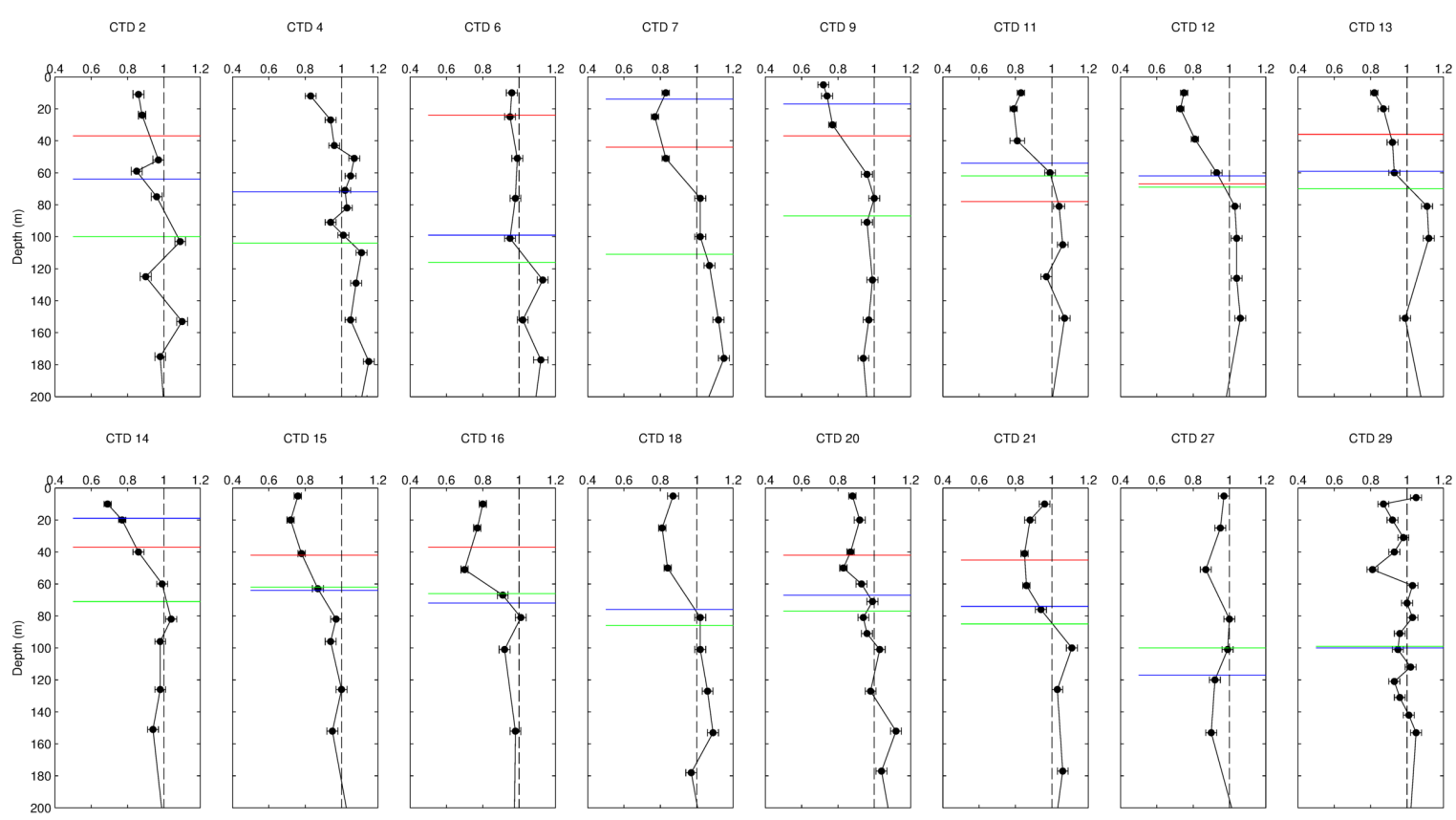

Figure 15 Profiles of ${ }^{234} \mathrm{Th} /{ }^{238} \mathrm{U}$ ratios off the West Antarctic Peninsula in March and April 2010. Refer to Figure 2 for sample locations. Solid, horizontal lines represent the depth of the mixed layer (in blue), the depth of the euphotic zone (1\% light level, in red), and the fluorocline (in green). 

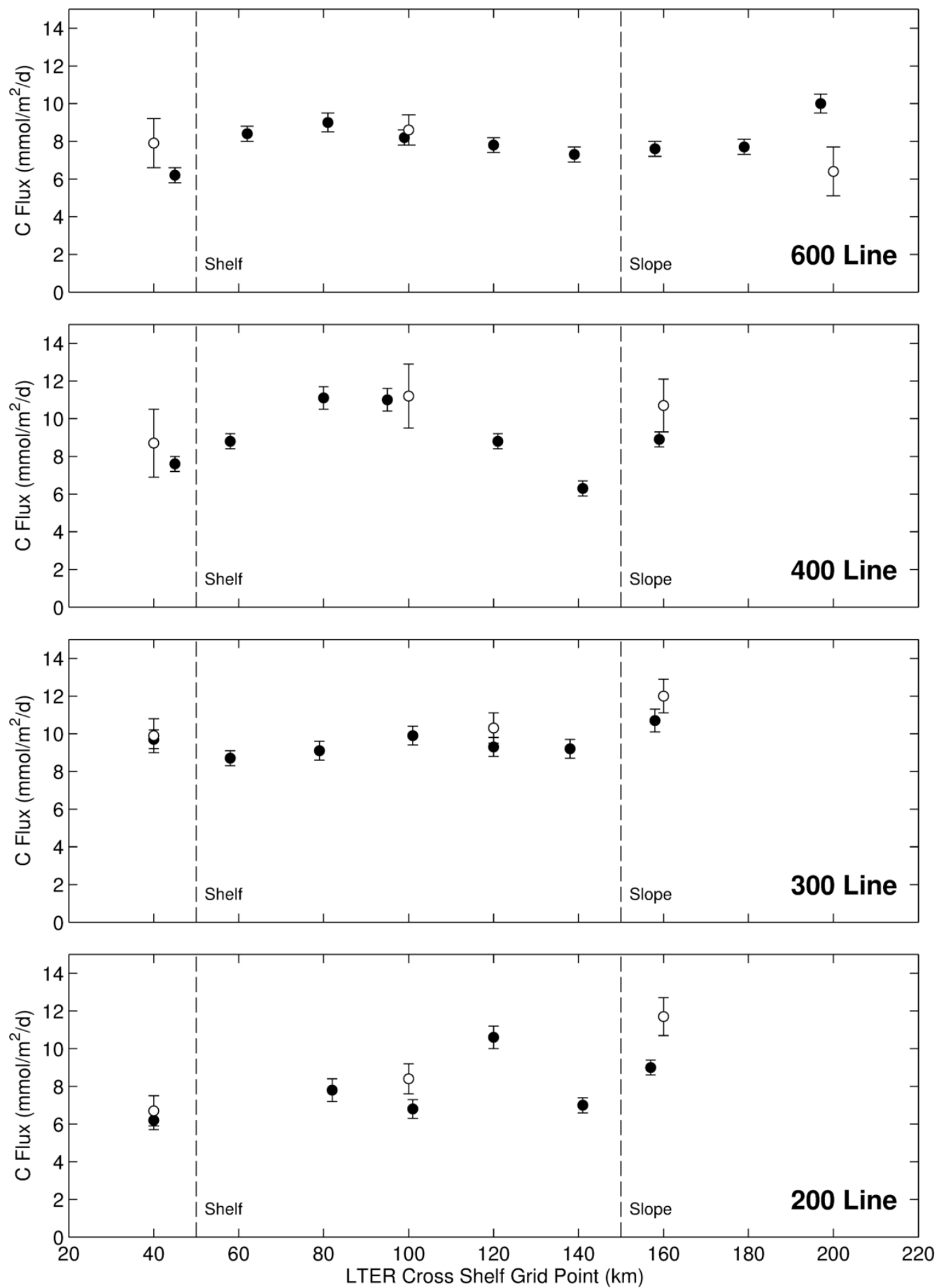

Figure 16 Comparison of estimated carbon fluxes at the fluorocline on four cross-shelf lines on the LTER grid (see Figure 1). Fluxes from water-column samples are in white and fluxes derived from surface measurements are in black. 

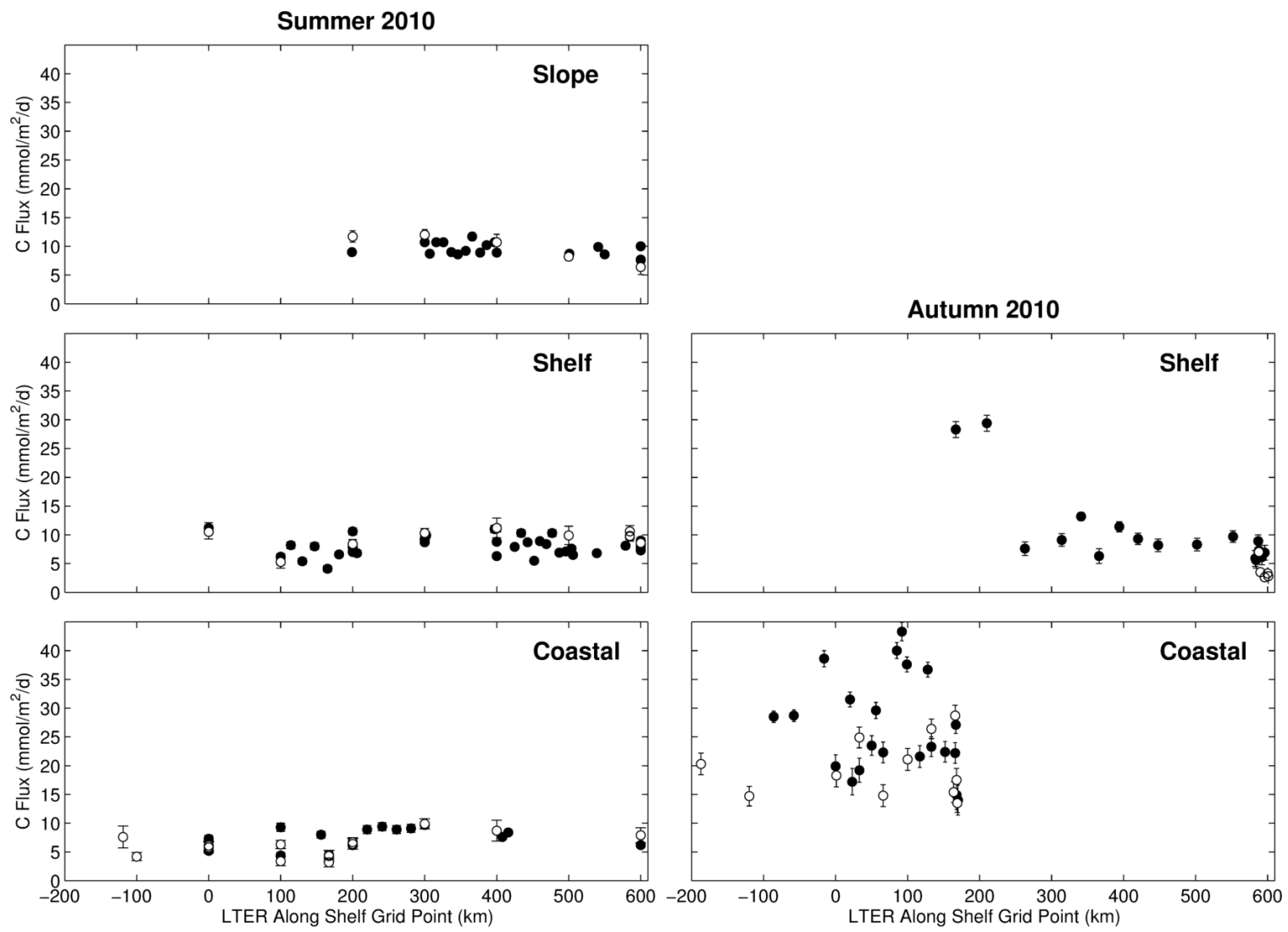

Figure 17 Comparison of carbon fluxes at the fluorocline along the West Antarctica Peninsula in summer and autumn 2010. Fluxes from water-column samples are in white and fluxes derived from surface measurements are in black. 

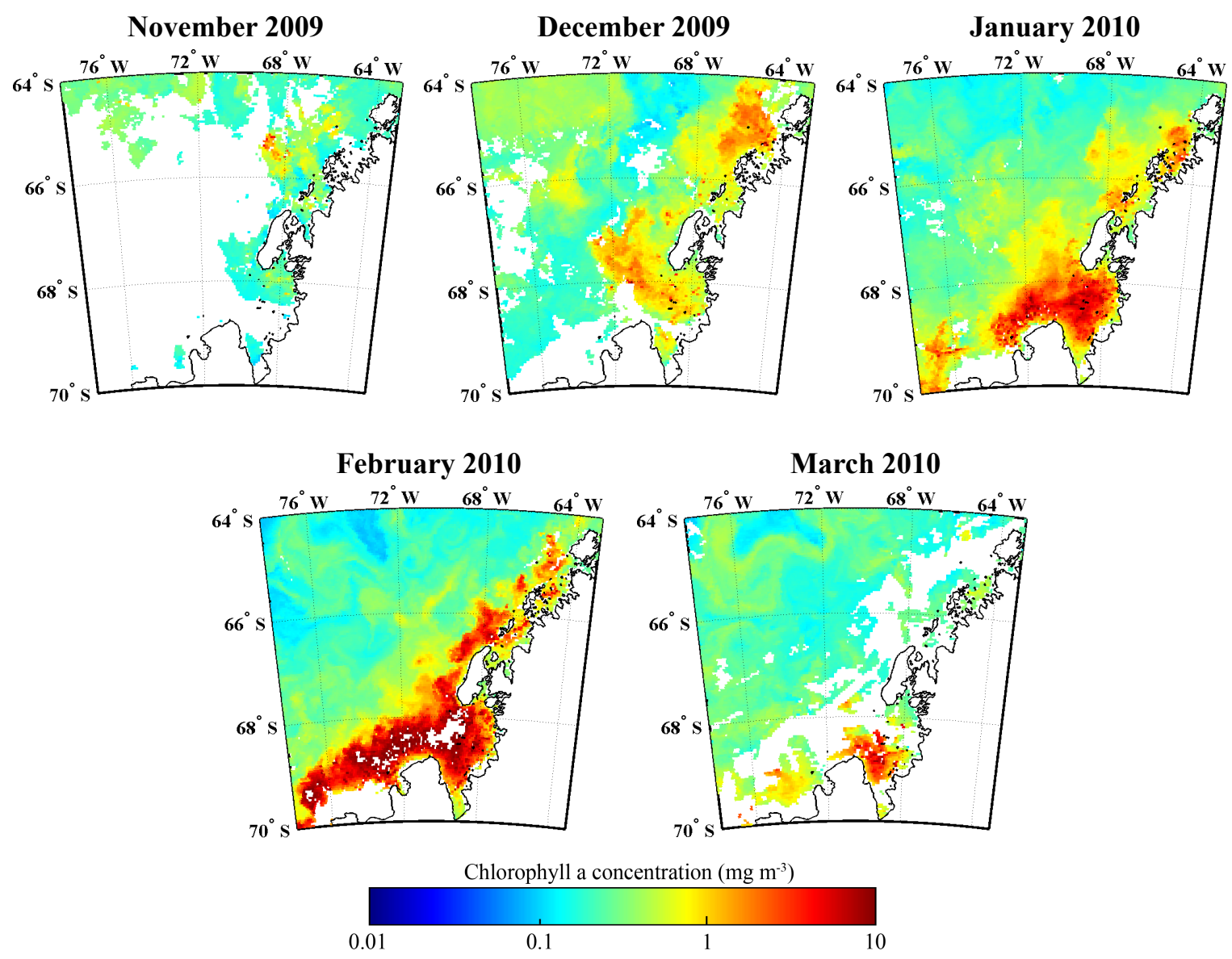

Figure 18 Monthly mean chlorophyll $a$ concentrations from MODIS adapted from McDonnell (2011). 

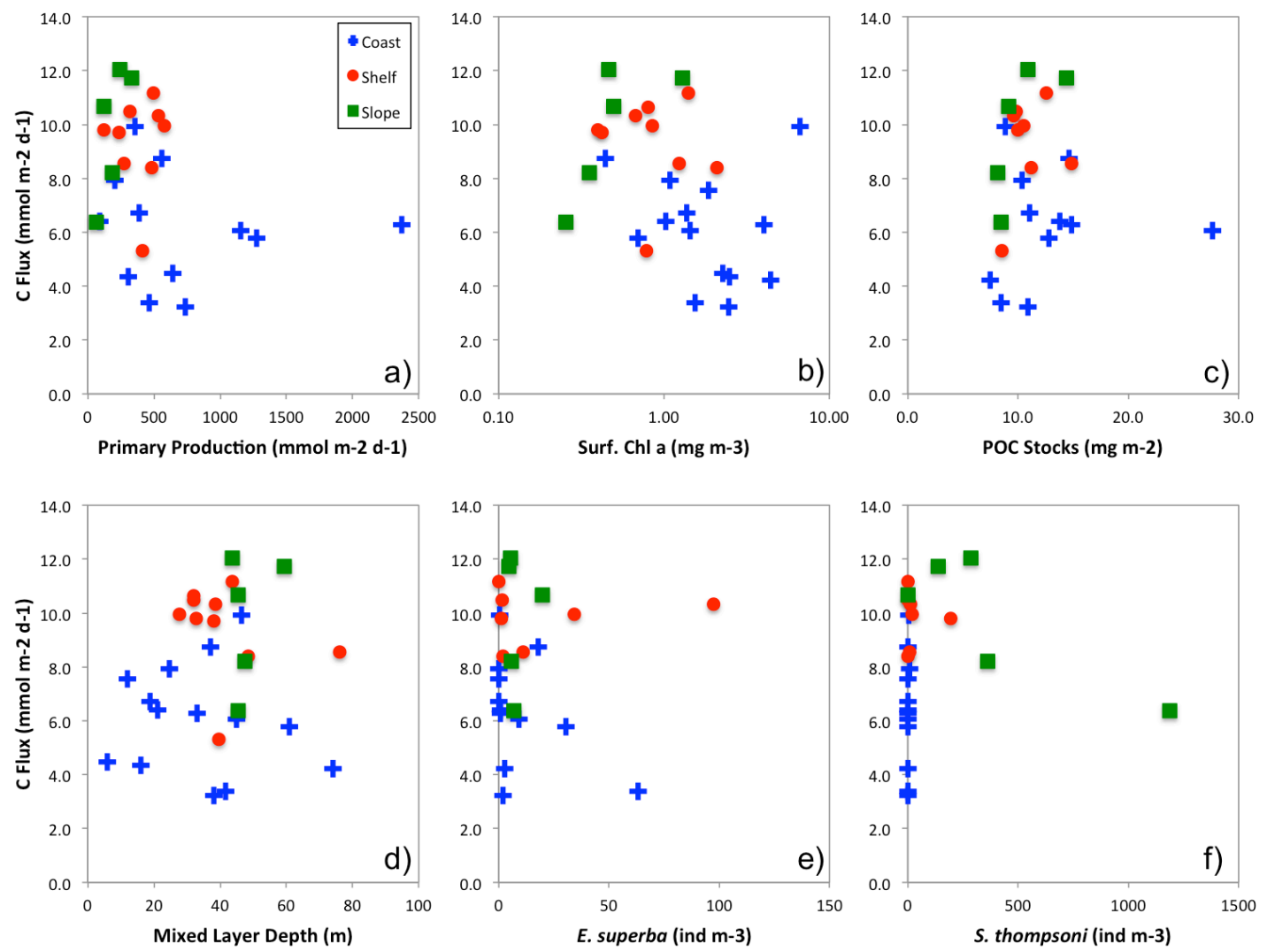

Figure 19 Carbon flux measurements from the January 2010 cruise derived from ${ }^{234} \mathrm{Th}$ fluxes and $\mathrm{C}^{234} \mathrm{Th}$ ratios. Shown are the data binned as coastal, shelf, and slope stations versus biological and physical properties of the WAP determined for this time period. Note that the $\mathrm{x}$-axis for $19 \mathrm{~b}$ is logarithmic. 


\section{Chapter 5:}

Thorium-234 as a tracer of particle dynamics in the Atlantic Ocean 


\section{Introduction}

The goal of the international GEOTRACES program is to identify processes and quantify fluxes that control the distribution of trace elements and isotopes in the ocean (GEOTRACES Planning Group, 2006). Trace elements play important roles in marine biogeochemical cycles, including the carbon cycle and GEOTRACES is a unique effort to quantify their role on a global scale. Isotopes are a key component of the GEOTRACES program as they can be used to measure rates of the physical, biological, and geochemical processes altering trace element distributions. Radioisotopes in particular can be used to estimate the time-scales on which these processes are important. Thorium-234 $\left({ }^{234} \mathrm{Th}\right)$, the subject of this work, can be used determine rates of upper ocean particle export and remineralization and in combination with other isotopes of thorium, can be used to determine rates of particle aggregation and disaggregation (Waples et al., 2006). Both scavenged-type trace metals, like aluminum, and nutrient-type trace metals, like iron and zinc, can be affected by the removal of particles from the surface ocean and remineralization at depth (Bruland and Lohan, 2003). Thus information on these processes from ${ }^{234} \mathrm{Th}$ measurements is essential for understanding their distributions.

Thorium-234 $\left(\mathrm{t}_{1 / 2}=24.1 \mathrm{~d}\right)$ is the particle-reactive daughter of uranium-238 $\left({ }^{238} \mathrm{U}\right.$; $\mathrm{t}_{1 / 2}=4.468 \times 10^{9} \mathrm{y}$ ), which is highly soluble in seawater (Djogić et al., 1986). Due to the significantly longer half-life of ${ }^{238} \mathrm{U}$ than ${ }^{234} \mathrm{Th}$, the two species are in secular equilibrium (Activity ${ }^{234} \mathrm{Th} /{ }^{238} \mathrm{U}=1$ ) when there are no net removal or addition processes acting on either species. The primary use of this isotope system in the ocean has been quantifying upper ocean particle export (Bhat et al., 1969; Coale and Bruland, 1987; Buesseler et al., 1992). Particles in the surface ocean from biological production or aeolian deposition scavenge ${ }^{234} \mathrm{Th}$. If these particles sink to deeper depths, they create a deficit of ${ }^{234} \mathrm{Th}$ relative to ${ }^{238} \mathrm{U}\left({ }^{234} \mathrm{Th} /{ }^{238} \mathrm{U}<1\right)$ in the upper ocean. This deficit can be quantified and used to derive the sinking flux of ${ }^{234}$ Th on sinking particles. Furthermore, the sinking fluxes of other particulate species such as carbon, minerals, or trace elements can be estimated by multiplying the ${ }^{234} \mathrm{Th}$ flux by the ratio of the species of interest to ${ }^{234} \mathrm{Th}$ on the particles (Weinstein and Moran, 2005; Buesseler et al., 2006). ${ }^{234}$ Th has also been 
used to identify regions of intense particle remineralization, when ${ }^{234} \mathrm{Th} /{ }^{238} \mathrm{U}>1$ (Savoye et al., 2004; Buesseler et al., 2008a). ${ }^{234}$ Th has been widely in other systems beyond the upper ocean including benthic boundary layers, surface sediments, and hydrothermal systems (Waples et al., 2006).

Much effort has been expended in recent years to improve methods for collection and analysis of ${ }^{234} \mathrm{Th}$ in seawater. Early surveys using ${ }^{234} \mathrm{Th}$ were limited both in their spatial and depth resolution due to the large sample volume requirements. One such study, conducted on the IOC 1996 baseline metals survey, was able to identify regions of increased particle export influenced by aeolian input from the Sahara (Charette and Moran, 1999). In that study however, ${ }^{234} \mathrm{Th}$ species were only measured at five stations ( $<10$ depths/station) because each sample required $\sim 200 \mathrm{~L}$ seawater. New small-volume methods require as little as $4 \mathrm{~L}$ of water (Benitez-Nelson et al., 2001b; Buesseler et al., 2001; Pike et al., 2005) and have been widely adopted in both process-studies and oceans transects (Buesseler et al., 2008b; Cai et al., 2008; Rutgers van der Loeff et al., 2011).

Here we present the ${ }^{234} \mathrm{Th}$ results from two transects of the Atlantic Ocean undertaken as part of the US and Dutch GEOTRACES programs. These data are a significant contribution to the rapidly growing global ${ }^{234} \mathrm{Th}$ data set (Henson et al., 2011). In this work we describe the variability in upper ocean export fluxes and derive estimates of carbon export in the Atlantic Ocean. We also highlight other interesting features of

this data set including the distribution of ${ }^{234} \mathrm{Th}$ in the mid- and deep-water column and the effect of the TAG hydrothermal plume emanating from the mid-Atlantic ridge. This work is an important contribution to the GEOTRACES program and when combined with other data sets from these studies, will be used to probe questions related to trace element cycling and particle dynamics in the ocean.

\section{Methods}

\subsection{GEOTRACES Cruises}

Samples were collected on two US GEOTRACES cruises to the North Atlantic (Section GA03) and a Dutch GEOTRACES cruise to the South Atlantic (Section GA02; 
Figure 1). The first leg of the North Atlantic cruise took place on the R/V/ Knorr (KN199-4, October 15 - November 4, 2010, hereafter referred to as L1) and headed due southwest from Lisbon, Portugal to $20^{\circ} \mathrm{W}$, then south towards the Cape Verde islands, concluding with a four-station transect from the Mauritanian coastline (Station 9) to the ocean time-series station TENATSO (Station 12). Due to a malfunction of the ship near Station 8, the cruise was abandoned until a later date. Sampling was resumed in 2011, on the R/V Knorr from Woods Hole, MA to the Cape Verde islands (KN204, November 6 December 11, 2011, hereafter referred to as L2). Stations of note on the second leg included an occupation of the Bermuda Atlantic Time-series Study (BATS) site at Station 10, sampling of the TAG hydrothermal plume at Station 16, and re-occupation of the TENATSO time-series site at Station 24. On these US GEOTRACES cruises, the full water column was sampled for dissolved and particulate parameters at "full" and "super" stations (denoted by filled symbols in Figure 1). To increase spatial resolution, a subset of parameters were collected at "demi" stations (denoted by open symbols in Figure 1) to $\sim 1000 \mathrm{~m}$.

Sampling was carried out on the Dutch GEOTRACES cruise in the South Atlantic on the RRS James Cook (JC057) from March 1 to April 7, 2011. Originating in Punta Arenas, Chile, the cruise track headed north from the Falkland Islands and followed the South American coastline, concluding in Grand Canary, Spain. Full water column sampling was carried out at all "regular" and "hyper" stations for most parameters, though sampling for ${ }^{234} \mathrm{Th}$ was more limited. Particulate sampling was carried out at only six stations and was restricted to the upper water column (denoted by filled symbols in Figure 1).

\subsection{Total $^{234}$ Th sampling and analyses}

US GEOTRACES:

Combined, on legs 1 and 2 of the US GEOTRACES cruises, 591 samples were collected for total ${ }^{234} \mathrm{Th}$ at 22 full water column stations ( $21 \mathrm{depths} / \mathrm{station}$ ) and at 21 upper-1000 m stations (13 depths/station). Surface samples at each station were collected 
using a pump located in the aft hangar of the ship with a sampling pipe extending $\sim 1-2 \mathrm{~m}$ below the surface. Twelve samples in the upper $\sim 1000 \mathrm{~m}$ were collected from a rosette and eight deeper samples were collected from Niskin bottles hung above the eight in situ pumps. At regular and super stations, eight of the twelve shallow ${ }^{234} \mathrm{Th}$ samples matched in situ pump and official GEOTRACES depths. The remaining four samples were used to increase sample resolution through the upper $200 \mathrm{~m}$ to better define the surface ${ }^{234} \mathrm{Th}$ deficit.

\section{Dutch GEOTRACES:}

Samples for total ${ }^{234} \mathrm{Th}$ were collected at 4 full water column stations (24 depths/station) and at 14 stations to $1000 \mathrm{~m}$ (13 depths/station), for a total of 276 samples. All samples were collected using the TITAN ultra-clean trace metal rosette system (De Baar et al., 2008).

\section{Both cruises:}

Archive water samples for ${ }^{238} \mathrm{U}$ were collected concurrently with ${ }^{234} \mathrm{Th}$ samples using acid-washed vials $\left(20 \mathrm{~mL}, 10 \% \mathrm{HCl}, 5 \% \mathrm{HNO}_{3}\right)$. Activity of ${ }^{238} \mathrm{U}$ was determined using the relationship between ${ }^{238} \mathrm{U}$ and salinity derived in Owens et al. (2011). ${ }^{234} \mathrm{Th}$ samples were collected in calibrated $4 \mathrm{~L}$ bottles. Immediately after collection, samples were acidified with $7 \mathrm{~mL}$ of concentrated nitric acid $\left(\mathrm{HNO}_{3}\right)$ to $\mathrm{pH} \sim 1.5 . \mathrm{A}{ }^{230} \mathrm{Th}$ spike (1 mL; Dutch and US L1: $95.49 \mathrm{dpm} \mathrm{g}^{-1}$; US L2: $48.07 \mathrm{dpm} \mathrm{g}^{-1}$ ) was added to each sample using a calibrated repeater pipette and samples were allowed to equilibrate for 7-8 hours. Next, the $\mathrm{pH}$ of the samples was raised to $\sim 8.0$ using concentrated ammonium hydroxide $\left(\mathrm{NH}_{4} \mathrm{OH}\right)$ and checked with a $\mathrm{pH}$ meter. Potassium permanganate $\left(\mathrm{KMnO}_{4}\right.$, $100 \mu \mathrm{L}$ ) and manganese chloride ( $\left.\mathrm{MnCl}_{2}, 100 \mu \mathrm{L}\right)$ were added in separate doses and the samples were agitated in between. Samples were again left for 7-8 hours, then the manganese precipitate was filtered onto QMA filters. When filtration was complete, samples were rinsed with $\mathrm{pH} 9$ milli-Q to remove salts from the filter. Finally, samples were dried in an oven for several hours at $60{ }^{\circ} \mathrm{C}$. Between uses, ${ }^{234} \mathrm{Th}$ sample bottles and filtration heads were rinsed with a solution of $1.0 \mathrm{M} \mathrm{HNO}_{3}$ with $1 \% \mathrm{H}_{2} \mathrm{O}_{2}$ then milli-Q. 
In preparation for beta counting, filters were placed on plastic mounts and covered with a single layer of Mylar and a double layer of aluminum foil. All samples were counted at sea on RISØ Laboratories anti-coincidence beta counters for twelve hours; samples were counted a second time and the mean value of two counts, decay corrected to collection time are reported here. Samples were recounted 5-6 months later to determine background radioactivity due to beta decay of isotopes. At the start and conclusion of each cruise, low and high activity ${ }^{238} \mathrm{U}$ standards and background counts were measured to confirm correct operation of the RIS $\varnothing$ detectors. On the US cruises, a helium $/ 1 \%$ butane mixture was used for quench gas in the detectors and on the Dutch cruise, an argon $/ 1 \%$ isobutane mixture was used.

After samples were counted for a final time, they were prepared for ICP-MS to determine the percent recovery of the ${ }^{230} \mathrm{Th}$ spike and thus ${ }^{234} \mathrm{Th}$ in the sample. The method used here was adapted from that of Pike et al. (2005); here, the samples were not purified using column chemistry techniques. Briefly, the samples were dissolved, spiked with a ${ }^{229}$ Th tracer, equilibrated overnight, and then diluted before analysis by ICP-MS. The mean percent recovery for typical samples that were not noted as having broken filters or lost material was $87 \%$. The overall efficiency of the method was determined using ${ }^{234}$ Th data between $1000 \mathrm{~m}$ and $1000 \mathrm{~m}$ above the bottom and minimizing the percent difference between the mean values of ${ }^{238} \mathrm{U}$ and ${ }^{234} \mathrm{Th}$. Efficiencies of 44.5, 46.4, and $51.8 \%$ were used for L1, L2, and Dutch GEOTRACES, respectively.

\subsection{Particulate Th-234 and carbon sampling and analyses}

US GEOTRACES:

Particulate ${ }^{234}$ Th samples were collected using McLane in situ pumps modified to accommodate two filter heads (Morris et al., 2011). At "full" and "super" stations, in situ pumps were deployed at sixteen depths that matched total ${ }^{234} \mathrm{Th}$ depths. Both filter heads contained $51 \mu \mathrm{m}$ pre-filters. Below these pre-filters, one filter head contained a Supor filter and the other contained an acid-cleaned QMA filter. Particles from half of the Supor pre-filter on L1 and the whole Supor pre-filter on L2 were rinsed onto silver filters 
using $1.0 \mu \mathrm{m}$-filtered seawater. The mean volume pumped through the whole Supor prefilter was $475 \mathrm{~L}$. The whole QMAs were oven dried and then a $25 \mathrm{~mm}$-diameter subsample was taken for beta counting. The mean effective volume for the $25 \mathrm{~mm}$ QMA subsample was $47 \mathrm{~L}$. The $>51 \mu \mathrm{m}$ samples were also oven-dried and both sets of samples were prepared for beta counting as described for total ${ }^{234} \mathrm{Th}$ samples above. Additional $12 \mathrm{~mm}$ punches were taken from the whole QMA for determination of total carbon. Both these $12 \mathrm{~mm}$ punches and subsamples of the Ag filters were analyzed for total carbon using a ThermoQuest Flash EA112 Carbon/Nitrogen Analyzer. Particulate inorganic carbon analyses are also being carried out on these samples by the Lam group and will be available at a later date in order to determine particulate organic carbon by difference.

Dutch GEOTRACES:

In situ pumps were deployed at three depths between 50 and $200 \mathrm{~m}$ at six stations with one filter head, containing only a $51 \mu \mathrm{m}$ pre-filter. Pump deployment times were $\sim 30$ minutes and the mean pumped volume was $\sim 450 \mathrm{~L}$. Particles were rinsed onto silver filters, oven-dried, and beta counted using RIS $\varnothing$ detectors. The silver filters were subsampled and analyzed only for total carbon.

\section{Results and discussion}

\section{$3.1{ }^{234}$ Th in the upper water column: export and remineralization}

The primary use of the ${ }^{234} \mathrm{Th} /{ }^{238} \mathrm{U}$ disequilibrium method has been for determining particle export from the upper water column, a key pathway in the biological carbon pump and a conduit for trace elements. To determine this export flux, it is necessary to define the surface deficit of ${ }^{234} \mathrm{Th}$ as well as possible (Figures $2-4$ ). On the US GEOTRACES cruises, this was accomplished by using the deck-mounted pump to gain an extra sample on the water-column cast and also by matching only 8 "official" depths and relocating the remaining four to the upper $200 \mathrm{~m}$. At demi-stations (L1: 2, 4, $6,8 ; \mathrm{L} 2: 5,11,13,15,17,19,21,23)$ however, while the deck pump was used to obtain a 
surface sample, less sample resolution in the upper $200 \mathrm{~m}$ was obtained. On Dutch GEOTRACES, higher resolution was obtained on all casts (Figure 4).

In our discussion of spatial trends, we have classified our sampling locations as in Thomalla et al. (2006): temperate $\left(35^{\circ}-50^{\circ} \mathrm{N}\right.$ and $\left.35^{\circ}-50^{\circ} \mathrm{S}\right)$, oligotrophic $\left(20^{\circ}-35^{\circ} \mathrm{N}\right.$ and $\left.5^{\circ}-35^{\circ} \mathrm{S}\right)$, upwelling $\left(5^{\circ}-20^{\circ} \mathrm{N}\right)$, and equatorial $\left(5^{\circ} \mathrm{N}-5^{\circ} \mathrm{S}\right)$ (Figure 1, Table 1). In the northern hemisphere, the largest deficits were found in the temperate and upwelling regions and the smallest were found across the oligotrophic region (Figure 5). In the southern hemisphere, deficits were largest at the highest latitudes and were smaller in the oligotrophic region, though not as small as in the northern hemisphere. At stations between 5 and $25^{\circ} \mathrm{S}$, the deficits extended deeper in the water column compared to other stations to the north and south.

To calculate the flux of ${ }^{234} \mathrm{Th}$, an expression of ${ }^{234} \mathrm{Th}$ activity with time $\left(\delta^{234} \mathrm{Th} / \delta t\right)$ is required:

$$
\delta^{234} T h / \delta t=\left({ }^{238} U-{ }^{234} T h\right) \lambda-P+V
$$

where ${ }^{238} \mathrm{U}$ is the activity of uranium, ${ }^{234} \mathrm{Th}$ is the measured activity of total ${ }^{234} \mathrm{Th}, \lambda$ is the decay constant of ${ }^{234} \mathrm{Th}\left(0.0288 \mathrm{day}^{-1}\right), \mathrm{V}$ is the sum of advective and vertical diffusive fluxes of ${ }^{234} \mathrm{Th}$, and $\mathrm{P}$ is the export of ${ }^{234} \mathrm{Th}$ on sinking particles. Here we assume that $\delta^{234} T h / \delta t$ equals zero, in other words, that the system is in steady state. A non-steady state model would require measurements of ${ }^{234} \mathrm{Th}$ profiles every few weeks at the same site, which is not possible on these transect cruises. Non-steady state effects are most important in periods of significant ${ }^{234} \mathrm{Th}$ drawdown, like during and at the end of phytoplankton blooms (Charette and Buesseler, 2000). The sampling periods of this study should not coincide with any significant seasonal blooms. Typically, the contribution of horizontal and vertical transport processes of ${ }^{234} \mathrm{Th}$ are not considered because of their minor contribution relative to the downward flux and the uncertainty of these flux estimates (Savoye et al., 2006). This is a reasonable assumption for the majority of the stations sampled on these cruises as concluded in prior studies (Thomalla et al., 2006; Buesseler et al., 2008a; Resplandy et al., 2012). This assumption may not hold in regions such as the Gulf Stream, sampled on L2, and the upwelling region off the 
coast of Mauritania, sampled on L1. In the Gulf Stream, lateral transport of ${ }^{234} \mathrm{Th}$ may be important however, the gradient in the direction of the Gulf Stream was not sampled and thus we cannot evaluate this assumption here. Off the coast of Mauritania, winds drive coastal water offshore and very close to the coast, water upwells to compensate (Mittelstaedt, 1991). Here we can consider the effects of not including offshore advection and vertical diffusivity in our flux calculations. There was a small offshore gradient of increasing ${ }^{234} \mathrm{Th}$ activity in the upper $100 \mathrm{~m}$ of $0.0007 \mathrm{dpm} \mathrm{L}^{-1} \mathrm{~km}^{-1}$ from Stations 9 to 12. Assuming an advection rate of $4 \mathrm{~cm} \mathrm{~s}^{-1}$ (Mittelstaedt, 1991), this translates to a ${ }^{234} \mathrm{Th}$ flux of $245 \mathrm{dpm} \mathrm{m}{ }^{-2} \mathrm{~d}^{-1}$ or the amount by which ${ }^{234} \mathrm{Th}$ export at the offshore stations would be overestimated. Vertical diffusivity rates from this cruise have been estimated using ${ }^{228} \mathrm{Ra}$ (Morris et al., 2012) and range from $0.33-0.88 \mathrm{~cm}^{2} \mathrm{~s}^{-1}$. Using the maximum estimate of diffusivity rates and the maximum gradient in ${ }^{234} \mathrm{Th}$ from Station $9(0.52 \mathrm{dpm} / \mathrm{L})$, vertical diffusion of ${ }^{234} \mathrm{Th}$ is on the order of $75 \mathrm{dpm} \mathrm{m}^{-2} \mathrm{~d}^{-1}$, which is less than the uncertainty on the downward ${ }^{234} \mathrm{Th}$ flux estimates. At present, we assume that horizontal and vertical processes are not significant in the ${ }^{234} \mathrm{Th}$ budget relative to the downward flux. In the future, when additional tracer information from these GEOTRACES cruises is available, we may be able to improve our model by incorporating these processes.

${ }^{234} \mathrm{Th}$ fluxes were integrated to the depth of the primary production zone (PPZ; Figures 2-4), defined here as the depth where fluorescence reaches $10 \%$ of its maximum value (Figure 6, Table 1). In general, these depths matched well the depth at which ${ }^{234} \mathrm{Th}$ and ${ }^{238} \mathrm{U}$ came into equilibrium (Figures 2-4). ${ }^{234} \mathrm{Th}$ fluxes in the Atlantic ranged from less than zero at oligotrophic stations in the North Atlantic to $1848 \mathrm{dpm} \mathrm{m}^{-2} \mathrm{~d}^{-1}$ at $40{ }^{\circ} \mathrm{S}$ in the temperate South Atlantic (Figure 7). In the oligotrophic regions, the mean fluxes were very different, $307 \pm 281 \mathrm{dpm} \mathrm{m}^{-2} \mathrm{~d}^{-1}\left(-275-805 \mathrm{dpm} \mathrm{m}^{-2} \mathrm{~d}^{-1}\right)$ in the North Atlantic versus $1106 \pm 334 \mathrm{dpm} \mathrm{m}^{-2} \mathrm{~d}^{-1}\left(533-1709 \mathrm{dpm} \mathrm{m}^{-2} \mathrm{~d}^{-1}\right)$ in the South Atlantic. In 2009, on L1, there was a trend of decreasing ${ }^{234} \mathrm{Th}$ flux offshore of Mauritania, with the lowest flux at the TENATSO site (Station 12). When the same site was reoccupied the following year, the ${ }^{234}$ Th flux was 6 times higher (Station 24) and the second highest 
flux value measured in the North Atlantic, perhaps due to a difference in atmospheric delivery of nutrients, which is known to be an important process in this region..

Carbon to ${ }^{234} \mathrm{Th}$ ratios $\left(\mathrm{C} /{ }^{234} \mathrm{Th}\right)$ on sinking particles, which are operationally defined here as $>51 \mu \mathrm{m}$, can be multiplied by the ${ }^{234}$ Th fluxes at the PPZ to derive estimates of carbon export. Particulate sampling was carried out at a subset of the stations where total ${ }^{234} \mathrm{Th}$ was measured, thus site-specific $\mathrm{C} /{ }^{234} \mathrm{Th}$ ratios at the PPZ are not available for every station. Consistent with previous studies (Buesseler et al., 2006), across all stations, $\mathrm{C} /{ }^{234} \mathrm{Th}$ ratios were highest in the surface and decreased with depth (Figure 8). Only samples from Station 1 in the northeast Atlantic at 185 and $235 \mathrm{~m}$ deviated from the general trend due to very low particulate ${ }^{234} \mathrm{Th}$ values at these depths. In order to obtain $\mathrm{C}^{234} \mathrm{Th}$ ratios at the PPZ depth at each site, data between 70 and $250 \mathrm{~m}$ (except L1 Station 1 samples) were sorted into $20 \mathrm{~m}$ bins and averaged. A power law relationship was derived using these average values (Figure 9) and $\mathrm{C} /{ }^{234} \mathrm{Th}$ ratios at the PPZ were calculated for each site (Table 1). For L1 Station 1, a site-specific C ${ }^{234} \mathrm{Th}$ ratio was used because of the anomalous features at depth. For L2 Station 1, the sitespecific $C /^{234}$ Th ratio was also used because of the shallow PPZ depth, outside the bounds of the regression. Uncertainty on the carbon fluxes is propagated from the ${ }^{234} \mathrm{Th}$ flux calculations and the standard deviations on the mean $\mathrm{C} /{ }^{234} \mathrm{Th}$ ratios in each depth bin.

The station-to-station trends in carbon fluxes (Figure 10) are not dramatically different from the trends in ${ }^{234} \mathrm{Th}$ flux because of the relatively small differences in $\mathrm{C} /{ }^{234} \mathrm{Th}$ ratios used at each station. The relative change between oligotrophic stations in the Northern and Southern Atlantic was small, from a factor of 3.6 difference in mean ${ }^{234} \mathrm{Th}$ fluxes to a factor of 3.2 difference in mean $\mathrm{C}$ fluxes (Table 2). The larger error bars on some of the flux values are due to higher uncertainty on $\mathrm{C} /{ }^{234} \mathrm{Th}$ ratios when the $\mathrm{PPZ}$ was relatively shallow. When compared to results from other studies, based on a recent compilation (Henson et al., 2011), our estimates are all lower (Figure 11, Table 2). A significant difference between our flux values and those compiled by Henson et al. (2011) is that we have calculated fluxes at the base of the PPZ versus at $100 \mathrm{~m}$ (Charette 
and Moran, 1999; Santschi et al., 1999; Charette et al., 2001; Thomalla et al., 2006) and $150 \mathrm{~m}$ (Buesseler et al., 2008a). Across all regions, except the temperate South Atlantic, the mean carbon flux at $100 \mathrm{~m}$ was higher than the mean PPZ flux. However, the percent difference between mean $\mathrm{C}$ fluxes at the PPZ and $\mathrm{C}$ fluxes from previous studies was greater than the percent difference between mean C fluxes at the PPZ versus 100; in other words, the differences between this and previous studies exceeds the difference in flux integration depths. Our few measurements of equatorial fluxes in late March are six times lower than previous measurements in two separate studies, in May 1996 and 2004. Fluxes in the oligotrophic regions are more similar however; interestingly Thomalla et al. (2006) also measured zero fluxes in the northern subtropical gyre, during a non-seasonal bloom period in the North Atlantic. These new data contributes a significant number of new measurements to the existing data set and will provide greater framework for parameterization of carbon export in global biogeochemical models.

Excesses of ${ }^{234} \mathrm{Th}$ immediately below the surface deficit have been reported in prior studies (Savoye et al., 2004; Buesseler et al., 2008a; Maiti et al., 2010) and are indicative of particle remineralization by heterotrophic bacteria and zooplankton. Higher resolution sampling made possible by small-volume ${ }^{234} \mathrm{Th}$ methods has allowed for the elucidation of these features. The short half-life of ${ }^{234} \mathrm{Th}$ implies that this remineralization has happened within days to several weeks of sampling. In the ${ }^{234} \mathrm{Th}$ profiles from the North Atlantic, examples of these excesses are evident throughout the temperate, oligotrophic, and upwelling regions (Figures 2 and 3). In most cases, these excesses are small deviations from equilibrium, regardless of the size of the deficit above. Significant deviations from equilibrium ( $>10 \%$ ) were observed at L1 Station 12 and L2 Stations $3,4,6,8,10,16,19$, and 22, even though ${ }^{234}$ Th fluxes were indistinguishable from zero at some of these stations. The presence of these remineralization features at these extremely low flux stations combined with the short half-life of ${ }^{234} \mathrm{Th}$ could be indicative of episodic export events where the flux signal has occurred previously, but remineralization is still occurring. Another possibility is that these features have been advected from regions of high export and thus higher remineralization. In the South 
Atlantic, significant excesses, those defined with two or more data points, were only observed at the stations in the temperate region of the transect (Figure 4). In the only other study to publish ${ }^{234} \mathrm{Th}$ profiles of comparable resolution in the South Atlantic ${ }^{234} \mathrm{Th}$ excess was observed at a single station in the southern part of the oligotrophic region (Thomalla et al., 2006).

\section{$3.2{ }^{234}$ Th in intermediate and deep-waters}

Sampling of ${ }^{234} \mathrm{Th}$ in the intermediate water column has been limited because of its primary application in the upper water column. It has been used however to examine near-bottom particle dynamics including sediment resuspension and scavenging by hydrothermal plumes. This new data set, primarily from the US GEOTRACES cruises, is the most extensive survey of ${ }^{234} \mathrm{Th}$ below $1000 \mathrm{~m}$. Below the depths of intense particle production, flux, and remineralization in the surface, ${ }^{234} \mathrm{Th}$ and ${ }^{238} \mathrm{U}$ are expected to be in equilibrium. As these new data reveal, this may not always be the case.

\subsubsection{Evidence of Mediterranean Outflow Water}

Mediterranean Outflow Water (MOW) spills out of the Mediterranean Sea through the Strait of Gibraltar into the Gulf of Cadiz and the Eastern Atlantic Ocean (Ambar et al., 2002). This warm, saline water mass is evident between depths of 800 to $1200 \mathrm{~m}$. The MOW also carries with it a plume of suspended particulate matter from its interaction with the seafloor in the Strait and the Gulf of Cadiz. In a previous study of the effect of MOW on particle dynamics in this region, Schmidt (2006) measured radionuclide distributions of this water immediately before and after its transit through the Strait and in eddies formed at intermediate depths from MOW. In the immediate outflow they found that total ${ }^{234} \mathrm{Th}$ and ${ }^{238} \mathrm{U}$ were in equilibrium but particulate ${ }^{234} \mathrm{Th}$ activity increased by a factor of four. Further west, they found a mid-water column deficit of total and dissolved ${ }^{234} \mathrm{Th}$ at $1000 \mathrm{~m}$. This feature implied recent particle export, likely from resuspended particulate material that was also corroborated by sediment trap data. 
Stations 1 to 6 on L1 were within the propagation region for eddies formed from MOW, but the influence of MOW on ${ }^{234} \mathrm{Th}$ is only evident at Station 1 (Figure 12). The MOW at this station ranged from 500 to $1500 \mathrm{~m}$. At these depths, there was a $10 \%$ deficit of total ${ }^{234} \mathrm{Th}$ relative to ${ }^{238} \mathrm{U}$. Large particles were only measured to $1000 \mathrm{~m}$, but at this depth, there was approximately a four-fold increase in $>51 \mu \mathrm{m}{ }^{234} \mathrm{Th}$. In the smaller size class, particulate ${ }^{234} \mathrm{Th}$ was elevated over the same depth range and was higher than even surface values. The increase in particulate ${ }^{234} \mathrm{Th}$ and deficit in total ${ }^{234} \mathrm{Th}$ imply recent scavenging of ${ }^{234} \mathrm{Th}$ by particles and subsequent removal to deeper in the water column. Based on these observations, we predict that there will be evidence of seafloor interaction in the radium isotope data at these depths and expect there will be a significant lithogenic component to the particles.

\subsection{2 ${ }^{234}$ Th in the TAG hydrothermal plume}

Neutrally buoyant plumes can emanate from hydrothermal systems and extend up to tens or hundreds of kilometers from their source. Iron and manganese rich particles in these plumes can scavenge reactive species from the water column includes some trace metals and radioisotopes like lead, polonium, and thorium (Kadko, 1996). These isotopes can then be used to determine scavenging rates of species onto particles and removal rates to the seafloor. This technique has been demonstrated using ${ }^{234} \mathrm{Th}$ at venting sites on the Juan de Fuca ridge in the Pacific (Kadko et al., 1994) and at the TAG hydrothermal site in the Atlantic (German et al., 1991). The TAG hydrothermal field was sampled at Station 16 on L2 and the depth range of the plume was identified based on transmissometry (Figure 13). The depth of the plume can vary on relative short time scales; on the down-cast of the in situ pumps, the maximum beam attenuation coefficient value was at $3318 \mathrm{~m}$ whereas on the up-cast the maximum was at $3186 \mathrm{~m}$. Previous observations of the plume placed it between 3300 and $3500 \mathrm{~m}$ (German et al., 1991). Through the plume, there was little disequilibrium between total ${ }^{234} \mathrm{Th}$ and ${ }^{238} \mathrm{U}$, only a very small excess from $7-10 \%$. However, there was a large deficit of dissolved ${ }^{234} \mathrm{Th}$ (total minus particulate) relative to ${ }^{238} \mathrm{U}$ at $3300 \mathrm{~m}$. At this depth, $50 \%$ of the total ${ }^{234} \mathrm{Th}$ 
was particulate, significantly different from the background conditions ( $>95 \%$ dissolved ${ }^{234} \mathrm{Th}$ ) above and below the plume. This dramatic increase in particulate ${ }^{234} \mathrm{Th}$ is consistent with measurements from TAG and other hydrothermal plumes (German et al., 1991; Kadko et al., 1994).

With the dissolved and particulate ${ }^{234} \mathrm{Th}$ data, we can calculate the rate of scavenging of ${ }^{234} \mathrm{Th}\left(J_{T h}\right)$ onto particles in the plume. The equation to express the rate of change in dissolved ${ }^{234} \mathrm{Th}$ with respect to time is:

$$
\delta^{234} T h_{d} / \delta t=\left({ }^{238} U-{ }^{234} T h_{d}\right) \lambda-J_{T h}
$$

${ }^{234} \mathrm{Th}_{\mathrm{d}}$ and ${ }^{238} \mathrm{U}$ are the activities of the dissolved species integrated over the depth of the plume and $\lambda$ is the decay constant of ${ }^{234} \mathrm{Th}$. In the above formulation, physical transport processes are neglected as we only have measurements of this plume from one station and cannot assess the gradient in ${ }^{234} \mathrm{Th}$ as a result of such processes. Assuming steady state, the rate of ${ }^{234} \mathrm{Th}$ scavenging onto particles is:

$$
J_{T h}=\left({ }^{238} U-{ }^{234} T h_{d}\right) \lambda
$$

The mean lifetime of dissolved ${ }^{234} \mathrm{Th}$ with respect to removal onto particles $\left(\tau_{\mathrm{d}}\right)$ is:

$$
\tau_{\mathrm{d}}={ }^{234} T h_{d} / J_{T h}
$$

Integrating from 3000 to 3505 , where there was a deficit of dissolved ${ }^{234} \mathrm{Th}$, the scavenging rate was $0.91 \mathrm{dpm} \mathrm{cm}^{-2} \mathrm{~d}^{-1}$ and the mean lifetime of dissolved ${ }^{234} \mathrm{Th}$ in the plume was 100 days. Where the dissolved ${ }^{234} \mathrm{Th}$ was lowest, the mean life of ${ }^{234} \mathrm{Th}$ was as low as 33 days. These values are of a similar order of magnitude as those measured on the Juan de Fuca ridge (Kadko et al., 1994). Whereas there was scavenging occurring in the plume, the lack of a deficit in total ${ }^{234} \mathrm{Th}$ indicates that the particles were slow sinking and there was no removal occurring on the time-scales observable with ${ }^{234} \mathrm{Th}$. Previously at the TAG site, German et al. (1991) found large (50\%) excesses of total ${ }^{230} \mathrm{Th}_{\left(\mathrm{t}_{1 / 2}=\right.}$ $75,380 \mathrm{y}$ ), which could only be explained by recycling of particles that had already settled out of the plume. Our data suggest that on the time-scale of ${ }^{234} \mathrm{Th}$ that this process is very small or inconsequential. 


\subsubsection{Disequilibria at intermediate depths}

Deficits of ${ }^{234} \mathrm{Th}$ at intermediate depths ( $>500 \mathrm{~m}$ to $1000 \mathrm{~m}$ off the bottom) have been identified in only a few studies. One case, as described above, was caused by the influence of Mediterranean Outflow Water (Schmidt, 2006). Other instances however have been identified further away from ocean margins in the subtropical Atlantic (Owens et al., 2011) and Pacific (Benitez-Nelson et al., 2001a) and the Southern Ocean (Coppola et al., 2005).

On the GEOTRACES transects in the North Atlantic, mid-water column deficits were observed at Stations 7 and 12 on L1 (Figure 14) and Stations 12, 18, and 24 on L2 (Figure 15). In two of these cases, the deficits were only measured at a single depth (L1 St. 12 and L2 St. 18), but in the other three cases, the deficits spanned up to $3500 \mathrm{~m}$. In all cases, the deviation from equilibrium ranged from 4 to $9 \%$ and there was no change in the partitioning of total ${ }^{234} \mathrm{Th}$ between the dissolved and particulate phases. This implies that scavenging and particle export had occurred on the time scale of a few weeks. At the two stations in the center of the gyre, it is unlikely that these features were due to interactions with the seafloor and are more likely due to a local process. In the previous observation of these features in the subtropical Atlantic, one instance was caused by low ${ }^{238} \mathrm{U}$ concentrations, but in the second case, the feature was unique to ${ }^{234} \mathrm{Th}$ (Owens et al., 2011). A local process that transforms suspended particles into sinking particles, such as fecal pellet production, could possibly create deficits in ${ }^{234} \mathrm{Th}$ at these depths (Sutherland et al., 2010). The other stations where deficits were observed at depth were closer to the ocean margin in the Eastern Atlantic, so it is possible that these features may be due to interaction with continental shelf material and horizontal transport. Once available, measurements of seafloor interaction and horizontal transport from radium isotopes and particle composition may be helpful in determining the source of these deficit signals. It might also be worthwhile to analyze ${ }^{238} \mathrm{U}$ samples from some of these stations to confirm that the changes occur in ${ }^{234} \mathrm{Th}$ rather its parent (Owens et al., 2011). 
In addition to excesses of ${ }^{234} \mathrm{Th}$ immediately below the PPZ, at many of the stations in the North Atlantic, excesses were also observed deeper in the water column (L1: St. 3, 9, 10, 11, 12, Fig. 12; L2: 2, 6, 8, 14, 20, 22, Fig. 13). The deviations from equilibrium ranged from 4 to $12 \%$. At these depths, $>95 \%$ of the total ${ }^{234} \mathrm{Th}$ was dissolved ${ }^{234} \mathrm{Th}$. The cause of these excesses that span hundreds to thousands of meters is not apparent. There was no significant change in partitioning of ${ }^{234} \mathrm{Th}$ between dissolved and particulate phases or changes in the beam attenuation coefficient at these depths. It will be interesting to compare these results to profiles of ${ }^{228} \mathrm{Th}\left(\mathrm{t}_{1 / 2}=1.9 \mathrm{y}\right)$, which integrates over a longer time scale. This comparison may shed some insight into whether these features are real or an artifact of our techniques for measuring ${ }^{234} \mathrm{Th}$.

\subsubsection{Near-bottom disequilibria}

While few measurements of ${ }^{234} \mathrm{Th}$ have been made in the mid-water column, ${ }^{234} \mathrm{Th}$ has been more widely applied to understand particle dynamics near the seafloor in benthic nepheloid layers (BNL). As in the upper ocean, particle rich nepheloid layers near the seafloor can scavenge reactive elements and isotopes including ${ }^{234} \mathrm{Th}$. Generally, this process manifests itself as an increase in particulate ${ }^{234} \mathrm{Th}$ and a decrease in dissolved and total ${ }^{234} \mathrm{Th}$, implying scavenging onto particles and resettling to the seafloor (Bacon and Rutgers van der Loeff, 1989; Turnewitsch and Springer, 2001; Rutgers van der Loeff et al., 2002; Inthorn et al., 2006; Turnewitsch et al., 2008). At sites where BNL are not present, ${ }^{234} \mathrm{Th}$ and ${ }^{238} \mathrm{U}$ have been observed in secular equilibrium. Here we report characteristics of the near-bottom behavior $\left(<1000 \mathrm{~m}\right.$ above bottom) of ${ }^{234} \mathrm{Th}$ at fourteen stations where both total and particulate ${ }^{234} \mathrm{Th}$ were sampled almost to the seafloor. Complete analysis of the residence time of ${ }^{234} \mathrm{Th}$ in these BNL would require concurrent measurements of ${ }^{234} \mathrm{Th}$ in the sediments, which were not sampled on these cruises. Below, we describe the behavior of ${ }^{234} \mathrm{Th}$ in three different instances observed in the North Atlantic: 1) when no BNL was present, 2) when a small BNL was present, defined by a small change in the beam attenuation coefficient, and 3) when a large BNL was present, defined by a dramatic increase in beam attenuation coefficient near the seafloor 
(Figures 14 and 15). Dissolved ${ }^{234} \mathrm{Th}$ was determined by the difference between total and particulate thorium. At many stations, ${ }^{234} \mathrm{Th}$ was only measured in the small particle size class at depth, thus ${ }^{234} \mathrm{Th}$ in the large size class, which is a very small fraction of the total ${ }^{234} \mathrm{Th}$, is neglected.

1) No BNL (L1: Station 3; L2: Stations 18 and 20)

At station 20, where four depths very close to the seafloor were sampled, the deviation from equilibrium was not larger than the uncertainty on ${ }^{234} \mathrm{Th}$ and ${ }^{238} \mathrm{U}$. This behavior is consistent with prior measurements of ${ }^{234} \mathrm{Th}$ in settings with no BNL (Bacon and Rutgers van der Loeff, 1989). At stations 3 (L1) and 18 (L2), although there was no evidence of a BNL, ${ }^{234} \mathrm{Th}$ values taken within 7 and $30 \mathrm{~m}$ of the seafloor, respectively, were below equilibrium. These deficits may have been caused by transient BNL that were present within several weeks of our measurements or the deficits could be advected signals from regions where BNL are present as in Turnewitsch et al. (2008).

2) Small BNL (L1: Stations 5, 7, 11, and 12; L2: Stations 1, 2, 12, 14, and 24)

The behavior of ${ }^{234} \mathrm{Th}$ varied in the small BNL that were observed at the eastern and western margins and east of Bermuda. At the TENATSO site (L1 Station 12 and L2 Station 24), from $3000 \mathrm{~m}$ to the bottom, there was a deficit of total ${ }^{234} \mathrm{Th}$ and an increase in particulate ${ }^{234} \mathrm{Th}$, which is consistent particle resuspension, scavenging, and settling in a BNL (Bacon and Rutgers van der Loeff, 1989). The depth range of the BNL at this station matched the approximate depth of the continental shelf to the east of this station. At Station 1 in the northwest Atlantic, there appeared to be two BNL, one between 1250 and $1675 \mathrm{~m}$ and a second from $1815 \mathrm{~m}$ to the bottom. Both of these layers corresponded with increases in particulate ${ }^{234} \mathrm{Th}$ and deficits of total ${ }^{234} \mathrm{Th}$. An excess of ${ }^{234} \mathrm{Th}$ was observed between the two layers, indicating remineralization of particles. Despite the presence of small BNL, at some stations, equilibrium values were measured near the seafloor (L1 Stations 5 and 7; L2 Stations 2, 12, and 14); both deficits and excesses of ${ }^{234} \mathrm{Th}$ were measured further away from the seafloor at these stations. Finally, at Station 11 (L1), ${ }^{234} \mathrm{Th}$ was in excess near the seafloor. Near-bottom deficits of ${ }^{234} \mathrm{Th}$ typically found in BNL are often mirrored by excesses of ${ }^{234} \mathrm{Th}$ in the sediments below (Rutgers 
van der Loeff et al., 2002). The equilibrium or excess values observed at stations where the BNL were weak might indicate local resuspension of high ${ }^{234} \mathrm{Th}$ activity sediments coupled with low scavenging rates or particle dissolution further away from the bottom. 3) Large BNL (L2: Stations 8, and 10)

Large BNL were observed at Stations 4-10 in the western North Atlantic, but the full water column was only sampled at Stations 8 and 10 due to high current speeds and angling of the wire during deployments at Stations 4 and 6. At Station 8, particulate ${ }^{234} \mathrm{Th}$ increased towards the bottom, total ${ }^{234} \mathrm{Th}$ was in equilibrium, and dissolved ${ }^{234} \mathrm{Th}$ decreased. The deficit of dissolved ${ }^{234} \mathrm{Th}$ is indicative of scavenging of ${ }^{234} \mathrm{Th}$ onto particles but the equilibrium of total ${ }^{234} \mathrm{Th}$ with ${ }^{238} \mathrm{U}$ suggests that settling rates out of the BNL are slow. The BNL at Station 10 spanned a larger depth range but was less intense compared to Station 8. There was an excess of total ${ }^{234} \mathrm{Th}$ in the upper part of the BNL, but ${ }^{234} \mathrm{Th}$ was in equilibrium near the bottom. At the bottom, there was a deficit of dissolved ${ }^{234} \mathrm{Th}$ due to the peak in particulate ${ }^{234} \mathrm{Th}$. This deficit in dissolved ${ }^{234} \mathrm{Th}$ implies scavenging, but the unusual excess further above the seafloor might suggest some complex recycling of local or advected particulate material. Measurements of radium isotopes and longer-lived thorium isotopes will provide more information on mixing rates and scavenging near the seafloor.

\section{Summary \& Conclusions}

Total and particulate ${ }^{234}$ Th were sampled on two transects of the Atlantic Ocean as part of the international GEOTRACES effort. These new data dramatically increased the spatial and depth resolution of ${ }^{234} \mathrm{Th}$ in this region. ${ }^{234} \mathrm{Th}$ fluxes were derived at the base of the PPZ, defined by the gradient in the chlorophyll fluorescence profile. Here $\mathrm{C} /{ }^{234} \mathrm{Th}$ ratios were applied to these fluxes to derive estimates of upper ocean carbon export. Once data on particulate composition become available, these measurements may be used to derive export fluxes of other species including ballast materials and trace elements. In both the North and South Atlantic, carbon fluxes were lowest in the oligotrophic gyres and were higher near the coastal margins. Estimates of carbon export 
were generally lower than prior measurements though these differences may be due to temporal differences of the measurements. Sub-PPZ remineralization peaks were observed even at stations where export flux of ${ }^{234} \mathrm{Th}$ was near zero, perhaps suggesting past episodic fluxes of ${ }^{234} \mathrm{Th}$.

While much emphasis has been placed on ${ }^{234} \mathrm{Th}$ in the upper ocean, less has been placed on its distribution in the mid-water column, in part because ${ }^{234} \mathrm{Th}$ is expected to be in equilibrium with ${ }^{238} \mathrm{U}$ at these depths. Although we cannot yet identify a cause for the deficits and excesses observed at these depths, their recurrence lends to credence to prior observations of these features. Analysis of archive ${ }^{238} \mathrm{U}$ samples at some of these stations may be worthwhile, to confirm that the observed features are due to ${ }^{234} \mathrm{Th}$. Also, results from concurrent measurements of ${ }^{228} \mathrm{Th}$ should reveal some evidence of these features. ${ }^{234} \mathrm{Th}$ near the seafloor has been used in prior studies to understand particle dynamics in benthic nepheloid layers (BNL). In the North Atlantic however, a wider range of behavior of ${ }^{234} \mathrm{Th}$ was observed near the seafloor both where BNL occurred and where they were absent. Whether ${ }^{234} \mathrm{Th}$ and ${ }^{238} \mathrm{U}$ were in equilibrium also varied with depth above the sea floor. Finally, unique effects of boundary processes on ${ }^{234} \mathrm{Th}$ were observed as a result of Mediterranean Outflow Water (MOW) in the Eastern Atlantic and at the TAG hydrothermal site. In the depth range of MOW, there was a deficit of total ${ }^{234} \mathrm{Th}$, likely caused by export of particles swept off the seafloor as the MOW passes through its narrow channel. At the TAG hydrothermal site, total ${ }^{234} \mathrm{Th}$ was near equilibrium, but there was a deficit of dissolved ${ }^{234} \mathrm{Th}$ implying scavenging of ${ }^{234} \mathrm{Th}$ onto particles, but slow settling of particles relative to the time scales observable by ${ }^{234} \mathrm{Th}$.

These high depth and spatial resolution data will be analyzed jointly with other data sets in the future such as radium and other thorium isotopes and particle composition with the aim of enhancing our understanding of particle dynamics and trace element cycling in the ocean. 


\section{Acknowledgments}

Thank you to the captain and crew of the R/V Knorr and RRS James Cook for their support of this work. Many thanks also to the lead principal investigators of the U.S. and Dutch GEOTRACES programs. Finally, thank you to the at-sea "pump group" members including Dan Ohnemus, Paul Morris, Kuanbo Zhou, Sylvain Rigaud, and Steve Pike. 


\section{References}

Ambar, I., Serra, N., Brogueira, M.J., Cabecadas, G., Abrantes, F., Freitas, P., Goncalves, C., Gonzalex, N., 2002. Physical, chemical, and sedimentological aspects of teh Mediterranean Outflow off Iberia. Deep-Sea Research I 49, 4163-4177.

Bacon, M.P., Rutgers van der Loeff, M.M., 1989. Removal of thorium-234 by scavenging in the bottom nepheloid layer of the ocean. Earth and Planetary Science Letters 92 (2), 157-164.

Benitez-Nelson, C., Buesseler, K.O., Karl, D.M., Andrews, J., 2001a. A time-series study of particulate matter export in the North Pacific Subtropical Gyre based on Th234 : U-238 disequilibrium. Deep-Sea Research I 48 (12), 2595-2611.

Benitez-Nelson, C.R., Buesseler, K.O., van der Loeff, M.R., Andrews, J., Ball, L., Crossin, G., Charette, M.A., 2001b. Testing a new small-volume technique for determining ${ }^{234} \mathrm{Th}$ in seawater. Journal of Radioanalytical and Nuclear Chemistry $248(3), 795-799$.

Bhat, S.G., Krishnaswamy, S., Lal, D., Rama, Moore, W.S., $1969 .{ }^{234} \mathrm{Th} /{ }^{238} \mathrm{U}$ ratios in the ocean. Earth and Planetary Science Letters 5, 483-491.

Bruland, K.W., Lohan, M.C., 2003. Controls of Trace Metals in Seawater. In: Elderfield, H. (Ed.), The Oceans and Marine Geochemistry. Elsevier Ltd., pp. 23-47.

Buesseler, K.O., Bacon, M.P., Cochran, J.K., Livingston, H.D., 1992. Carbon and nitrogen export during the JGOFS North Atlantic Bloom Experiment estimated from ${ }^{234} \mathrm{Th}:{ }^{238} \mathrm{U}$ disequilibria. Deep-Sea Research I 39 (7-8), 1115-1137.

Buesseler, K.O., Benitez-Nelson, C.R., Moran, S.B., Burd, A., Charette, M., Cochran, J.K., Coppola, L., Fisher, N.S., Fowler, S.W., Gardner, W., Guo, L.D., Gustafsson, O., Lamborg, C., Masque, P., Miquel, J.C., Passow, U., Santschi, P.H., Savoye, N., Stewart, G., Trull, T., 2006. An assessment of particulate organic carbon to thorium-234 ratios in the ocean and their impact on the application of ${ }^{234} \mathrm{Th}$ as a POC flux proxy. Marine Chemistry 100 (3-4), 213-233.

Buesseler, K.O., Benitez-Nelson, C.R., Rutgers van der Loeff, M., Andrews, J., Ball, L., Crossin, G., Charette, M.A., 2001. An intercomparison of small- and largevolume techniques for thorium-234 in seawater. Marine Chemistry 74 (1), 15-28.

Buesseler, K.O., Lamborg, C., Cai, P., Escoube, R., Johnson, R., Pike, S., Masque, P., McGillicuddy, D., Verdeny, E., 2008a. Particle fluxes associated with mesoscale eddies in the Sargasso Sea. Deep-Sea Research II 55 (10-13), 1426-1444.

Buesseler, K.O., Pike, S., Maiti, K., Lamborg, C.H., Siegel, D.A., Trull, T.W., 2008b. Thorium-234 as a tracer of spatial, temporal and vertical variability in particle 
flux in the North Pacific. Deep-Sea Research Part I-Oceanographic Research Papers 56 (7), 1143-1167.

Cai, P., Chen, W., Dai, M., Wan, Z., Wang, D., Li, Q., Tang, T., Lv, D., 2008. A highresolution study of particle export in the southern South China Sea based on Th234/U-238 disequilibrium. Journal of Geophysical Research 113.

Charette, M.A., Buesseler, K.O., 2000. Does iron fertilization lead to rapid carbon export in the Southern Ocean? Geochemistry, Geophysics, Geosystems 1, 2000GC000069.

Charette, M.A., Moran, S.B., 1999. Rates of particle scavenging and particulate organic carbon export estimated using ${ }^{234} \mathrm{Th}$ as a tracer in the subtropical and equatorial Atlantic Ocean. Deep-Sea Research II 46 (5), 885-906.

Charette, M.A., Moran, S.B., Pike, S.M., Smith, J.N., 2001. Investigating the carbon cycle in the Gulf of Maine using the natural tracer thorium 234. Journal of Geophysical Research-Oceans 106 (C6), 11553-11579.

Coale, K.H., Bruland, K.W., 1987. Oceanic stratified euphotic zone as elucidated by ${ }^{234} \mathrm{Th}:{ }^{238} \mathrm{U}$ disequilibria. Limnology and Oceanography 32 (1), 189-200.

Coppola, L., Roy-Barman, M., Mulsow, S., Povinec, P., Jeandel, C., 2005. Low particulate organic carbon export in the frontal zone of the Southern Ocean (Indian sector) revealed by ${ }^{234} \mathrm{Th}$. Deep-Sea Research I 52 (1), 51-68.

De Baar, H.J.W., Timmermans, K.R., Laan, P., De Porto, H.H., Ober, S., Blom, J.J., Bakker, M.C., Schilling, J., Sarthou, G., Smit, M.G., Klunder, M., 2008. Titan: A new facility for ultraclean sampling of trace elements and isotopes in the deep oceans in the international GEOTRACES program. Marine Chemistry 111 (1-2), 4-21.

Djogić, R., Sipos, L., Branica, M., 1986. Characterization of uranium (VI) in seawater. Limnology \& Oceanography 31 (5), 1122-1131.

GEOTRACES Planning Group, 2006. GEOTRACES Science Plan. Scientific Committee on Oceanic Research, Baltimore, Maryland.

German, C.R., Fleer, A.P., Bacon, M.P., Edmond, J.M., 1991. Hydrothermal Scavenging at the Mid-Atlantic Ridge - Radionuclide Distributions. Earth and Planetary Science Letters 105 (1-3), 170-181.

Henson, S.A., Sanders, R., Madsen, E., Morris, P.J., Le Moigne, F., Quartly, G.D., 2011. A reduced estimate of the strength of the ocean's biological carbon pump. Geophysical Research Letters 38 (L04606). 
Inthorn, M., Rutgers van der Loeff, M., Zabel, M., 2006. A study of particle exchange at the sediment-water interface in the Benguela upwelling area based on Th-234/U238 disequilibrium. Deep-Sea Research I 53, 1742-1761.

Kadko, D., 1996. Radioisotopic studies of submarine hydrothermal vents. Review of Geophysics 34 (3), 349-366.

Kadko, D., Feely, R., Massoth, G., 1994. Scavenging of Th-234 and phosphorus removal from the hydrothermal effluent plume over the North Cleft segment of the Juan de Fuca Ridge. Journal of Geophysical Research 99, 5017-5024.

Maiti, K., Benitez-Nelson, C.R., Buesseler, K.O., 2010. Insights into particle formation and remineralization using the short-lived radionuclide, thorium-234. Geophysical Research Letters 37.

Mittelstaedt, E., 1991. The ocean boundary along the northwest African coast: Circulation and oceanographic properties at the sea surface. Progress in Oceanography 26, 307-355.

Morris, P.J., Charette, M.A., Buesseler, K.O., Lam, P.J., Auro, M., Henderson, P., Manganini, S., Murray, J., Ohnemus, D., Owens, S.A., Pike, S.M., Zhou, K., 2011. The collection of trace elements and isotopes using a newly modified in situ pump - radium as a case study. Liege Colloquium, Liege, Belgium.

Morris, P.J., Charette, M.A., Jenkins, W.J., Henderson, G.M., Moore, W.S., 2012. Radium-derived mixing rates in the North Atlantic. 4th International Ra-Rn Workshop, Rhode Island, USA.

Owens, S.A., Buesseler, K.O., Sims, K.W.W., 2011. Re-evaluating the U-238-salinity relationship in seawater: Implications for the U-238/Th-234 disequilibrium method. Marine Chemistry 127, 31-39.

Pike, S.M., Buesseler, K.O., Andrews, J., Savoye, N., 2005. Quantification of ${ }^{234} \mathrm{Th}$ recovery in small volume sea water samples by inductively coupled plasma mass spectrometry. Journal of Radioanalytical and Nuclear Chemistry 263 (2), 355360.

Resplandy, L., Martin, A.P., Le Moigne, F., Martin, P., Aquilina, A., Mémery, M., Lévy, M., Sanders, R., 2012. How does dynamical spatial variability impact Th-234 derived estimates of organic export? Deep-Sea Research I.

Rutgers van der Loeff, M., Cai, P.H., Stimac, I., Bracher, A., Middag, R., Klunder, M.B., van Heuven, S.M.A.C., 2011. Th-234 in surface waters: Distribution of particle export flux across the Antarctic Circumpolar Current and in the Weddell Sea 
during the GEOTRACES expedition ZERO and DRAKE. Deep Sea Research Part II: Topical Studies in Oceanography 58 (25-26), 2749-2766.

Rutgers van der Loeff, M.M., Meyer, R., Rudels, B., Rachor, E., 2002. Resuspension and particle transport in the benthic nepheloid layer in and near Fram Strait in relation to faunal abundances and Th-234 depletion. Deep-Sea Research I 49 (11), 19411958.

Santschi, P.H., Guo, L., Walsh, I.D., Quigley, M.S., Baskaran, M., 1999. Boundary exchange and scavenging of radionuclides in continental margin waters of the Middle Atlantic Bight: implications for organic carbon fluxes. Continental Shelf Research 19 (5), 609-636.

Savoye, N., Benitez-Nelson, C., Burd, A.B., Cochran, J.K., Charette, M., Buesseler, K.O., Jackson, G.A., Roy-Barman, M., Schmidt, S., Elskens, M., 2006. ${ }^{234} \mathrm{Th}$ sorption and export models in the water column: A review. Marine Chemistry 100 (3-4), 234-249.

Savoye, N., Buesseler, K.O., Cardinal, D., Dehairs, F., 2004. Th-234 deficit and excess in the Southern Ocean during spring 2001: Particle export and remineralization. Geophysical Research Letters 31 (12), art. no.-L12301.

Schmidt, S., 2006. Impact of the Mediterranean Outflow Water on the particle dynamics in intermediate waters of the Northeast Atlantic as revealed by Th-234 and Th228. Marine Chemistry 100, 289-298.

Sutherland, K.R., Madin, L.P., Stocker, R., 2010. Filtration of submicrometer particles by pelagic tunicates. Proceedings of the National Academy of Sciences 107 (34), 15129-15134.

Thomalla, S., Turnewitsch, R., Lucas, M., Poulton, A., 2006. Particulate organic carbon export from the North and South Atlantic gyres: The ${ }^{234} \mathrm{Th} /{ }^{238} \mathrm{U}$ disequilibrium approach. Deep-Sea Research II 53 (14-16), 1629-1648.

Turnewitsch, R., Reyss, J.-L., Nycander, J., Waniek, J., Lampitt, R.S., 2008. Internal tides and sediment dynamics in the deep sea - Evidence from radioactive Th234/U-238 disequilibria. Deep-Sea Research I 55, 1727-1747.

Turnewitsch, R., Springer, B.M., 2001. Do bottom mixed layers influence Th-234 dynamics in the abyssal near-bottom water column? Deep-Sea Research I 48 (5), 1279-1307.

Waples, J.T., Benitez-Nelson, C., Savoye, N., Rutgers van der Loeff, M., Baskaran, M., Gustafsson, O., 2006. An introduction to the application and future use of ${ }^{234} \mathrm{Th}$ in aquatic systems. Marine Chemistry 100 (3-4), 166-189. 
Weinstein, S.E., Moran, S.B., 2005. Vertical flux of particulate Al, Fe, Pb, and Ba from the upper ocean estimated from Th-234/U-238 disequilibria. Deep-Sea Research I $52,1477-1488$. 
Table 1

Results from three GEOTRACES cruises in the Atlantic basin. ${ }^{234}$ Th fluxes were integrated to the depth of the primary production zone (PPZ). Carbon fluxes at each site were estimated using $\mathrm{C} /{ }^{234} \mathrm{Th}$ ratios based on a power law regression of $\mathrm{C} /{ }^{234} \mathrm{Th}$ ratios versus depth across all $>51 \mu \mathrm{m} \mathrm{C} / \mathrm{Th}$ data. Stations are classified as temperate $(\mathrm{T})$, oligotrophic $(\mathrm{O})$, upwelling $(\mathrm{U})$, or equatorial $(\mathrm{E})$.

\begin{tabular}{|c|c|c|c|c|c|c|c|c|c|c|}
\hline & St. & Lat & Long & Region & $\begin{array}{c}\mathrm{PPZ} \\
\mathrm{m}\end{array}$ & $\begin{array}{r}234- \\
\mathrm{dpn}\end{array}$ & $\mathrm{hF}$ & & $\begin{array}{c}\mathrm{C} / \mathrm{Th} \\
\text { umol dpm } \\
\text {-1 }\end{array}$ & $\begin{array}{c}\text { C Flux } \\
\mathrm{mmol} \mathrm{m}^{-2} \mathrm{~d}^{-}\end{array}$ \\
\hline US 1 & 1 & 38.33 & -9.66 & $\mathrm{~T}$ & 113 & 1041 & \pm & 107 & 4.1 & $4.2 \pm 0.4$ \\
\hline US 1 & 2 & 36.76 & -12.83 & $\mathrm{~T}$ & 131 & 928 & \pm & 170 & 2.8 & $2.6 \pm 0.8$ \\
\hline US 1 & 3 & 35.20 & -16.00 & $\mathrm{~T}$ & 116 & 326 & \pm & 107 & 3.1 & $1.0 \pm 0.5$ \\
\hline US 1 & 4 & 33.10 & -19.00 & $\mathrm{O}$ & 142 & 534 & \pm & 151 & 2.6 & $1.4 \pm 0.5$ \\
\hline US 1 & 5 & 31.00 & -22.00 & $\mathrm{O}$ & 164 & 472 & \pm & 165 & 2.3 & $1.1 \pm 0.5$ \\
\hline US 1 & 6 & 27.52 & -22.01 & $\mathrm{O}$ & 158 & -227 & \pm & 134 & 2.4 & $-0.5 \pm 0.4$ \\
\hline US 1 & 7 & 24.00 & -22.00 & $\mathrm{O}$ & 114 & 623 & \pm & 98 & 3.1 & $2.0 \pm 0.7$ \\
\hline US 1 & 8 & 21.00 & -22.00 & $\mathrm{O}$ & 144 & 805 & \pm & 130 & 2.6 & $2.1 \pm 0.7$ \\
\hline US 1 & 9 & 17.35 & -18.26 & $\mathrm{U}$ & 95 & 1150 & \pm & 91 & 3.6 & $4.2 \pm 1.8$ \\
\hline US 1 & 10 & 17.35 & -20.82 & $\mathrm{U}$ & 101 & 820 & \pm & 96 & 3.5 & $2.8 \pm 1.3$ \\
\hline US 1 & 11 & 17.35 & -22.78 & $\mathrm{U}$ & 98 & 741 & \pm & 85 & 3.5 & $2.6 \pm 1.2$ \\
\hline US 1 & 12 & 17.40 & -24.50 & $\mathrm{U}$ & 118 & 186 & \pm & 94 & 3.0 & $0.6 \pm 0.3$ \\
\hline US 2 & 1 & 39.69 & -69.81 & $\mathrm{~T}$ & 54 & 801 & \pm & 68 & 6.7 & $5.3 \pm 0.4$ \\
\hline US 2 & 2 & 39.35 & -69.54 & $\mathrm{~T}$ & 73 & 1436 & \pm & 60 & 4.5 & $6.4 \pm 2.9$ \\
\hline US 2 & 3 & 38.68 & -69.08 & $\mathrm{~T}$ & 87 & 554 & \pm & 80 & 3.9 & $2.2 \pm 1.1$ \\
\hline US 2 & 4 & 38.32 & -68.87 & $\mathrm{~T}$ & 157 & 148 & \pm & 113 & 2.4 & $0.4 \pm 0.3$ \\
\hline US 2 & 5 & 38.08 & -68.72 & $\mathrm{~T}$ & 156 & 499 & \pm & 136 & 2.4 & $1.2 \pm 0.5$ \\
\hline US 2 & 6 & 37.54 & -68.43 & $\mathrm{~T}$ & 106 & 835 & \pm & 89 & 3.3 & $2.8 \pm 1.3$ \\
\hline US 2 & 8 & 35.43 & -66.66 & $\mathrm{~T}$ & 117 & 286 & \pm & 97 & 3.1 & $0.9 \pm 0.4$ \\
\hline US 2 & 10 & 31.74 & -64.19 & $\mathrm{O}$ & 197 & -275 & \pm & 159 & 2.0 & $-0.6 \pm 0.3$ \\
\hline US 2 & 11 & 30.82 & -60.79 & $\mathrm{O}$ & 155 & 480 & \pm & 160 & 2.5 & $1.2 \pm 0.5$ \\
\hline US 2 & 12 & 29.70 & -56.82 & $\mathrm{O}$ & 184 & 495 & \pm & 158 & 2.1 & $1.1 \pm 0.5$ \\
\hline US 2 & 13 & 28.64 & -53.23 & $\mathrm{O}$ & 182 & 449 & \pm & 185 & 2.2 & $1.0 \pm 0.5$ \\
\hline US 2 & 14 & 27.58 & -49.63 & $\mathrm{O}$ & 181 & 148 & \pm & 138 & 2.2 & $0.3 \pm 0.3$ \\
\hline US 2 & 15 & 26.86 & -47.23 & $\mathrm{O}$ & 191 & 421 & \pm & 199 & 2.1 & $0.9 \pm 0.4$ \\
\hline US 2 & 16 & 26.14 & -44.83 & $\mathrm{O}$ & 185 & 66 & \pm & 154 & 2.1 & $0.1 \pm 0.3$ \\
\hline US 2 & 17 & 25.14 & -42.52 & $\mathrm{O}$ & 186 & 206 & \pm & 197 & 2.1 & $0.4 \pm 0.4$ \\
\hline US 2 & 18 & 24.15 & -40.22 & $\mathrm{O}$ & 193 & 181 & \pm & 153 & 2.1 & $0.4 \pm 0.3$ \\
\hline US 2 & 19 & 23.25 & -38.05 & $\mathrm{O}$ & 172 & 251 & \pm & 168 & 2.3 & $0.6 \pm 0.4$ \\
\hline US 2 & 20 & 22.33 & -35.87 & $\mathrm{O}$ & 174 & 266 & \pm & 146 & 2.2 & $0.6 \pm 0.4$ \\
\hline US 2 & 21 & 20.88 & -32.62 & $\mathrm{O}$ & 126 & 318 & \pm & 151 & 2.9 & $0.9 \pm 0.5$ \\
\hline US 2 & 22 & 19.43 & -29.38 & $\mathrm{U}$ & 139 & -14 & \pm & 141 & 2.7 & $0.0 \pm 0.4$ \\
\hline US 2 & 23 & 18.39 & -26.76 & $\mathrm{U}$ & 140 & 604 & \pm & 221 & 2.7 & $1.6 \pm 0.7$ \\
\hline
\end{tabular}




\begin{tabular}{|c|c|c|c|c|c|c|c|c|c|c|}
\hline & St. & Lat & Long & Region & $\begin{array}{c}\mathrm{PPZ} \\
\mathrm{m}\end{array}$ & $\begin{array}{r}234- \\
\mathrm{dpn}\end{array}$ & $\mathrm{hF}$ & $\begin{array}{l}\mathrm{ux} \\
\mathrm{d}^{-1}\end{array}$ & $\begin{array}{c}\mathrm{C} / \mathrm{Th} \\
\text { umol dpm } \\
\text {-1 }\end{array}$ & $\begin{array}{c}\text { C Flux } \\
\mathrm{mmol} \mathrm{m}^{-2} \mathrm{~d}^{-}\end{array}$ \\
\hline US 2 & 24 & 17.40 & -24.50 & $\bar{U}$ & 111 & 1088 & \pm & 138 & 3.2 & $3.5 \pm 1.2$ \\
\hline DT & 1 & -49.55 & -52.69 & $\mathrm{~T}$ & 99 & 1503 & \pm & 65 & 3.5 & $5.3 \pm 2.3$ \\
\hline DT & 2 & -48.97 & -48.88 & $\mathrm{~T}$ & 94 & 1848 & \pm & 63 & 3.6 & $6.7 \pm 2.8$ \\
\hline DT & 3 & -46.93 & -47.22 & $\mathrm{~T}$ & 89 & 1077 & \pm & 61 & 3.8 & $4.1 \pm 2.2$ \\
\hline DT & 4 & -44.70 & -45.55 & $\mathrm{~T}$ & 86 & 1227 & \pm & 59 & 3.9 & $4.8 \pm 2.5$ \\
\hline DT & 5 & -42.38 & -44.02 & $\mathrm{~T}$ & 69 & 1679 & \pm & 61 & 4.6 & $7.8 \pm 3.4$ \\
\hline DT & 6 & -39.97 & -42.49 & $\mathrm{~T}$ & 88 & 1655 & \pm & 60 & 3.8 & $6.4 \pm 3.3$ \\
\hline DT & 7 & -37.84 & -41.13 & $\mathrm{~T}$ & 153 & 1317 & \pm & 93 & 2.5 & $3.3 \pm 1.0$ \\
\hline DT & 8 & -35.01 & -39.44 & $\mathrm{~T}$ & 149 & 882 & \pm & 90 & 2.5 & $2.2 \pm 0.7$ \\
\hline DT & 9 & -32.09 & -37.46 & $\mathrm{O}$ & 160 & 922 & \pm & 96 & 2.4 & $2.2 \pm 0.7$ \\
\hline DT & 10 & -29.06 & -35.78 & $\mathrm{O}$ & 146 & 533 & \pm & 89 & 2.6 & $1.4 \pm 0.4$ \\
\hline DT & 11 & -26.09 & -34.28 & $\mathrm{O}$ & 168 & 1075 & \pm & 100 & 2.3 & $2.5 \pm 0.8$ \\
\hline DT & 12 & -22.47 & -32.73 & $\mathrm{O}$ & 188 & 1018 & \pm & 108 & 2.1 & $2.1 \pm 0.7$ \\
\hline DT & 13 & -17.02 & -30.59 & $\mathrm{O}$ & 194 & 1267 & \pm & 111 & 2.1 & $2.6 \pm 0.6$ \\
\hline DT & 14 & -12.89 & -29.22 & $\mathrm{O}$ & 231 & 1078 & \pm & 126 & 1.8 & $1.9 \pm 0.6$ \\
\hline DT & 15 & -9.15 & -28.00 & $\mathrm{O}$ & 197 & 1709 & \pm & 113 & 2.0 & $3.5 \pm 0.7$ \\
\hline DT & 16 & -5.68 & -28.46 & $\mathrm{O}$ & 163 & 1242 & \pm & 96 & 2.4 & $2.9 \pm 0.9$ \\
\hline DT & 17 & -2.64 & -28.91 & E & 119 & 1723 & \pm & 76 & 3.0 & $5.2 \pm 1.7$ \\
\hline DT & 18 & -0.18 & -32.88 & $\mathrm{E}$ & 137 & 1218 & \pm & 85 & 2.7 & $3.3 \pm 0.9$ \\
\hline
\end{tabular}




\section{Table 2}

Summary of carbon flux estimates in the regions shown in Figure 1 from this study and prior studies.

\begin{tabular}{ccccccc}
\hline & \multicolumn{3}{c}{ This Study } & \multicolumn{3}{c}{ Other Studies } \\
& $\mathrm{n}$ & $\begin{array}{c}\text { C Flux } \\
\text { at PPZ } \\
\mathrm{mmol} \mathrm{m}^{-2} \mathrm{~d}^{-1}\end{array}$ & $\begin{array}{c}\text { C Flux } \\
\text { at } 100 \mathrm{~m} \\
\mathrm{mmol} \mathrm{m}^{-2} \mathrm{~d}^{-1}\end{array}$ & $\mathrm{n}$ & $\begin{array}{c}\text { C Flux } \\
\text { at } 100 \mathrm{~m} \\
\mathrm{mmol} \mathrm{m}^{-2} \mathrm{~d}^{-1}\end{array}$ \\
\hline Temperate & $35^{\circ}-45^{\circ} \mathrm{N}$ & 10 & $2.7 \pm 2.0$ & $3.0 \pm 1.3$ & $10^{\mathrm{a}, \mathrm{b}, \mathrm{c}}$ & $10.7 \pm 11.8$ \\
Oligotrophic & $20^{\circ}-35^{\circ} \mathrm{N}$ & 17 & $0.8 \pm 0.7$ & $1.8 \pm 1.0$ & $6^{\mathrm{c}, \mathrm{d}}$ & $1.5 \pm 1.6$ \\
Upwelling & $5^{\circ}-20^{\circ} \mathrm{N}$ & 7 & $2.2 \pm 1.5$ & $2.4 \pm 1.4$ & $1^{\mathrm{c}}$ & 15.2 \\
Equatorial & $5^{\circ} \mathrm{S}-5^{\circ} \mathrm{N}$ & 2 & $4.3 \pm 1.4$ & $5.1 \pm 1.2$ & $7^{\mathrm{c}, \mathrm{e}, *}$ & $24.5 \pm 7.2$ \\
Oligotrophic & $5^{\circ}-35^{\circ} \mathrm{S}$ & 8 & $2.4 \pm 0.6$ & $3.0 \pm 0.4$ & $5^{\mathrm{c}, \mathrm{e}}$ & $5.3 \pm 3.9$ \\
Temperate & $35^{\circ}-50^{\circ} \mathrm{S}$ & 8 & $5.1 \pm 1.9$ & $4.9 \pm 1.5$ & $1^{\mathrm{c}}$ & 7.0 \\
\hline
\end{tabular}

${ }^{\text {a }}$ Charette et al. (2001)

${ }^{\mathrm{b}}$ Santschi et al. (1999)

c Thomalla et al. (2006)

${ }^{\mathrm{d}}$ Buesseler et al. (2008a)

${ }^{\mathrm{e}}$ Charette and Moran (1999)

* Values from Charette and Moran (1999) were included in the equatorial rather than the upwelling mean because of their distance from the Mauritanian upwelling and proximity to the equator. 


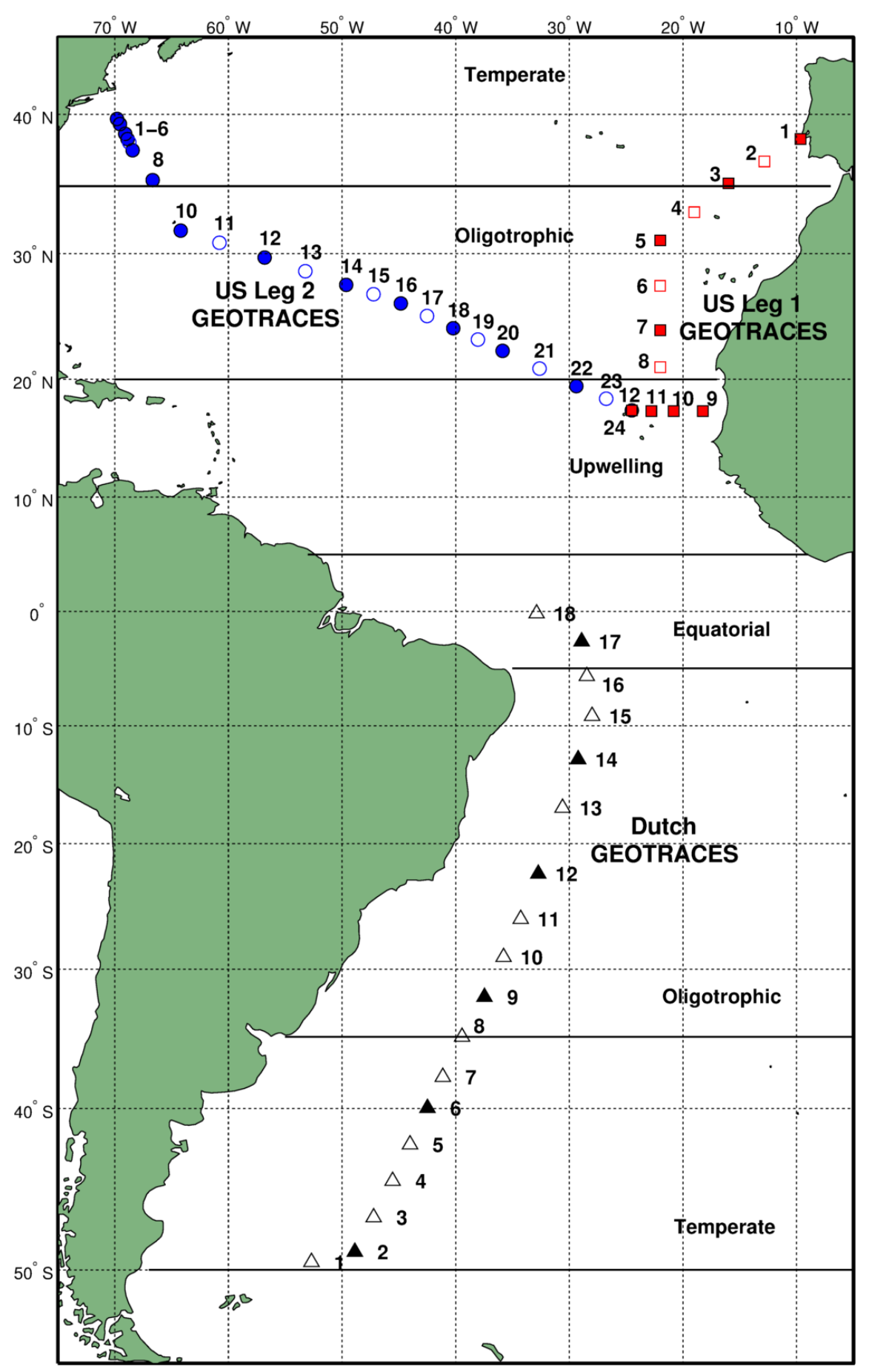

Figure 1 Sampling locations from Atlantic GEOTRACES campaigns. The northern Atlantic transect was sampled in two parts in October/November 2010 (red) and November/December 2011 (blue). The southern Atlantic was sampled in March/April 2011 (black). Filled symbols are where total and particulate ${ }^{234} \mathrm{Th}$ were sampled and hollow symbols are where only total ${ }^{234} \mathrm{Th}$ was sampled. 

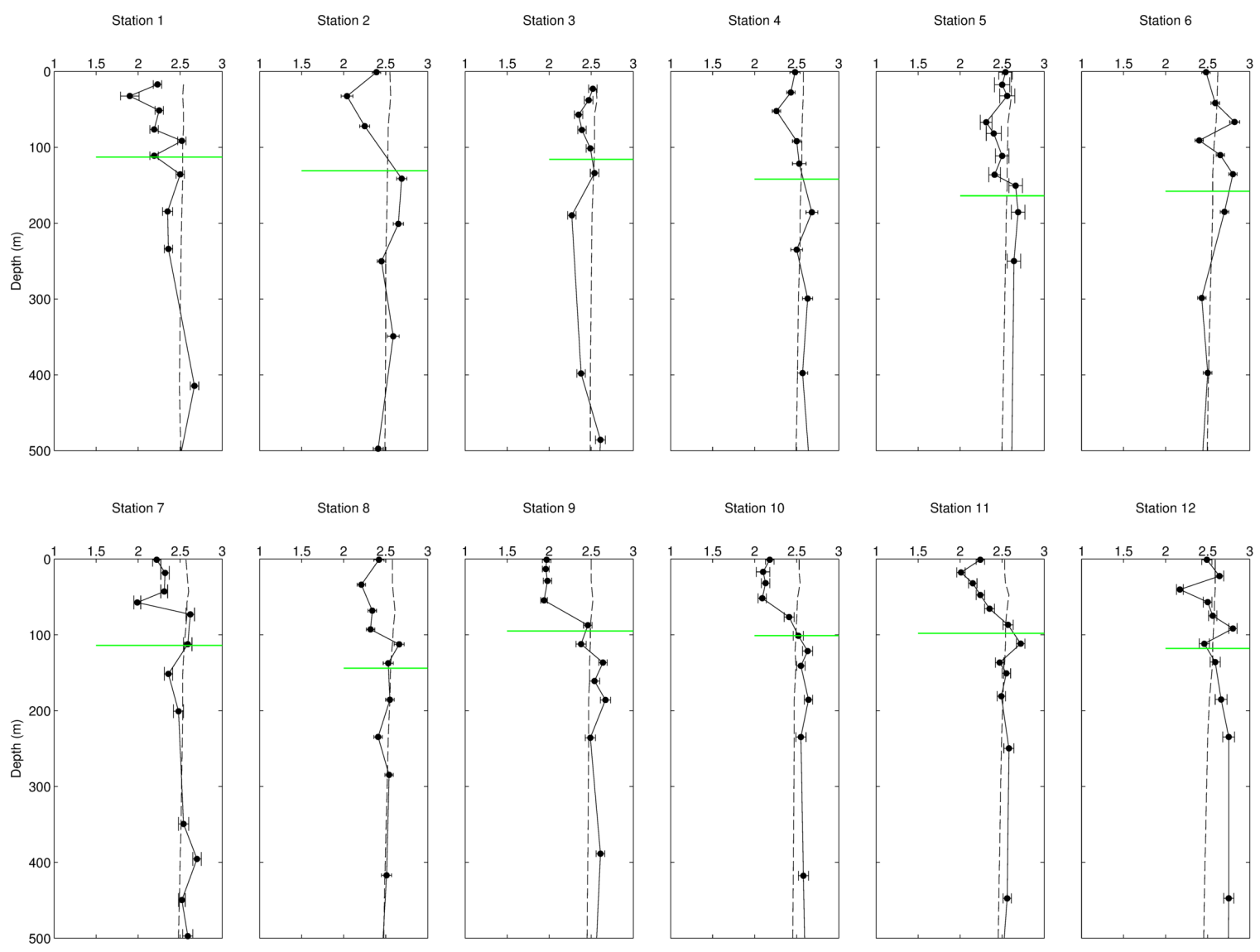

Figure $2{ }^{234} \mathrm{Th}$ profiles in the upper $500 \mathrm{~m}$ of the water column from US GEOTRACES Leg 1 (in red, Figure 1). The vertical dashed line is ${ }^{238} \mathrm{U}$ activity and the horizontal green line is the calculated PPZ depth. The same convention for ${ }^{238} \mathrm{U}$ and ${ }^{234} \mathrm{Th}$ is used throughout the rest of the figures. 


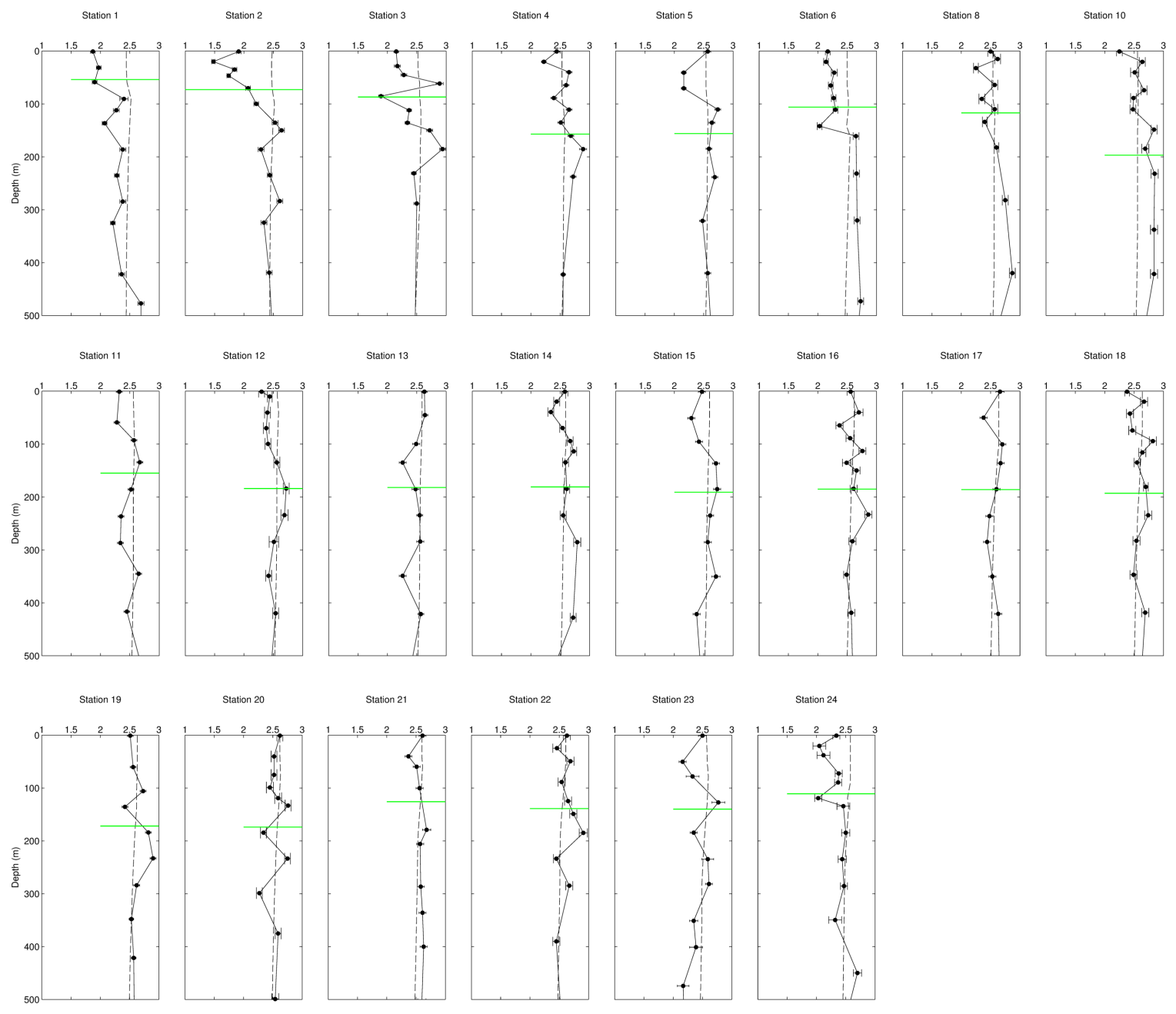

Figure $3{ }^{234} \mathrm{Th}$ profiles in the upper $500 \mathrm{~m}$ of the water column from US GEOTRACES Leg 2 (in blue, Figure 1). 

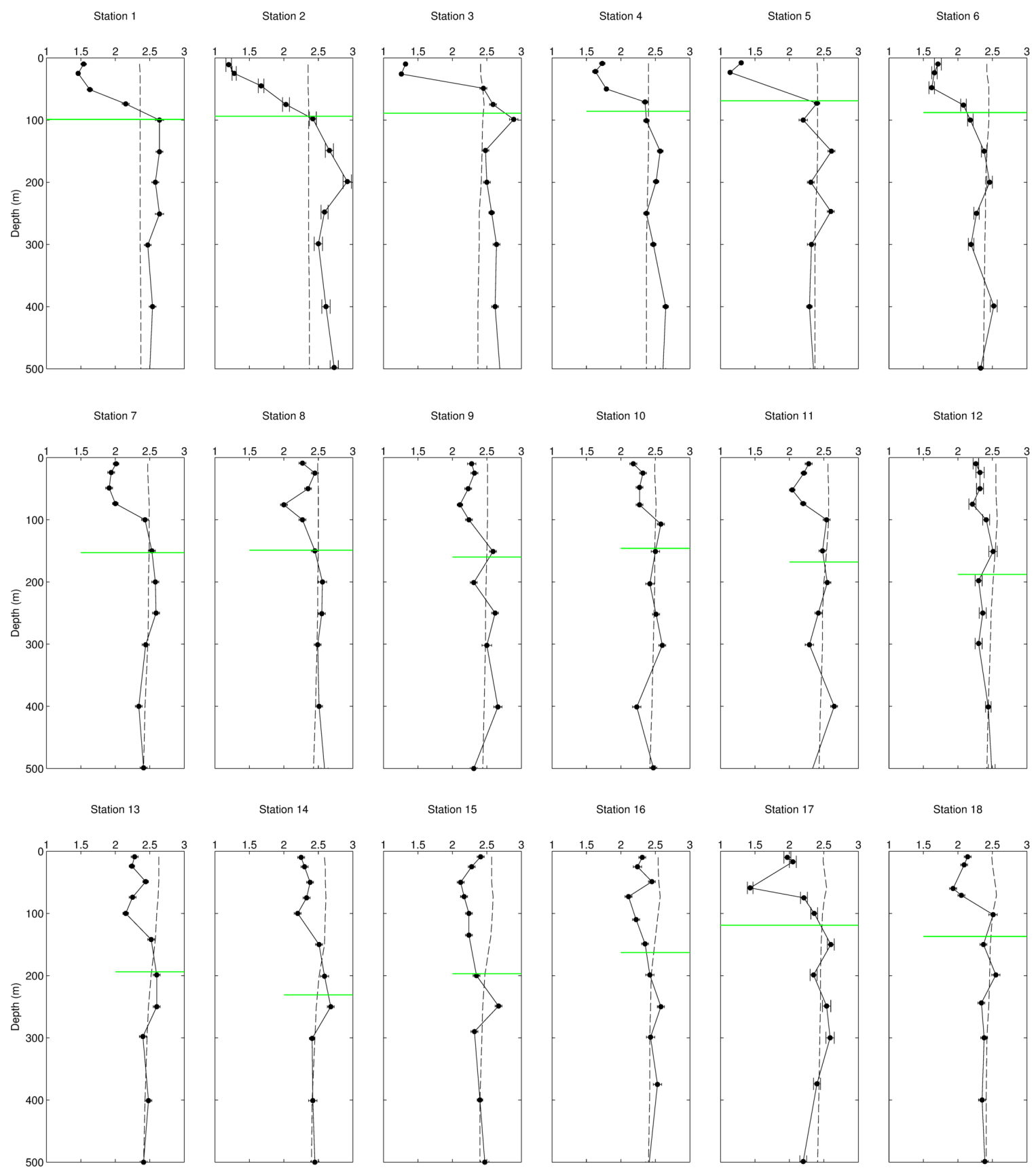

Figure $4{ }^{234}$ Th profiles in the upper $500 \mathrm{~m}$ of the water column from the South Atlantic Dutch GEOTRACES campaign (in black, Figure 1). 


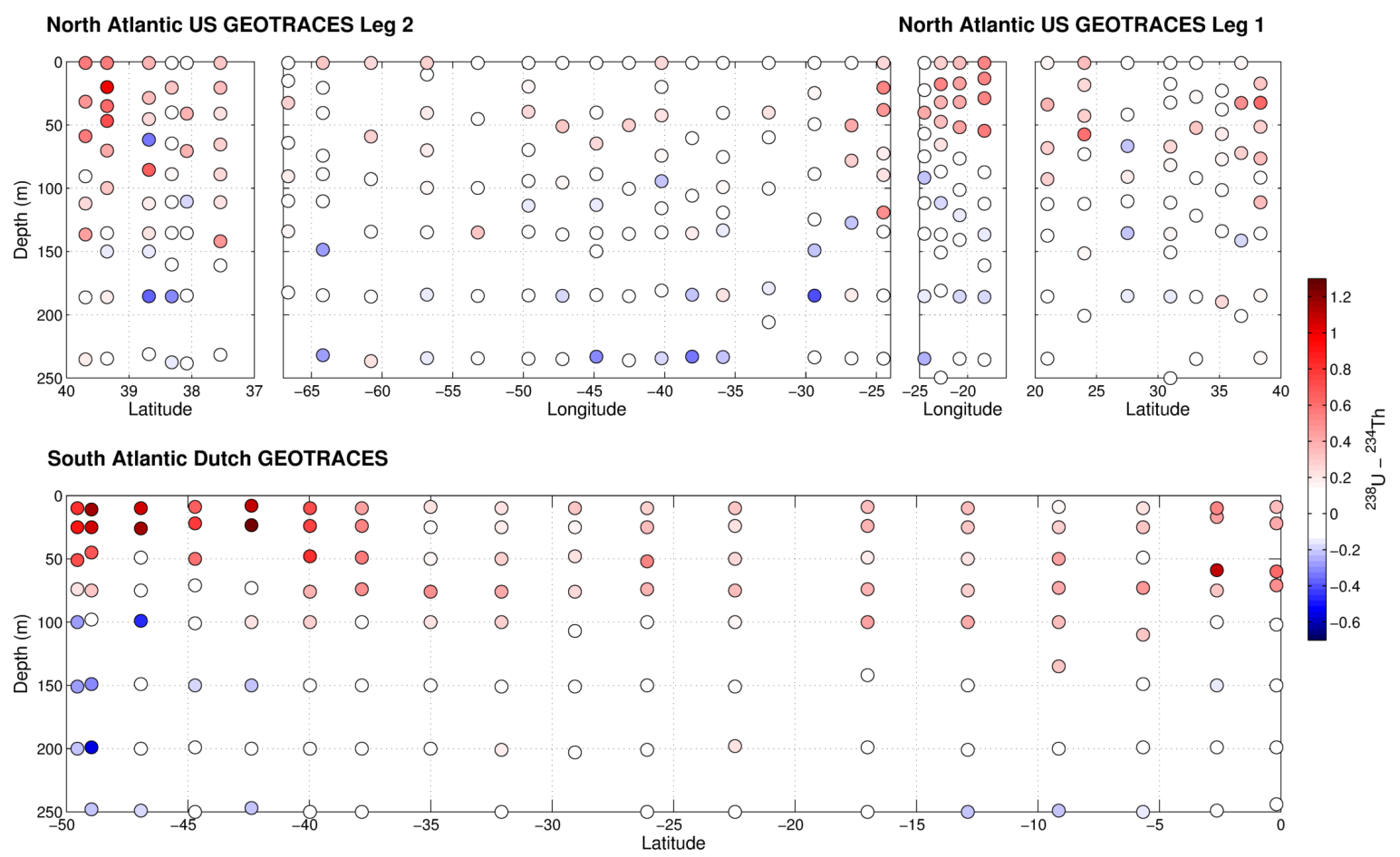

Figure 5 Summary of ${ }^{234} \mathrm{Th}$ deficits $\left({ }^{238} \mathrm{U}\right.$ minus $\left.{ }^{234} \mathrm{Th}\right)$ in the upper water column along three GEOTRACES transects. Red shades are areas of deficit, blue shades are areas of excess, and white values are where ${ }^{234} \mathrm{Th}$ and ${ }^{238} \mathrm{U}$ are within the analytical uncertainty of secular equilibrium. 

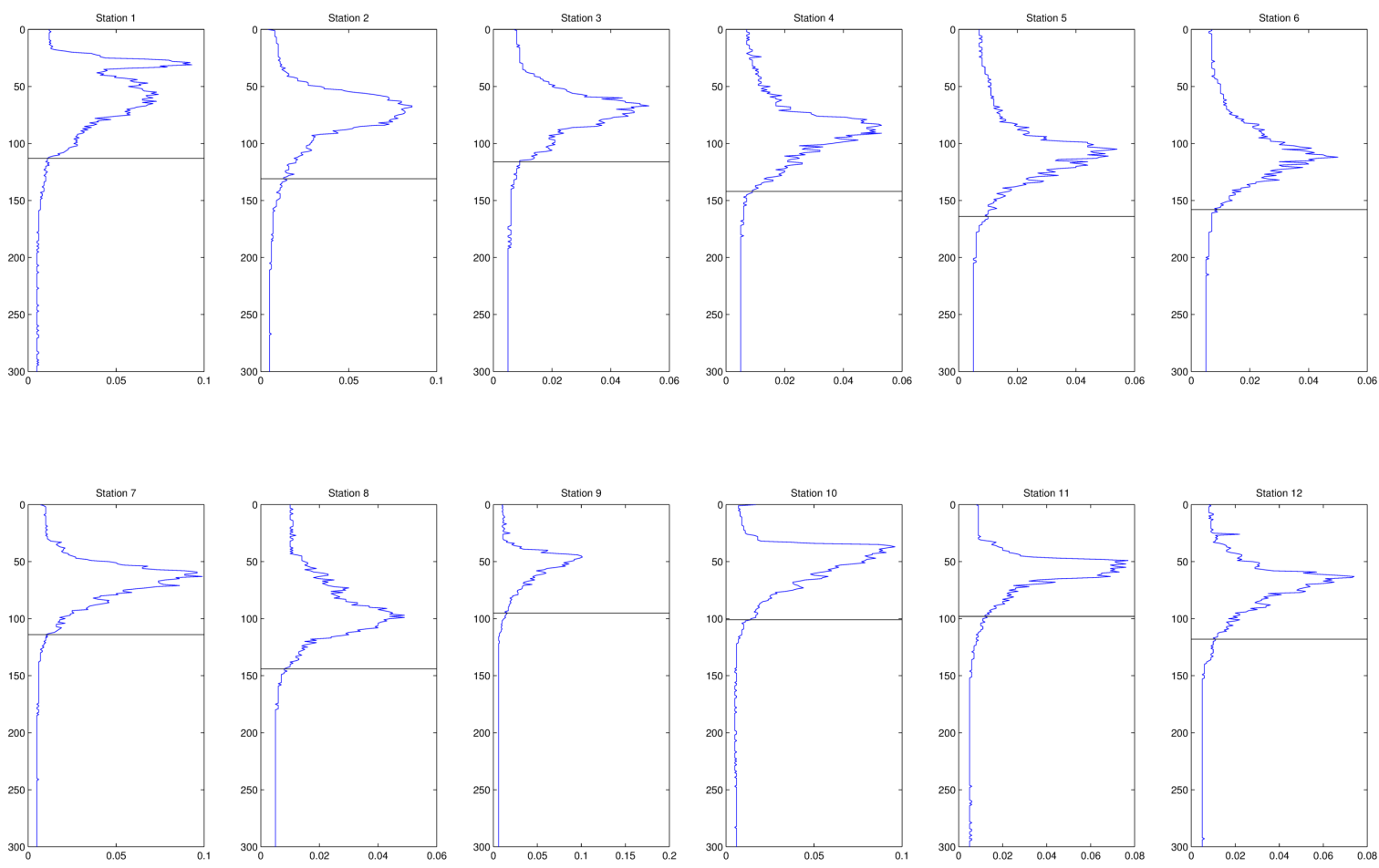

Figure 6 Sample calculations of PPZ depths based on fluorescence profiles (depth versus volts), shown here in blue from U.S. GEOTRACES Leg 1. The PPZ depth is denoted by the black line and is the depth below the fluorescence maximum at which fluorescence is $10 \%$ its maximum value. 

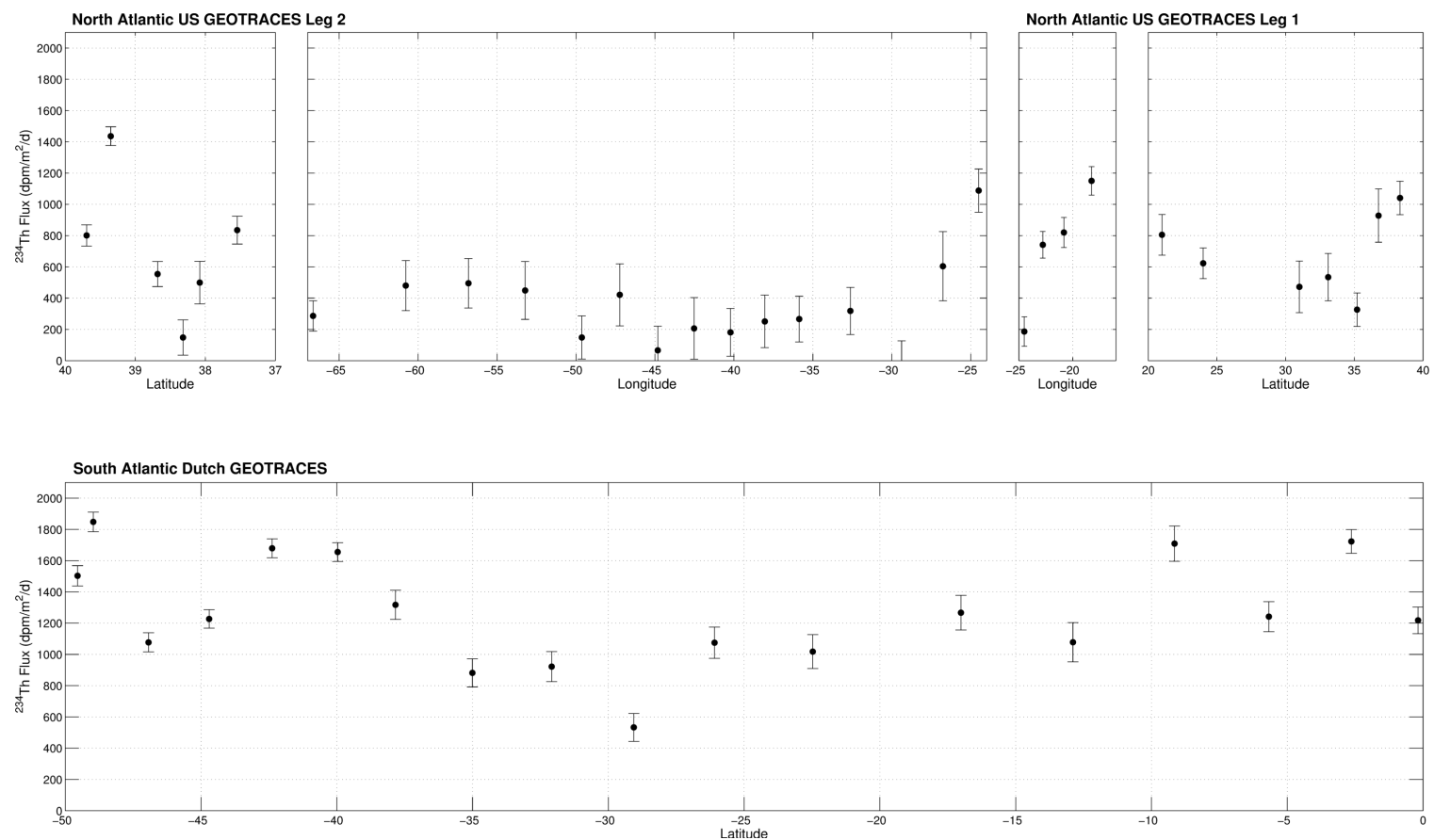

Figure $7{ }^{234}$ Th fluxes at the PPZ depth in the North and South Atlantic. 


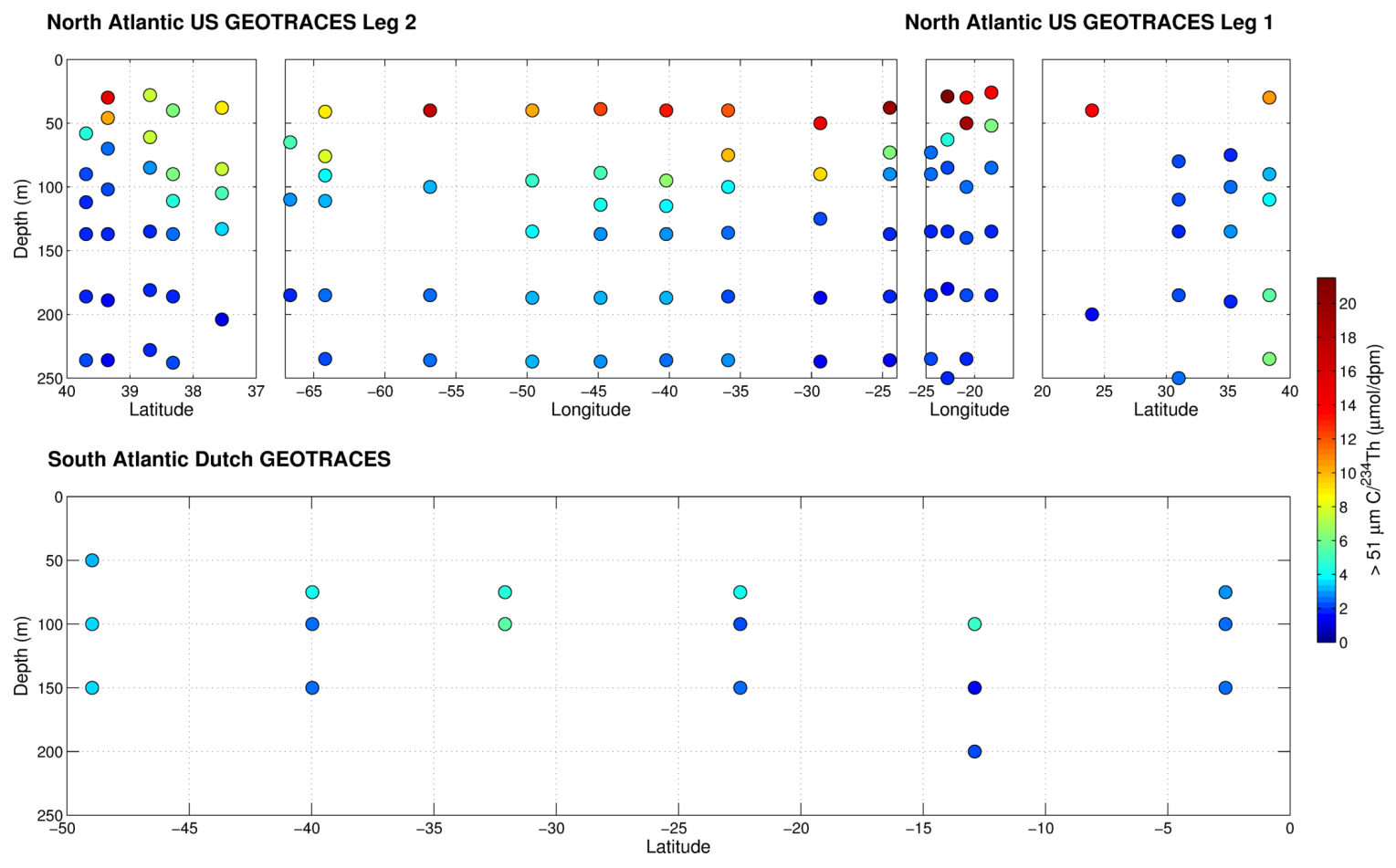

Figure $8 \mathrm{C} /{ }^{234} \mathrm{Th}$ geographic distribution in the North and South Atlantic. 


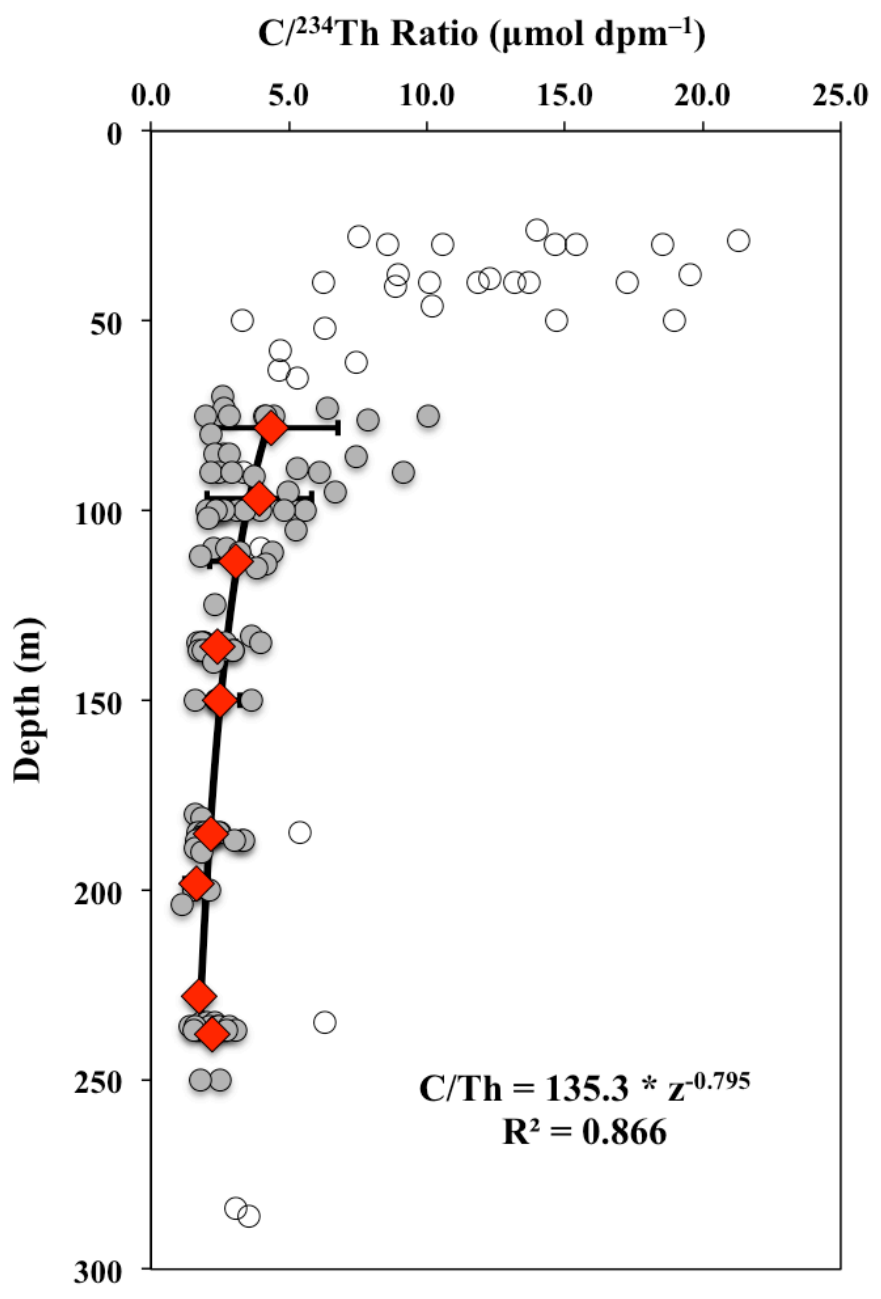

Figure $9 \mathrm{C} /{ }^{234} \mathrm{Th}$ ratios determined on large $(>51 \mu \mathrm{m})$ particles from all three GEOTRACES cruises. A power law regression was derived within the depth ranges of calculated PPZs (values in grey), using $20 \mathrm{~m}$-binned averages. This regression was used to calculate $\mathrm{C} /{ }^{234} \mathrm{Th}$ ratios at the PPZ depth of individual stations (Table 1). In white are values shallower and deeper than the range of PPZ depths. Also in white and not included in the regression are samples from L1 Station 1. 

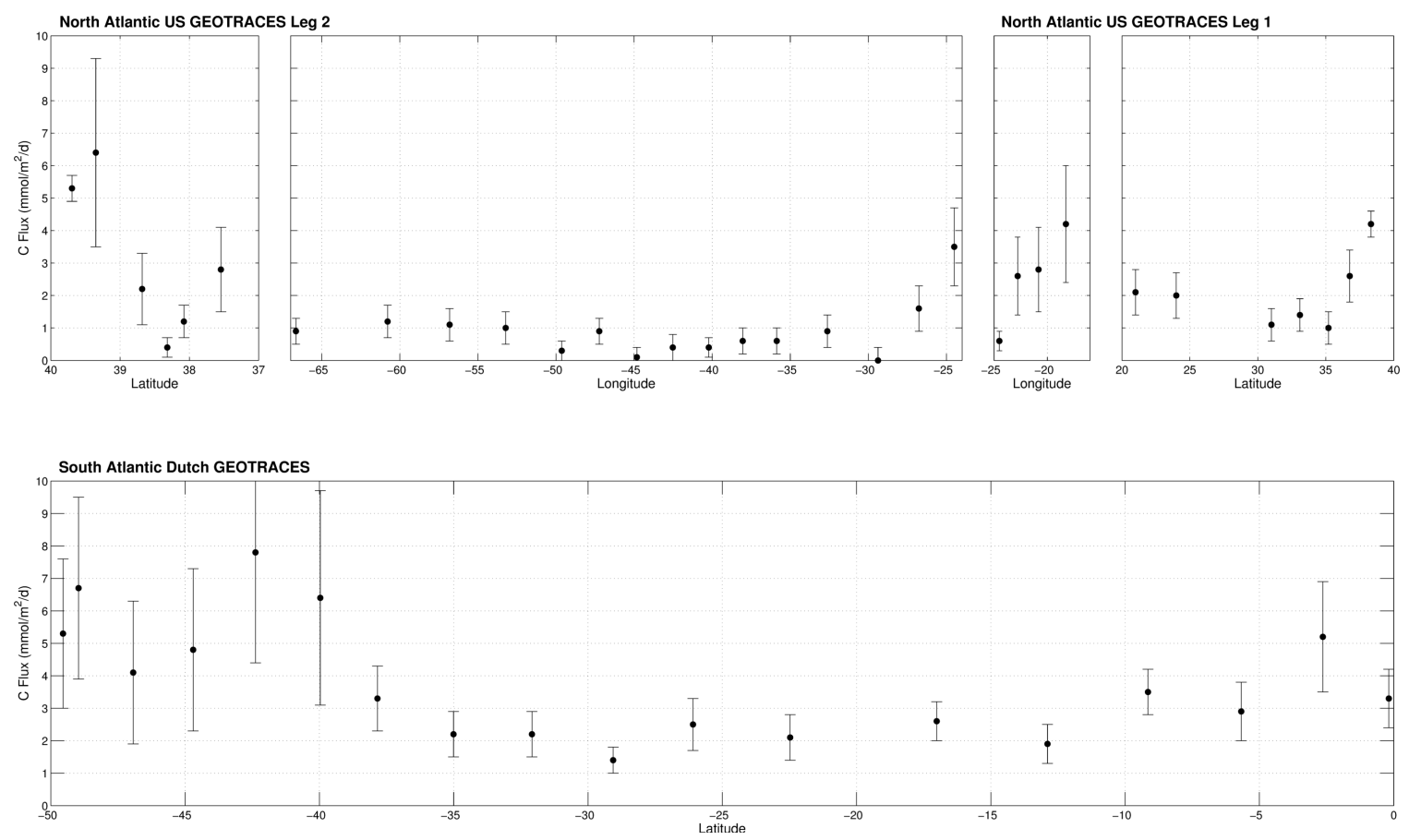

Figure 10 Carbon fluxes estimated from ${ }^{234} \mathrm{Th}$ fluxes and $\mathrm{C} /{ }^{234} \mathrm{Th}$ ratios at the PPZ depth. 


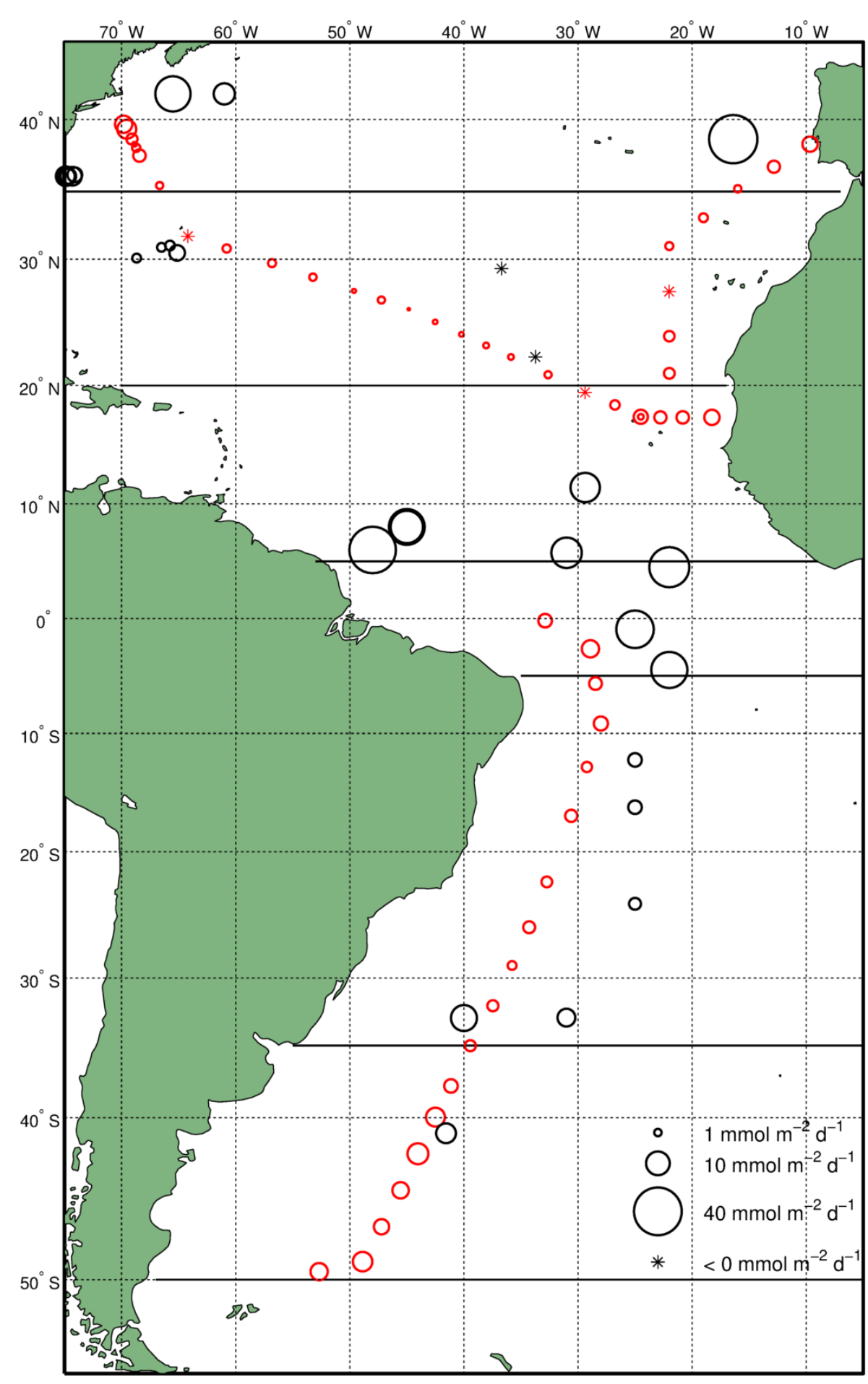

Figure 11 Comparison of POC fluxes from this study (in red) to other ${ }^{234} \mathrm{Th}$-derived estimates of POC export (in black) taken from the compilation by Henson et al (2011). 

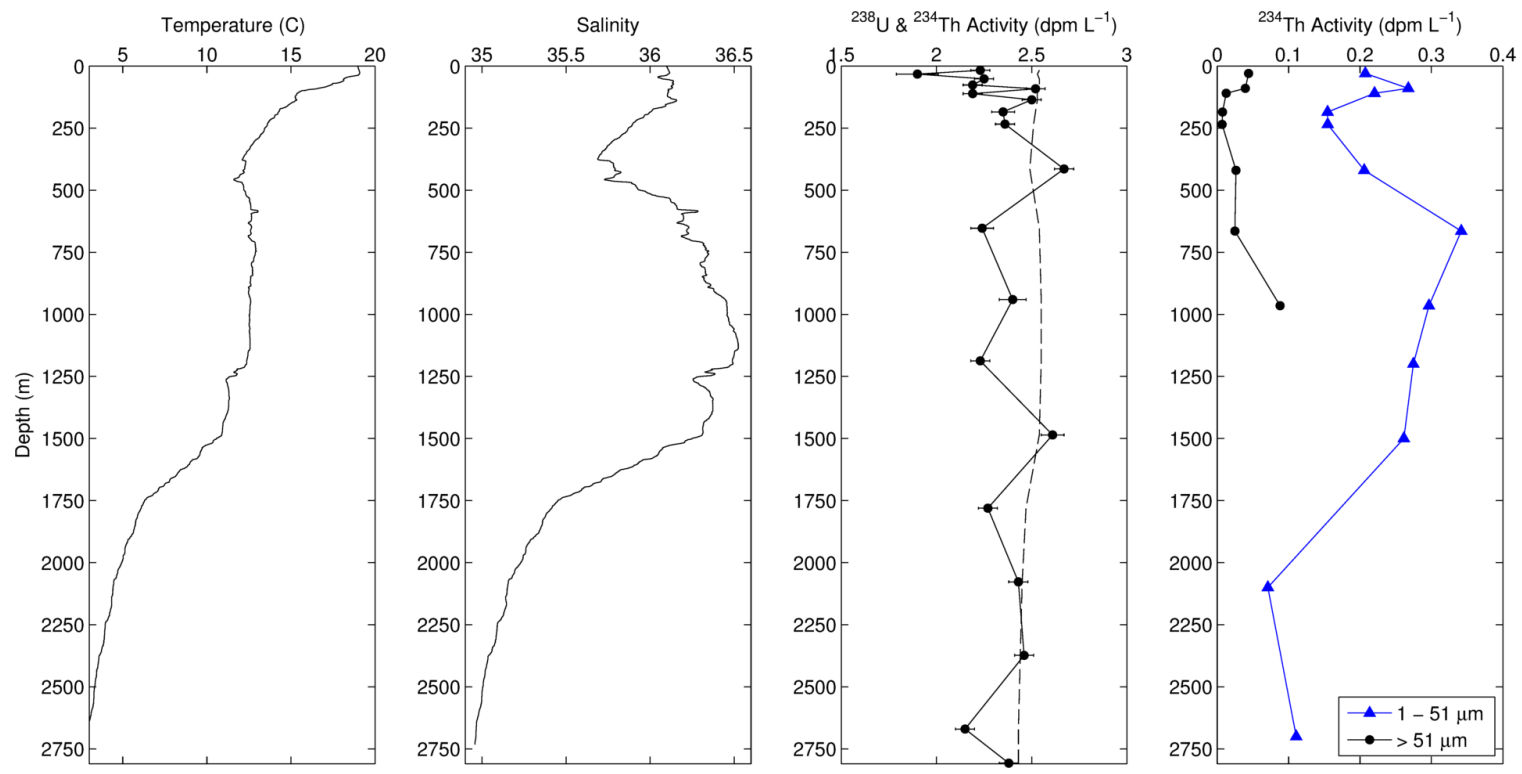

Figure 12 Hydrographic and ${ }^{234}$ Th data from L1 Station 1, where the influence of Mediterranean Outflow Water on total and particulate ${ }^{234} \mathrm{Th}$ is visible between 500 and $1500 \mathrm{~m}$. 

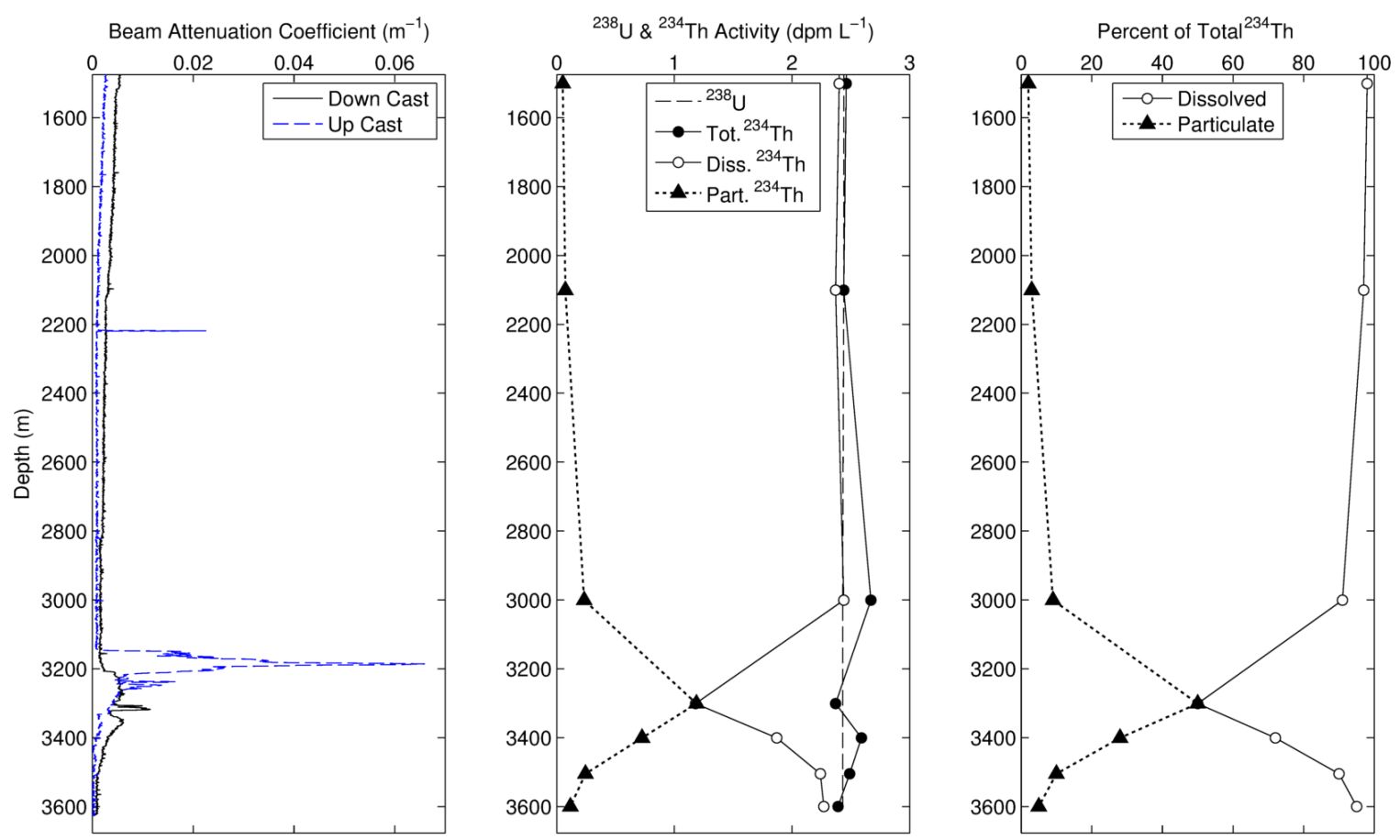

Figure 13 Beam attenuation coefficient (derived from transmission measured by the CTD below the in situ pumps) near the TAG hydrothermal plume (left). The effect of the hydrothermal plume on activity and partitioning of ${ }^{234} \mathrm{Th}$ (center and right). 

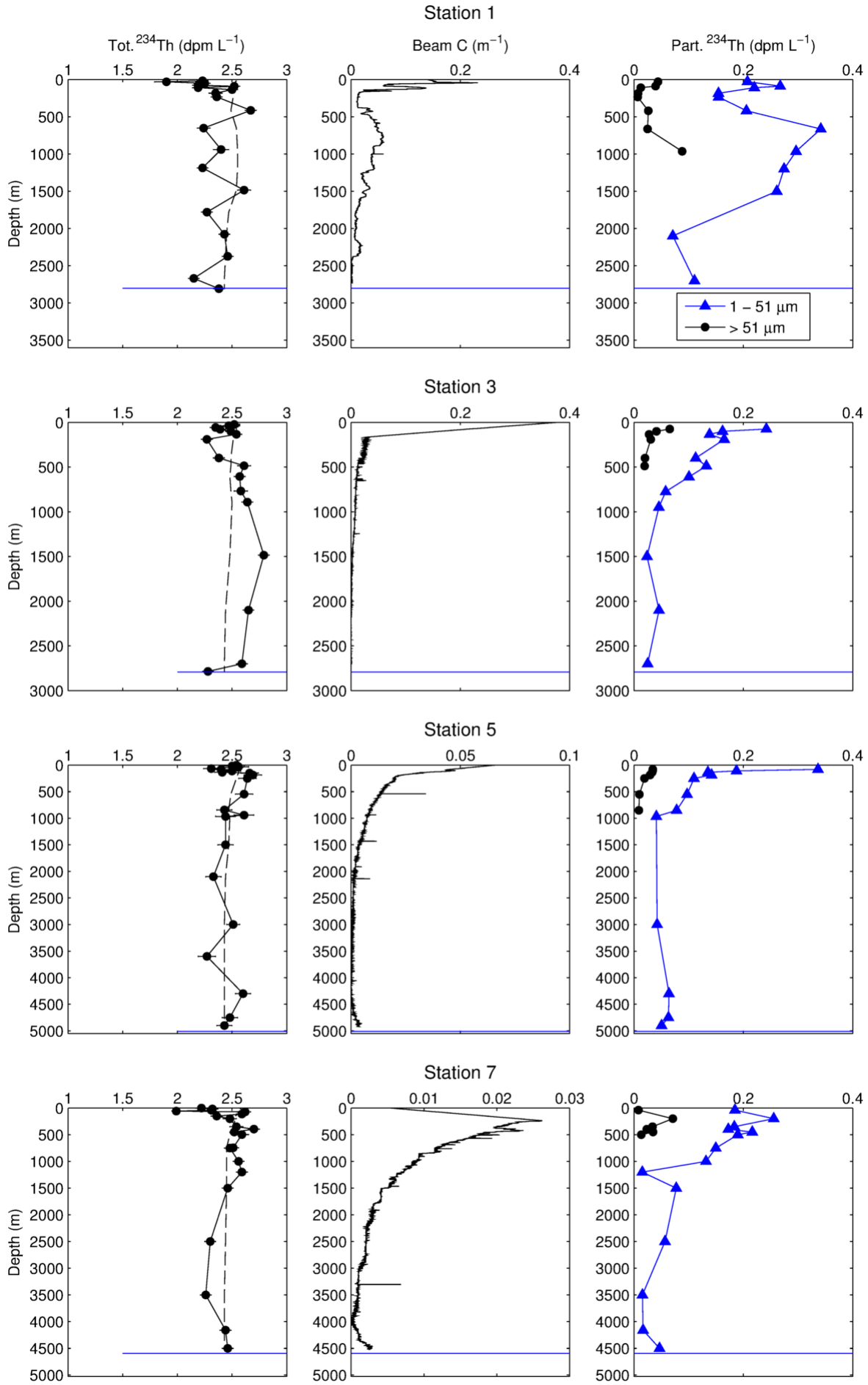

Figure 14 Full profiles of total and particulate ${ }^{234} \mathrm{Th}$ and the beam attenuation coefficient on L1. Bottom depth is denoted by the solid blue line. Note the variable axis ranges of beam-c; the purpose of these plots is to denote changes in particle abundance in the water column. 

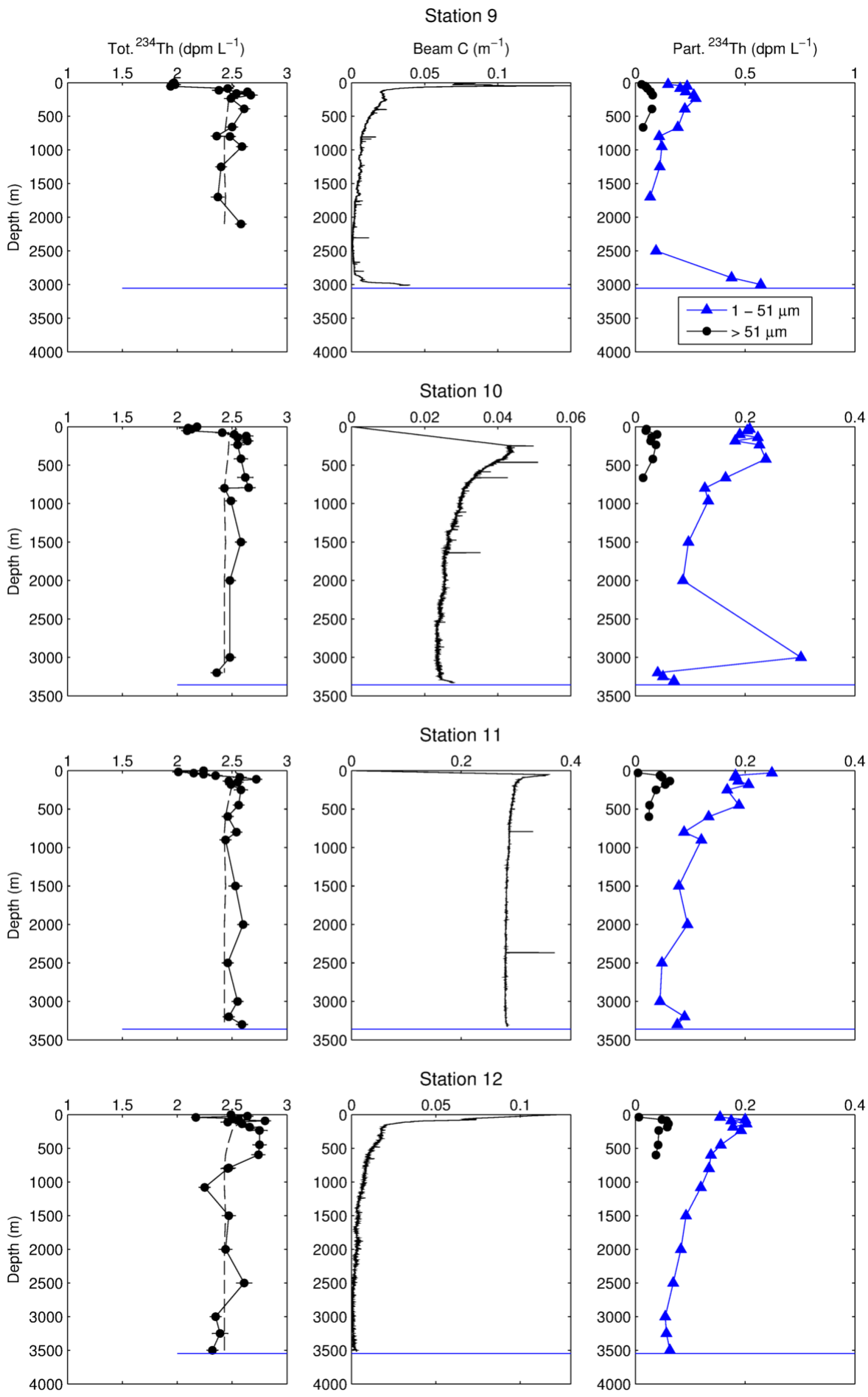

\section{Figure 14 (continued)}



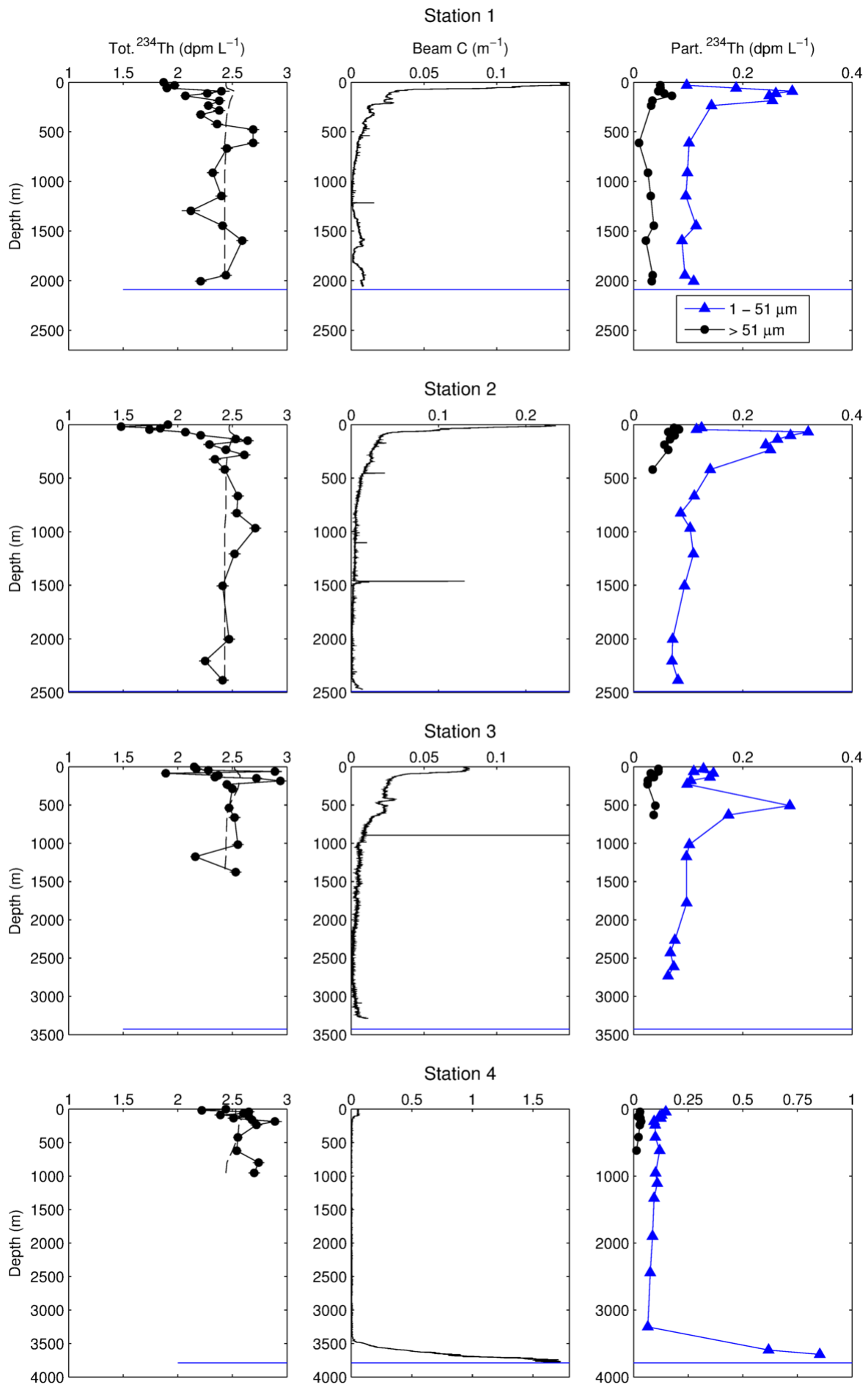

Figure 15 Full water column profiles of total and particulate Th-234 and the beam attenuation coefficient on L2. 

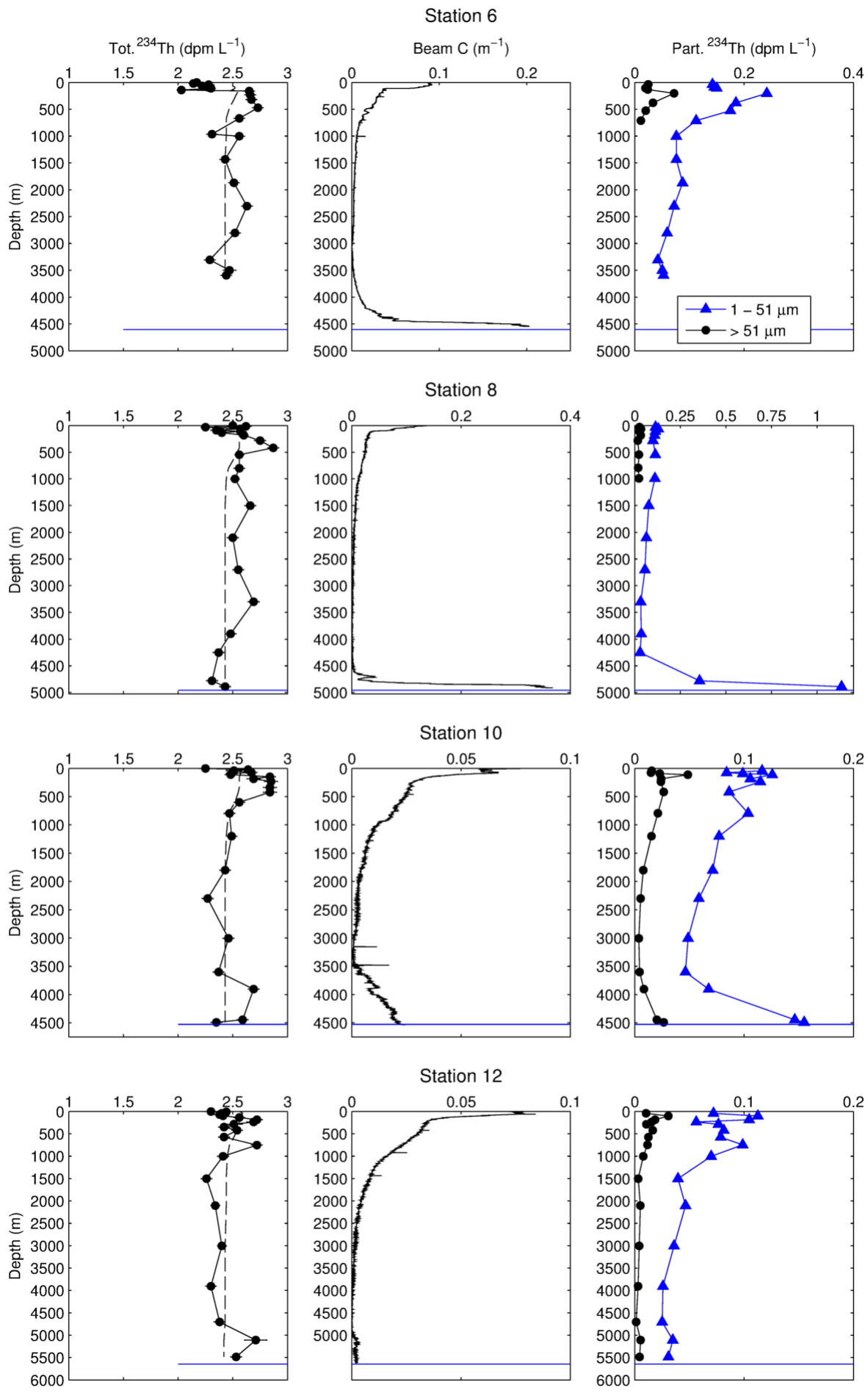

\section{Figure 15 (continued)}



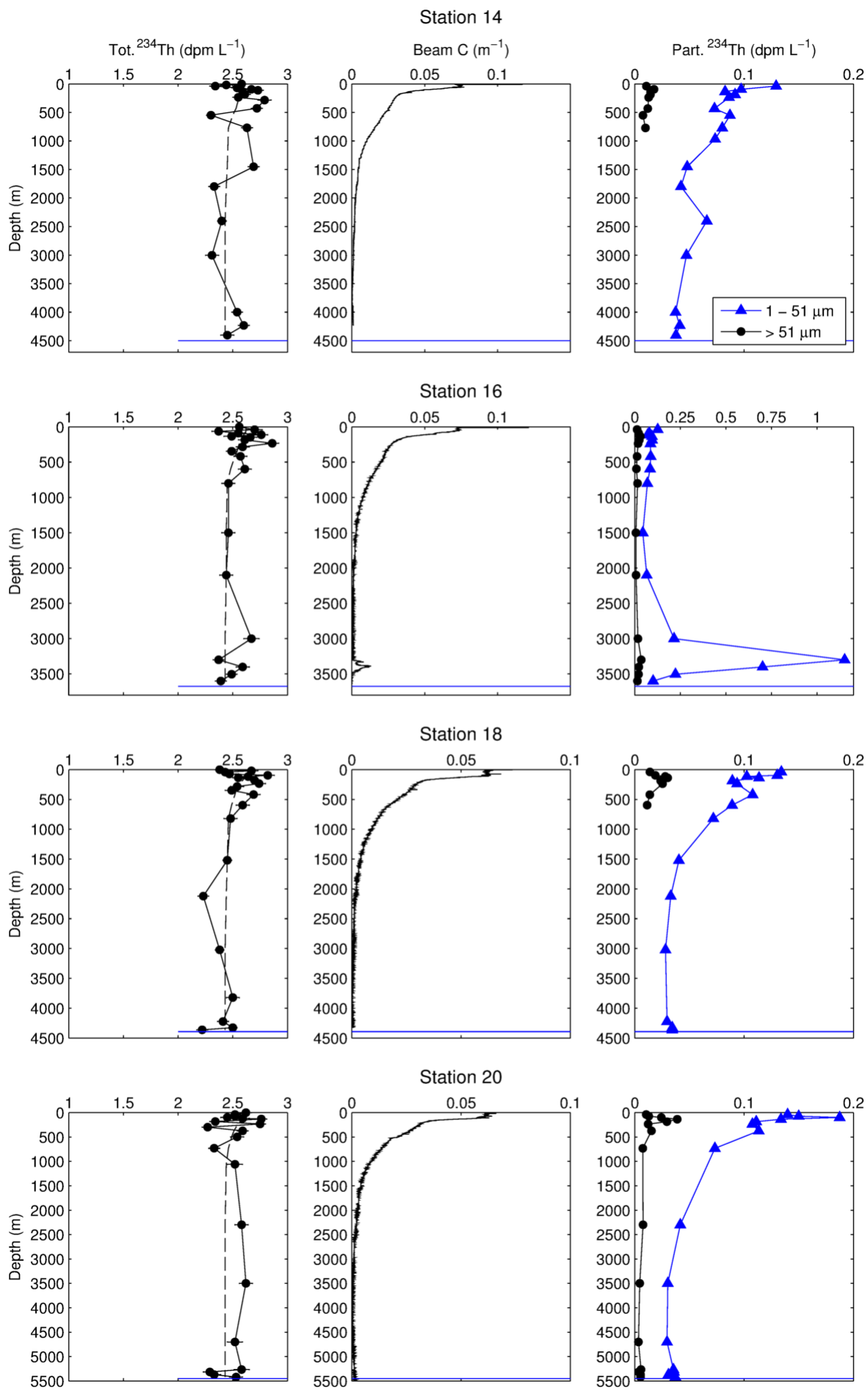

\section{Figure 15 (continued)}



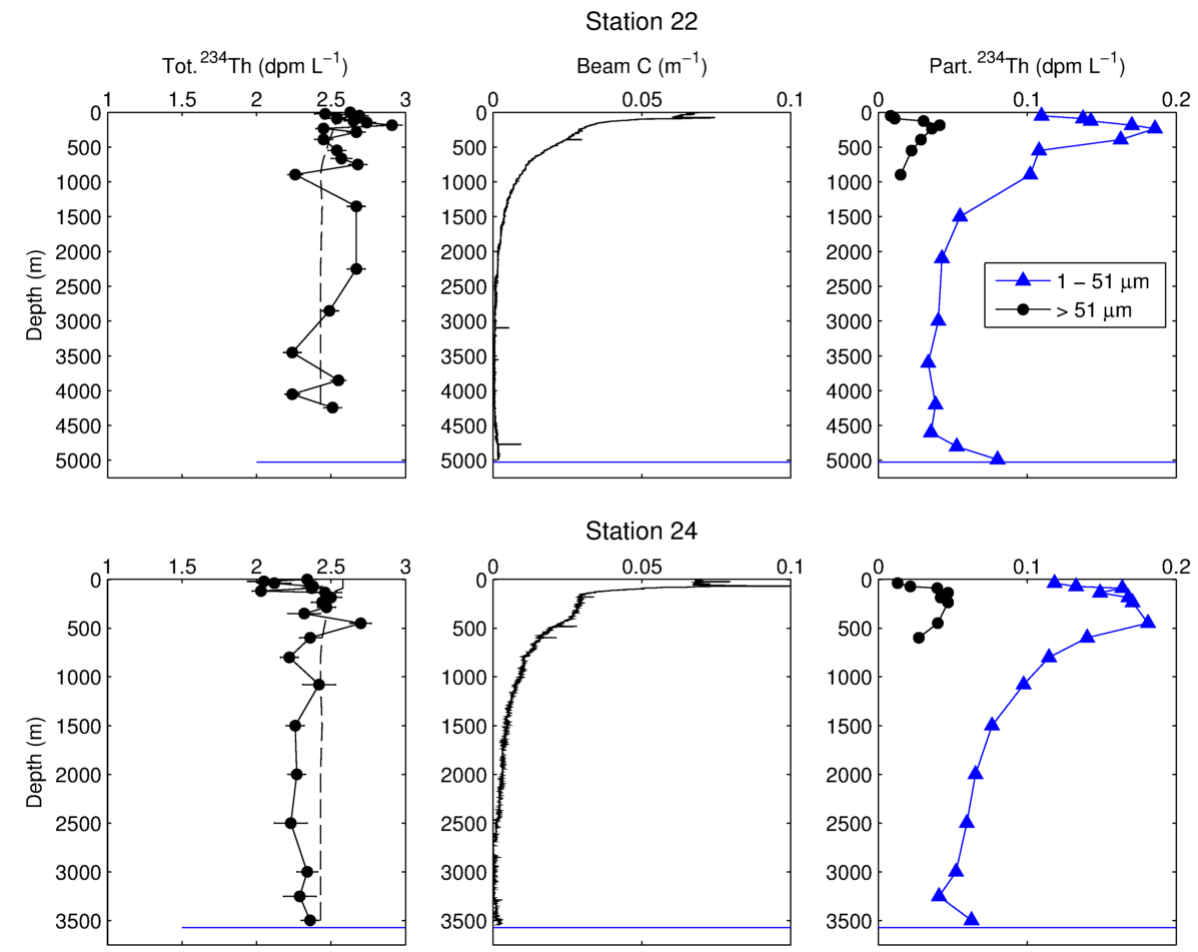

Figure 15 (continued) 


\section{Chapter 6: Conclusions}

The overarching goal of this thesis was to improve our understanding of particle export from the ocean's biological carbon pump. The approach was to improve existing methods used to measure export, specifically upper ocean sediment traps and the ${ }^{238} \mathrm{U}$ ${ }^{234} \mathrm{Th}$ method, and then apply these methods, particularly ${ }^{234} \mathrm{Th}$, at increased spatial resolution. An improved understanding of the spatial variability of export could then be used in the planning of future studies of particle export. In addition, better constraining export is important for linking upper ocean processes to export and parameterizing particle export in biogeochemical models. Below, the contributions of each chapter are summarized and future work or recommendations are posited.

\section{Determining ${ }^{238} \mathrm{U}$ activity in seawater for the ${ }^{238} \mathrm{U}-{ }^{234} \mathrm{Th}$ method}

In Chapter 2, the relationship used to determine ${ }^{238} \mathrm{U}$ activity from salinity was reevaluated. The new relationship spans a wider range and included a larger number of samples than the most widely used relationship, originally published by Chen et al. (1986). Deviations from this conservative behavior were observed however, between 500 and $1000 \mathrm{~m}$ in the subtropical Atlantic. It was hypothesized that this depletion of ${ }^{238} \mathrm{U}$ at depth was the advected signal of a distant removal process, perhaps in reducing 
continental shelf sediments. At the time, we lacked additional tracers to test this hypothesis. We also observed deficits of ${ }^{234} \mathrm{Th}$ relative to ${ }^{238} \mathrm{U}$ at depth in other years, which indicated scavenging and removal of ${ }^{234} \mathrm{Th}$ onto particles, deep below the surface region of particle production. While similar features have been reported in a few prior instances, this data was the best-resolved example of these features to date.

In light of these results, we suggested that small samples should be collected concurrently with ${ }^{234} \mathrm{Th}$ to be kept in archive and analyzed for ${ }^{238} \mathrm{U}$, as needed. This recommendation was also made in anticipation of the large scale transects of ${ }^{234} \mathrm{Th}$ to be undertaken in the GEOTRACES program where samples from the full water column would be collected. These transects, as reported in Chapter 5, and discussed further below, were the ideal opportunity to better resolve ${ }^{234} \mathrm{Th}$ in the mid-water column. Combined with additional tracers of thorium $\left({ }^{228} \mathrm{Th},{ }^{230} \mathrm{Th}\right)$ and the quartet of radium isotopes, we hope to be able to identify the source of mid-water column deficits. We may also want to consider analyzing a subset of the ${ }^{238} \mathrm{U}$ samples collected on the GEOTRACES transects.

\section{Neutrally buoyant sediment traps and time series studies}

The three-year time-series study with neutrally buoyant sediment traps (NBSTs), presented in Chapter 3, has implications for sediment trap methodology and carbon cycling in the subtropical Atlantic. Our results reaffirmed the importance of separating zooplankton "swimmers" from trap samples and we demonstrated that screening through a $350 \mu \mathrm{m}$ mesh worked well at this site. Process blanks of sediment trap samples were shown to be important for NBSTs and particle interceptor traps (PITs) deployed by the Bermuda Atlantic Time-series Study (BATS). These blank corrections for carbon are particularly important in the very low flux setting of the BATS site. While the two sediment trap systems agreed within the variability of two NBSTs in most months, in three periods, the differences between the two were larger than a factor of three. In one instance when PITs collected $>3$ times the flux measured by the NBSTs, both trap systems had been deployed in a deep mixed layer, a region where particles may have 
more than one opportunity to sink into sediment traps. We discourage deployment of traps in this layer and regard any flux results from these events cautiously. Another period where PITS collected more than the NBSTs occurred over four months in the summer, when there was no evidence that any changes occurred in the surface ocean to cause this increase in export. Finally, in one month, the NBSTs collected near-zero carbon flux while the PITs carbon flux was more than three times larger. Periods of very low flux were more abundant in the NBST record compared to the PITs record and may support the hypothesis that shear-induced aggregation at the mouth of PITs leads to an inherent positive bias in these data (Buesseler, 1994).

Prior to this study, it was hypothesized that the imbalance between carbon stocks and carbon fluxes in the Sargasso Sea was due to undersampling by the PITs or horizontal advection (Michaels et al., 1994). These new data suggest however that particle export was not underestimated in this budget. In fact, the magnitude and efficiency of export may slightly lower than previously thought, at least based on the time period of our study.

During this work, the sensitive issue of how to adapt time-series studies to developments in instruments and methods arose. Probably the most important consideration is maintaining the continuity of the time-series record. It would be unfortunate to make changes to a measurement technique that renders prior collected data not useful. On the other hand, when, if new technology is available, such as the NBSTs, should it be considered as a replacement for older tools, like the PITs, which we know from this and prior studies have sampling biases? The NBSTs were designed to minimize flow over the mouth of the collection tubes, however there were no in situ sensors on the NBSTs in this study to confirm whether this was true. A newly developed NBST has additional sensors and will hopefully provide more information on the motion of the NBST during deployment. At a minimum, some overlap between the outgoing technology or method and the newer approach would be required. The completion of this NBST time-series is therefore an ideal time to question whether the PITs should be grandfathered out. There are also significant differences in sediment trap sample 
processing techniques between the U.S.-funded ocean time-series programs including swimmer removal and blank determination, which are ripe to be addressed.

\section{Particle export off the West Antarctic Peninsula}

Prior to our study of particle export off the West Antarctic Peninsula (WAP), measurements of export in this region were limited to a single sediment trap over the shelf, near Palmer Station, and a few inshore studies, particularly in Marguerite Bay. With this work, we expanded the range of information on export off the WAP both geographically and also by sampling in summer and autumn. The fact that we had two opportunities to sample was critical, as the peak in the phytoplankton bloom occurred between the two cruises. Timing was also important because where primary production was increasing and chlorophyll stocks were building up the most in January was where the highest export was observed in March/April. In this study, we measured ${ }^{234} \mathrm{Th}$ both in the water-column and at higher frequency at the surface and were able to extrapolate fluxes from the surface-only stations. This allowed us better describe coastal to offshore and north to south trends off the WAP. These data have laid the groundwork for us to be able to derive semivariograms, in the future, to describe the scale of variability of export relative to upper ocean properties and processes that play a role in controlling export. The results of these calculations could then be used to determine the resolution required to resolve export variability in the WAP system.

Now that the measurements of export from these two cruises are complete, we hope to work with other colleagues on understanding changes in surface biological pump properties and how they might relate to export in this region. Iron availability was found to be an important controlling factor for net community production off the WAP (Huang et al., 2012). Rob Sherrell of Rutgers University collected samples for iron in January 2010 and we will use these data to see if there is any correlation with where export was highest in 2010. Samples for size-fractionated chlorophyll and HPLC pigments were also collected at the ${ }^{234} \mathrm{Th}$ surface stations. Working with Oscar Schofield of Rutgers University, we would like to use this data to investigate the role of phytoplankton 
community structure in controlling export off the WAP. Finally, working with Andrew McDonnell of University of Alaska, we will compare the export results from this study to his flux estimates based on particle abundances from an underwater camera system. Better constraining carbon export off the WAP is important for understanding how the carbon cycle and organisms off the WAP respond to rising temperatures and global climate change.

\section{${ }^{234} \mathrm{Th}$ from GEOTRACES transects of the Atlantic Ocean}

With the two transects of ${ }^{234} \mathrm{Th}$ across the North and South Atlantic, the spatial information on particle export from this tracer has increased dramatically. Particle flux patterns, highest near the margins and equator and lowest in the subtropical regions, were consistent with expectations and previous measurements. With the GEOTRACES program, changes in ${ }^{234} \mathrm{Th}$ with depth have also been better resolved than ever before. Of particular interest are the large deficits, as observed in Chapter 2, and excesses through the mid-water column (1000 $\mathrm{m}$ to $1000 \mathrm{~m}$ above the bottom). In one case, such a deficit was due to the Mediterranean Outflow Water, but the sources of the other features are still unknown. Once combined with long-lived thorium tracers, radium isotopes to indicate lithogenic interaction of the water mass, and possibly measurements of ${ }^{238} \mathrm{U}$, we hope to be able to pin point the cause of these features. Our values of ${ }^{234} \mathrm{Th}$ export will also be important for constraining budgets of trace metals by determining trace metal export fluxes with metal to ${ }^{234} \mathrm{Th}$ ratios on particles.

In collaboration with colleagues, this ${ }^{234} \mathrm{Th}$ data set can also contribute to two issues relevant to the marine particle community: 1) rates of particle cycling and 2) the role of biominerals and lithogenic material in export. Marchal and Lam (2012) demonstrated that the GEOTRACES programs are well poised to improve estimates of rates of adsorption, desorption, remineralization and aggregation of small particles, and disaggregation and sinking of larger particles in the ocean. The US GEOTRACES program can provide data of ${ }^{234} \mathrm{Th},{ }^{228} \mathrm{Th}$, and ${ }^{230} \mathrm{Th}$ with good depth resolution and in the dissolved phase and two particulate size classes. In their initial model of particle cycling, 
however, total ${ }^{234} \mathrm{Th}$ was in secular equilibrium over most of the water column. In many of our profiles from the North Atlantic, this is not the case. It will be interesting to test the effect that deficit and excess features in the mid-water column have on the rates derived from this model. A second path of investigation is the role that biominerals and lithogenic material play in transporting carbon to depth (or vice versa) (Dunne et al., 2007; Sanders et al., 2010; Lam et al., 2011). From the U.S. GEOTRACES cruises, data on particle flux from ${ }^{234} \mathrm{Th}$ and ${ }^{228} \mathrm{Th}$, particle composition, and community structure from phytoplankton pigments (on US L2) will be available. With these data, we hope to be able to test the importance of particle composition on export from the surface and transport through the mesopelagic. Both community structure and particle composition data may shed light on the dominant species driving export or lack thereof in the Atlantic Ocean. 


\section{References}

Buesseler, K.O., Michaels, A.F., Siegel, D.A., Knap, A.H., 1994. A three dimensional time-dependent approach to calibrating sediment trap fluxes. Global Biogeochemical Cycles 8 (2), 179-193.

Chen, J.H., Edwards, R.L., Wasserburg, G.J., 1986. ${ }^{238} \mathrm{U},{ }^{234} \mathrm{U}$ and ${ }^{232} \mathrm{Th}$ in seawater. Earth and Planetary Science Letters 80 (3-4), 241-251.

Dunne, J.P., Sarmiento, J.L., Gnanadesikan, A., 2007. A synthesis of global particle export from the surface ocean and cycling through the ocean interior and on the seafloor. Global Biogeochemical Cycles 21 (4).

Huang, K., Ducklow, H.W., Vernet, M., Cassar, N., Bender, M.L., 2012. Export production and its regulating factors in the West Antarctic Peninsula region of the Southern Ocean. Global Biogeochemical Cycles 26.

Lam, P.J., Doney, S.C., Bishop, J.K.B., 2011. The dynamic ocean biological pump: Insights from a global compilation of particulate organic carbon, $\mathrm{CaCO} 3$, and opal concentration profiles from the mesopelagic. Global Biogeochemical Cycles 25, GB3009.

Marchal, O., Lam, P.J., 2012. What can paired measurements of Th isotope activity and particle concentration tell us about particle cycling in the ocean? Geochimica et Cosmochimica Acta 90, 126-148.

Michaels, A.F., R., B.N., Buesseler, K.O., Carlson, C.A., Knap, A.H., 1994. Carboncycle imbalances in the Sargasso Sea. Nature 372, 537-540.

Sanders, R., Morris, P.J., Poulton, A.J., Stinchcombe, M.C., Charalampopoulou, A., Lucas, M.I., Thomalla, S.J., 2010. Does a ballast effect occur in the surface ocean? Geophysical Research Letters 37, L08602. 


\section{Appendix 1: Data Tables}


Table 1 Monthly fluxes from NBSTs at BATS from Chapter 3.

\begin{tabular}{|c|c|c|c|c|c|c|c|c|c|c|c|c|c|c|c|c|c|}
\hline & & ID & $\begin{array}{c}\text { Sw. C } \\
\mathrm{mg} \\
\mathrm{m}^{-2} \\
\mathrm{~d}^{-1} \\
\end{array}$ & $\begin{array}{c}{ }^{\mathrm{CH4}^{2} \mathbf{T h}} \\
\mathrm{dpm}^{-2} \\
\mathrm{~m}^{-2} \\
\mathrm{~d}^{-1}\end{array}$ & $S D$ & $\begin{array}{c}\text { POC } \\
\mathrm{mg} \\
\mathrm{m}^{-2} \\
\mathrm{~d}^{-1}\end{array}$ & $S D$ & $\begin{array}{c}\mathbf{P N} \\
\mathrm{mg} \\
\mathrm{m}^{-2} \\
\mathrm{~d}^{-1}\end{array}$ & $S D$ & $\mathrm{POC} / \mathrm{N}$ & $S D$ & $\begin{array}{c}\text { Mass } \\
\mathrm{mg} \\
\mathrm{m}^{-2} \\
\mathrm{~d}^{-1}\end{array}$ & $S D$ & $\begin{array}{c}\mathbf{b S i} \\
\mathrm{mg} \\
\mathrm{m}^{-2} \\
\mathrm{~d}^{-1}\end{array}$ & $S D$ & $\begin{array}{c}\text { PIC } \\
\mathrm{mg} \\
\mathrm{m}^{-2} \\
\mathrm{~d}^{-1}\end{array}$ & $S D$ \\
\hline \multicolumn{18}{|l|}{2007} \\
\hline \multirow[t]{2}{*}{ Jun } & 2007.47 & 100 & 17.68 & 196 & 20 & 10.9 & 2.9 & 2.3 & 0.5 & 5.5 & 0.7 & 34 & 9 & 0.08 & 0.10 & 0.73 & 0.13 \\
\hline & & 103 & 25.07 & 141 & 15 & 9.0 & 1.4 & 2.1 & 0.3 & 5.1 & 0.5 & 35 & 5 & 0.31 & 0.28 & 0.68 & 0.07 \\
\hline \multirow[t]{2}{*}{ Jul } & 2007.55 & 107 & 33.37 & 308 & 20 & 10.9 & 0.4 & 2.2 & 0.3 & 5.8 & 0.7 & 56 & 2 & 0.57 & 0.70 & 1.56 & 0.01 \\
\hline & & 110 & 31.00 & 258 & 38 & 10.2 & 2.5 & 2.1 & 0.4 & 5.7 & 1.0 & 54 & 7 & 0.49 & 0.42 & 1.37 & 0.03 \\
\hline \multirow[t]{2}{*}{ Aug } & 2007.63 & 113 & 7.69 & 222 & 14 & 8.6 & 1.5 & 1.8 & 0.5 & 5.7 & 0.6 & 39 & 4 & 0.41 & 0.21 & 0.87 & 0.16 \\
\hline & & 116 & 21.77 & 246 & 18 & 10.5 & 1.1 & 2.4 & 0.4 & 5.2 & 0.4 & 48 & 9 & 0.22 & 0.38 & 0.78 & 0.00 \\
\hline \multirow[t]{2}{*}{ Sep } & 2007.68 & 119 & 36.73 & 154 & 17 & 6.9 & 1.7 & 1.8 & 0.3 & 4.4 & 0.4 & 27 & 9 & 0.07 & 0.13 & 0.19 & 0.06 \\
\hline & & 121 & 8.97 & 205 & 9 & 9.2 & 1.2 & 2.1 & 0.1 & 5.2 & 0.3 & 31 & 6 & 0.00 & 0.00 & 0.28 & 0.02 \\
\hline \multirow[t]{2}{*}{ Oct } & 2007.76 & 124 & 4.88 & 206 & 6 & 7.0 & 0.7 & 1.6 & 0.1 & 5.1 & 0.2 & 34 & 6 & 0.15 & 0.26 & 1.08 & 0.11 \\
\hline & & 127 & 30.53 & 203 & 19 & 12.5 & 2.4 & 3.1 & 0.5 & 4.8 & 0.7 & 34 & 1 & 0.22 & 0.39 & 0.83 & 0.01 \\
\hline Nov & 2007.87 & 135 & 18.00 & 77 & 8 & 6.3 & 0.5 & 2.1 & 0.5 & 3.7 & 1.2 & 16 & 4 & 0.29 & 0.01 & 0.23 & 0.06 \\
\hline Dec & 2007.93 & 137 & 1.35 & 89 & 13 & 0.7 & 0.5 & 1.5 & 0.7 & 0.5 & 0.2 & 21 & 2 & 0.00 & 0.00 & 0.60 & 0.01 \\
\hline \multicolumn{18}{|l|}{2008} \\
\hline \multirow[t]{2}{*}{ Jan } & 2008.04 & 144 & 4.89 & 223 & 35 & 11.8 & 1.6 & 2.3 & 0.3 & 5.9 & 0.2 & 74 & 11 & 3.90 & 0.63 & 2.13 & 0.46 \\
\hline & & 146 & 9.05 & 171 & 18 & 8.3 & 0.9 & 1.6 & 0.2 & 6.1 & 0.2 & 34 & 3 & 2.19 & 0.33 & 1.29 & 0.14 \\
\hline Mar & 2008.20 & 148 & 6.56 & 135 & 8 & 6.6 & 1.5 & 1.8 & 0.5 & 4.2 & 0.3 & 43 & 5 & 0.21 & 0.25 & 1.32 & 0.05 \\
\hline Apr & 2008.30 & 153 & 24.52 & 213 & 19 & 16.8 & 2.6 & 3.2 & 0.5 & 6.1 & 0.1 & 120 & 4 & 1.06 & 0.41 & 3.00 & 0.04 \\
\hline \multirow[t]{2}{*}{ May } & 2008.41 & 161 & 43.49 & 397 & 73 & 16.8 & 5.0 & 3.1 & 0.8 & 6.4 & 0.5 & 134 & 11 & 8.65 & 1.70 & 2.78 & 0.18 \\
\hline & & 165 & 29.50 & 359 & 39 & 29.8 & 3.2 & 5.2 & 0.6 & 6.7 & 0.6 & 200 & 22 & 7.25 & 1.19 & 3.45 & 0.51 \\
\hline \multirow[t]{2}{*}{ Jun } & 2008.49 & 171 & 21.30 & 244 & 18 & 14.7 & 1.3 & 2.7 & 0.1 & 6.3 & 0.7 & 46 & 1 & 0.04 & 0.05 & 1.52 & 0.02 \\
\hline & & 173 & 45.59 & 216 & 16 & 33.7 & 5.2 & 5.0 & 0.2 & 7.9 & 1.1 & 77 & 44 & 0.24 & 0.17 & 1.23 & 0.28 \\
\hline \multirow[t]{2}{*}{ Jul } & 2008.55 & 179 & 19.17 & 368 & 13 & 15.8 & 1.2 & 3.0 & 0.0 & 6.0 & 0.5 & 54 & 5 & 0.88 & 0.06 & 2.02 & 0.22 \\
\hline & & 180 & 28.88 & 362 & 37 & 17.3 & 0.6 & 3.4 & 0.5 & 6.0 & 0.6 & 59 & 4 & 1.24 & 0.24 & 2.07 & 0.02 \\
\hline \multirow[t]{2}{*}{ Aug } & 2008.62 & 189 & 10.65 & 259 & 26 & 12.2 & 0.3 & 2.4 & 0.4 & 6.1 & 1.0 & 66 & 14 & 0.39 & 0.43 & 1.04 & 0.02 \\
\hline & & 190 & 24.23 & 250 & 26 & 16.8 & 2.4 & 3.5 & 0.4 & 5.6 & 0.4 & 65 & 12 & 0.40 & 0.31 & 0.57 & 0.09 \\
\hline \multirow[t]{2}{*}{ Sep } & 2008.70 & 194 & 14.59 & 279 & 48 & 15.4 & 4.2 & 2.9 & 0.7 & 6.2 & 0.4 & 55 & 8 & 0.41 & 0.53 & 1.28 & 0.16 \\
\hline & & 195 & 9.58 & 269 & 34 & 18.3 & 0.8 & 3.0 & 0.3 & 7.0 & 0.4 & 40 & 21 & 0.27 & 0.47 & 0.79 & 0.67 \\
\hline \multirow[t]{2}{*}{ Oct } & 2008.78 & 206 & 9.62 & 206 & 17 & 16.3 & 1.4 & 3.1 & 0.4 & 6.2 & 1.2 & - & - & 1.22 & 0.15 & - & - \\
\hline & & 208 & 22.21 & 206 & 9 & 14.9 & 0.7 & 2.9 & 0.5 & 6.1 & 1.0 & - & - & 0.88 & 0.46 & - & - \\
\hline \multirow[t]{2}{*}{ Nov } & 2008.86 & 215 & 35.39 & 89 & 10 & 14.2 & 0.3 & 3.2 & 0.4 & 5.2 & 0.6 & 47 & 3 & 0.17 & 0.15 & 0.89 & 0.13 \\
\hline & & 217 & 22.04 & 125 & 7 & 17.4 & 0.9 & 3.1 & 0.6 & 6.6 & 1.3 & 53 & 22 & 0.06 & 0.11 & 1.19 & 0.70 \\
\hline Dec & 2008.96 & 224 & 48.34 & 360 & 28 & 20.7 & 2.9 & 3.2 & 0.9 & 8.1 & 3.1 & 97 & 10 & 6.15 & 1.53 & 3.26 & 0.08 \\
\hline
\end{tabular}




\begin{tabular}{|c|c|c|c|c|c|c|c|c|c|c|c|c|c|c|c|c|c|}
\hline & & ID & Sw. C & ${ }^{234} \mathrm{Th}$ & $S D$ & POC & $S D$ & PN & $S D$ & $\mathbf{P O C} / \mathbf{N}$ & $S D$ & Mass & $S D$ & $\mathbf{b S i}$ & $S D$ & PIC & $S D$ \\
\hline & & 227 & 62.99 & 545 & 48 & 35.9 & 5.7 & 7.1 & 0.7 & 5.9 & 0.8 & 338 & 27 & 9.50 & 2.35 & 22.09 & 0.11 \\
\hline \multicolumn{18}{|l|}{2009} \\
\hline \multirow[t]{2}{*}{ Feb } & 2009.11 & 228 & 38.72 & 135 & 11 & 18.7 & 1.3 & 3.8 & 0.5 & 5.7 & 0.3 & 45 & 10 & 0.85 & 0.87 & 0.16 & 0.05 \\
\hline & & 230 & 23.80 & 135 & 11 & 13.1 & 1.3 & 2.4 & 0.5 & 6.7 & 2.2 & 35 & 8 & 1.32 & 0.21 & 0.16 & 0.04 \\
\hline \multirow[t]{2}{*}{ Mar } & 2009.21 & 233 & 27.58 & 41 & 11 & 18.0 & 1.2 & 3.1 & 0.5 & 7.0 & 1.7 & 57 & 4 & 2.60 & 0.98 & 0.00 & 0.00 \\
\hline & & 235 & 1.72 & 53 & 7 & 14.5 & 1.2 & 2.7 & 0.2 & 6.2 & 0.3 & 39 & 1 & 1.79 & 0.37 & 0.00 & 0.00 \\
\hline Apr & 2009.29 & 238 & 48.12 & 178 & 5 & 21.5 & 0.3 & 3.9 & 1.3 & 7.0 & 3.0 & 59 & 17 & 0.00 & 0.00 & 1.29 & 0.17 \\
\hline May & 2009.38 & 245 & 22.11 & 98 & 10 & 17.8 & 0.8 & 3.7 & 0.2 & 5.5 & 0.0 & 52 & 12 & 0.00 & 0.00 & 0.35 & 0.04 \\
\hline Jun & 2009.44 & 252 & 20.51 & 200 & 49 & 22.1 & 3.5 & 3.9 & 1.2 & 6.9 & 1.8 & 120 & 83 & 0.49 & 0.40 & 0.59 & 0.03 \\
\hline Jul & 2009.54 & 255 & 13.44 & 409 & 25 & 21.7 & 0.3 & 2.8 & 0.0 & 8.9 & 0.1 & 36 & 4 & 0.96 & 0.61 & 0.96 & 0.02 \\
\hline Aug & 2009.62 & 262 & 32.77 & 405 & 11 & 21.6 & 0.2 & 3.5 & 0.6 & 7.4 & 1.1 & 50 & 5 & 3.60 & 0.58 & 1.13 & 0.19 \\
\hline Sep & 2009.70 & 269 & 13.43 & 456 & 40 & 23.2 & 1.1 & 2.8 & 0.1 & 9.5 & 0.3 & 52 & 7 & 1.95 & 0.20 & 1.53 & 0.03 \\
\hline Sep & 2009.73 & 273 & 4.06 & 242 & 15 & 11.7 & 2.8 & 1.4 & 1.2 & 14.4 & 10.4 & 35 & 2 & 0.85 & 0.28 & 1.03 & 0.07 \\
\hline Sep & 2009.74 & 280 & 19.60 & 187 & 13 & 12.7 & 1.2 & 1.7 & 0.3 & 8.7 & 0.6 & 32 & 3 & 0.61 & 0.04 & 0.71 & 0.11 \\
\hline \multirow[t]{2}{*}{ Oct } & 2009.78 & 286 & 1.36 & 124 & 11 & 15.1 & 5.0 & 2.0 & 1.7 & 21.6 & 24.3 & 42 & 10 & 0.44 & 0.04 & 0.76 & 0.09 \\
\hline & & 288 & 1.13 & 181 & 18 & 26.0 & 20.5 & 4.5 & 4.2 & 8.2 & 3.7 & 53 & 13 & 0.92 & 0.09 & 0.90 & 0.48 \\
\hline Nov & 2009.85 & 291 & 5.52 & 72 & 10 & 7.9 & 0.1 & 0.5 & 0.6 & 56.8 & 54.2 & 14 & 5 & 1.08 & 0.18 & 0.14 & 0.03 \\
\hline \multirow[t]{2}{*}{ Dec } & 2009.94 & 294 & 9.09 & 309 & 26 & - & - & - & - & - & - & 40 & 10 & - & - & 1.17 & 0.81 \\
\hline & & 296 & 3.87 & 294 & 23 & - & - & - & - & - & - & 46 & 15 & - & - & 1.66 & 0.06 \\
\hline \multicolumn{18}{|l|}{2010} \\
\hline \multirow[t]{2}{*}{ Feb } & 2010.10 & 297 & 27.52 & 457 & 17 & 35.7 & 5.2 & 6.2 & 0.7 & 6.7 & 0.8 & 132 & 9 & 3.45 & 0.64 & 7.12 & 0.02 \\
\hline & & 299 & 34.28 & 422 & 56 & 35.0 & 4.4 & 6.2 & 0.9 & 6.6 & 0.2 & 118 & 6 & 3.60 & 0.19 & 5.78 & 0.23 \\
\hline \multirow[t]{2}{*}{ Mar } & 2010.23 & 305 & 35.89 & 416 & 11 & 45.3 & 0.1 & 7.0 & 0.1 & 7.6 & 0.1 & 154 & 29 & 3.82 & 0.24 & 5.75 & 1.53 \\
\hline & & 307 & 29.01 & 401 & 65 & 53.2 & 3.0 & 7.8 & 0.1 & 8.0 & 0.6 & 91 & 6 & 8.74 & 7.48 & 3.11 & 0.23 \\
\hline Apr & 2010.30 & 312 & 2.06 & 148 & 12 & 9.3 & 1.8 & & 0.0 & - & - & 49 & 33 & 1.51 & 0.40 & 1.47 & 0.07 \\
\hline \multirow[t]{2}{*}{ May } & 2010.37 & 316 & 6.15 & 334 & 38 & 40.7 & 5.3 & 5.8 & 1.0 & 8.2 & 0.4 & 85 & 19 & 5.05 & 1.00 & 1.47 & 0.60 \\
\hline & & 318 & 0.15 & 348 & 21 & 34.3 & 3.9 & 5.6 & 0.8 & 7.1 & 0.3 & 97 & 16 & 5.13 & 0.41 & 2.86 & 0.06 \\
\hline \multirow[t]{2}{*}{ Jun } & 2010.48 & 320 & 23.51 & 198 & 10 & 12.6 & 1.0 & 1.4 & 0.5 & 11.3 & 3.8 & 40 & 8 & 1.63 & 0.21 & 1.01 & 0.33 \\
\hline & & 322 & 19.07 & 275 & 23 & 16.9 & 2.1 & 1.9 & 0.5 & 10.6 & 1.2 & 38 & 4 & 4.06 & 3.10 & 1.13 & 0.35 \\
\hline \multirow[t]{2}{*}{ Jul } & 2010.56 & 366 & 12.90 & 295 & 12 & 21.9 & 1.9 & 3.1 & 0.8 & 8.4 & 1.6 & 37 & 12 & 1.23 & 0.18 & 0.73 & 0.11 \\
\hline & & 368 & 13.69 & 346 & 24 & 21.6 & 3.2 & 2.7 & 0.9 & 9.7 & 2.6 & 36 & 11 & 1.75 & 0.28 & 0.86 & 0.19 \\
\hline
\end{tabular}


Table 2 Underway sensor, nutrient, and size-fractionated chlorophyll data collected off the WAP in 2010.

\begin{tabular}{|c|c|c|c|c|c|c|c|c|c|c|c|c|c|c|c|}
\hline $\begin{array}{c}\text { Julian } \\
\text { Day }\end{array}$ & $\begin{array}{c}\text { Lat } \\
\mathrm{S}\end{array}$ & $\begin{array}{c}\text { Long } \\
\text { W }\end{array}$ & ID & $\begin{array}{c}\text { Temp } \\
{ }^{\circ} \mathrm{C}\end{array}$ & Sal & $\begin{array}{c}\text { Fl. } \\
\mathrm{mg} \mathrm{m}^{-3}\end{array}$ & $\begin{array}{l}\text { Tr. } \\
\%\end{array}$ & $\begin{array}{c}\mathbf{p C O}_{2} \\
\mu \mathrm{atm}\end{array}$ & $\begin{array}{c}\mathbf{N O}_{3}+\mathbf{N O}_{2} \\
\mu \mathrm{M}\end{array}$ & $\begin{array}{c}\text { PO4 } \\
\mu \mathrm{M}\end{array}$ & $\begin{array}{c}\mathrm{SiO2} \\
\mu \mathrm{M}\end{array}$ & $\begin{array}{c}>\mathbf{2 0} \boldsymbol{\mu m} \\
\mathbf{C h l} \mathbf{a} \\
\mu \mathrm{g} \mathrm{L}^{-1}\end{array}$ & $\begin{array}{c}\mathbf{5 - 2 0} \boldsymbol{\mu m} \\
\mathbf{C h l} \mathbf{a} \\
\mu \mathrm{g} \mathrm{L}^{-1}\end{array}$ & $\begin{array}{c}2-5 \mu m \\
\text { Chl a } \\
\mu g L^{-1}\end{array}$ & $\begin{array}{c}0.2-2 \mu \mathrm{m} \\
\text { Chl a } \\
\mu \mathrm{g} \mathrm{L}^{-1}\end{array}$ \\
\hline \multicolumn{16}{|c|}{ Summer Cruise } \\
\hline 6 & 64.90 & 64.48 & 11 & 0.46 & 33.69 & 0.52 & 82.1 & 310.8 & 19.4 & 1.3 & 67.9 & 0.015 & 0.108 & 0.928 & 1.447 \\
\hline 6 & 64.80 & 64.76 & 12 & 0.45 & 33.91 & 0.38 & 89.5 & 382.2 & - & - & - & 1.069 & 0.446 & 0.267 & 1.230 \\
\hline 6 & 64.69 & 65.05 & 13 & 0.23 & 33.91 & 0.37 & 89.5 & - & 24.3 & 1.5 & 60.1 & 0.064 & 0.522 & 0.134 & 1.526 \\
\hline 6 & 64.58 & 65.33 & 14 & 0.15 & 33.91 & 0.34 & 90.6 & 493.3 & 24.6 & 1.5 & 58.5 & 0.068 & 0.221 & 0.312 & 0.134 \\
\hline 6 & 64.45 & 65.66 & 35 & 0.72 & 33.88 & 0.28 & 91.2 & 365.9 & 25.6 & 1.5 & 55.8 & 0.070 & 0.244 & 0.264 & 1.013 \\
\hline 7 & 64.22 & 66.23 & 37 & 0.21 & 33.79 & 0.32 & 93.6 & 369.2 & 25.9 & 1.6 & 49.0 & 0.081 & 0.177 & 0.157 & 0.617 \\
\hline 7 & 64.10 & 66.54 & 38 & 0.22 & 33.76 & 0.33 & 93.6 & 367.8 & 26.6 & 1.6 & 43.6 & 0.063 & 0.178 & 0.106 & 0.365 \\
\hline 7 & 63.99 & 66.81 & 39 & 0.39 & 33.70 & 0.33 & 94.7 & 352.9 & 25.8 & 1.5 & 32.7 & 0.127 & 0.010 & 0.246 & 0.214 \\
\hline 7 & 64.29 & 67.57 & 50 & 0.04 & 33.78 & 0.25 & 92.1 & 356.4 & 26.7 & 1.6 & 49.4 & 0.062 & 0.192 & 0.151 & 0.444 \\
\hline 7 & 64.60 & 68.27 & 51 & 0.04 & 33.75 & 0.23 & 94.4 & 378.9 & 26.8 & 1.6 & 40.5 & 0.067 & 0.252 & 0.059 & 0.293 \\
\hline 8 & 64.55 & 67.20 & 62 & 0.36 & 33.80 & 0.32 & 94.4 & 372.6 & 26.8 & 1.6 & 49.5 & 0.075 & 0.114 & 0.126 & 0.359 \\
\hline 8 & 64.50 & 66.18 & 63 & 0.73 & 33.81 & 0.32 & 93.8 & 377.8 & 28.9 & 1.5 & 52.2 & 0.079 & 0.099 & 0.179 & 0.139 \\
\hline 11 & 64.87 & 66.49 & 103 & 0.77 & 33.89 & 0.37 & 90.3 & 359.8 & 27.0 & 1.6 & 58.2 & 0.050 & 0.232 & 0.343 & 0.621 \\
\hline 11 & 65.19 & 66.68 & 115 & 0.69 & 33.82 & 0.33 & 89.5 & 377.5 & - & - & - & - & - & - & - \\
\hline 11 & 65.29 & 66.77 & 116 & 0.53 & 33.80 & 0.35 & 88.2 & 336.2 & 25.8 & 1.5 & 59.0 & 0.032 & 0.244 & 0.544 & 0.240 \\
\hline 11 & 65.37 & 66.85 & 117 & 0.49 & 33.82 & 0.37 & 87.3 & 337.8 & - & - & - & - & - & - & - \\
\hline 11 & 65.46 & 66.90 & 118 & 0.75 & 33.82 & 0.35 & 87.3 & 330.8 & 23.2 & 1.4 & 63.3 & 0.017 & 0.171 & 0.523 & 0.347 \\
\hline 11 & 65.55 & 66.95 & 119 & 0.67 & 33.82 & 0.32 & 88.6 & 377.2 & - & - & - & - & - & - & - \\
\hline 11 & 65.64 & 67.00 & 120 & 1.17 & 33.74 & 0.38 & 84.9 & 316.3 & 23.4 & 1.4 & 64.8 & 0.017 & 0.323 & 0.916 & - \\
\hline 11 & 65.73 & 67.04 & 121 & 0.54 & 33.72 & 0.39 & 85.6 & 321.5 & - & - & - & - & - & - & - \\
\hline 11 & 65.81 & 67.09 & 122 & 0.81 & 33.72 & 0.36 & 84.9 & 323.9 & 22.5 & 1.4 & 61.7 & 0.045 & 0.227 & 1.180 & 1.459 \\
\hline 11 & 65.91 & 67.14 & 123 & 0.69 & 33.73 & 0.40 & 84.5 & - & - & - & - & - & - & - & - \\
\hline 11 & 66.00 & 67.19 & 124 & 0.80 & 33.77 & 0.41 & 83.9 & 315.5 & 23.1 & 1.4 & 65.9 & 0.041 & 0.153 & 0.957 & 3.479 \\
\hline 11 & 66.09 & 67.24 & 125 & 0.59 & 33.79 & 0.41 & 85.4 & 315.3 & - & - & - & - & - & - & - \\
\hline 11 & 66.18 & 67.29 & 126 & 0.87 & 33.79 & 0.45 & 82.8 & 305.9 & 22.4 & 1.3 & 63.0 & 0.172 & 0.269 & 0.884 & 3.605 \\
\hline 11 & 66.14 & 67.62 & 137 & 0.66 & 33.73 & 0.50 & 83.4 & 311.4 & 21.9 & 1.4 & 67.6 & 0.051 & 0.426 & 0.381 & 4.989 \\
\hline 11 & 66.00 & 67.97 & 138 & 0.50 & 33.69 & 0.49 & 87.1 & 383.5 & 23.2 & 1.4 & 65.4 & 0.027 & 0.125 & 0.683 & 1.882 \\
\hline 11 & 65.93 & 68.25 & 139 & 0.56 & 33.71 & 0.51 & 87.1 & 327.3 & 23.2 & 1.4 & 63.6 & 0.050 & 0.254 & 0.752 & 1.887 \\
\hline 12 & 65.75 & 68.60 & 140 & 0.20 & 33.74 & 0.47 & 88.8 & 329.2 & 24.6 & 1.4 & 60.0 & 0.066 & 0.340 & 0.792 & 2.139 \\
\hline
\end{tabular}




\begin{tabular}{|c|c|c|c|c|c|c|c|c|c|c|c|c|c|c|c|}
\hline $\begin{array}{c}\text { Julian } \\
\text { Day }\end{array}$ & $\begin{array}{c}\text { Lat } \\
\mathrm{S}\end{array}$ & $\begin{array}{c}\text { Long } \\
\text { W }\end{array}$ & ID & $\begin{array}{c}\text { Temp } \\
{ }^{\circ} \mathrm{C}\end{array}$ & Sal & $\begin{array}{c}\text { Fl. } \\
\mathrm{mg} \mathrm{m}^{-3}\end{array}$ & $\begin{array}{c}\text { Tr. } \\
\%\end{array}$ & $\begin{array}{c}\mathbf{p C O}_{2} \\
\mu a t m\end{array}$ & $\begin{array}{c}\mathbf{N O}_{3}+\mathbf{N O}_{2} \\
\mu \mathrm{M}\end{array}$ & $\begin{array}{c}\text { PO4 } \\
\mu \mathrm{M}\end{array}$ & $\begin{array}{c}\mathrm{SiO2} \\
\mu \mathrm{M}\end{array}$ & $\begin{array}{c}>20 \mu m \\
\text { Chl a } \\
\mu g L^{-1}\end{array}$ & $\begin{array}{c}\text { 5-20 } \boldsymbol{\mu m} \\
\mathbf{C h l} \mathbf{a} \\
\mu \mathrm{g} \mathrm{L}^{-1}\end{array}$ & $\begin{array}{c}2-5 \boldsymbol{\mu m} \\
\text { Chl a } \\
\mu \mathrm{g} \mathrm{L}^{-1}\end{array}$ & $\begin{array}{c}\text { 0.2-2 } \boldsymbol{\mu m} \\
\text { Chl a } \\
\mu \mathrm{g} \mathrm{L}^{-1}\end{array}$ \\
\hline 12 & 65.62 & 68.91 & 141 & 0.26 & 33.74 & 0.36 & 91.0 & 376.8 & 25.4 & 1.5 & 57.8 & 0.050 & 0.214 & 0.871 & 0.285 \\
\hline 12 & 65.51 & 69.25 & 166 & 0.22 & 33.70 & 0.24 & 94.2 & 355.2 & - & - & - & - & - & - & - \\
\hline 12 & 65.58 & 69.41 & 167 & 0.18 & 33.71 & 0.26 & 93.8 & 383.5 & 25.9 & 1.5 & 44.2 & 0.082 & 0.262 & 0.140 & 0.222 \\
\hline 12 & 65.64 & 69.56 & 168 & 0.18 & 33.72 & 0.26 & 92.9 & 354.3 & - & - & - & - & - & - & - \\
\hline 12 & 65.70 & 69.73 & 169 & 0.19 & 33.71 & 0.26 & 93.6 & 355.9 & 25.9 & 1.5 & 47.4 & 0.100 & 0.365 & 0.143 & - \\
\hline 12 & 65.76 & 69.87 & 170 & 0.18 & 33.72 & 0.26 & 92.9 & 352.6 & - & - & - & - & - & - & - \\
\hline 12 & 65.83 & 70.04 & 171 & 0.00 & 33.72 & 0.26 & 92.1 & 383.5 & 26.1 & 1.5 & 59.5 & 0.044 & 0.003 & 0.454 & - \\
\hline 12 & 65.89 & 70.20 & 172 & 0.21 & 33.72 & 0.26 & 92.1 & 347.9 & - & - & - & - & - & - & - \\
\hline 12 & 65.95 & 70.37 & 173 & 0.27 & 33.69 & 0.27 & 92.9 & 347.9 & 25.3 & 1.5 & 43.1 & 0.118 & 0.150 & 0.161 & 1.414 \\
\hline 12 & 66.01 & 70.53 & 174 & 0.25 & 33.70 & 0.27 & 92.5 & 384.8 & - & - & - & - & - & - & - \\
\hline 12 & 66.07 & 70.67 & 175 & 0.20 & 33.70 & 0.26 & 93.6 & 494.7 & 25.0 & 1.5 & 41.6 & 0.046 & 0.532 & 0.112 & 0.296 \\
\hline 13 & 66.13 & 70.75 & 186 & 0.35 & 33.69 & 0.40 & 94.2 & - & 25.6 & 1.5 & 38.9 & 0.127 & 0.000 & 0.080 & 0.152 \\
\hline 13 & 66.26 & 70.45 & 187 & 0.22 & 33.72 & 0.39 & 92.9 & 350.7 & 25.4 & 1.5 & 46.0 & 0.090 & 0.420 & 0.146 & 0.196 \\
\hline 13 & 66.38 & 70.18 & 188 & 0.18 & 33.72 & 0.40 & 93.2 & 384.1 & 26.0 & 1.5 & 46.2 & 0.128 & 0.440 & 0.132 & 0.264 \\
\hline 13 & 66.64 & 69.54 & 200 & 0.04 & 33.73 & 0.30 & 90.1 & 335.8 & 25.3 & 1.4 & 57.5 & 0.338 & 0.474 & 0.467 & 0.727 \\
\hline 13 & 66.78 & 69.21 & 201 & 0.27 & 33.66 & 0.27 & 91.6 & - & 25.3 & 1.5 & 61.0 & 0.164 & 0.246 & 0.375 & 0.212 \\
\hline 13 & 66.89 & 68.92 & 202 & 0.38 & 33.66 & 0.29 & 90.3 & 338.4 & 25.3 & 1.4 & 62.5 & 0.147 & 0.388 & 0.479 & 1.160 \\
\hline 13 & 67.01 & 69.23 & 213 & 0.29 & 33.69 & 0.34 & 91.2 & 237.5 & 25.4 & 1.5 & 63.7 & 0.302 & 0.332 & 0.441 & 0.794 \\
\hline 13 & 67.13 & 69.57 & 214 & 0.15 & 33.74 & 0.36 & 91.6 & 342.0 & 25.8 & 1.5 & 59.6 & 0.190 & 0.331 & 0.352 & 0.474 \\
\hline 14 & 67.26 & 69.90 & 215 & 0.16 & 33.71 & 0.38 & 91.6 & 494.5 & 24.7 & 1.5 & 61.2 & 0.148 & 0.148 & 0.361 & 0.867 \\
\hline 14 & 67.38 & 70.25 & 216 & 0.17 & 33.69 & 0.39 & 90.8 & 336.1 & 24.4 & 1.4 & 65.8 & 0.101 & 0.166 & 0.427 & 1.847 \\
\hline 14 & 67.51 & 70.58 & 217 & 0.03 & 33.69 & 0.40 & 90.6 & 366.2 & 24.4 & 1.5 & 65.3 & 0.085 & 0.353 & 0.544 & - \\
\hline 14 & 67.24 & 71.24 & 239 & 0.08 & 33.77 & 0.45 & 88.8 & 340.1 & - & - & - & - & - & - & - \\
\hline 14 & 67.08 & 71.45 & 238 & 0.05 & 33.76 & 0.35 & 91.0 & 341.9 & - & - & - & - & - & - & - \\
\hline 14 & 66.98 & 71.84 & 240 & 0.26 & 33.70 & 0.29 & 93.2 & 345.9 & - & - & - & - & - & - & - \\
\hline 14 & 66.84 & 72.16 & 241 & 0.16 & 33.65 & 0.29 & 92.3 & 341.8 & - & - & - & - & - & - & - \\
\hline 16 & 66.74 & 72.42 & 252 & 0.09 & 33.65 & 0.67 & 92.1 & 334.6 & 26.3 & 1.0 & 37.4 & 1.393 & 1.380 & 0.169 & 0.301 \\
\hline 16 & 66.91 & 72.57 & 253 & 0.02 & 33.65 & 0.64 & 92.3 & 370.0 & 25.8 & 1.4 & 37.4 & 1.327 & - & 0.208 & 0.560 \\
\hline 16 & 67.06 & 72.73 & 254 & 0.21 & 33.67 & 0.55 & 93.4 & 341.7 & 23.9 & 1.4 & 38.6 & 0.830 & 1.993 & 0.164 & 0.420 \\
\hline 16 & 67.24 & 72.88 & 255 & 0.14 & 33.70 & 0.47 & 94.0 & 369.8 & 25.8 & 1.4 & 44.6 & 0.679 & 1.610 & 0.184 & 0.946 \\
\hline
\end{tabular}




\begin{tabular}{|c|c|c|c|c|c|c|c|c|c|c|c|c|c|c|c|}
\hline $\begin{array}{c}\text { Julian } \\
\text { Day }\end{array}$ & $\begin{array}{c}\text { Lat } \\
\text { S }\end{array}$ & $\begin{array}{c}\text { Long } \\
\text { W }\end{array}$ & ID & 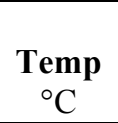 & Sal & $\begin{array}{c}\text { Fl. } \\
\mathrm{mg} \mathrm{m}^{-3}\end{array}$ & $\begin{array}{c}\text { Tr. } \\
\%\end{array}$ & $\begin{array}{l}\mathbf{p C O}_{2} \\
\mu \mathrm{atm}\end{array}$ & $\begin{array}{c}\mathbf{N O}_{3}+\mathbf{N O}_{2} \\
\mu \mathrm{M}\end{array}$ & $\begin{array}{c}\text { PO4 } \\
\mu \mathrm{M}\end{array}$ & $\begin{array}{c}\mathrm{SiO2} \\
\mu \mathrm{M}\end{array}$ & $\begin{array}{c}>20 \mu \mathbf{m} \\
\mathbf{C h l} \mathbf{a} \\
\mu g \mathrm{~L}^{-1}\end{array}$ & $\begin{array}{c}\mathbf{5 - 2 0} \boldsymbol{\mu m} \\
\text { Chl a } \\
\mu \mathrm{g} \mathrm{L}^{-1}\end{array}$ & $\begin{array}{c}\text { 2-5 } \boldsymbol{\mu m} \\
\text { Chl a } \\
\mu \mathrm{g} \mathrm{L}^{-1}\end{array}$ & $\begin{array}{c}\mathbf{0 . 2 - 2} \boldsymbol{\mu m} \\
\text { Chl a } \\
\mu \mathrm{g} \mathrm{L}^{-1}\end{array}$ \\
\hline 16 & 67.70 & 73.28 & 258 & 0.19 & 33.73 & 0.32 & 94.0 & - & 26.9 & 1.6 & 50.2 & 0.333 & 0.573 & 0.320 & 0.807 \\
\hline 16 & 67.99 & 72.64 & 270 & 0.30 & 33.83 & 0.32 & 92.9 & - & 26.8 & 1.6 & 62.2 & 0.694 & 0.325 & 0.470 & 1.064 \\
\hline 16 & 68.11 & 72.34 & 271 & 0.37 & 33.81 & 0.34 & 91.4 & - & 27.2 & 1.0 & 64.1 & 0.474 & 0.280 & 0.467 & 1.508 \\
\hline 20 & 68.16 & 70.42 & 325 & 0.89 & 33.68 & 0.33 & 87.5 & 372.0 & 23.3 & 1.3 & 68.2 & 0.155 & 0.362 & 1.100 & 3.298 \\
\hline 21 & 68.14 & 75.42 & 334 & 0.23 & 33.75 & 0.36 & 95.1 & 365.4 & 28.2 & 1.7 & 52.7 & 0.144 & 0.299 & 0.218 & 0.376 \\
\hline 21 & 68.69 & 74.19 & 355 & 0.31 & 33.65 & 0.42 & 88.0 & 379.3 & 25.7 & 1.5 & 62.9 & 1.234 & 0.307 & 0.862 & 3.321 \\
\hline 21 & 68.97 & 73.56 & 356 & 0.34 & 33.27 & 1.50 & 84.5 & 229.4 & 16.1 & 0.8 & 68.3 & 16.876 & 1.264 & 2.016 & 1.917 \\
\hline 22 & 68.38 & 71.70 & 367 & 0.63 & 33.61 & 0.63 & 86.0 & 109.3 & 21.4 & 1.3 & 66.6 & 1.714 & 0.941 & 1.840 & 3.331 \\
\hline \multicolumn{16}{|c|}{ Autumn Cruise } \\
\hline 80 & 64.89 & 64.29 & 500 & 0.95 & 33.74 & 2.83 & 93.1 & 332.2 & 22.7 & 1.5 & 61.8 & 0.015 & 0.044 & 0.189 & 0.861 \\
\hline 80 & 64.84 & 65.14 & 501 & 1.06 & 33.74 & 0.96 & 94.4 & 349.6 & 22.2 & 1.4 & 61.2 & 0.015 & 0.026 & 0.055 & 0.496 \\
\hline 80 & 64.73 & 65.45 & 502 & 1.01 & 33.74 & 0.98 & 94.8 & 349.6 & 23.4 & 1.3 & 60.0 & 0.023 & 0.026 & 0.066 & 0.580 \\
\hline 80 & 64.62 & 65.77 & 503 & 1.07 & 33.83 & 1.07 & 95.2 & 359.7 & 24.8 & 1.4 & 56.6 & 0.034 & 0.150 & 0.361 & 0.577 \\
\hline 80 & 64.47 & 65.97 & 504 & 1.09 & 33.86 & 1.04 & 95.7 & 369.1 & 25.0 & 1.5 & 53.7 & 0.104 & 0.055 & 0.145 & 0.603 \\
\hline 80 & 64.44 & 65.17 & 528 & 1.05 & 33.82 & 1.11 & 95.3 & 357.0 & 23.3 & 1.3 & 57.0 & 0.018 & 0.022 & 0.037 & 0.354 \\
\hline 82 & 64.82 & 65.12 & 549 & 0.96 & 33.66 & 1.74 & 94.0 & 335.2 & 22.2 & 1.3 & 61.4 & 0.019 & 0.017 & 0.082 & 0.675 \\
\hline 82 & 64.67 & 65.36 & 550 & 1.00 & 33.74 & 1.68 & 95.1 & 351.3 & 22.9 & 1.3 & 59.6 & 0.022 & 0.024 & 0.040 & 0.660 \\
\hline 83 & 64.52 & 65.61 & 551 & 0.98 & 33.84 & 1.72 & 95.9 & 353.8 & 24.6 & 1.5 & 59.6 & 0.060 & 0.043 & 0.076 & 0.445 \\
\hline 83 & 64.37 & 65.80 & 552 & 1.00 & 33.85 & 1.89 & 95.7 & 370.9 & 25.0 & 1.4 & 54.7 & 0.159 & 0.053 & 0.153 & 0.454 \\
\hline 83 & 64.82 & 66.20 & 563 & 0.93 & 33.79 & 5.39 & 95.9 & 364.2 & 23.7 & 1.4 & 59.3 & 0.034 & 0.014 & 0.024 & 0.185 \\
\hline 83 & 65.28 & 66.59 & 564 & 0.85 & 33.78 & 4.85 & 95.4 & 374.0 & 26.0 & 1.5 & 52.0 & 0.136 & 0.042 & 0.147 & 0.916 \\
\hline 83 & 65.71 & 67.20 & 589 & 0.63 & 33.73 & 4.34 & 95.0 & 363.7 & 24.1 & 1.5 & 59.8 & 0.054 & 0.030 & 0.103 & 0.932 \\
\hline 83 & 65.90 & 67.61 & 590 & 0.57 & 33.64 & 5.91 & 94.0 & 346.1 & 22.5 & 1.3 & 62.4 & 0.048 & 0.031 & 0.083 & 1.090 \\
\hline 83 & 66.08 & 67.98 & 591 & 0.62 & 33.62 & 6.49 & 95.5 & 335.2 & 22.9 & 1.3 & 63.0 & 0.062 & 0.036 & 0.058 & 0.577 \\
\hline 83 & 66.26 & 68.38 & 592 & 0.61 & 33.59 & 7.19 & 96.1 & 334.5 & 21.8 & 1.4 & 60.2 & 0.230 & 0.034 & 0.063 & 0.438 \\
\hline 83 & 66.43 & 68.75 & 593 & 0.59 & 33.70 & 0.84 & 95.4 & 351.5 & 25.0 & 0.9 & 49.9 & 0.784 & 0.027 & 0.175 & 0.858 \\
\hline 84 & 66.62 & 69.15 & 594 & 0.58 & 33.65 & 3.11 & 94.9 & 352.1 & 24.7 & 1.4 & 55.9 & 0.722 & 0.114 & 0.129 & 0.775 \\
\hline 84 & 66.96 & 69.92 & 595 & 0.36 & 33.71 & 1.54 & 93.3 & 343.0 & 24.7 & 1.3 & 46.6 & 1.463 & 0.355 & 0.301 & 0.297 \\
\hline 84 & 67.32 & 70.72 & 596 & 0.29 & 33.65 & 0.72 & 95.4 & 350.0 & 23.0 & 1.4 & 56.1 & 0.671 & 0.086 & 0.073 & 0.305 \\
\hline 84 & 67.61 & 71.39 & 597 & 0.23 & 33.69 & 0.82 & 95.0 & 325.0 & 23.0 & 1.3 & 52.6 & 1.602 & 0.155 & 0.156 & 0.564 \\
\hline
\end{tabular}




\begin{tabular}{|c|c|c|c|c|c|c|c|c|c|c|c|c|c|c|c|}
\hline $\begin{array}{c}\text { Julian } \\
\text { Day }\end{array}$ & $\begin{array}{c}\text { Lat } \\
\mathrm{S}\end{array}$ & $\begin{array}{c}\text { Long } \\
\text { W }\end{array}$ & ID & $\begin{array}{c}\text { Temp } \\
{ }^{\circ} \mathrm{C}\end{array}$ & Sal & $\begin{array}{c}\text { Fl. } \\
\mathrm{mg} \mathrm{m}^{-3}\end{array}$ & $\begin{array}{c}\text { Tr. } \\
\%\end{array}$ & $\begin{array}{c}\mathbf{p C O}_{2} \\
\mu a t m\end{array}$ & $\begin{array}{c}\mathbf{N O}_{3}+\mathbf{N O}_{2} \\
\mu \mathrm{M}\end{array}$ & $\begin{array}{c}\text { PO4 } \\
\mu \mathrm{M}\end{array}$ & $\begin{array}{c}\mathrm{SiO2} \\
\mu \mathrm{M}\end{array}$ & $\begin{array}{c}>20 \mu m \\
\text { Chl a } \\
\mu g L^{-1}\end{array}$ & $\begin{array}{c}\text { 5-20 } \boldsymbol{\mu m} \\
\mathbf{C h l} \mathbf{a} \\
\mu \mathrm{g} \mathrm{L}^{-1}\end{array}$ & $\begin{array}{c}2-5 \boldsymbol{\mu m} \\
\text { Chl a } \\
\mu \mathrm{g} \mathrm{L}^{-1}\end{array}$ & $\begin{array}{c}\text { 0.2-2 } \boldsymbol{\mu m} \\
\text { Chl a } \\
\mu \mathrm{g} \mathrm{L}^{-1}\end{array}$ \\
\hline 84 & 68.37 & 73.15 & 600 & 0.06 & 33.75 & 0.58 & 95.0 & 347.2 & 24.9 & 1.5 & 57.9 & 0.051 & 0.061 & 0.150 & 1.338 \\
\hline 84 & 68.86 & 74.33 & 602 & 0.76 & 33.39 & 0.53 & 96.0 & 293.5 & 18.3 & 1.3 & 62.2 & 0.064 & 0.036 & 0.064 & 0.548 \\
\hline 84 & 69.14 & 75.02 & 603 & 0.60 & 33.22 & 0.67 & 95.8 & 264.6 & 13.6 & 1.1 & 59.5 & 0.556 & 0.147 & 0.061 & 0.258 \\
\hline 85 & 69.39 & 75.38 & 604 & 1.47 & 33.08 & 0.60 & 95.5 & 247.2 & 14.8 & 1.0 & 61.2 & 0.300 & 0.147 & 0.084 & 0.355 \\
\hline 91 & 68.69 & 74.19 & 695 & 0.19 & 33.63 & 0.19 & 95.6 & 339.5 & 24.9 & 1.6 & 55.6 & 0.061 & 0.055 & 0.076 & 0.773 \\
\hline 91 & 68.56 & 73.77 & 696 & 0.13 & 33.63 & 0.22 & 96.0 & 345.6 & 24.2 & 1.5 & 55.1 & 0.063 & 0.058 & 0.069 & 0.507 \\
\hline 91 & 68.50 & 73.58 & 697 & 0.17 & 33.64 & 0.07 & 95.4 & 348.9 & 26.6 & 1.6 & 56.3 & 0.032 & 0.059 & 0.097 & 0.699 \\
\hline 92 & 68.40 & 73.26 & 698 & 0.53 & 33.49 & 0.51 & 95.7 & 327.6 & 19.6 & 1.3 & 57.8 & 0.280 & 0.066 & 0.068 & 0.610 \\
\hline 92 & 68.31 & 72.96 & 699 & 0.28 & 33.65 & 0.44 & 95.7 & 337.5 & 22.4 & 1.4 & 58.1 & 0.058 & 0.020 & 0.045 & 0.675 \\
\hline 92 & 68.20 & 72.63 & 700 & 1.13 & 33.14 & 1.25 & 93.7 & 269.2 & 13.6 & 0.8 & 53.5 & 3.174 & 0.668 & 0.211 & 0.300 \\
\hline 92 & 68.11 & 72.39 & 701 & 1.04 & 33.13 & 0.72 & 95.5 & 271.4 & 15.5 & 1.1 & 59.4 & 1.021 & 0.207 & 0.094 & 0.127 \\
\hline 92 & 68.00 & 72.07 & 702 & 0.22 & 33.51 & 1.06 & 94.8 & 274.8 & 21.4 & 1.3 & 59.0 & 2.689 & 0.252 & 0.142 & 1.911 \\
\hline 92 & 67.91 & 71.76 & 703 & 0.45 & 33.44 & 1.30 & 94.5 & 290.1 & 18.9 & 1.2 & 56.4 & 2.459 & 0.403 & 0.203 & 0.508 \\
\hline 92 & 67.80 & 71.42 & 704 & 0.39 & 33.51 & 1.08 & 94.7 & 295.5 & 20.1 & 1.3 & 56.2 & 2.797 & 0.342 & 0.192 & 0.645 \\
\hline 92 & 67.90 & 70.70 & 706 & 0.88 & 33.37 & 1.37 & 93.8 & 288.3 & 18.0 & 1.2 & 57.9 & 2.303 & 0.794 & 0.238 & 0.508 \\
\hline 93 & 68.17 & 70.00 & 707 & 0.08 & 33.51 & 0.57 & 95.0 & 334.1 & 22.1 & 1.3 & 45.7 & 0.867 & 0.103 & 0.142 & 0.467 \\
\hline 99 & 68.14 & 69.99 & 745 & 0.13 & 33.46 & 0.51 & 95.6 & 342.1 & 23.7 & 1.5 & 54.5 & 0.586 & 0.076 & 0.067 & 1.030 \\
\hline
\end{tabular}


Table $3{ }^{234}$ Th profiles over the continental shelf of the Northwest Atlantic, collected on Line $\mathrm{W}$ cruise in September 2010. These data were not discussed in any chapter and are included here as a record of additional work that was carried out during the thesis.

\begin{tabular}{|c|c|c|c|c|c|c|c|}
\hline Station & Date & CTD & Bottle & $\begin{array}{c}\text { Depth } \\
\text { m }\end{array}$ & $\begin{array}{c}{ }^{{ }^{238} \mathbf{U}} \\
\mathrm{dpm} \mathrm{L}^{-1}\end{array}$ & $\begin{array}{c}{ }^{{ }^{234} \mathbf{T h}} \\
\mathrm{dpm} \mathrm{L}{ }^{-1}\end{array}$ & error \\
\hline \multirow[t]{10}{*}{4} & $9 / 14 / 10$ & 9 & - & 13 & 2.16 & 1.56 & 0.06 \\
\hline & & & - & 39 & 2.21 & 1.78 & 0.07 \\
\hline & & & 18,19 & 88 & 2.36 & 2.16 & 0.06 \\
\hline & & & 16,17 & 228 & 2.45 & 2.74 & 0.11 \\
\hline & & & 14,15 & 388 & 2.44 & 2.85 & 0.11 \\
\hline & & & 9,13 & 488 & 2.43 & 2.69 & 0.08 \\
\hline & & & 7,8 & 589 & 2.43 & 3.21 & 0.09 \\
\hline & & & 5,6 & 789 & 2.43 & 3.14 & 0.08 \\
\hline & & & 3,4 & 980 & 2.43 & 2.55 & 0.10 \\
\hline & & & 1,2 & 1044 & 2.43 & 2.93 & 0.07 \\
\hline \multirow[t]{18}{*}{6} & $9 / 16 / 10$ & 19 & 23 & 27 & 2.43 & 2.05 & 0.07 \\
\hline & & & 22 & 50 & 2.50 & 2.28 & 0.07 \\
\hline & & & 21 & 101 & 2.52 & 2.38 & 0.08 \\
\hline & & & 20 & 201 & 2.49 & 2.40 & 0.11 \\
\hline & & & 19 & 250 & 2.47 & 2.33 & 0.07 \\
\hline & & & 18 & 301 & 2.46 & 2.55 & 0.08 \\
\hline & & & 17 & 350 & 2.45 & 2.38 & 0.08 \\
\hline & & & 16 & 500 & 2.44 & 2.18 & 0.07 \\
\hline & & & 15 & 751 & 2.43 & 2.39 & 0.08 \\
\hline & & & 14 & 1001 & 2.43 & 2.57 & 0.08 \\
\hline & & & 13 & 1251 & 2.43 & 2.20 & 0.07 \\
\hline & & & 9 & 1501 & 2.43 & 2.51 & 0.07 \\
\hline & & & 7 & 2001 & 2.43 & 2.07 & 0.10 \\
\hline & & & 5 & 2542 & 2.43 & 2.37 & 0.08 \\
\hline & & & 4 & 2751 & 2.43 & 2.24 & 0.07 \\
\hline & & & 3 & 2911 & 2.43 & 2.11 & 0.08 \\
\hline & & & 2 & 2946 & 2.43 & 2.57 & 0.10 \\
\hline & & & 1 & 2966 & 2.43 & 1.99 & 0.07 \\
\hline \multirow[t]{12}{*}{8} & $9 / 19 / 10$ & 32 & 23 & 31 & 2.51 & 2.32 & 0.11 \\
\hline & & & 22 & 51 & 2.56 & 2.26 & 0.09 \\
\hline & & & 21 & 100 & 2.56 & 2.87 & 0.11 \\
\hline & & & 20 & 202 & 2.55 & 2.71 & 0.06 \\
\hline & & & 19 & 250 & 2.53 & 2.54 & 0.07 \\
\hline & & & 18 & 349 & 2.49 & 2.43 & 0.06 \\
\hline & & & 17 & 498 & 2.45 & 2.80 & 0.06 \\
\hline & & & 16 & 751 & 2.43 & 2.43 & 0.07 \\
\hline & & & 15 & 1000 & 2.43 & 2.69 & 0.08 \\
\hline & & & 14 & 1501 & 2.43 & 2.20 & 0.07 \\
\hline & & & 13 & 1999 & 2.43 & 2.59 & 0.11 \\
\hline & & & 9 & 2551 & 2.43 & 2.26 & 0.10 \\
\hline
\end{tabular}




\begin{tabular}{|c|c|c|c|c|c|c|c|}
\hline Station & Date & CTD & Bottle & $\begin{array}{c}\text { Depth } \\
\text { m }\end{array}$ & $\begin{array}{c}{ }^{\mathbf{2 3 8}} \mathbf{U} \\
\mathrm{dpm} \mathrm{L}^{-1}\end{array}$ & $\begin{array}{c}{ }^{{ }^{234} \mathbf{T h}} \\
\mathrm{dpm} \mathrm{L} \mathrm{L}^{-1}\end{array}$ & error \\
\hline & & & 8 & 2749 & 2.43 & 2.64 & 0.11 \\
\hline & & & 7 & 3000 & 2.43 & 2.67 & 0.06 \\
\hline & & & 6 & 3501 & 2.43 & 2.17 & 0.05 \\
\hline & & & 5 & 4000 & 2.43 & 2.18 & 0.07 \\
\hline & & & 4 & 4250 & 2.42 & 2.38 & 0.10 \\
\hline & & & 2 & 4424 & 2.42 & 2.32 & 0.05 \\
\hline & & & 1 & 4476 & 2.42 & 2.61 & 0.07 \\
\hline \multirow[t]{10}{*}{11} & $9 / 22 / 10$ & 40 & 23,24 & 10 & 2.46 & 1.80 & 0.05 \\
\hline & & & 21,22 & 28 & 2.47 & 1.73 & 0.07 \\
\hline & & & 19,20 & 250 & 2.47 & 2.70 & 0.07 \\
\hline & & & 17,18 & 300 & 2.46 & 2.27 & 0.10 \\
\hline & & & 15,16 & 343 & 2.45 & 2.74 & 0.08 \\
\hline & & & 13,14 & 400 & 2.44 & 2.62 & 0.10 \\
\hline & & & 7,8 & 575 & 2.43 & 2.42 & 0.06 \\
\hline & & & 5,6 & 750 & 2.43 & 2.44 & 0.05 \\
\hline & & & 3 & 900 & 2.43 & 2.90 & 0.06 \\
\hline & & & 1,2 & 1125 & 2.43 & 2.44 & 0.09 \\
\hline \multirow[t]{19}{*}{12} & $9 / 23 / 10$ & 46 & 24 & 21 & 2.45 & 1.46 & 0.09 \\
\hline & & & 22,23 & 65 & 2.46 & 2.18 & 0.08 \\
\hline & & & 21 & 101 & 2.51 & 2.54 & 0.11 \\
\hline & & & 20 & 175 & 2.49 & 2.57 & 0.11 \\
\hline & & & 19 & 241 & 2.47 & 2.37 & 0.08 \\
\hline & & & 18 & 340 & 2.45 & 2.50 & 0.09 \\
\hline & & & 17 & 359 & 2.45 & 2.13 & 0.09 \\
\hline & & & 16 & 500 & 2.44 & 2.19 & 0.10 \\
\hline & & & 15 & 630 & 2.44 & 2.11 & 0.07 \\
\hline & & & 14 & 850 & 2.43 & 2.36 & 0.07 \\
\hline & & & 13 & 1000 & 2.43 & 2.57 & 0.10 \\
\hline & & & 9 & 1201 & 2.43 & 2.41 & 0.10 \\
\hline & & & 8 & 1500 & 2.43 & 2.22 & 0.07 \\
\hline & & & 7 & 1841 & 2.43 & 2.95 & 0.11 \\
\hline & & & 6 & 2149 & 2.43 & 2.28 & 0.07 \\
\hline & & & 5 & 2500 & 2.43 & 3.08 & 0.09 \\
\hline & & & 4 & 2801 & 2.43 & 2.75 & 0.09 \\
\hline & & & 3 & 2900 & 2.43 & 3.18 & 0.09 \\
\hline & & & 2 & 2940 & 2.43 & 2.44 & 0.08 \\
\hline \multirow[t]{10}{*}{14} & $9 / 26 / 10$ & 61 & 24 & 26 & 2.52 & 2.31 & 0.08 \\
\hline & & & 23 & 100 & 2.57 & 1.93 & 0.07 \\
\hline & & & 22 & 251 & 2.56 & 2.35 & 0.10 \\
\hline & & & 21 & 352 & 2.56 & 2.36 & 0.08 \\
\hline & & & 20 & 501 & 2.55 & 2.49 & 0.08 \\
\hline & & & 19 & 750 & 2.48 & 2.14 & 0.09 \\
\hline & & & 18 & 875 & 2.45 & 2.14 & 0.08 \\
\hline & & & 17 & 950 & 2.45 & 1.91 & 0.08 \\
\hline & & & 16 & 1000 & 2.44 & 2.68 & 0.10 \\
\hline & & & 15 & 1075 & 2.44 & 2.94 & 0.09 \\
\hline
\end{tabular}




\begin{tabular}{|c|c|c|c|c|c|c|c|}
\hline Station & Date & CTD & Bottle & $\begin{array}{l}\text { Depth } \\
\text { m }\end{array}$ & $\begin{array}{c}{ }^{238} \mathbf{U} \\
\text { dpm L } L^{-1}\end{array}$ & $\begin{array}{c}{ }^{234} \mathbf{T h} \\
\text { dpm L L }\end{array}$ & error \\
\hline \multirow{21}{*}{15} & \multirow{21}{*}{$9 / 28 / 10$} & \multirow{21}{*}{66} & 14 & 1176 & 2.44 & 2.11 & 0.10 \\
\hline & & & 13 & 1500 & 2.43 & 2.41 & 0.10 \\
\hline & & & 9 & 2001 & 2.43 & 2.26 & 0.09 \\
\hline & & & 24 & 26 & 2.55 & 2.40 & 0.08 \\
\hline & & & 23 & 50 & 2.55 & 2.59 & 0.09 \\
\hline & & & 21 & 101 & 2.57 & 2.53 & 0.08 \\
\hline & & & 20 & 251 & 2.56 & 2.66 & 0.10 \\
\hline & & & 19 & 501 & 2.56 & 2.57 & 0.08 \\
\hline & & & 18 & 675 & 2.55 & 2.87 & 0.10 \\
\hline & & & 17 & 1045 & 2.46 & 2.30 & 0.08 \\
\hline & & & 16 & 1201 & 2.44 & 2.44 & 0.08 \\
\hline & & & 15 & 1350 & 2.44 & 3.00 & 0.09 \\
\hline & & & 14 & 1500 & 2.43 & 2.20 & 0.08 \\
\hline & & & 13 & 2001 & 2.39 & 2.66 & 0.09 \\
\hline & & & 9 & 2501 & 2.43 & 2.45 & 0.08 \\
\hline & & & 8 & 3000 & 2.43 & 2.36 & 0.08 \\
\hline & & & 5 & 4199 & 2.43 & 2.75 & 0.08 \\
\hline & & & 4 & 4301 & 2.43 & 2.50 & 0.07 \\
\hline & & & 3 & 4400 & 2.43 & 2.28 & 0.08 \\
\hline & & & 2 & 4461 & 2.43 & 2.54 & 0.10 \\
\hline & & & 1 & 4490 & 2.43 & 2.20 & 0.08 \\
\hline \multirow[t]{15}{*}{17} & \multirow[t]{15}{*}{$10 / 2 / 10$} & 76 & 24 & 26 & 2.45 & 1.99 & 0.08 \\
\hline & & \multirow[t]{6}{*}{74} & 23 & 51 & 2.46 & 2.36 & 0.08 \\
\hline & & & 21 & 101 & 2.49 & 2.28 & 0.08 \\
\hline & & & 19 & 175 & 2.46 & 2.76 & 0.09 \\
\hline & & & 15 & 250 & 2.45 & 2.28 & 0.08 \\
\hline & & & 7 & 500 & 2.44 & 3.13 & 0.10 \\
\hline & & & 3 & 751 & 2.43 & 2.56 & 0.09 \\
\hline & & \multirow[t]{4}{*}{73} & 20 & 1000 & 2.43 & 2.61 & 0.09 \\
\hline & & & 9 & 1500 & 2.43 & 2.46 & 0.08 \\
\hline & & & 7 & 2000 & 2.43 & 2.20 & 0.07 \\
\hline & & & 3 & 2501 & 2.43 & 2.16 & 0.08 \\
\hline & & \multirow[t]{4}{*}{75} & 18 & 2750 & 2.43 & 2.18 & 0.07 \\
\hline & & & 13 & 2926 & 2.43 & 2.52 & 0.09 \\
\hline & & & 7 & 2966 & 2.43 & 2.82 & 0.07 \\
\hline & & & 1 & 3000 & 2.43 & 2.40 & 0.08 \\
\hline \multirow[t]{9}{*}{18} & \multirow[t]{9}{*}{$10 / 3 / 10$} & \multirow[t]{9}{*}{82} & 22 & 50 & 2.43 & 1.81 & 0.05 \\
\hline & & & 20 & 110 & 2.49 & 2.62 & 0.05 \\
\hline & & & 18 & 130 & 2.49 & 2.37 & 0.06 \\
\hline & & & 17 & 285 & 2.45 & 2.33 & 0.05 \\
\hline & & & 15 & 401 & 2.44 & 2.51 & 0.06 \\
\hline & & & 9 & 600 & 2.43 & 2.66 & 0.07 \\
\hline & & & 7 & 751 & 2.43 & 2.54 & 0.06 \\
\hline & & & 5 & 880 & 2.43 & 3.01 & 0.06 \\
\hline & & & 3 & 1021 & 2.43 & 2.66 & 0.06 \\
\hline
\end{tabular}


Table 4 Particulate $(>53 \mu \mathrm{m})$ data from over the continental shelf of the Northwest Atlantic, collected with in situ pumps on Line W cruise in September 2010.

\begin{tabular}{|c|c|c|c|c|c|c|c|c|}
\hline Station & Cast & Pump & $\begin{array}{c}\text { Depth } \\
\text { m }\end{array}$ & $\begin{array}{c}{ }^{\mathbf{2 3 4}} \mathbf{T h} \\
\mathrm{dpm} \mathrm{L}^{-1}\end{array}$ & error & $\begin{array}{c}\mathbf{C} \\
\mu \mathrm{mol} \mathrm{L}\end{array}$ & $\begin{array}{c}\mathbf{N} \\
\mu \mathrm{mol} \mathrm{L}\end{array}$ & $\begin{array}{c}\mathbf{C} / \mathbf{T h} \\
\mu \mathrm{mol} \mathrm{dpm}^{-1}\end{array}$ \\
\hline \multirow[t]{8}{*}{4} & 8 & 10 & 25 & 0.020 & 0.001 & 0.374 & 0.035 & 18.26 \\
\hline & & 9 & 50 & 0.097 & 0.003 & 0.964 & 0.089 & 9.92 \\
\hline & & 8 & 100 & 0.042 & 0.001 & 0.156 & 0.013 & 3.70 \\
\hline & & 6 & 400 & 0.061 & 0.001 & 0.114 & 0.008 & 1.86 \\
\hline & & 5 & 500 & 0.025 & 0.001 & 0.070 & 0.006 & 2.83 \\
\hline & & 3 & 800 & 0.020 & 0.000 & 0.054 & 0.004 & 2.73 \\
\hline & & 2 & 1000 & 0.024 & 0.001 & 0.062 & 0.005 & 2.60 \\
\hline & & 1 & 1055 & 0.036 & 0.001 & 0.079 & 0.006 & 2.18 \\
\hline \multirow[t]{9}{*}{6} & 18 & 11 & 25 & 0.008 & 0.001 & 0.080 & 0.009 & 9.90 \\
\hline & & 10 & 50 & 0.039 & 0.001 & 0.176 & 0.019 & 4.49 \\
\hline & & 8 & 100 & 0.030 & 0.001 & 0.069 & 0.007 & 2.27 \\
\hline & & 7 & 200 & 0.023 & 0.001 & 0.045 & 0.003 & 1.95 \\
\hline & & 6 & 250 & 0.024 & 0.001 & 0.043 & 0.004 & 1.79 \\
\hline & & 5 & 300 & 0.027 & 0.001 & 0.041 & 0.003 & 1.51 \\
\hline & & 3 & 350 & 0.018 & 0.001 & 0.034 & 0.003 & 1.85 \\
\hline & & 2 & 500 & 0.021 & 0.001 & 0.031 & 0.002 & 1.44 \\
\hline & & 1 & 1000 & 0.013 & 0.000 & 0.026 & 0.002 & 2.03 \\
\hline \multirow[t]{9}{*}{6} & 16 & 11 & 1250 & 0.012 & 0.001 & 0.028 & 0.001 & 2.38 \\
\hline & & 10 & 1500 & 0.011 & 0.001 & 0.023 & 0.001 & 2.08 \\
\hline & & 8 & 2000 & 0.012 & 0.000 & 0.024 & 0.002 & 1.97 \\
\hline & & 7 & 2250 & 0.009 & 0.001 & 0.021 & 0.001 & 2.23 \\
\hline & & 6 & 2540 & 0.016 & 0.001 & 0.029 & 0.001 & 1.82 \\
\hline & & 5 & 2750 & 0.012 & 0.001 & 0.025 & 0.001 & 2.06 \\
\hline & & 3 & 2910 & 0.011 & 0.001 & 0.021 & 0.001 & 1.88 \\
\hline & & 2 & 2945 & 0.016 & 0.000 & 0.034 & 0.002 & 2.11 \\
\hline & & 1 & 2965 & 0.018 & 0.001 & 0.039 & 0.001 & 2.15 \\
\hline \multirow[t]{10}{*}{8} & 31 & 15 & 25 & 0.011 & 0.001 & 0.111 & 0.009 & 9.88 \\
\hline & & 11 & 50 & 0.025 & 0.001 & 0.115 & 0.010 & 4.57 \\
\hline & & 10 & 100 & 0.034 & 0.001 & 0.068 & 0.004 & 2.03 \\
\hline & & 8 & 200 & 0.010 & 0.000 & 0.023 & 0.002 & 2.33 \\
\hline & & 7 & 250 & 0.012 & 0.000 & 0.020 & 0.002 & 1.70 \\
\hline & & 6 & 350 & 0.020 & 0.000 & 0.029 & 0.002 & 1.47 \\
\hline & & 5 & 500 & 0.027 & 0.001 & 0.036 & 0.003 & 1.31 \\
\hline & & 3 & 750 & 0.018 & 0.001 & 0.026 & 0.002 & 1.41 \\
\hline & & 2 & 1000 & 0.008 & 0.000 & 0.021 & 0.002 & 2.54 \\
\hline & & 1 & 1500 & 0.010 & 0.001 & 0.021 & 0.001 & 2.15 \\
\hline \multirow[t]{7}{*}{8} & 28 & 15 & 2000 & 0.004 & 0.000 & 0.016 & 0.001 & 4.41 \\
\hline & & 11 & 2550 & 0.004 & 0.000 & 0.020 & 0.001 & 4.81 \\
\hline & & 10 & 2750 & 0.005 & 0.000 & 0.019 & 0.001 & 3.78 \\
\hline & & 8 & 3000 & 0.003 & 0.000 & 0.015 & 0.001 & 4.46 \\
\hline & & 7 & 3500 & 0.006 & 0.000 & 0.016 & 0.001 & 2.86 \\
\hline & & 6 & 4000 & 0.008 & 0.001 & 0.020 & 0.001 & 2.42 \\
\hline & & 5 & 4250 & 0.011 & 0.000 & 0.020 & 0.002 & 1.86 \\
\hline
\end{tabular}




\begin{tabular}{|c|c|c|c|c|c|c|c|c|}
\hline Station & Cast & Pump & $\begin{array}{l}\text { Depth } \\
\text { m }\end{array}$ & $\begin{array}{c}{ }^{234} \mathbf{T h} \\
\mathrm{dpm} \mathrm{L}^{-1}\end{array}$ & error & $\begin{array}{c}\mathbf{C} \\
\mu \mathrm{mol} \mathrm{L}{ }^{-1}\end{array}$ & $\begin{array}{c}\mathbf{N} \\
\mu \mathrm{mol} \mathrm{L}\end{array}$ & $\begin{array}{c}\mathbf{C} / \mathbf{T h} \\
\mu \mathrm{mol} \mathrm{dpm}^{-1}\end{array}$ \\
\hline & & 2 & 4425 & 0.022 & 0.001 & 0.045 & 0.002 & 1.99 \\
\hline & & 1 & 4475 & 0.026 & 0.001 & 0.060 & 0.003 & 2.30 \\
\hline \multirow[t]{9}{*}{11} & 39 & 15 & 10 & 0.016 & 0.001 & 0.493 & 0.036 & 30.53 \\
\hline & & 10 & 250 & 0.041 & 0.002 & 0.059 & 0.005 & 1.42 \\
\hline & & 8 & 300 & 0.033 & 0.001 & 0.046 & 0.004 & 1.38 \\
\hline & & 7 & 343 & 0.034 & 0.001 & 0.045 & 0.003 & 1.34 \\
\hline & & 6 & 400 & 0.029 & 0.000 & 0.055 & 0.004 & 1.86 \\
\hline & & 5 & 575 & 0.033 & 0.000 & 0.063 & 0.005 & 1.92 \\
\hline & & 3 & 750 & 0.039 & 0.001 & 0.093 & 0.007 & 2.40 \\
\hline & & 2 & 900 & 0.086 & 0.004 & 0.113 & 0.008 & 1.32 \\
\hline & & 1 & 1125 & 0.055 & 0.002 & 0.165 & 0.011 & 3.03 \\
\hline \multirow[t]{10}{*}{12} & 43 & 15 & 20 & 0.038 & 0.001 & 0.389 & 0.044 & 10.12 \\
\hline & & 11 & 65 & 0.065 & 0.001 & 0.115 & 0.010 & 1.77 \\
\hline & & 10 & 100 & 0.034 & 0.001 & 0.071 & 0.007 & 2.05 \\
\hline & & 8 & 175 & 0.014 & 0.000 & 0.030 & 0.003 & 2.10 \\
\hline & & 7 & 240 & 0.018 & 0.000 & 0.030 & 0.003 & 1.70 \\
\hline & & 6 & 340 & 0.033 & 0.000 & 0.044 & 0.003 & 1.33 \\
\hline & & 5 & 360 & 0.036 & 0.000 & 0.050 & 0.004 & 1.39 \\
\hline & & 3 & 500 & 0.028 & 0.000 & 0.042 & 0.004 & 1.52 \\
\hline & & 2 & 630 & 0.021 & 0.000 & 0.038 & 0.004 & 1.83 \\
\hline & & 1 & 850 & 0.018 & 0.001 & 0.034 & 0.002 & 1.85 \\
\hline \multirow[t]{4}{*}{14} & 54 & 10 & 350 & 0.016 & 0.001 & 0.031 & 0.003 & 1.96 \\
\hline & & 6 & 875 & 0.016 & 0.000 & 0.027 & 0.003 & 1.72 \\
\hline & & 5 & 950 & 0.028 & 0.001 & 0.047 & 0.003 & 1.69 \\
\hline & & 1 & 1175 & 0.022 & 0.001 & 0.050 & 0.004 & 2.28 \\
\hline \multirow[t]{3}{*}{15} & 63 & 11 & 25 & 0.005 & 0.000 & 0.064 & 0.006 & 12.91 \\
\hline & & 10 & 50 & 0.011 & 0.001 & 0.034 & 0.004 & 3.17 \\
\hline & & 5 & 675 & 0.007 & 0.000 & 0.014 & 0.001 & 2.20 \\
\hline \multirow{3}{*}{15} & 68 & 14 & 1500 & 0.006 & 0.000 & 0.016 & 0.002 & 2.62 \\
\hline & & 10 & 3000 & 0.009 & 0.000 & 0.018 & 0.002 & 1.93 \\
\hline & & 5 & 4300 & 0.024 & 0.001 & 0.038 & 0.002 & 1.61 \\
\hline \multirow[t]{14}{*}{17} & 72 & 15 & 25 & 0.034 & 0.001 & 0.304 & 0.031 & 9.04 \\
\hline & & 14 & 50 & 0.041 & 0.001 & 0.363 & 0.040 & 8.92 \\
\hline & & 12 & 100 & 0.035 & 0.001 & 0.045 & 0.004 & 1.26 \\
\hline & & 11 & 175 & 0.003 & 0.000 & 0.013 & 0.001 & 4.55 \\
\hline & & 10 & 250 & 0.020 & 0.001 & 0.030 & 0.003 & 1.47 \\
\hline & & 8 & 500 & 0.006 & 0.000 & 0.023 & 0.002 & 3.88 \\
\hline & & 7 & 1000 & 0.005 & 0.000 & 0.016 & 0.002 & 3.08 \\
\hline & & 9 & 1500 & 0.010 & 0.000 & 0.021 & 0.001 & 2.04 \\
\hline & & 6 & 2000 & 0.010 & 0.000 & 0.024 & 0.002 & 2.26 \\
\hline & & 4 & 2500 & 0.006 & 0.000 & 0.015 & 0.001 & 2.50 \\
\hline & & 5 & 2750 & 0.011 & 0.000 & 0.023 & 0.001 & 2.14 \\
\hline & & 3 & 2925 & 0.009 & 0.000 & 0.018 & 0.002 & 2.04 \\
\hline & & 2 & 2965 & 0.018 & 0.001 & 0.042 & 0.002 & 2.31 \\
\hline & & 1 & 3000 & 0.004 & 0.000 & 0.014 & 0.002 & 3.54 \\
\hline 18 & 80 & 10 & 25 & 0.038 & 0.001 & 0.511 & 0.055 & 13.58 \\
\hline
\end{tabular}




\begin{tabular}{|c|c|c|c|c|c|c|c|c|}
\hline Station & Cast & Pump & $\begin{array}{c}\text { Depth } \\
\text { m }\end{array}$ & $\begin{array}{c}{ }^{234} \mathbf{T h} \\
\mathrm{dpm} \mathrm{L} \mathrm{L}^{-1}\end{array}$ & error & $\begin{array}{c}\mathbf{C} \\
\mu \mathrm{mol} \mathrm{L}\end{array}$ & $\begin{array}{c}\mathbf{N} \\
\mu \mathrm{mol} \mathrm{L}^{-1}\end{array}$ & $\begin{array}{c}\text { C/Th } \\
\mu \mathrm{mol} \mathrm{dpm}^{-1}\end{array}$ \\
\hline & & 9 & 50 & 0.136 & 0.002 & 3.615 & 0.385 & 26.65 \\
\hline & & 8 & 110 & 0.036 & 0.001 & 0.071 & 0.007 & 1.96 \\
\hline & & 7 & 130 & 0.034 & 0.001 & 0.056 & 0.005 & 1.64 \\
\hline & & 6 & 285 & 0.055 & 0.001 & 0.078 & 0.006 & 1.42 \\
\hline & & 5 & 400 & 0.030 & 0.001 & 0.051 & 0.004 & 1.71 \\
\hline & & 4 & 600 & 0.027 & 0.001 & 0.091 & 0.005 & 3.40 \\
\hline & & 3 & 750 & 0.023 & 0.001 & 0.049 & 0.003 & 2.13 \\
\hline & & 2 & 880 & 0.033 & 0.000 & 0.073 & 0.005 & 2.23 \\
\hline
\end{tabular}


Appendix 2: Calculation of PPZ depth 
Below is an example excerpt of Matlab code that was used to derive primary production (PPZ depths) for the US GEOTRACES cruises. First, the index value of the fluorescence maximum is determined. Then the background fluorescence value is determined by scanning downward in the profile to find the minimum. Then, the fluorescence profile is normalized to 100 and the depth at which fluorescence is $10 \%$ of the maximum is determined.

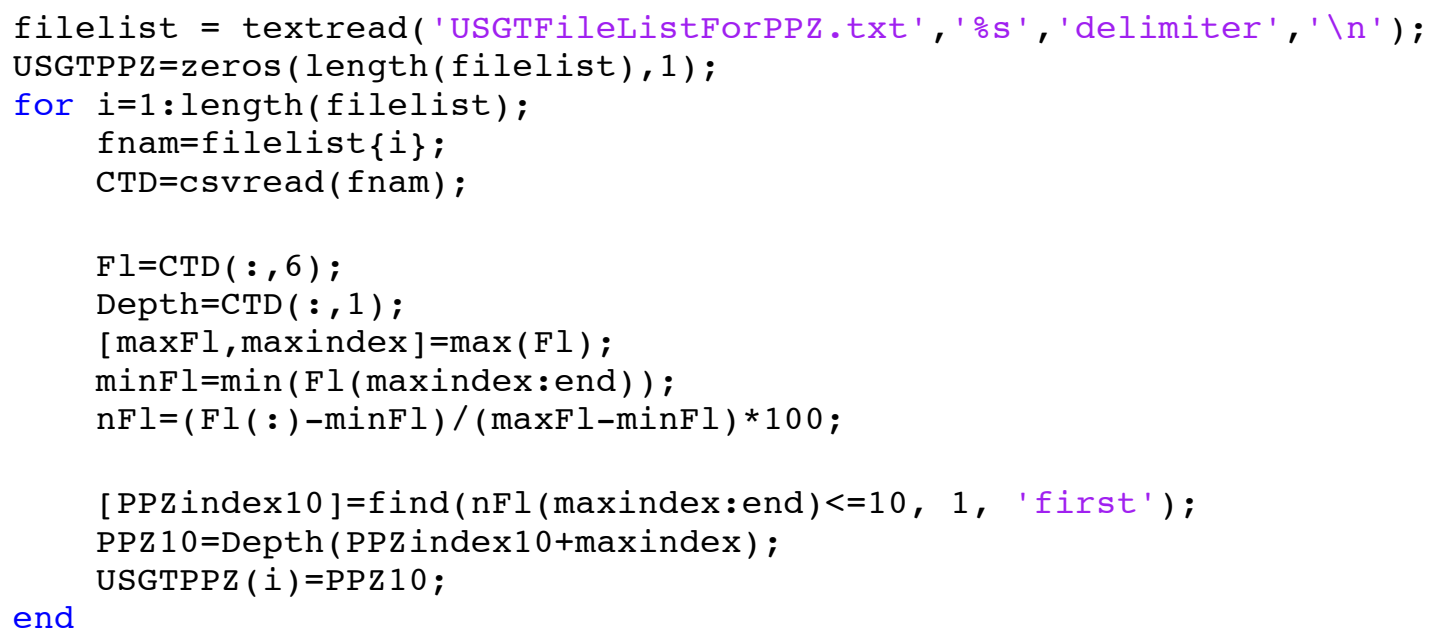


